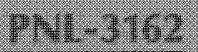

UC -70

Assessment of Effecinyeness of

Geologic Isolation Systems

\title{
PATHS Groundwater Hydrologic Model
}

R. W. Melson

1. A. Schur

April 1980

Prepared for

the Office of Nuclear Waste Isolation

under its Contract with the

U.5. Depantment of Energy

Pacific Norihwest Laboratory

Operated for the U.S. Department of Energy

by Hatlelle Memorial Instilute 


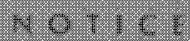

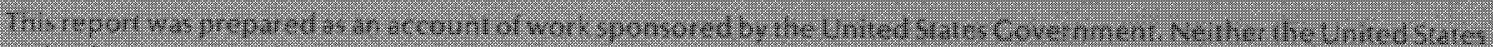

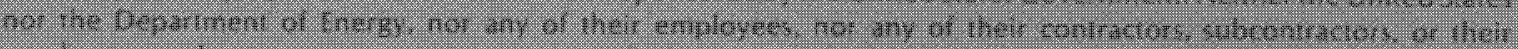

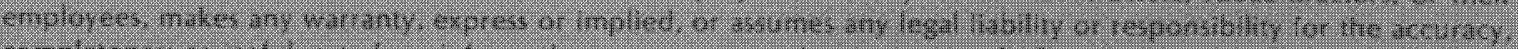

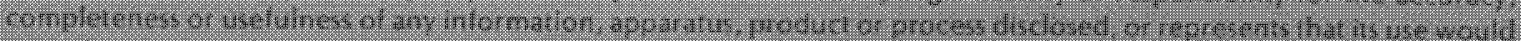

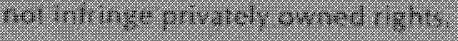

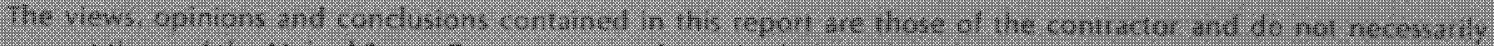
te.

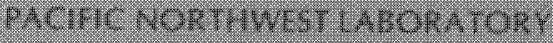

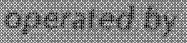 \\ THTTELE \\ T: : : : it:?:

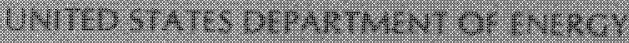

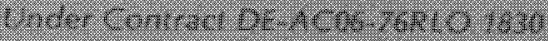

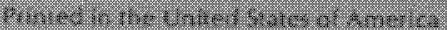

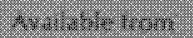

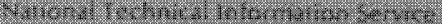

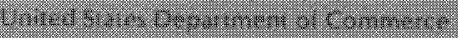

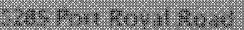

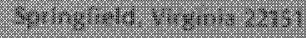

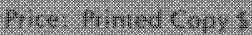

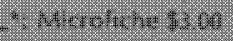

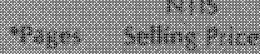

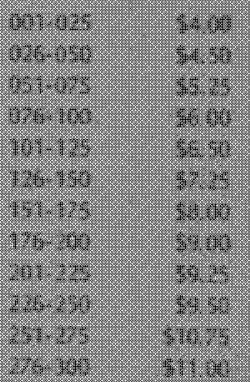


Assessment of Effectiveness of

Geologic Isolation Systems

PATHS GROUNDWATER HYDROLOGIC MODEL

R. W. Nelson

J. A. Schur

Apri1 1980

Prepared for

the Office of Nuclear Waste Isolation under its Contract with the

U.S. Department of Energy

Pacific Northwest Laboratory

Richland, Washington 99352 


\section{FOREWORD}

The Assessment of Effectiveness of Geologic Isolation Systems (AEGIS) Program is developing and applying the methodology for assessing the far-field, long-term post-closure safety of deep geologic nuclear waste repositories. AEGIS is being performed by Pacific Northwest Laboratory (PNL) under contract with the Office of Nuclear Waste Isolation (ONWI) for the Department of Energy (DOE). One task within AEGIS is to develop the methodology for analysis of the consequences (water pathway) from loss of repository containment as defined by various release scenarios.

Analysis of the long-term, far-field consequences of release scenarios requires the application of numerical codes which simulate the hydrologic systems, mode 1 the transport of released radionuclides through the hydrologic systems to the biosphere, and, where applicable, assess the radiological dose to humans.

Essentially three modeling technologies are involved in assessing the water pathway release consequence. These models are: 1) hydrologic models that define the groundwater flow field and provide water flow paths and travel times, 2) transport models that describe the movement and concentrations of the radionuclides in the flow field, and 3 ) dose models that determine the resultant dose burdens to individuals and/or populations. Figure $i$ is a schematic flow diagram for the release consequence analysis.

The various input parameters required in the analysis are compiled in data systems. The data are organized and prepared by various input subroutines for use by the hydraulic and transport codes. The hydrologic models simulate the groundwater flow systems and provide water flow directions, rates, and velocities as inputs to the transport models. Outputs from the transport models are basically graphs of radionuclide outflow rate in groundwater plotted against time. After dilution in the receiving surfacewater body (e.g., lake, river, bay), these data are the input source terms for the dose models, if dose assessments are required. The dose models calculate radiation dose to individuals and populations. 


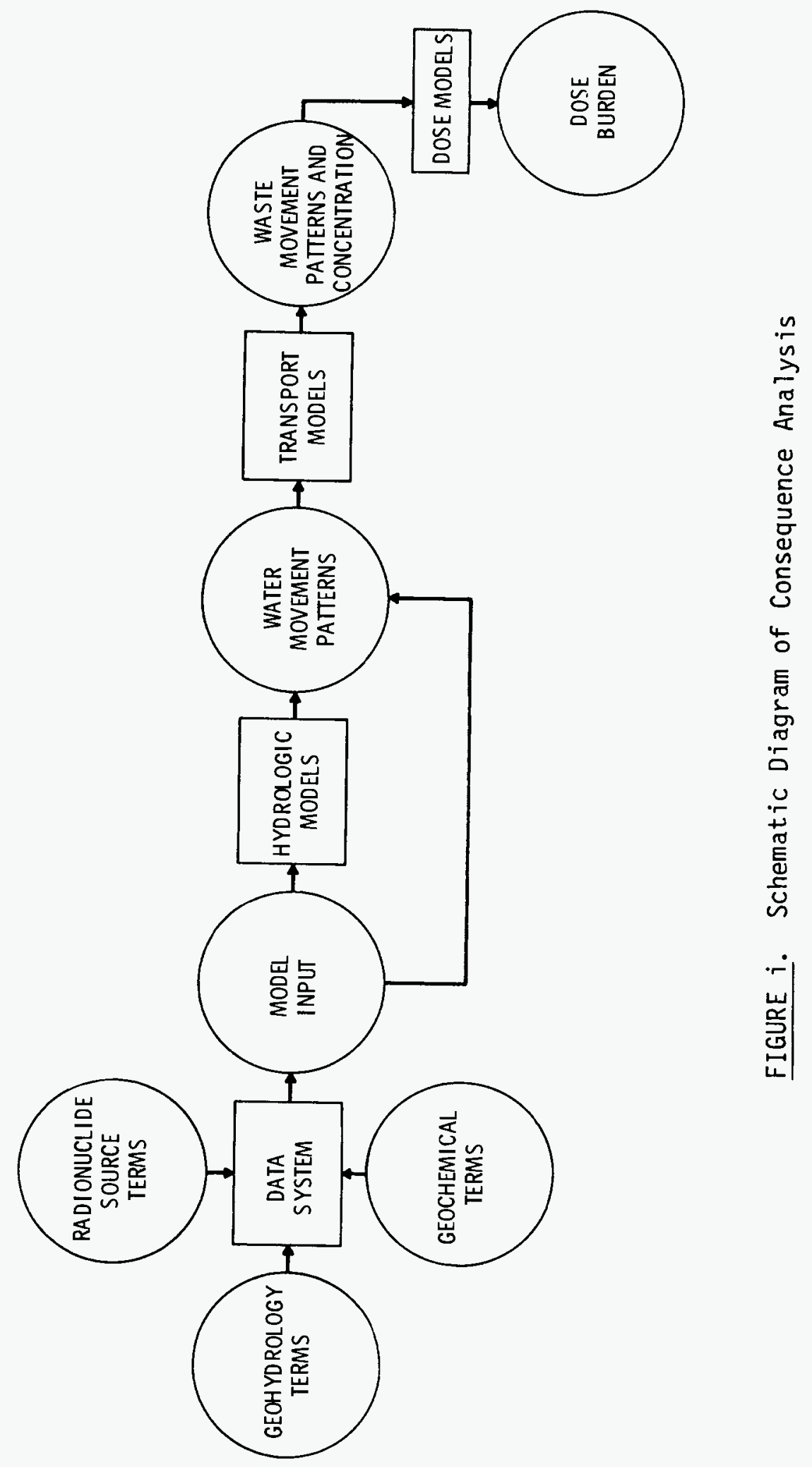


Hydrologic and transport models are available at several levels of complexity or sophistication. Model selection and use are determined by the quantity and quality of input data. Model development under AEGIS and related programs provides three levels of hydrologic models, two levels of transport models, and one level of dose models (with several separate models). The models and data systems are documented as follows:

- HYDROLOGIC MODELS:

PNL-3162 PATHS Groundwater Hydrologic Model - first level (simplest) idealized hybrid analytical/numerical model for twodimensional, saturated groundwater flow and single component transport; homogeneous geology.

PNL-3160 VTT (Variable Thickness Transient) Groundwater Hydrologic Model - second level (intermediate complexity) twodimensional saturated groundwater flow, Boussinesq approximation, finite difference approach; two-dimensional (quasi three-dimensional) multiaquifer capability; heterogeneous geology.

PNL-2939 FE3DGW (Finite Element, Three-Dimensional Groundwater) Hydrologic Model - third level (high complexity) threedimensional, finite element approach (Galerkin formulation) for saturated groundwater flow; heterogeneous geology.

- TRANSPORT MODELS:

PNL-2970 GETOUT Transport Mode1 - first level one-dimensional analytical solution considering radioactive chain decay with capability for only simple release and hydrologic functions; single speciation, constant flow rate, dispersion and sorption three-member, straight decay chains.

PNL-3179 MMT (Multicomponent Mass Transport) Model - second level, one-dimensional numerical, discrete parcel random walk (DPRW) algorithm; chain decay, single speciation, equilibrium sorption, time-variant leach rate and dispersion, n-membered straight or branched decay chains. 
- DOSE MODELS:

PNL-3180 ARRRG - drinking water, water immersion, external shoreline, and aquatic food; and FOOD - terrestrial food.

PNL-3209 PABLM - Combination of ARRRG and FOOD with additional features related to chronic releases.

BNWL-B-264 KRONIC - chronic external dose from air pathways.

BNWL-B-351 SUBDOSA - acute external dose from air pathways.

BNWL-B-389 DACRIN - chronic or acute inhalation dose from air pathways.

- DATA SYSTEMS:

PNL-3139 SIRS (Sorption Information Retrieval System) - storage and retrieval system for experimental data on sorption/desorption analyses for a wide variety of radionuclides, groundwater compositions, and rocks and minerals.

PNL-3161 CIRMIS (Comprehensive Information Retrieval and Model Input Sequence) Data System - storage and retrieval system for model input and output data, including graphical interpretation and display.

This document consists of the description of the PATHS groundwater hydrologic model.

Return the form on the last page to remain on the distribution list for future revisions of the model. 
This work was done at Boeing Computer Services Richland, Inc. (BCSR) with the support of the Pacific Northwest Laboratory and was first published by BCSR as A Preliminary Evaluation Capability for Some Two-Dimensional Groundwater Contamination Problems, BCSR-38. That publication is reproduced here with minor modification by the authors.

The authors wish to express special appreciation to George A. Urmston, Department Manager, Scientific Consulting and Programming Department, Boeing Computer Services Richland.

This report is issued by the Assessment of Effectiveness of Geologic Isolation Systems (AEGIS) Program conducted by Pac ific Northwest Laboratory. This program is sponsored by the Office of Nuclear Waste Isolation, which is managed by Battelle Memorial Institute under contract DE-AC06-76RLO with the Department of Energy. 


\section{CONTENTS}

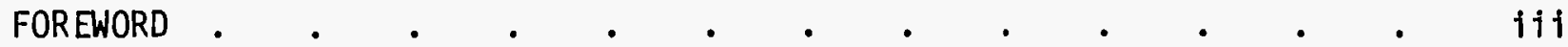

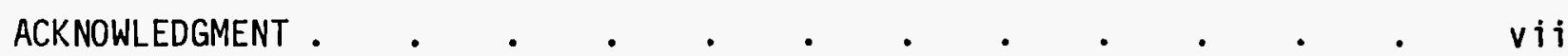

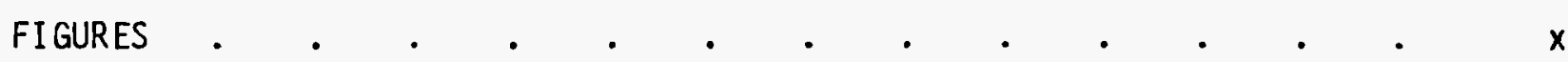

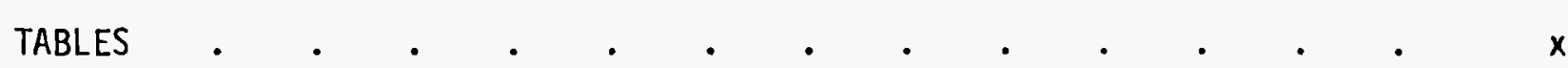

INTRODUCTION

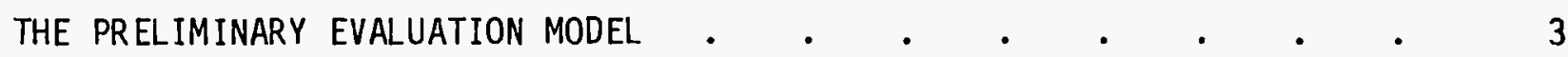

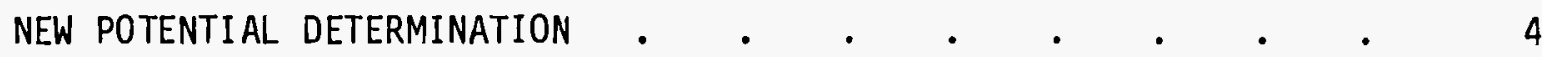

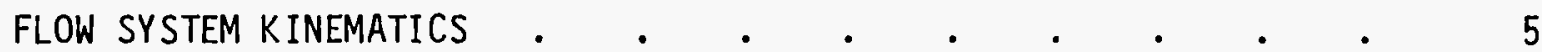

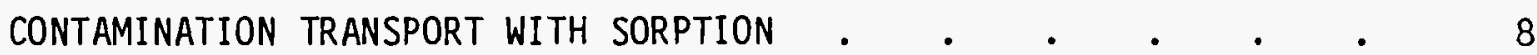

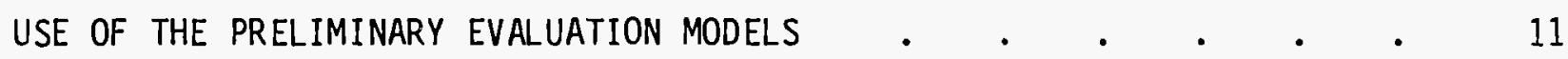

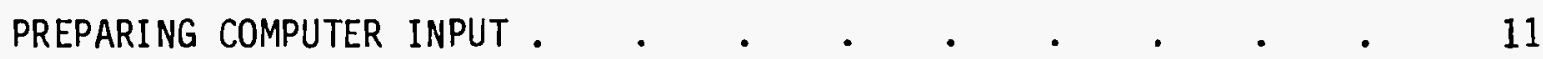

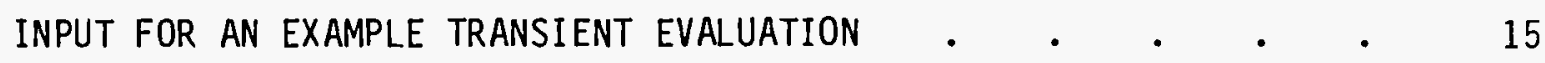

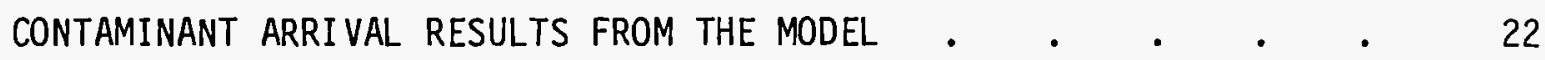

Fluid Pathlines and Advancing Fronts . . . . . 22

Location/Arrival-Time Distribution . . . . . . 23

Location/Outflow-Quantity Distribution . . . . . . 28

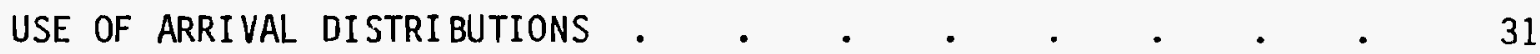

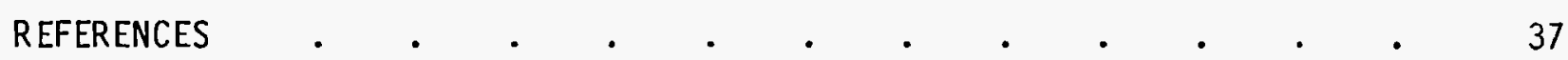

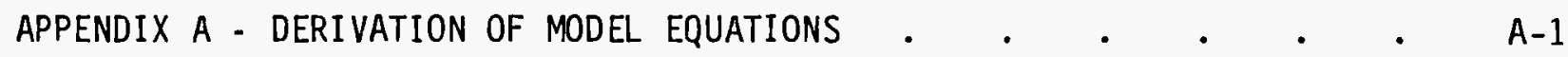

APPENDIX B - USER'S GUIDE FOR THE PRELIMINARY EVALUATION MODELS • • B B-1

APPENDIX C - MAINTAINING OR MODIFYING THE COMPUTER PROGRAMS . • . . C- 1

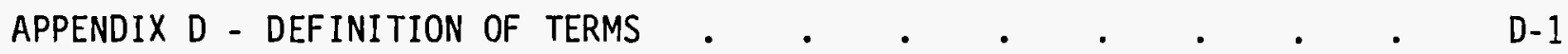




\section{FIGURES}

i Schematic Diagram of Consequence Analysis . . . . . . . . . . iv

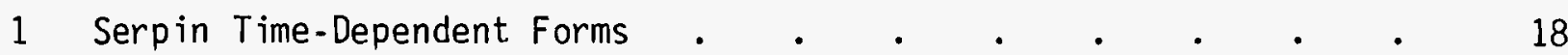

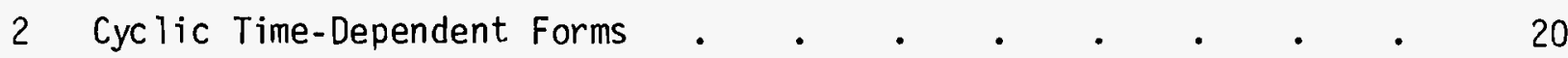

3 Example Transient Flow Results for Fluid Particles Departing Pond

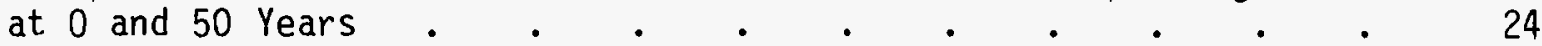

4 Example Transient Flow Results for Fluid Particles Departing Pond at 75 and 100 Years . . . . . . . . . . . . . 25

5 Contamination Location/Arrival-Time Distribution for the Example

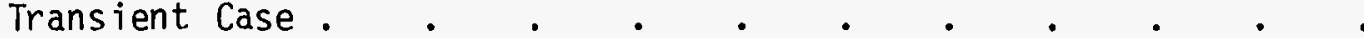

6 Contaminant Location/Outflow-Quantity Distribution at the River for the Example Transient Case . . . . . . .

7 The Concentration of Contamination Entering the River at Various Locations and Times for the Example Transient Case . . .

8 Outflow Rate of Groundwater Contamination with Time for the Example Transient Case . . . . . . . . . . . 34

A-1 Approximation Error at the Major Source or Pond Boundary Caused by the Proximity of the jth Well . . . . . . . A A 6

\section{TABLES}

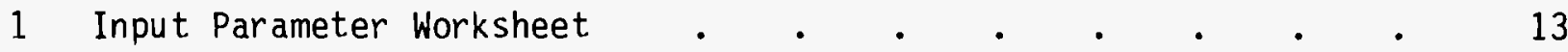

2 Input Parameter Worksheet for the Example Transient Case . $\quad 16$

3 Contaminant Arrival Time at River and Outflow Locations Along

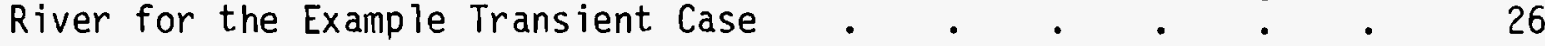

4 Contaminant Arrival Location Along River and Unit Outflow Rate

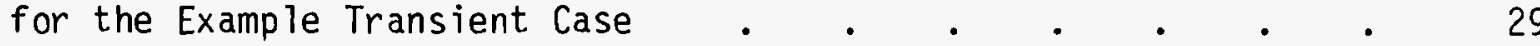

A-1 Definition of Parameters for the Serpintine Equation Form (A-18) . A-9

A-2 Definition of Parameters for the Cyclic Equation Form (A-18) - A-9

B-1 Input Parameter Worksheet for Example Steady Case with Tc-99 Exchange. 


\section{INTRODUCTION}

There are a variety of two-dimensional groundwater contamination problems where a preliminary evaluation is needed. Some of these cases involve sma11, localized problems where elaborate evaluations are not feasible. Even in large, complicated problems requiring extensive long-term studies, a preliminary evaluation is usually the first step. Common to all of these problems is the lack of sufficient data to support comprehensive initial evaluations.

Accordingly, there is a real need for assessment procedures that seek a balance between predictive sophistication and the amount and quality of data available. Further, such procedures must be easy to use and must provide the results needed in a moderate amount of time and at a minimal cost.

A preliminary evaluation capability for two-dimensional groundwater pollution problems was developed as part of the Transport Modeling Task for the Waste Isolation Safety Assessment Program (WISAP). Our approach was to use the data limitations as a guide in setting the level of modeling detail.

This evaluation capability has grown out of earlier developmental efforts and numerous enhancements made in the process of solving a variety of related problems over the past decade. A project for the Research and Development Department of Atlantic Richfield Hanford Company (Nelson 1970) in the late sixties provided a simplified single source leakage model. Later, while working with pollution problems of a commercial mining operation, the features for considering several injection or pumping wells in addition to the central source were incorporated. Shortly after that, the original central source expression was replaced by the more complete and useful doublet expression used now. Recently, out of an underground siting study of nuclear power plants (Allensworth, et a1. 1977), the feature to consider nuclide holdup due to ion exchange of a single component was first included. 
In 1977 WISAP, as part of the Pacific Northwest Laboratory operated for the Department of Energy, conducted a detailed evaluation of fluid and contaminant transport models for use in assessing the safety of geological repositories for solidified nuclear wastes. The preliminary two-dimensional evaluation tool that had evolved during the previous decade was selected by WISAP as the needed preliminary evaluation capability.

This document describes the preliminary evaluation capability prepared for WISAP, including the enhancements that were made because of the authors' experience using the earlier capability. Appendixes $A$ through $D$ supplement the report as follows: Complete derivations of the background equations are provided in Appendix A. Appendix B is a comprehensive set of instructions for users of PATHS. It is written for users who have little or no experience with computers. Appendix $C$ is for the programmer. It contains information on how input parameters are passed between programs in the system. It also contains program listings and test case listings. Appendix $D$ is a definition of terms. 


\section{THE PRELIMINARY EVALUATION MODEL}

A preliminary analys is commonly is restricted by lack of field data. In particular, there is insufficient hydraulic conductivity, porosity, or stratum configuration data to enable a detailed description of the actual field situation. Accordingly, the approach used here involved idealizing the model to keep it within the available data bounds, followed by selecting conservative alternatives at decision points to assure that the predicted results will represent a worst-case situation.

Several idealizations are involved in the model. The fluid release postulated by the model represents a severe, worst possible failure for the storage structure, if one exists. We are assuming that any metal, concrete or lining material of the structure offers no resistance to flow. In effect, the fluid is assumed to be standing in an unlined, cylindrical, vertical cavity in the porous material. The leakage rate of fluid from the pond or vertical cavern is governed only by the hydraulic conductivity of the material, the hydraulic head in the unlined vertical cavity and the other flow system variables.

The two-dimensional, initial-assessment model represents flow in a confined stratum of uniform vertical thickness, and is of large lateral extent in the horizontal plane. The stratum is assumed homogeneous, having isotropic hydraulic conductivity and constant effective porosity. A uniform lateral flow gradient is assumed within the stratum, and the superimposed leakage is from a vertical, cylindrical pond or cavern that completely penetrates the entire stratum. A potential energy head is applied at the pond or structure and is completely dissipated at finite radial distance rather than at an infinite distance, thereby introducing a worst-case situation into the evaluation procedure.

The model can consider as many as 35 wells at optional locations. Wells are represented as completely penetrating, vertical 1 ine sources with steady or time-dependent flow rates.

The model considers both steady and transient saturated flow systems. The steady cases are evaluated by holding the uniform gradient, the head in 
the pond, and the well strengths constant. Under such steady conditions, only one set of flow paths, advancing fronts, and travel times must be calculated, since fluid subsequently leaving the pond or wells traverses identical flow paths, gives duplicate contaminant-front configurations, and has the same elapsed travel times. In the transient cases each new set of fluid particles leaving the pond or wells encounters changing velocity effects. Therefore, a range of typical departure times is selected and the flow paths, front configurations, and travel times are calculated successively for each selected set of fluid particles leaving the contaminant source. Usually the moderate extra effort to get the transient results is more than compensated for by the more realistic representation provided for practical problems.

The model also considers the effect of equilibrium ion exchange reactions for a single contaminant at trace ion concentration. The approximate equilibrium coefficient, or $k_{d}$ approach is utilized to give the ion exchange delay effects for a single constituent. There are, however, no dispersion effects considered in the preliminary model, since field dispersion data is seldom, if ever, available for preliminary evaluations. Omitting dispersion effects also yields the worst overall results in terms of the amount of contaminants reaching the biosphere.

The preliminary evaluation capability is based on an idealized analytical expression for the groundwater potential in a two-dimensional flow system and direct numerical solution of the kinematic pathline equations to allow the approximate contaminant transport evaluation. This approach, though idealized, provides a fast, inexpensive first-cut evaluation tool, consistent with the amount of field data usually available.

The basis of the evaluation tools is summarized in the following paragraphs. Complete derivation of these summary relations is in Appendix $A$; symbols are defined in Appendix D.

\section{NEW POTENTIAL DETERMINATION}

The potential distribution for the two-dimensional flow system can be approximated satisfactorily by superposition of elementary flows. In particular, a uniform lateral flow of gradient strength, $U$, inducing flow in the 
positive $x$ coordinate direction, is added to a combined source and positive doublet (Shames 1962) centered at the origin to represent outflow from the completely penetrating cylindrical pond or cavern of radius $r_{0}$. The pumped wells and injection wells are superimposed as vertical line sinks and sources, respectively, with the center of the $j$ th well located at the point $x_{j}, y_{j}$, to yield an expression for the overall groundwater potential, $\phi$, throughout the porous stratum. Specifically,

$$
\begin{aligned}
\phi= & H-\frac{U R}{H_{0}} x+\frac{U R r_{0}^{2}}{H_{0}}\left(\frac{x}{x^{2}+y^{2}}\right)-\frac{M_{0}}{2 \pi H_{0}} \ln \left(\frac{\sqrt{x^{2}+y^{2}}}{r_{0}}\right) \\
& -\sum_{j=1}^{j=N} \frac{M_{j}}{2 \pi H_{0}} \ln \sqrt{\frac{\left(x-x_{j}\right)^{2}+\left(y-y_{j}\right)^{2}}{x_{j}{ }^{2}+y_{j}^{2}}}
\end{aligned}
$$

with the remaining variables and parameters defined in Appendix $D$.

The potential, $\phi$, is defined by Equation (1) in the region for all locations $\left(x^{2}+y^{2}\right)>r_{0}{ }^{2}\left(r_{0}\right.$ is the central pond radius) except at the well coordinates $x_{j}$ and $y_{j}$. The potential satisfies the LaPlace Equation describing flow in homogeneous isotropic material. The potential, $\phi$, also satisfies the boundary conditions that $\phi=H \pm \varepsilon$ when $x^{2}+y^{2}=r_{0}{ }^{2}$. As Appendix A shows, $\varepsilon$ is negligibly small if

$$
\sqrt{\frac{r_{0}{ }^{2}}{\left(x_{j}^{2}+y_{j}^{2}\right)}}<0.01
$$

Equation (1), subject to Equation (2), provides the potential distribution for subsequent use in determining the flow system kinematics.

\section{FLOW SYSTEM KINEMATICS}

The flow system kinematics provide the pattern, or geometry of flow, in the subsurface system. The pathlines for individual fluid particles through the flow system provide the points of emergence at outflow boundaries. These locations and the arrival time of fluids at outflow boundaries are determined by the path function. The stream function gives the flux rate 
at the outflow boundary, and throughout the entire system. Together, the path function and stream function provide the results needed for the arrival distributions with fluid-coincident contaminants.

The characteristic equations for the pathlines are most useful in generating the flow paths and obtaining the travel times. They come directly from the definition of the macroscopic pore velocity utilizing Darcy's Law, as demonstrated by Equations (A-25) through (A-31) of Appendix $A$. In particular, from Equations (1) and (A-27), the pair of pathl ine differential equations are

$$
\begin{aligned}
\frac{d x}{d t}= & \frac{U R}{P H_{0}}\left\{1+\frac{r_{0}{ }^{2}}{\left(x^{2}+y^{2}\right)}\left[\frac{2 x^{2}}{x^{2}+y^{2}}-1\right]\right\}+\frac{H}{P \ln \left(\frac{1}{r_{0}}\right)}\left(\frac{x}{x^{2}+y^{2}}\right) \\
& +\sum_{j=1}^{j=N} \frac{M_{j}}{2 \pi H_{0} P}\left[\frac{\left(x-x_{j}\right)}{\left(x-x_{j}\right)^{2}+\left(y-y_{j}\right)^{2}}\right],
\end{aligned}
$$

and

$$
\begin{aligned}
\frac{d y}{d t}= & \frac{U R}{P H_{0}}\left[\frac{2\left(r_{0}\right)^{2} x y}{\left(x^{2}+y^{2}\right)^{2}}\right]+\frac{H}{P \ln \left(\frac{1}{r_{0}}\right)}\left(\frac{y}{x^{2}+y^{2}}\right) \\
& +\sum_{j=1}^{j=N} \frac{M_{j}}{2 \pi P H_{0}}\left[\frac{y-y_{j}}{\left(x-x_{j}\right)^{2}+\left(y-y_{j}\right)^{2}}\right]
\end{aligned}
$$

The contamination departs from the pond or vertical cavern at $t_{0}$; i.e.,

$$
x\left(t_{0}\right)=x_{0}
$$

and

$$
y\left(t_{0}\right)=y_{0}
$$

where

$$
\left(x_{0}\right)^{2}+\left(y_{0}\right)^{2}=r_{0}^{2} .
$$

Simultaneous solution of Equations (3) and (4) using the initial conditions in Equations (5) and (6) is accomplished numerically to yield pathlines and 
travel times to the pumped wells or to the remote outflow boundary. The calculations, using a fourth-order Runge-Kutta numerical solution scheme, are made using a computer program.

The flux, or fluid flow rate, at any outflow boundary is available from the instantaneous stream function, which is simply the complex conjugation of the potential expressions used in Equation (1). Upon superposition of the simple basic flows, the instantaneous stream function (derived in Equations $(A-34)$ through $(A-43)$ in Appendix $A)$ is

$$
\begin{aligned}
\frac{Q_{i}}{Q_{0}} & =\frac{U R \ln \left(\frac{1}{r_{0}}\right)}{2 \pi H_{0}} y+\frac{U R \ln \left(\frac{1}{r_{0}}\right) r_{0}{ }^{2} y}{2 \pi H_{0}\left(x^{2}+y^{2}\right)}+\frac{H}{2 \pi} \arctan \left(\frac{y}{x}\right) \\
& +\sum_{j=1}^{j=N}\left[\frac{M_{j} \ln \left(\frac{1}{r_{0}}\right)}{4 \pi^{2} H_{0}}\right]\left[\arctan \left(\frac{y-y_{j}}{x-x_{j}}\right)-\arctan \left(\frac{-y_{j}}{x_{0}-x_{j}}\right)\right]
\end{aligned}
$$

where

$$
Q_{0}=\frac{2 \pi D_{0} K_{0} H_{0}}{\ln \left(\frac{1}{r_{0}}\right)}
$$

from Equation $(A-41)$. Equations (8) and (9) are used to determine the relative flux and are most easily visualized in steady flow systems, al though they are equally useful on an instantaneous basis at any specific time in a transient flow system.

Often in transient flow systems it is helpful to calculate the variation of the groundwater unit outflow fluxes along a river, for example, rather than use the cumulative stream function. The instantaneous flux per unit outflow length, q, can be calculated using

$$
q=p \frac{d x}{d t}
$$

The equation for direct calculation of $q$ is obtained by substituting the expression for $\frac{d x}{d t}$ from Equation (3) into Equation (10).

Equations (8) through (10) provide the outflow rates either as the relative cumulative flux or as the flux per unit length of outflow. These 
results provide the outflow quantity component of the location/outflowquantity distribution required for evaluating the environmental consequences of a subsurface contamination problem. With this data, outflow quantities can be obtained easily on a computer.

The remaining part of the prel iminary evaluation capability is a simple extension of the flow kinematics al ready discussed. It includes the effect of ion sorption on contaminant transport.

\section{CONTAMINANT TRANSPORT WITH SORPTION}

A single chemical species at trace concentration with equilibrium sorption is readily considered with only minor modifications of the kinematic equations provided in the preceding section. Without considering dispersion, as shown in Appendix $A$ in Equations (A-44) through ( $A-52)$, the characteristic contaminant transport equations are

$$
\begin{aligned}
\frac{d x}{d t} & =\frac{U R}{P H_{0} K}\left\{1+\frac{r_{0}^{2}}{\left(x^{2}+y^{2}\right)}\left[\frac{2 x^{2}}{x^{2}+y^{2}}-1\right]\right\}+\frac{H}{K P \ln \left(\frac{1}{r_{0}}\right)}\left(\frac{x}{x^{2}+y^{2}}\right) \\
& +\sum_{j=1}^{j=N} \frac{M_{j}}{2 \pi H_{0} P K}\left[\frac{\left(x-x_{j}\right)}{\left(x-x_{j}\right)^{2}+\left(y-y_{j}\right)^{2}}\right]
\end{aligned}
$$

and

$$
\begin{aligned}
\frac{d y}{d t} & =\frac{U R}{P H_{0} K}\left[\frac{2\left(r_{0}\right)^{2} x y}{\left(x^{2}+y^{2}\right)^{2}}\right]+\frac{H}{K P \ln \left(\frac{1}{r_{0}}\right)}\left(\frac{y}{x^{2}+y^{2}}\right) \\
& +\sum_{j=1}^{j=N} \frac{M_{j}}{2 \pi P H_{0} K}\left[\frac{y-y_{j}}{\left(x-x_{j}\right)^{2}+\left(y-y_{j}\right)^{2}}\right]
\end{aligned}
$$

where

$$
k=1+\frac{B_{d} K_{d}}{P}
$$

with $B_{d}$ as the bulk density of the porous material; $K_{d}$, the equilibrium exchange distribution coefficient; and $P$, the porosity. 
Comparing Equations (11) and (12) with the original kinematic characteristic Equations (3) and (4) shows that the idealized transport involved only incorporating the new parameter $K$ defined by Equation (13). Accordingly, the approximate transport results can be readily obtained through applying the same Runge-Kutta numerical integration scheme as previously used. 


\section{USE OF THE PREL IMINARY EVALUATION MODELS}

The model equations and detailed formulation in Appendix $A$ were utilized to build interactive "self-help" or "coaching" computer programs. These programs allow a user to obtain the results for a specific problem simply and quickly via a remote job entry terminal. Every effort was made to get results to the user quickly and inexpensively. Our intent is to have the user on the computer as quickly as possible, without having to spend time mastering computer programming or learning machine-related details. Interactive programs make using the computer fairly easy. Through the computer terminal, the programs asks questions that the user responds to by typing in YES, NO, or by providing the input value requested. If the question is confusing, the user may at any time type in HELP, whereupon a more complete description or further suggestions are provided by the computer. The question is then repeated and the user must respond before the program proceeds to the next item.

In the course of this interactive process, all the data inputs and controls are provided. When all the necessary data have been entered, at the user's instruction, the program automatically submits a batch computer run to most economically generate the calculations, listings and plots needed. Subsequently, the results from the batch run are automatically stored in files awaiting interrogation from the terminal. Upon request, the summary results are provided to the user--usually within a short time-at the terminal; plots and more extensive printout, if requested, are produced in the computer center and sent to the user. This gives the user summary information in a matter of minutes and the more detailed results in a few hours. Appendix B provides complete instructions for using the interactive self-help computer programs. Example cases are given in the appendix and in the following section to help use the programs.

PREPARING COMPUTER INPUT

There are various ways to assemble the input values one needs to use the interactive computer programs. One of them is to collect the case data on the worksheet in Table 1. Benefits of using the worksheet are that consistent units are used for the various input values and that complete 
data are at hand. Another approach is to use the worksheet to collect the first few most pertinent input values and rely more on the coaching features of the programs.

A user may opt to rely exclusively on the coaching programs. This way a user can make a dry run with the programs on a terminal to build an input worksheet. This is done by entering the known input values and making the machine-coached selections. For unknown values or for difficult selections in the dry run, an arbitrary number or choice is made for the trial input. Subsequently, the dry run is terminated using the "escape" feature (as instructed by the program) and no actual batch run is made. In this way, for a few pennies of computer time, the user gets a quick terminal printout that serves as a draft input worksheet. After some checking and a few penciled corrections, the printout becomes a complete and detailed input aid for the actual run. However, the one-page input worksheet in Table 1 is used for the example preliminary evaluation in the following section. 


\section{TABLE 1. Input Parameter Worksheet.}

\section{INPUT PARAMETER WORKSHEET}

CASE :

1. $=D_{0}$ is the stratum thickness.

2. $\ldots R$ is the distance to the boundary. Units must be the same as $D_{0}$.

3. $=$ XMAX/TMAX are the stopping distance or time for pathlines.

4. $=r_{0}$ is the cavern or pond radius. Units must be the same as $D_{0}$.

5. $\longrightarrow=H_{0}$ is the head in the cavern. Units must be the same as $D_{0}$.

6. ${ }_{-}=K_{0}$ is the stratum hydraulic conductivity. Length units must be the same as $0_{0}$. Whatever time units are in $k_{0}$ sets the units of the travel time.

7. $=P$ is the effective porosity.

8. $\ldots$ S or T. A steady (S) or transient (T) case.

9. $=$ UO is the initial un iform gradient value. See Figure 1 .

10. $=U M$ is the laterial gradient value. See Figure 1 .

11. $=T M$ in time units of $K_{0}$.

12. _______ $=A, B, C$ are three time-related integers.

13. $=S$ or $E$ or $C$. Use the serpin (S), exponential (E), or cyclic (C) head variation in the cavern.

14. $=H I$ is the initial head.

15. $=H M$ is the maximum head.

16. $=T N$ in time units of $K_{0}$.

17. $, \quad=D, E, F$. See Figure 1 .

18. $=J$ is total number of wells.

19. $=00$ is the angle (deg) around the cavern wall to the starting point for the first pathline.

20. $=O M$ is the maximum angle (deg) to the last pathline starting point along the cavern wall.

21.

$=N \theta$ is the number of pathlines to be generated from $\Theta 0$ to and including $\Theta M$.

22.

$=k \theta$ is the number of pathlines wanted between OM and $179.99+{ }^{\circ}$.

23. is the departure time of the first fluid particles leaving the cavern.

24. $=t_{f}$ is the departure time of the final fluid particles.

25.

$=N T$ is the number of equally spaced departure times beginning with $t_{0}$ and ending with $t_{f}$.

26. ${ }_{-}=K_{d}$ is the equilibrium exchange distribution coefficient.

27. $=B_{d}$ is the bulk density of the porous material.

28. inch wide plots are desired. Request either a 30 " or 11" wide by 30 "plot.

29. $=$

30. $=x$ XENTER The location ( $x \& y$ in inches) on the plot where

31. $=$ SCALE is the scale for the plot. 


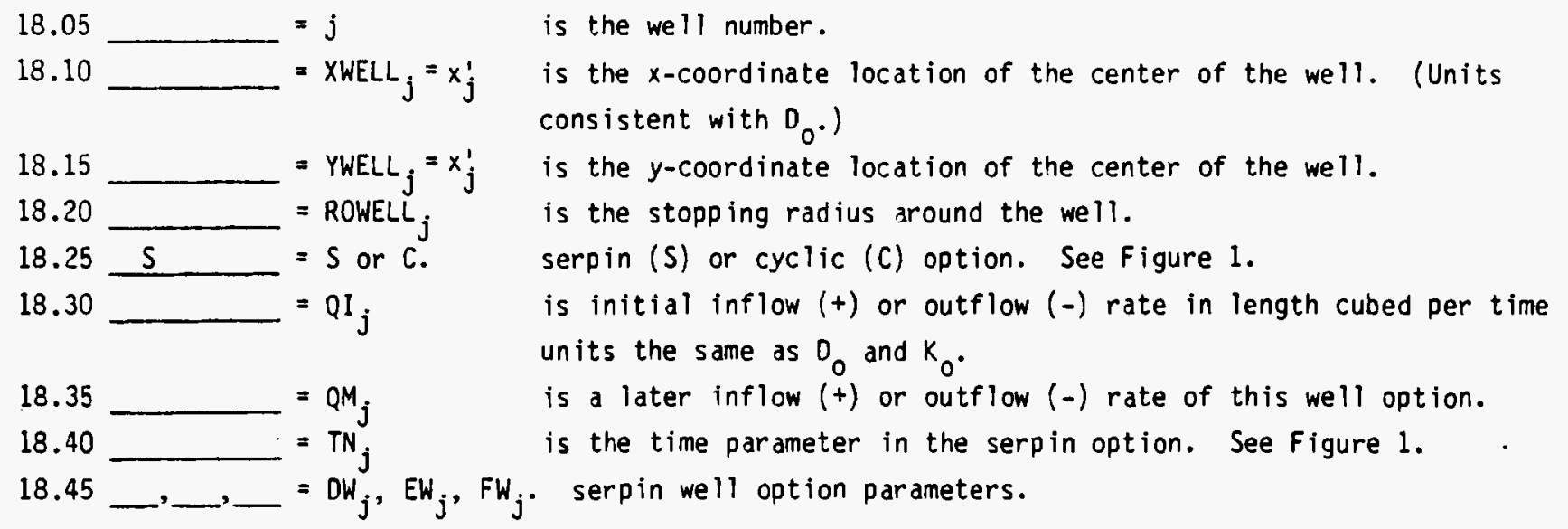

\section{CYCLIC OPTION}

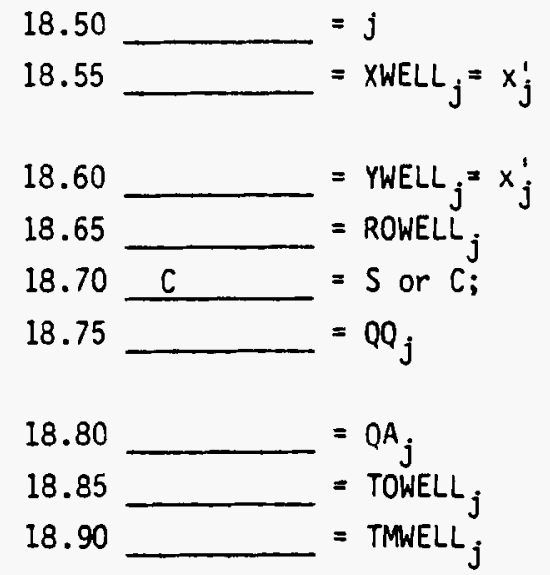

is the well number.

is the $x$-coordinate location of the center of the well. (Units consistent with $D_{0_{0}}$ )

is the $y$-coordinate location of the center of the well.

is the stopping radius around the well.

serpin (S) or cyclic (C). See Figure 2.

is the mean inflow $(+)$ or outflow $(-)$ rate in length cubed per time units the same as $D_{0}$ and $K_{0}$.

is the amplitude of the cyclic inflow $(+)$ or outflow $(-)$ rate. is the initial or beginning time for the cyclic well option. is the later cyclic time parameter.

PATHLINE - IRREGULAR STARTING COOROINATES

(If $\Theta 0$ in Item 19 equals $\Theta M$ in Item 20 then $N \theta$ pathlines

will be generated from the individual coordinates provided below.)

21. $=\mathrm{Ne}$ is the number of input data sets to be entered for starting pathlines $(1 \leq i \leq N O)$.

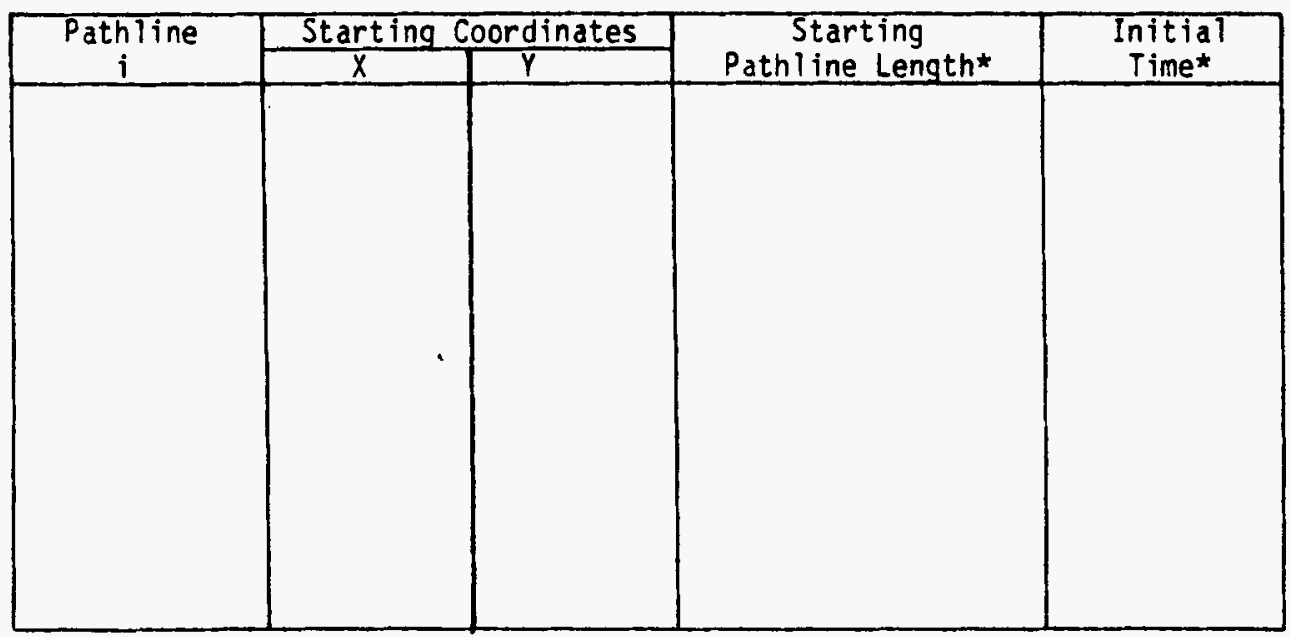




\section{INPUT FOR AN EXAMPLE TRANSIENT EVALUATION}

An example evaluation using the model is included to show what results are obtainable and to help expla in the inputs needed. Typical input values using the input parameter worksheet (Table 1) are provided and discussed.

The first seven parameters on the worksheet in Table 2 are the primary variables that must be entered in the model; they should represent the very best measurements or estimates of the respective properties that can be obtained. Parameter 8 simply indicates whether the system involves transient flow or is restricted to steady flow. Parameters 9 through 12 provide the flexibility to represent the change with time of the uniform gradient strength, $U$ (see Figure 1). For this particular example case, the uniform gradient is constant with a value of 0.001 . From Figure $1(a)$, we set $U_{0}=0.001$ and $U_{m}=0.001$ for input items 9 and 10 , which gives $U=U_{0}$ for values for $T M=A=B=C=1$, hence the value of 1 is used in items 11 and 12 .

Parameters 13 through 17 allow the user to represent a variety of pond or cavern head variations with time. If the user has detailed information about the time dependence, a programmer can easily build a subroutine for direct use. However, a look at the consequences of various types of time dependence, rather than a specific detailed representation in time, is probably most useful for an initial evaluation. In the latter case, a series of variations that can be easily used are very helpful. Three broad options have been built into the programs for direct use and we have found that they cover most situations.

The three time-dependent options are the serpin, exponential leakage, and cyclic options. Each is discussed in our example case. For input item 13 (in Table 2), the user selects one of the three time-variation options to be applied. The serpin ( $S$ ) option will be used for the example transient case so $S$ is entered in item 13. The specific time variation chosen for the example case from the several serpin alternatives is in Figure $1(\mathrm{~g})$. The desired pond or cavern head begins at a 4-foot head, gradually increases to a maximum of 8 feet at 50 years and then gradually returns to the original head of 4 feet. Using the schematic in Figure $1(\mathrm{~g})$, the tabular definitions and conditions provide the inputs: $H I=4 \mathrm{ft}, H M=8 \mathrm{ft}, T N=50 \mathrm{yr}, D=0$, $E=1$ and $F=1$, which are entered as input items 14 through 17 , respectively, on the example transient input worksheet in Table 2. 


\section{CASE: Example Transient Case (Two Wells)}

1. $100 \mathrm{Al}_{\mathrm{e}}=\mathrm{D}_{0}$ is the stratum thickness.

2. $8500 \mathrm{ft}_{\mathrm{f}}=\mathrm{R}$ is the distance to the boundary. Units must be the same as $0_{0}$.

3. $8500 \mathrm{ft}=$ XMAX/TMAX are the stopping distance or time for pathlines.

4. $250 \mathrm{ft}=r_{0}$ is the cavern or pond radius. Units must be the same as $D_{0}$.

5. $\frac{10 \mathrm{H}_{1}}{10}=\mathrm{H}_{0}$ is the head in the cavern. Units must be the same as $0_{0}$.

6. 1825 ft/yro $=K_{0}$ is the stratum hydraulic conductivity. Length units must be the same as $D_{0}$. Whatever time units are in $k_{0}$ sets the units of the travel time.

7. $0.2=P$ is the effective porosity.

8. $T=S$ or $T$. A steady $(S)$ or transient $(T)$ case.

9. $\underline{0.001}=40$ is the initial uniform gradient value. See Figure 1 . .

10. $0.001=U M$ is the laterial gradient value. See Figure 1 .

11. $\frac{1}{1}=M$ in time units of $K_{0}$.

12. $L, L, L=A, B, C$ are three time-related integers.

13. $S=S$ or $E$ or $C$. Use the serpin (S), exponential (E), or cyclic (C) head variation in the cavern.

14. $4 \mathrm{ft}$. $=\mathrm{HI}$ is the initial head.

15. $\frac{8 \mathrm{ft}}{\mathrm{s}}=\mathrm{HM}$ is the maximum head.

16. 50 Yr. $=T N$ in time units of $K_{0}$.

17. $0,1,1=D, E, F$. See Figure 1 .

18. $\frac{2}{0^{\circ}}=\mathrm{J}$ is total number of wells.

19. $\frac{0^{\circ}}{0^{\circ}}=\theta 0$ is the angle (deg) around the cavern wall to the starting point for the first pathline.

20. $160^{\circ}=6 M$ is the maximum angle (deg) to the last pathline starting point along the cavern wall.

21. $\frac{9}{9}=N \theta$ is the number of pathlines to be generated from $\theta 0$ to and including $\Theta M$.

22. $\frac{1}{1}=K \theta$ is the number of pathlines wanted between $\Theta M$ and $179.99+^{\circ}$.

23. - $y r_{-}=t_{0}$ is the departure time of the first fluid particles leaving the cavern.

24. $100 y r_{i}=t_{f}$ is the departure time of the final fluid particles.

25. $\frac{5}{5}=N T$ is the number of equally spaced departure times beginning with $t_{0}$ and ending with $t_{f}$.

26. $=K_{d}$ is the equilibrium exchange distribution coefficient.

27. $=B_{d}$ is the buik density of the porous material.

28. $30 \mathrm{me}=$ inch wide plots are desired. Request either a 30 " or 11" wide by 30 " plot.

29. 3 in $=$ XCENTER The location ( $x \& \mathrm{y}$ in inches) on the plot where

30. $\frac{210 .}{210}=$ YCENTER the cavern center is to be located.

31. $1000 \mathrm{ff} / \mathrm{m}=$ SCALE is the scale for the plot. Length in units of $D_{0}$ per inch. 


\section{TABLE 2. Continued}

INPUT FOR WELLS (J sets are required)

\section{SERPIN OPTION}

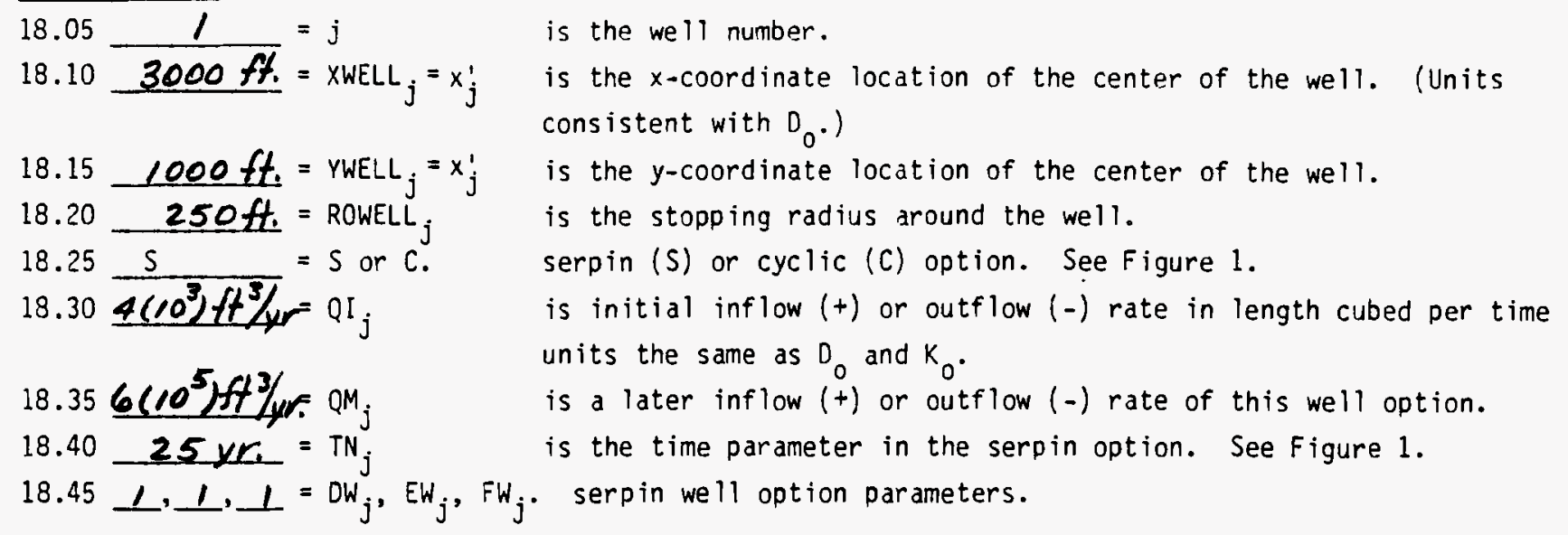

CYCLIC OPTION

\begin{tabular}{|c|c|c|}
\hline 18.50 & 2 & $=j$ \\
\hline 18.55 & $5500 \mathrm{ft}$ & $=X W E L L_{j}=x_{j}^{\prime}$ \\
\hline 3.60 & $3000 \mathrm{ft}$. & $=$ YWELL $_{i}=x_{i}^{\prime}$ \\
\hline 18.65 & $300 \mathrm{ft}$. & $=$ ROWELL $_{i}$ \\
\hline 18.70 & $C$ & $=S$ or $C_{i}$ \\
\hline 18.75 & 0.0 & $=Q_{j}$ \\
\hline 18.80 & $5\left(10^{5}\right) \mathrm{ft}^{3}$ & \\
\hline 18.85 & $50 \mathrm{yr}$. & TOWELL, \\
\hline 18.90 & $450 \mathrm{kr}$ & $=$ TMWELL $_{j}$ \\
\hline
\end{tabular}

is the well number.

is the $x$-coordinate location of the center of the well. (Units consistent with $D_{0}$. )

is the $y$-coordinate location of the center of the well.

is the stopping radius around the well.

serpin (S) or cyclic (C). See Figure 2.

is the mean inflow $(+)$ or outflow $(-)$ rate in length cubed per time units the same as $D_{0}$ and $K_{0}$.

is the amplitude of the cyclic inflow (t) or outflow $(-)$ rate.

is the initial or beginning time for the cyclic well option.

is the later cyclic time parameter.

\section{PATHLINE - IRREGULAR STARTING COORDINATES}

(If 00 in Item 19 equals $O M$ in Item 20 then $N O$ pathlines

will be generated from the individual coordinates provided below.)

21. $=N \theta$ is the number of input data sets to be entered for starting pathlines $(1 \leq i \leq N \theta)$.

\begin{tabular}{|c|c|c|c|}
\hline Pathline & $\frac{\text { Starting Coordinates }}{x}$ & Starting & Initial \\
\hline & & & \\
\hline & & & \\
\hline & & & \\
\hline & & & \\
\hline & & & \\
\hline & & & \\
\hline & & & \\
\hline & & & \\
\hline
\end{tabular}




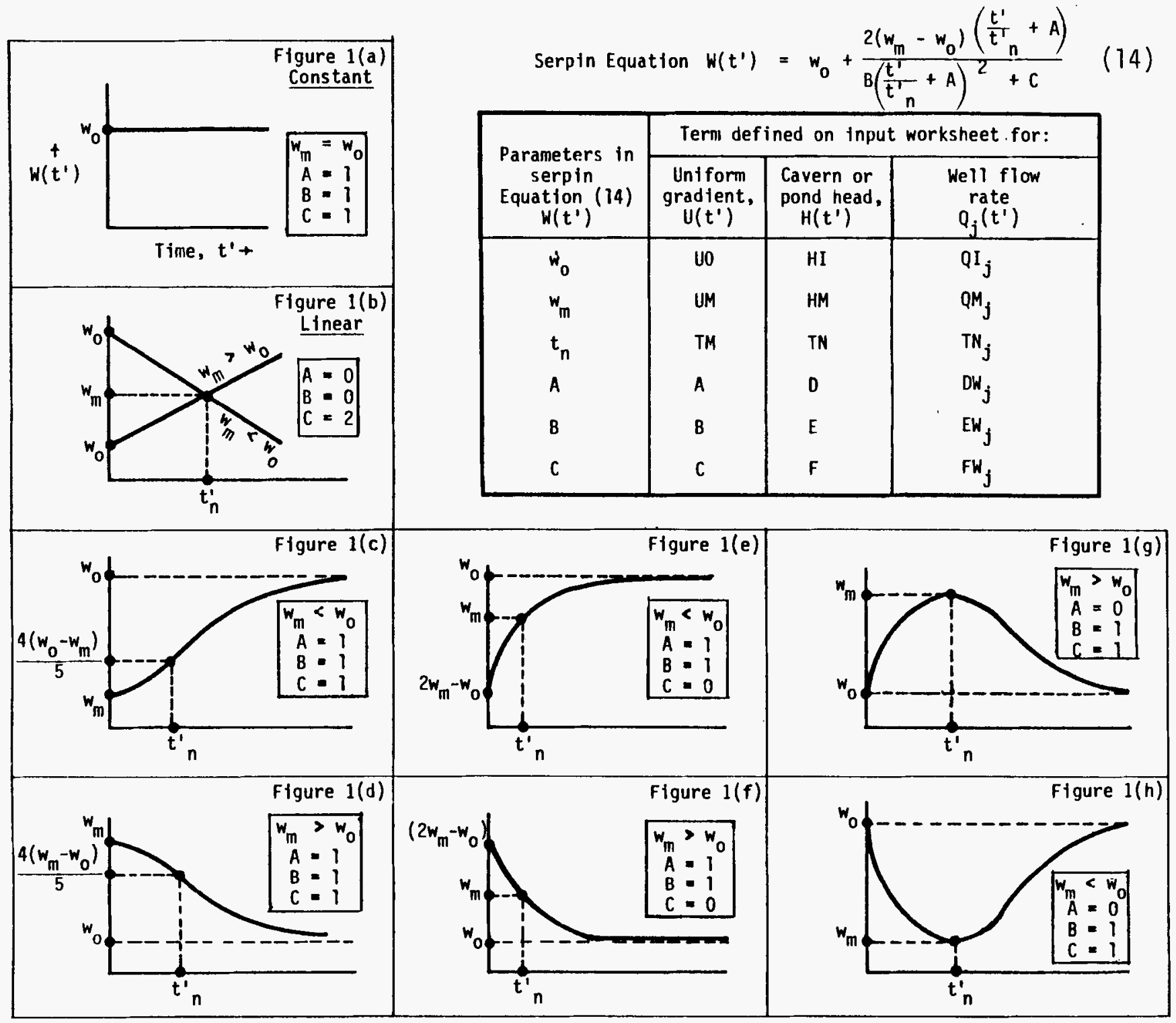

FIGURE 1. Serpin Time-Dependent Forms 
If the exponential leakage (E) option, which considers the case of the head diminishing as the fluid seeps from the cavern, had been chosen then no special inputs would be required for items 14 through 17 . The parameters necessary to calculate the falling head or exponential leakage case have been entered already (see Equations ( $A-23)$ and $(A-24)$ in Appendix $A$ ).

Input item 18 is the number of wells to be considered in the flow system. Two injection wells are used in the example transient case, so $J=2$. The specific well data needed are described on the back of the worksheet.

The first injection well with an inflow rate, $Q_{j}\left(t^{\prime}\right)$, is represented by the serpin time dependence illustrated in Figure $1(\mathrm{c})$. The center of the first well (i.e., $j=1$ entered in item 18.05 on the back of the worksheet) is located at $x_{1}=3000 \mathrm{ft}$ and $y_{1}=1000 \mathrm{ft}$. The $x$ and $y$ coordinate distances are always measured from the center of the pond or cavern, which has coordinates $x=0, y=0$. Accordingly, input items 18.10 and 18.15 are 3000 feet and 1000 feet, respectively. The stopping radius, ROWELL $j$, for item 18.20 is required since the well is represented as a singularity. Numerical difficulties will occur if one approaches a well too closely; two or three hundred feet is a reasonable distance away from such a well, so 250 feet was used in the example.

The injection rate of the first well is represented by the serpin-form time dependence with a lower injection rate $\mathrm{QI}_{1}=4000 \mathrm{ft}^{3} / \mathrm{yr}$, a maximum rate $Q M_{1}=600,000 \mathrm{ft}^{3} / \mathrm{yr}$, with a time parameter $\mathrm{TN}_{1}=25 \mathrm{yr}$, and integer parameters of $A=B=C=1$ to complete the input for the first well.

The second well represented by $j=2$ is located at $x_{2}=5500 \mathrm{ft}$ and $y_{2}=3000 \mathrm{ft}$ with a stopping radius of $300 \mathrm{feet}$. These values provide input items $18.50,18.55,18.60$ and 18.65. This well is used to illustrate the cyclic option for time dependence, so item 18.70 is specified as C. Figure 2 is convenient in selecting the cyclic parameters. For this example case, Figure $2(b)$ is used with a mean injection rate $Q_{2}=0$ beginning at $\mathrm{TO}_{2}=$ $50 \mathrm{yr}$. The amplitude of the injection rate $Q_{2}$ is $500,000 \mathrm{ft}^{3} / \mathrm{yr}$ with a maximum cycle time $\mathrm{TM}_{2}=450 \mathrm{yr}$, which completes the well input parameters for the example transient case. 


\section{Cyclic Equation}

$$
\begin{aligned}
& W\left(t^{\prime}\right)=W \quad \text { if } W>0 \\
& W\left(t^{\prime}\right)=0 \quad \text { if } W \leq 0 \\
& \text { where: } \\
& W=w_{m c}+w_{o c} \sin \left[\left(\frac{t^{\prime}-t_{O C}}{t_{m c}-t_{o c}}\right) 2 \pi\right]
\end{aligned}
$$

\begin{tabular}{|c|c|c|}
\hline \multirow{2}{*}{\begin{tabular}{c} 
Parameters in $\begin{array}{c}\text { Tyclic } \\
\text { Equation (16) }\end{array}$ \\
\cline { 2 - 3 }
\end{tabular}} & $\begin{array}{c}\text { Cavern or pond } \\
\text { head, } H\left(t^{\prime}\right)\end{array}$ & $\begin{array}{c}\text { Well flow rate, } \\
Q_{j}\left(t^{\prime}\right)\end{array}$ \\
\hline$w_{m C}$ & HMC & $Q Q_{j}$ \\
$w_{O C}$ & $H A C$ & $Q A_{j}$ \\
$t_{O C}$ & TOC & $T O_{j}$ \\
$t_{m c}$ & TMC & $T M_{j}$ \\
\hline
\end{tabular}

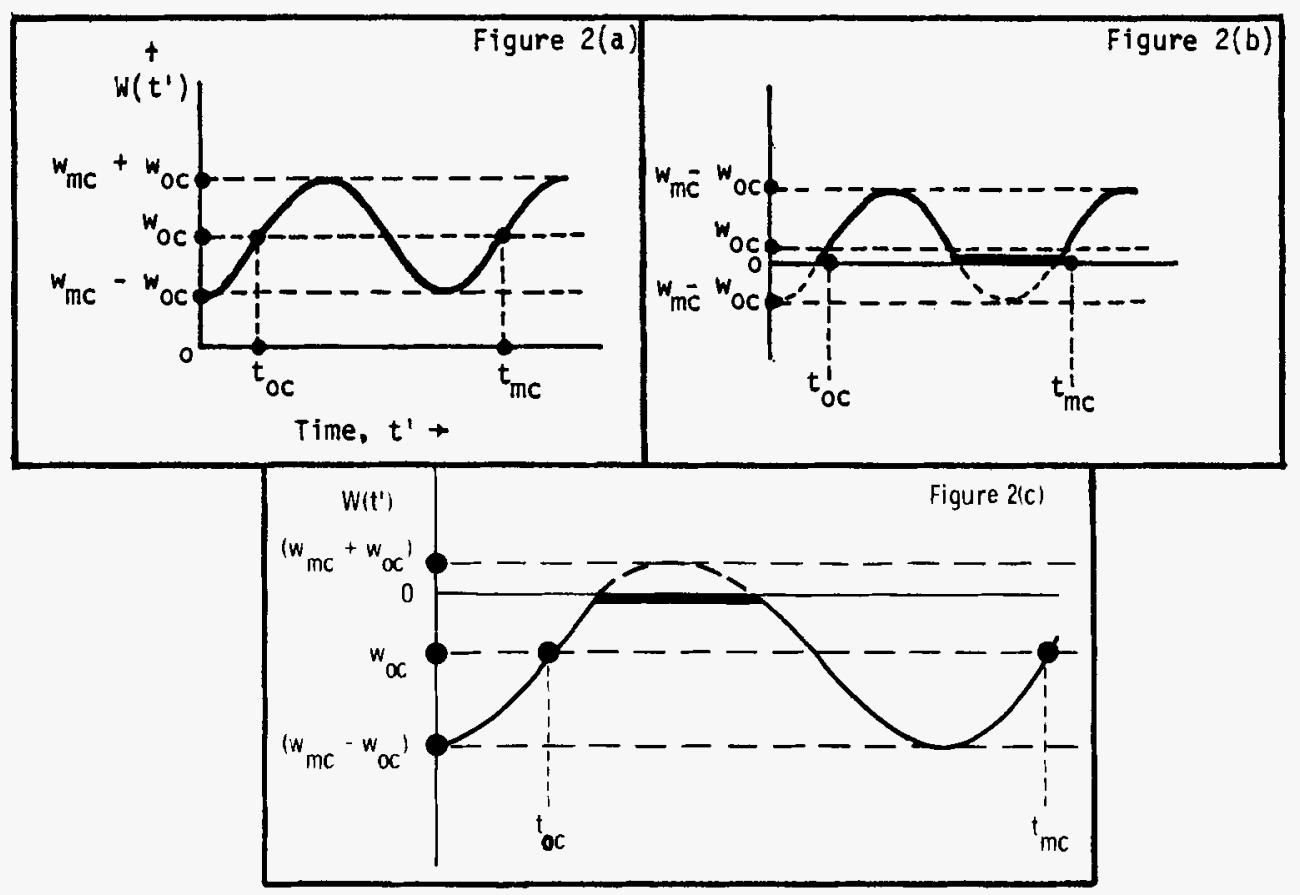

FIGURE 2. Cyclic Time-Dependent Forms 
The remaining input for the example case involves items 19 through 31 in Table 2. Items 19 through 22 allow the user to select the location for starting the pathlines, thereby allowing the fluid particles to be followed. In item 19, the user selects the angle between the $x$ axis and the point on the cavern or pond wall where the first pathline is to originate. One wants to look at the travel along the shortest pathline so a starting angle $\theta 0=0$ is used. The maximum angle of interest was set equal to 160 degrees for $\theta \mathrm{M}$. If $N \theta=9$, then a pathline originating at $\theta=0$ and pathlines beginning every $(160-0) /(9-1)=20 \mathrm{deg}$ around the cavern wall, up to and including the last pathline beginning at 160 degrees, are generated. This should provide a good beginning set of fluid particle pathlines. The input parameter $k \theta$ is also set to 1 here to get an additional pathline between 160 and 179.99 degrees. Use of the $K \theta$ parameter is helpful in getting more pathlines near 180 degrees without specifically using the latter value. There is a stagnation point (i.e., a point of zero velocity) upstream of $\theta=180$ that will use excessive computer time if one attempts to generate a path through or very near it. The $K \theta$ input feature allows pathlines to be generated near 180 degrees while minimizing the difficulties with the stagnation point.

The next three parameters (items 23 through 25) specify the times for which fluid particles leaving the cavern wall will be traced. The first contaminated fluid particles leaving the cavern should be followed so $t_{0}$ is set equal to zero (item 23). A useful final set of fluid particles to follow in time are those departing at 100 years, $t_{f}=100 \mathrm{yr}$ (item 24) . The value for NT $=5$ was chosen, which means the fluid particles departing at $0,25,50,75$ and 100 years will be generated by the model, so NT = 5 is shown for input item 25.

No input values are provided for data items 26 and 27 (the $k_{d}$ and bulk density) since exchange reactions for a particular ion are not considered in this example case. Individual fluid particles or the movement of a perfect tracer such as tritium, sulfate, or chloride are being evaluated in this example.

The remaining worksheet inputs in Table 2 are needed to generate plots of the results. Item 28 determines the width of the plot. If a rather narrow plot is expected, as in our example case, then 11-inch wide paper is specified. When in doubt, it is usually best to request the 30 -inch 
width. The XCENTER and YCENTER values in items 29 and 30 specify the location, in inches, from the lower right-hand corner of the plotting sheet where the center of the cavern or pond will be positioned on the plots. In this example, 3 inches to the right of the lower left-hand corner of the plotter paper and 2 inches above should work. The last input item is the plotting scale. It is the number of length units in the real problem to be represented per inch of length on the plot. A plot scale of $1000 \mathrm{ft} / \mathrm{in}$. is used in this case. This scale and the case title are automatically added to the finished computer-generated plot.

This example worksheet (Table 2) contains the major inputs needed by the user. Those few additional questions not specifically covered by the worksheet either will be obvious to the user or readily available using the HELP feature. So, armed with an input worksheet (that reflects the case at hand), a terminal and the Appendix B User's Guide, a computer novice should now be able to get the arrival results needed. (The example transient case is presented in complete detail in Appendix B.)

CONTAMINANT ARRIVAL RESULTS FROM THE MODEL

The contaminant arrival results are available from the interactive and batch runs described in Appendix B. Among the results provided are 1) the fluid or contaminant flow paths and the rate of advance and shape of the contaminant fronts moving through the subsurface region, 2) the location and time of contaminant arrival at the biosphere interface, and 3 ) the amount of contaminated fluid arriving with passing time. These are the results necessary to evaluate the environmental consequences ( $\mathrm{Nelson}, 1976$ ). The example case results will be used to illustrate the results obtained from the preliminary evaluation methods.

Fluid Pathlines and Advancing Fronts

The fluid pathline provides the expected location of the fluid at various times during the gradual movement from the pond or cavern to the remote boundary (river, in this example). The pattern of the advancing front is developed by following representative fluid particles along the paths traversed with passing time. If, at a specific time, a line is passed through the location of each particle on its pathline, an isochronal line 
(i.e., the position of the advancing front of fluid particles at that particular time) is determined. In this way, the changing locations of fluid particles are conveniently indicated by the pathl ines and isochronal 1 ines.

The pathl ines and isochronal lines for the example transient case, obtained using the PATHS program, are shown in Figures 3 and 4. In Figure 3, the pathl ines and advancing fronts in time denoted by the numbers are shown for the fluid departing from the pond at 0 and 50 years. Figure 4 shows the results for fluid particles leaving the pond at 75 and 100 years.

The flow results in the figures were obtained from the type of computergenerated plots shown near the end of Appendix $B$ as example output of the PATHS program. Each number placed along the pathlines in the machine plots corresponds to a time in the individual pathline. For example, the number one is for 100 years, 2 for 200 years. The advancing front isochronal 1 ines at a given time are represented by connecting like numbers on the plots in Figures 3 and 4 .

The overall flow pattern and advancing front results provide considerable insight into the system response. The pattern is also very useful in physically interpreting the arrival results provided in the next two sections. The Location/Arrival-Time Distribution

The location/arrival-time distribution gives the locations where the contaminants will reach the groundwater outflow boundary with passing time. In our example, this is the location, as a function of time, where the contaminated groundwater will enter the river.

The interactive model provides the arrival data as summary results, which are listed in Table 3. The results labeled "Y" in column 3 of the computer output table in the section, Summary File-BQ3VH_ in Appendix B and labeled as $S$ in column 3 of Table 3 are plotted against the travel times in column 2 to provide the location/arrival-time distribution shown in Figure 5. The several curves in the figure represent the arrival along the river bank of contaminated water that departed from the pond at time zero, 25, 50, 75, 100 and 125 years. The opening between 800 and 1200 feet along the river containing no arrival curves results from the injected uncontaminated water entering the first well (see Figures 3 and 4). Similarly, the vug-shaped open area in the arrival curves around 3000 feet in 


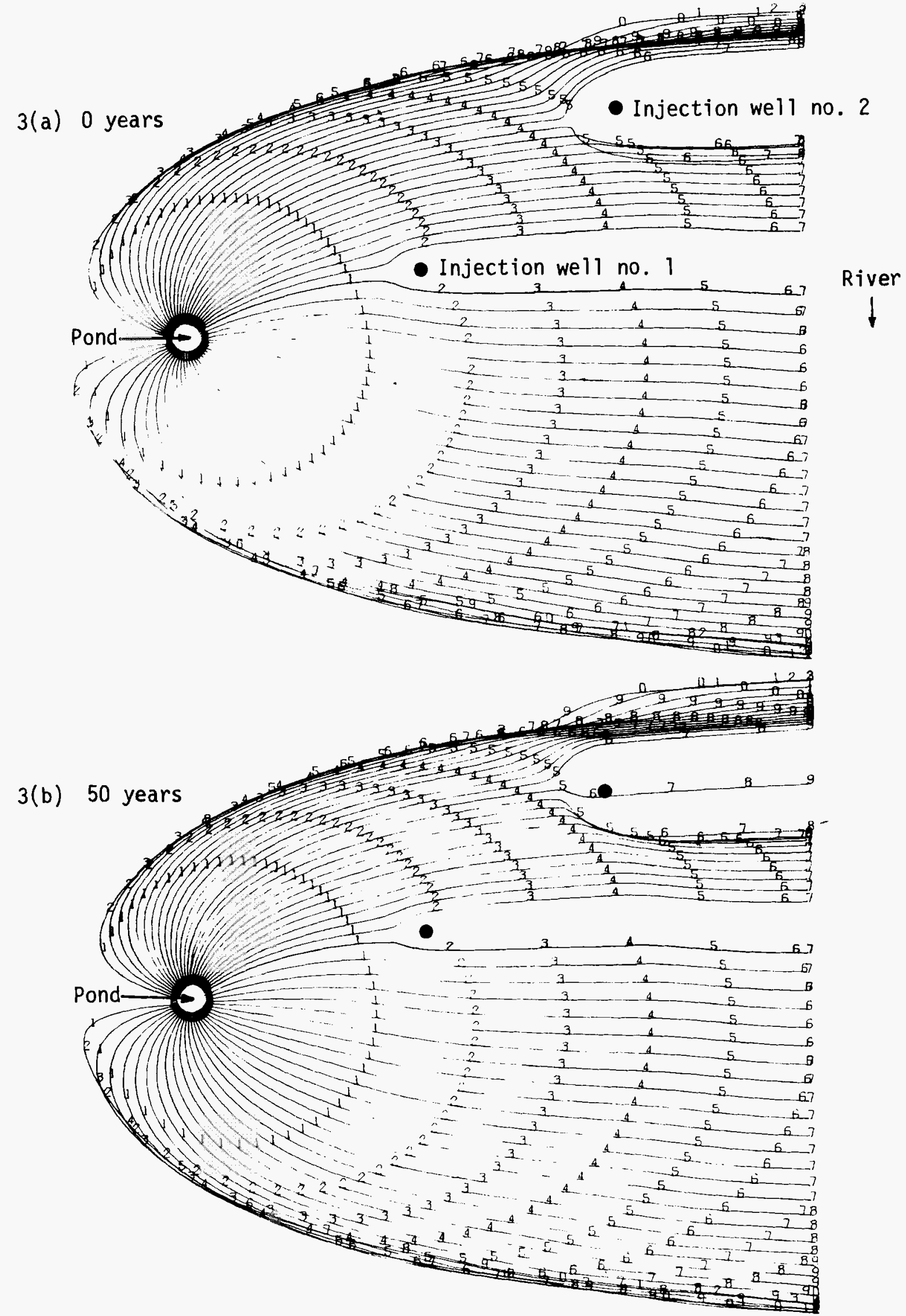

FIGURE 3. Example Transient Flow Results for Fluid Particles Departing Pond at 0 and 50 Years 

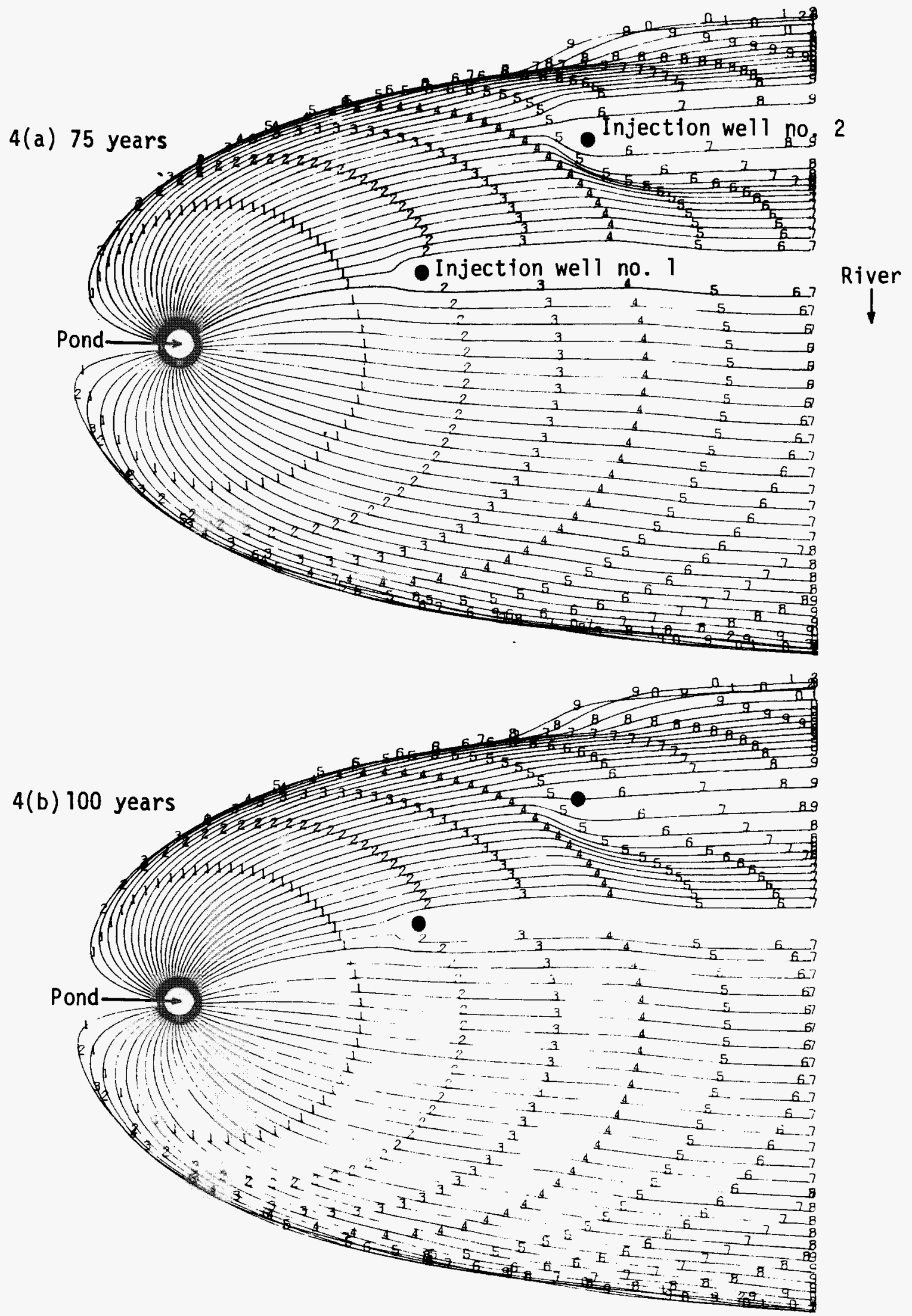

FIGURE 4. Example Transient Flow Results for Fluid Particles Departing Pond at 75 and 100 Years 
TABLE 3. Contaminant Arrival Time and Outflow Locations Along River for the Example Transient Case

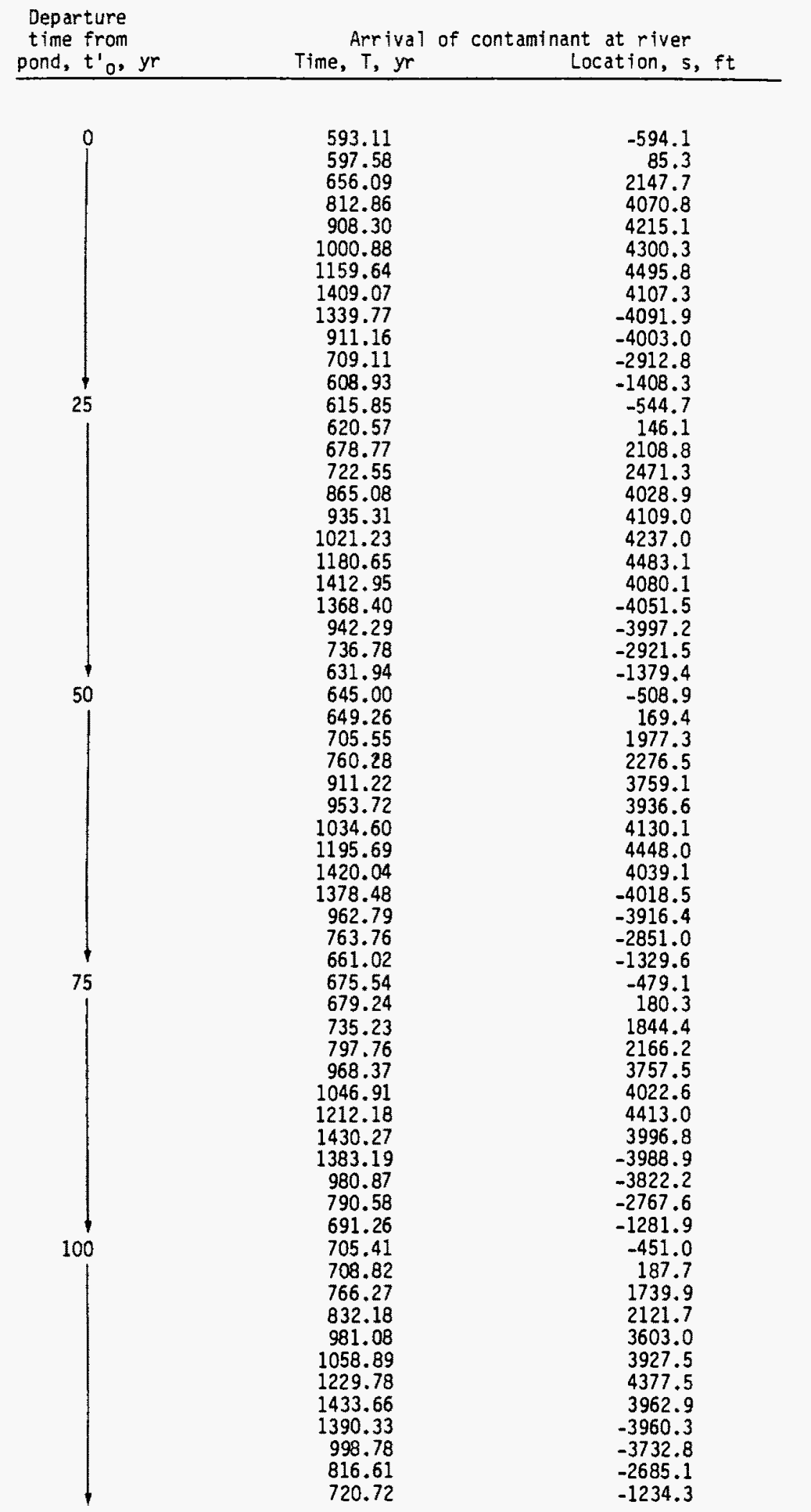




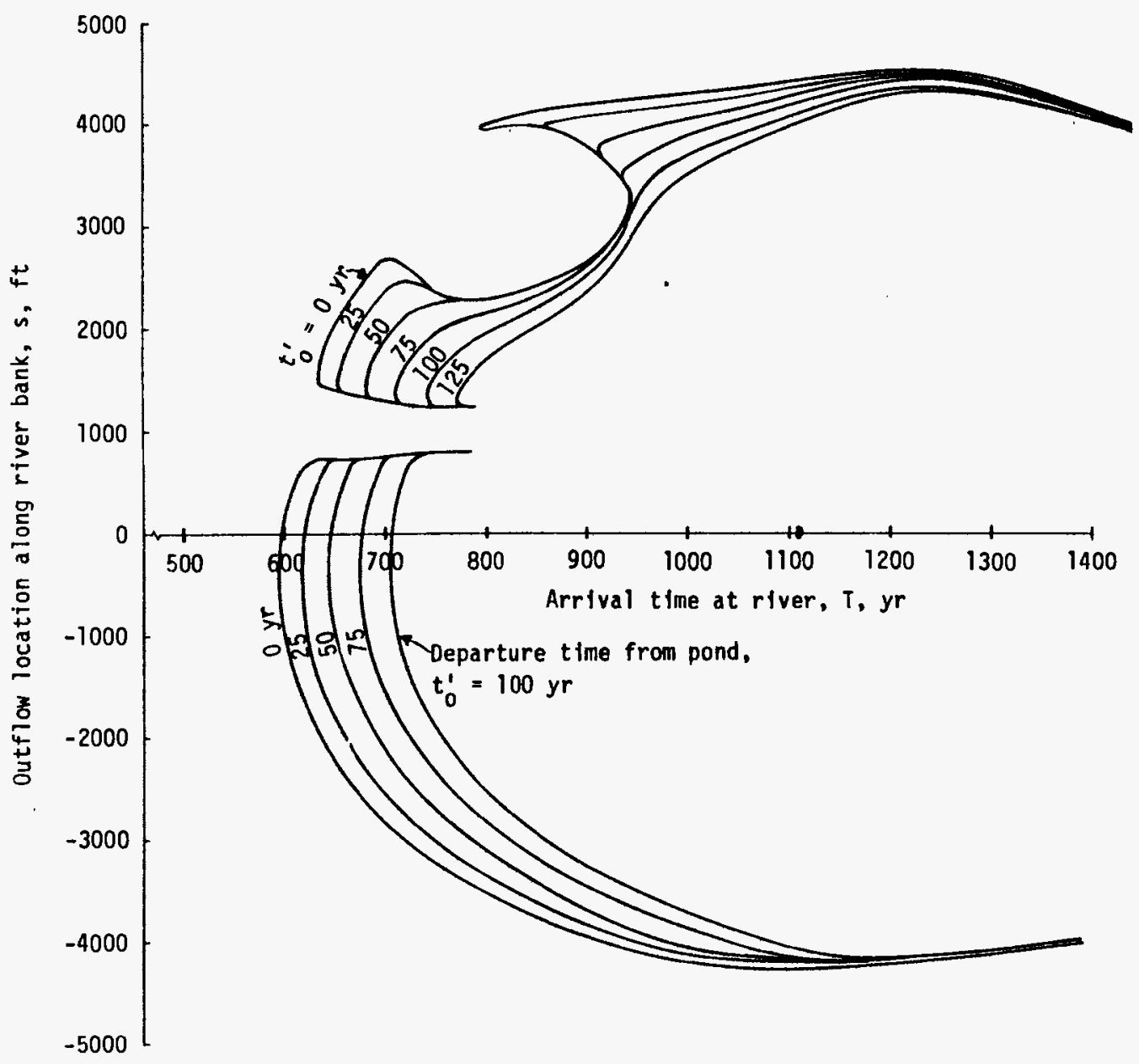

FIGURE 5. The Contaminant Location/Arrival-Time Distribution for the Transient Example Case. 
Figure 5 is caused by the fluid injected into the second well. In both instances, the flow system results in Figures 3 and 4 are helpful in understanding the outflow-location/arrival-time response functions shown in Figure 5 .

The location/arrival-time results (in Table 3 and shown in Figure 5) are the first results required to evaluate the environmental consequences. The second set of results is discussed in the next section using the example evaluation results. The two sets of results are then used to provide the overall environmental consequences.

The Location/Outflow-Quantity Distribution

The location/outflow-quantity results give the amount of contaminated groundwater outflow at the various locations along the river. The particular unit outflow rates are provided by the interactive LOCQAR program, discussed in detail for the example case in Appendix $B$.

The LOCQAR program is easy to execute; since it requires very limited input, no special input sheets are needed. As the GROUND program (i.e., batch computer run part of PATHS) is executed, most of the inputs required for LOCQAR are placed on a special file for subsequent use. Few requests for data from the user are made by the LOCQAR program. Those requests utilize the prompting and HELP features, as in PATHS, and can be answered directly from the location/arrival-time curves as in Figure 5 . Instructions for using LOCQAR and complete example runs are provided in Appendix $B$ in the section "Executing LOCQAR."

The results from LOCQAR are shown in Table 4. In particular, the arrival times at various locations along the river are provided along with the unit outflow rate of contaminated fluid. The unit outflow rate is the water outflow volume per unit time per unit distance along the river bank. Such a unit outflow rate is required since the rate changes both with location along the river and with time.

From the results in Table 4, the graph of the location/outflow-quantity distribution was prepared as shown in Figure 6 . Some caution in using the plotted results is necessary since the curves representing various arrival times can be confusing. The curve for an arrival time, $T=600 \mathrm{yr}$, has a maximum value for $q$ of $228.4 \mathrm{ft}^{3} / \mathrm{yr} / \mathrm{ft}$. The outflow rate values for the 
TABLE 4. Contaminant Arrival Location Along River and Unit Outflow Rate for Example Transient Case

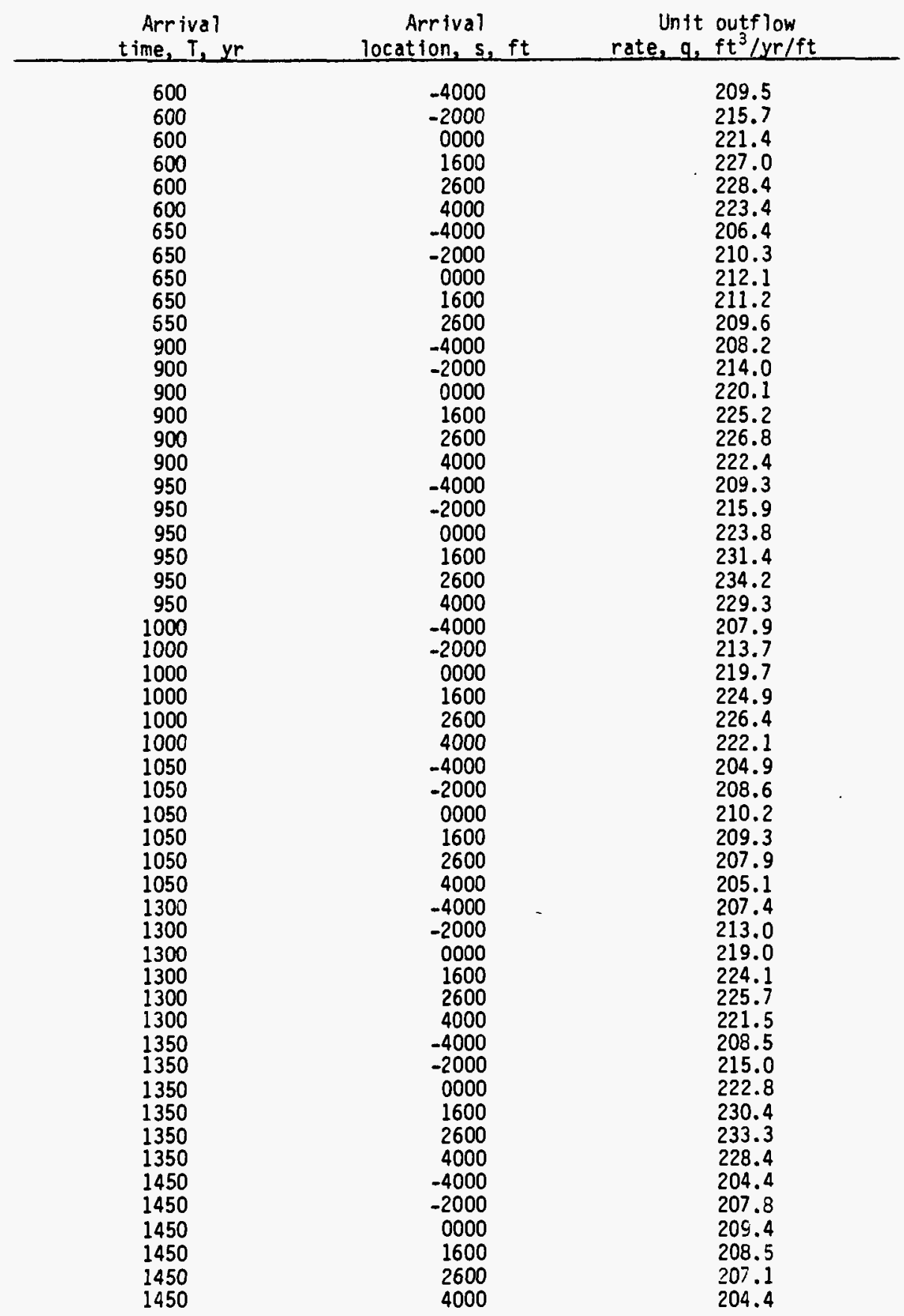




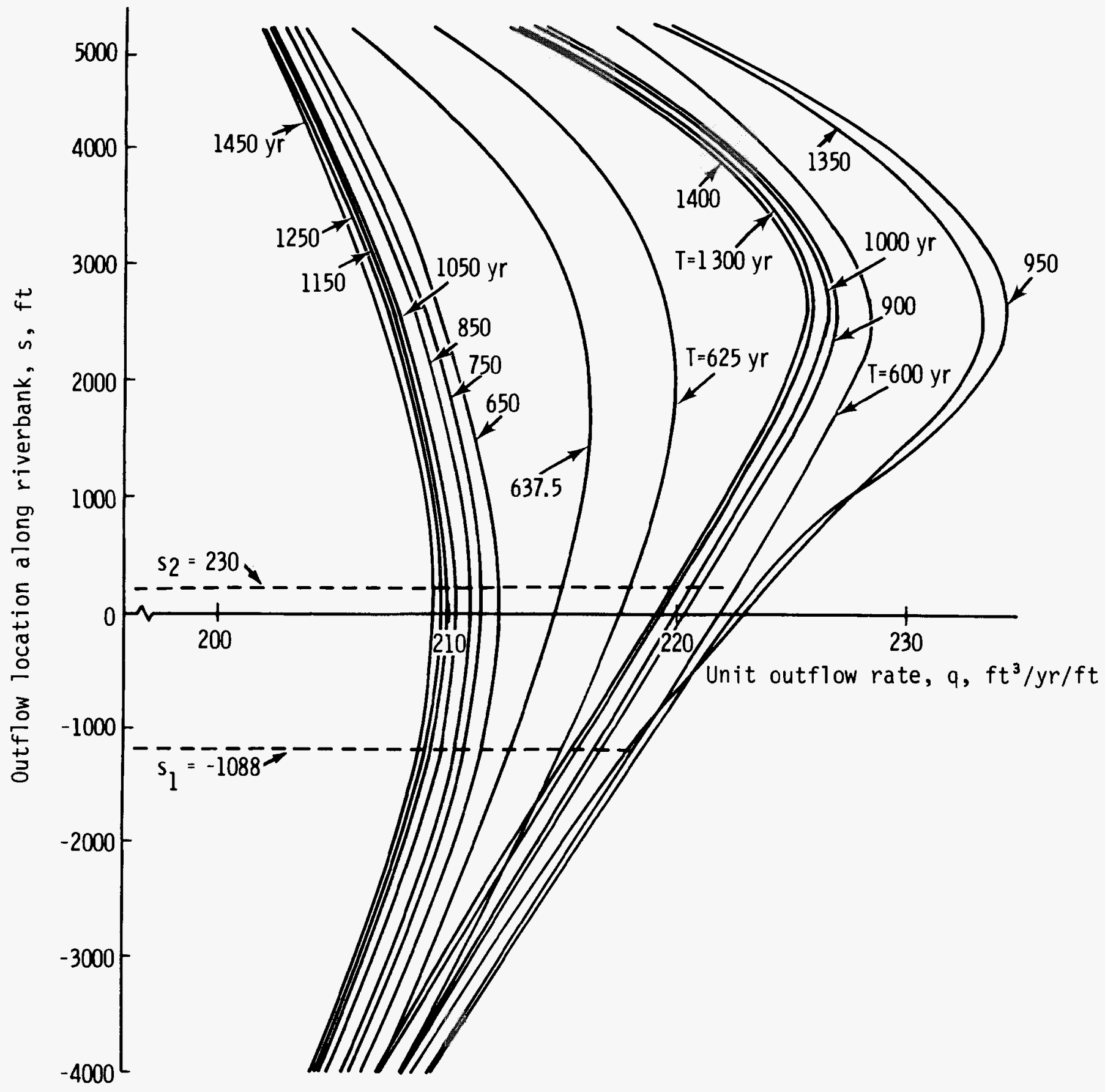

FIGURE 6. Contaminant Location/0utflowQuantity Distribution at the River for the Example Transient Case 
curve $\mathrm{T}=625 \mathrm{yr}$ in Figure 6 is smaller or lies to the left of the $600 \mathrm{yr}$ curve as do the curves for 637.5, 650, and $750 \mathrm{yr}$. The curve for $T=850 \mathrm{yr}$ is also displaced slightly to the left and is a local minimum curve. For $T=900 \mathrm{yr}$, the curve is displaced considerably to the right. The $950 \mathrm{yr}$ curve is still further displaced to the right and is the maximum $q$ curve in the Figure over most of the range of $\mathrm{s}$. The $1000 \mathrm{yr}$ curve recedes again to the left, with smaller q values, as do the $1050 \mathrm{yr}$ and $1150 \mathrm{yr}$ curves. Similarly, the $1250 \mathrm{yr}$ curve is slightly left and is another local minimum curve. However, the 1300 yr curve is again significantly displaced to the right with the trend continuing to the local maximum curve for $T=1350 \mathrm{yr}$. The curves recede again to the left passing the $1400 \mathrm{yr}$ curve and ending with $\mathrm{T}=1450 \mathrm{yr}$ as the most extreme left-hand curve. Such a pattern of initially diminishing unit outflow rates--which later reverse, then increase cyclically until a maximum is reached at $T=950 \mathrm{yr}$ and then recede--requires special care in using the plot.

USE OF ARRIVAL DISTRIBUTIONS

The two arrival distributions are easy to use to determine the concentrations and amount of contaminants that will interface with the environment. The concentration along the outflow boundary (the river, in the example) is always available from the location/arrival-time distribution.

The concentration arrival distribution is similar to the results in Figure 5 since only water-coincident contaminants are considered, and the input concentration at the pond is constant. No exchange reactions are considered in the example and the contaminant source concentration, $C_{0}$, is assumed constant over the first 25 years. After the first 25 years, no more contaminant will enter the pond or cavern. Under such conditions and with the worst-case assumption (no dispersion occurs), the concentration arrival distribution involved only using a portion of the location/arrival-time results from Figure 5 .

In Figure 7 , the concentration/arrival-time distribution is shown and provides the concentration entering the river with passing time. The same concentration as departed from the cavern reaches the river since the contaminant input was uniformly distributed between the zero and 25-year departure-time curves, and no exchange occurred with the porous material. 


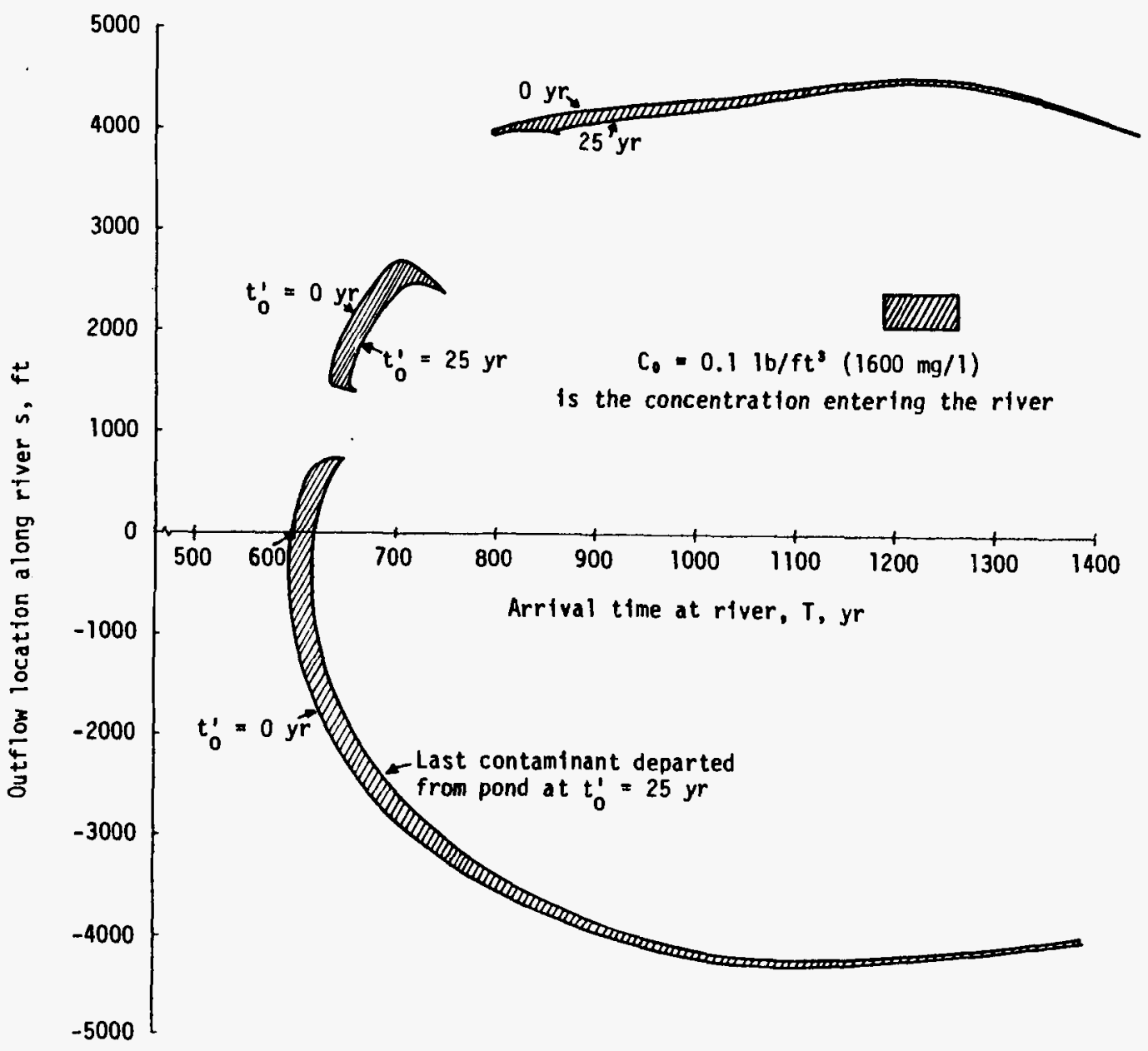

FIGURE 7. The Concentration of Contamination Entering the River at Various Locations and Times for the Example Transient 
Through the use of Figure 7 , various combinations of locations with times can be considered to yield the worst-case dose of contaminant to the biosphere. Accordingly, the concentration arrival distribution provides the first results required to evaluate the environmental consequences.

The second set of results needed is the outflow rate of contaminant into the river as time passes. Such results are available by using the concentration/arrival-time results and location/outflow-quantity distributions together. By combining the concentration and fluid outflow rate into the river, the actual contaminant outflow rate as a function of time is obtained. Specifically, the rate of contaminant entering the river, $W_{T}$, has the integral form

$$
w_{T}=\left.\int_{s_{1}}^{s_{2}} c_{0} \cdot q\right|_{T} d s
$$

where $W_{T}$ is the contaminant outflow rate.

$C_{0}$ is the concentration in the pond.

$q$ is the unit outflow rate of groundwater into the river.

$T$ is the particular arrival time at which $q$, hence $W_{T}$, is evaluated.

$s_{1}$ is the location (lower limit) where contaminated fluid enters the river.

$s_{2}$ is the location (upper 1 imit) where contaminated fluid is entering the river.

Suppose one wanted to evaluate the contaminant outflow rate using Equation (17) at $T=600 \mathrm{yr}$. From Table 3, or more directly from Figure 7, at $T=600 \mathrm{yr}$ the contaminated water is seen to enter the river between $s_{1}=-1088$ and the location $s_{2}=230 \mathrm{ft}$. Use of these locations in Figure 6 indicates the q variation with distance along the river. Using the q variation and the locations in Equation (17) and using $c_{0}=0.11 \mathrm{~b} / \mathrm{ft}^{3}$ gives

$$
w_{600}=\left.0.1 \int_{-1088}^{230} q\right|_{600} d s
$$


or upon evaluating

$$
W_{600}=28,8721 \mathrm{~b} / \mathrm{yr}=0.0549 \mathrm{lb} / \mathrm{min}
$$

As a second example, consider the arrival time $T=800 \mathrm{yr}$. From Figure 7, two outflow intervals are seen at $T=800$ years. The first outflow length, s, is between -3540 and -3400 feet. The second outflow is between 3973 and 4017 feet. Accordingly, the contaminant outflow is

$$
w_{800}=\left.0.1 \int_{-3540}^{-3400} q\right|_{800} d s+\left.0.1 \int_{3973}^{4017} q\right|_{800} d s
$$

or

$$
W_{800}=4,336 \mathrm{lb} / \mathrm{yr}=0.00825 \mathrm{lb} / \mathrm{min}
$$

Other evaluations of the type just illustrated provide the complete contaminant outflow rate in time that is shown in Figure 8.

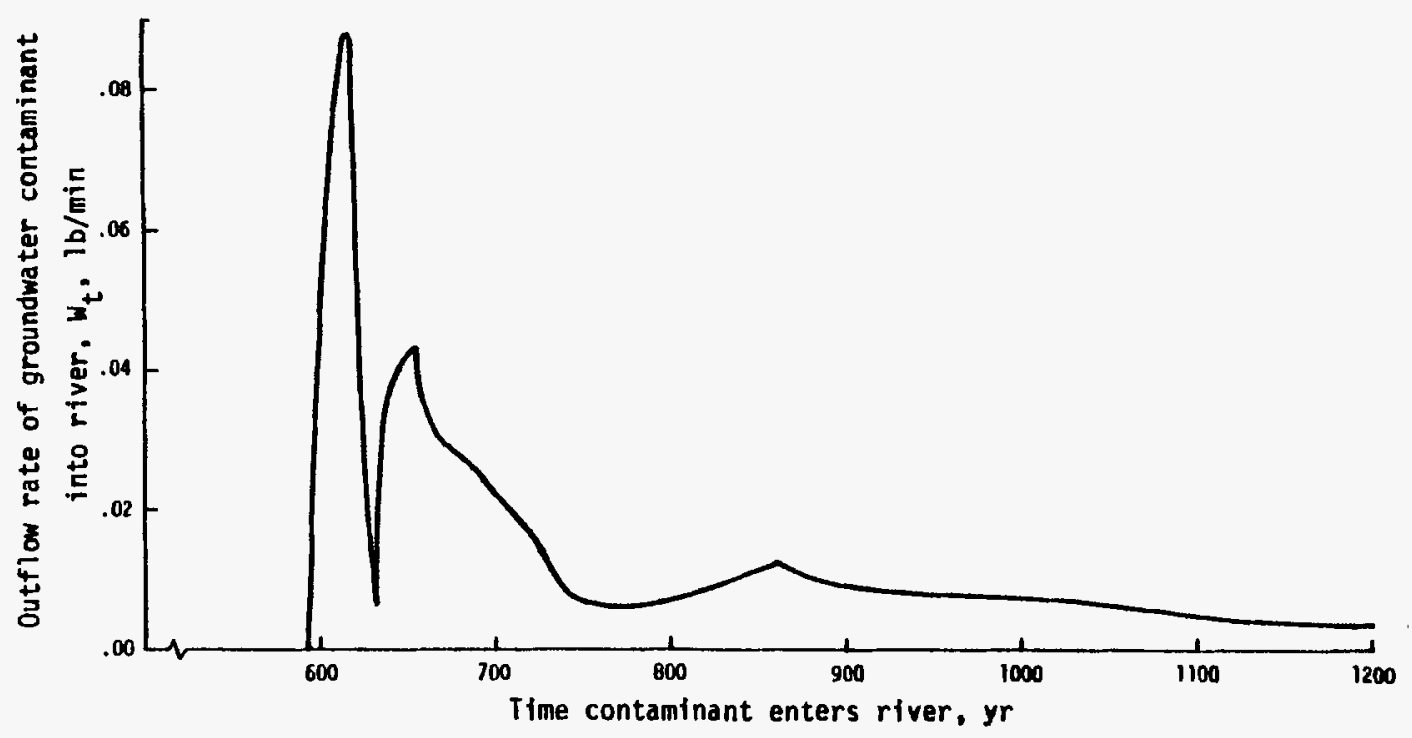

FIGURE 8. The Outflow Rate of Groundwater Contamination for the Example Transient Case. 
From the contaminant arrival curve in Figure 8, two consequences for the example are noted that are typical. The peak value is most important and, second, the significantly extended tail of the curve. The peak value of 0.087 pounds per minute is immediately apparent and always considered; however, the tail part of the curve is sometimes overlooked too quickly. By itself, this low value may not be significant, but, if it is combined with the tails of several other contaminant sources on a river or stream, then the additive effect may become important. Therefore, the entire curve is really needed if the environmental consequences are to be considered in any detail.

This completes the example evaluation using the prelininary evaluation capability. If a user wants more experience using the interactive programs, a second example steady case is provided in Appendix B. Our experience shows that the programs are quite helpful in providing preliminary evaluations for a group of two-dimensional subsurface pollution problems. 


\section{REFERENCES}

Allensworth, James A., et al. 1977. Underground Siting of Nuclear Power Plants: Potential Benefits and Penalties. U.S. Nuc lear Regulatory Commission Report NUREG-0255 - SAND75-0412. Prepared by Sandia Laboratory, Albuquerque, NM.

Gi11, S. 1951. "A Process for the Step-By-Step Integration of Differential Equations in an Automatic Digital Computing Machine", In Proceedings of the Cambridge Philosophical Soc iety. 47:96-108.

Houston, J. R., D. L. Strenge, and E. G. Watson. 1974, Reissued 1976, Errata 1977. DACRIN-A Computer Program for Calculating Organ Dose from Acute or Chronic Radionuclide Inhalation. BNWL-B-389 and BNWL-B-389 Supp., Pac if ic Northwest Laboratory, Richland, WA.

Nelson, R. William, Robert T. Toyooka, and David A. Moe. 1970. An Initial Model of Fluid Movement from Deep Underground Storage Caverns. Informal Report CSC-7006-01 to At lantic Richfield Hanford Company, Richland, WA.

Nelson, R. William. 1976. Evaluating the Environmental Consequences of Groundwater Contamination. Management Summary and Technical Papers. Report BCSR-6, Boe ing Computer Services (BCS) Richland, Inc., RichTand, WA.

Shames, I. H. 1962. Mechanics of Fluids. McGraw-Hi1l, New York.

Strenge, D. L. and E. C. Watson. 1973. KRONIC-A Computer Program for Calculating Annual Average External Doses from Chronic Atmospheric Releases of Radionuclides. BNWL-B-264, Pacific Northwest Laboratory, Richland, WA.

Strenge, D. L., E. C. Watson, and J. R. Houston. 1975. SUBDOSA-A Computer Program for Calculating External Doses from Accidental Atmospheric Releases of Radionuclides. BNWL-B-351, Pac if ic Northwest Laboratory, Richland, WA.

Strenge, D. L. 1975. DACRIN-A Computer Program for Calculating Organ Dose from Acute and Chronic Radionuclide Inhalation: Modification for Gastrointestinal Tract Dose. BNWL-B-389 SUPP, Pac if ic Northwest Laboratory, Richland, WA. 
APPENDIX A

DERIVATION OF MODEL EQUATIONS 
APPENDIX A

\section{DERIVATION OF MODEL EQUATIONS}

The equations for the idealized model described in the report are presented here and useful results are derived. The model was designed to enable estimates of expected contaminant transport consequences when limited field data is available. Accordingly, the model is necessarily simplified and idealized as the representation of the real situation. However, special care was exercised to assure that minimum worst-case estimates for the fluid travel times would be provided by the model.

\section{A GROUNDWATER POTENTIAL SOLUTION}

The model assumes isothermal conditions and describes the saturated flow of an incompressible fluid through a two-dimensional lateral stratum of thickness or depth, $D_{0}$. The stratum is a porous material that is homogeneous and isotropic with respect to hydraulic conductivity, $k_{0}$, and the effective porosity, $P$. A uniform lateral gradient, $U$, of the fluid in the stratum provides a velocity in the $x$ direction. Though the lateral gradient is uniform in direction, the gradient strength, $U$, may vary with time. A cylindrical cavity of radius $r^{\prime}{ }_{0}$ and length $D_{0}$ completely penetrates the stratum or porous slab. The flow from the cylindrical cavity depends upon the cavern head, $H^{\prime}$, which generally is some function of time. Wells are introduced into the model as completely penetrating vertical line sources again with time-varying injection or withdrawal rates.

The objective for the idealized model is to consider a range of typical transient situations. The time dependence enters through the uniform gradient, $U$, the cavern head, $H^{\prime}$, and the well flow rates. Each of these are represented by a moderately general variable/functional form for the time dependence. In this way, a variety of transient situations can be evaluated directly and most others can be approximated quite satisfactorily. The transient forms of variation are shown schematically in Figures 1 and 2 of the report; the steady situations are available by setting the time-varying parameters to appropriate constants. 
We begin by considering a potential function formed by superposition of elementary flows. A uniform lateral flow is added to a combined source and positive doublet centered at the origin. Away from the origin several pumping or injection wells are superimposed as completely penetrating vertical line sinks and sources. Specifically,

$$
\begin{aligned}
\phi^{\prime}= & -U x^{\prime}-\frac{M_{0}}{2 \pi} \ln \sqrt{\left(x^{\prime}\right)^{2}+\left(y^{\prime}\right)^{2}}+\frac{U x^{\prime}\left(r_{0}^{\prime}\right)^{2}}{\left(x^{\prime}\right)^{2}+\left(y^{\prime}\right)^{2}} \\
& -\sum_{j=1}^{j=N} \frac{M_{j}}{2 \pi} \ln \sqrt{\left(x^{\prime}-x_{j}^{\prime}\right)^{2}+\left(y^{\prime}-y_{j}^{\prime}\right)^{2}}+C_{0}^{\prime}
\end{aligned}
$$

where

$$
\begin{aligned}
\phi^{\prime}= & \phi^{\prime}\left(x^{\prime}, y^{\prime}, t^{\prime}\right) \text { is the potential energy function that } \\
& \text { satisfies the Laplace Equation } \\
U= & U\left(t^{\prime}\right) \text { is time-dependent uniform flow gradient } \\
M_{0}= & M_{0}\left(t^{\prime}\right) \text { is the major time dependent source strength } \\
& \text { located at the origin } \\
r_{0}^{\prime}= & \sqrt{\left(x_{0}^{\prime}\right)^{2}+\left(y_{0}^{\prime}\right)^{2}} \text { is the radius of the major source }
\end{aligned}
$$$$
M_{j}=M_{j}\left(t^{\prime}\right) \text { is the source or sink strength of the } j \text { th well 10- }
$$
cated with center at $\left(x_{j}^{\prime}, y_{j}^{\prime}\right)$

$x_{j}^{\prime}$ and $y_{j}^{\prime}$ are respectively $x^{\prime}$ and $y^{\prime}$ coordinates of the center of the $j$ th well

$\mathrm{N}$ is the total number of wells in the flow system

$C_{0}^{\prime}$ is a constant to be determined

$x^{\prime}$ and $y^{\prime}$ are the Cartesian coordinate variables

$t^{\prime}$ is time

A convenient set of dimensioniess variables is:

$$
\begin{aligned}
& x=\frac{x^{\prime}}{R} \\
& y=\frac{y^{\prime}}{R}
\end{aligned}
$$




$$
\begin{aligned}
& r_{0}=\frac{r_{0}^{\prime}}{R} \\
& r_{j}=\frac{r_{j}^{\prime}}{R} \\
& \phi=\frac{\phi^{\prime}}{H_{0}} \\
& H=\frac{H^{\prime}}{H_{0}} \\
& t=\frac{K_{0} H_{0}}{R^{2}} t^{\prime}
\end{aligned}
$$

Substituting Equation ( $A-2$ ) into ( $A-1)$ provides the potential in dimensionless form

$$
\begin{aligned}
\phi= & -\frac{U R}{H_{0}} x-\frac{M_{0}}{2 \pi H_{0}} \ln \sqrt{R^{2}\left(x^{2}+y^{2}\right)}+\frac{U R r_{0}^{2} x}{H_{0}\left(x^{2}+y^{2}\right)} \\
& -\sum_{j=1}^{j=N} \frac{M_{j}}{2 \pi H_{0}} \ln \sqrt{R^{2}\left[\left(x-x_{j}\right)^{2}+\left(y-y_{j}\right)^{2}\right]}+C_{1}
\end{aligned}
$$

$C_{1}$ is to be specified such that around the major source wall described by

$$
x_{0}^{2}+y_{0}^{2}=r_{0}^{2}
$$

the condition to be satisfied is

$$
\phi=H
$$

Therefore, upon substituting into $(A-3)$ and solving for $C$ gives

$$
C_{1}=H+\frac{M_{0}}{2 \pi H_{0}} \ln \left(R r_{0}\right)+\sum_{j=1}^{j=N} \frac{M_{j}}{2 \pi H_{0}} \ln \left[R \sqrt{\left(x_{0}-x_{j}\right)^{2}+\left(y_{0}-y_{j}\right)^{2}}\right]
$$


Substitution of Equation $(A-6)$ into $(A-3)$ yields

$$
\begin{aligned}
\phi= & H-\frac{U R}{H_{0}} x+\frac{U R r_{0}^{2}}{H_{0}}\left(\frac{x}{x^{2}+y^{2}}\right)-\frac{M_{0}}{2 \pi H_{0}} \ln \left(\sqrt{\frac{x^{2}+y^{2}}{r_{0}}}\right) \\
& -\sum_{j=1}^{j=N} \frac{M_{j}}{2 \pi H_{0}} \ln \sqrt{\frac{\left(x-x_{j}\right)^{2}+\left(y-y_{j}\right)^{2}}{x_{j}^{2}\left(1-\frac{x_{0}}{x_{j}}\right)^{2}+y_{j}^{2}\left(1-\frac{y_{0}}{y_{j}}\right)^{2}}}
\end{aligned}
$$

The dependence in Equation (A-7) would be simplified considerably if

$$
x_{0} \ll x_{j} \text { and } y_{0} \ll y_{j}
$$

which would imply that the wells with centers at $x_{j}, y_{j}$ cannot be too close to the main source wall defined by Equation $(A-4)$. If $(A-8)$ is true, then

$$
\left(1-\frac{x_{0}}{x_{j}}\right)^{2} \approx 1
$$

and

$$
\left(1-\frac{y_{0}}{y_{j}}\right)^{2} \approx 1
$$

We assume Equations (A-8) and (A-9) are satisfied and then derive the expression for the error introduced. That is, Equation $(A-7)$ becomes

$$
\begin{aligned}
\phi= & H-\frac{U R}{H_{0}} x+\frac{U R r_{0}^{2}}{H_{0}}\left(\frac{x}{x^{2}+y^{2}}\right)-\frac{M_{0}}{2 \pi H_{0}} \ln \left(\frac{\sqrt{x^{2}+y^{2}}}{r_{0}}\right) \\
& -\sum_{j=1}^{j=N} \frac{M_{j}}{2 \pi H_{0}} \ln \sqrt{\frac{\left(x-x_{j}\right)^{2}+\left(y-y_{j}\right)^{2}}{x_{j}^{2}+y_{j}^{2}}}
\end{aligned}
$$

The error term associated with assuming Equation $(A-9)$ is obtained by setting $x=x_{0}, y=y_{0}$ and using Equation $(A-4)$ in $(A-10)$ to give the error introduced by the $j$ th well as 


$$
(\phi-H)_{j}=\frac{M_{j}}{2 \pi H_{0}} \ln \sqrt{\frac{\left(x_{0}-x_{j}\right)^{2}+\left(y_{0}-y_{j}\right)^{2}}{\left(x_{j}{ }^{2}+y_{j}^{2}\right)}} .
$$

If we consider part of the expression under the radical and the sketch below, then using the Law of Cosines

$$
\begin{aligned}
& \left(x_{0}-x_{j}\right)^{2}+\left(y_{0}-y_{j}\right)^{2}= \\
& r_{j}^{2}+r_{0}^{2}-2 r_{j} r_{0} \cos \left(\theta_{0}-\theta_{j}\right) \\
& \text { or }
\end{aligned}
$$

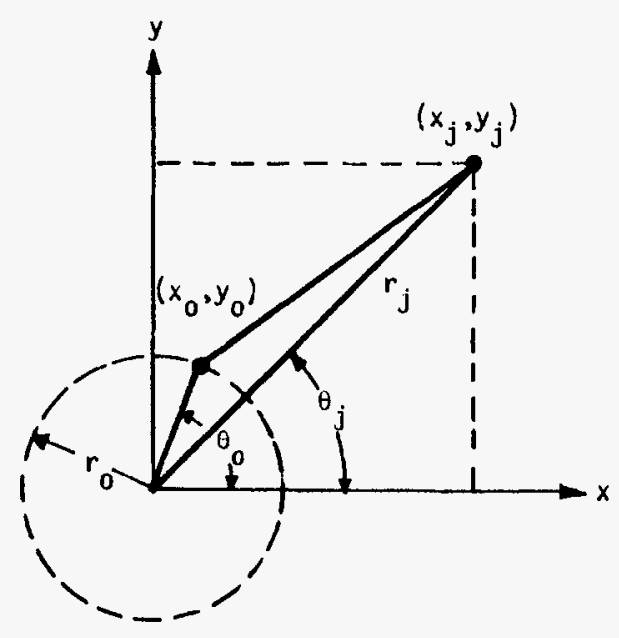

$$
\frac{\left(x_{0}-x_{j}\right)^{2}+\left(y_{0}-y_{j}\right)^{2}}{r_{j}^{2}}=1+\frac{r_{0}^{2}}{r_{j}^{2}}-\frac{2 r_{0}}{r_{j}^{2}} \cos \left(\theta_{0}-\theta_{j}\right),
$$

But the left-hand side is the expression under the radical in Equation $(A-11)$, so substituting and rearranging that equation gives

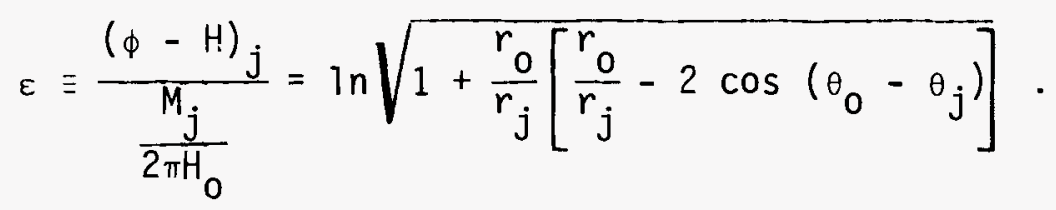

The approximation error, $\varepsilon$, is expressed as the ratio of the major source boundary condition to the jth well strength, which by the right-hand side of Equation $(A-13)$ is a function of $r_{0} / r_{j}$ and the differences of angles $\left(\theta_{0}-\theta_{j}\right)$. The magnitude of error depends primarily on the size of $r_{0} / r_{j}$ since the cosine is bounded. That is, if $r_{0} / r_{j}$ is small enough then negligible error will be introduced. In Figure $A-1$, the expression for error given by Equation $(A-13)$ is plotted for a range of $r_{0} / r_{j}$ values. As $r_{0} / r_{j}$ becomes smaller the error becomes essentially insignificant. For values of $r_{0} / r_{j}$ less than 0.01 , the error is always less than 1-percent maximum. Such a value is reasonable and is recommended for general use. Accordingly, Equation $(A-10)$ approximately satisfies the boundary conditions so long as: 


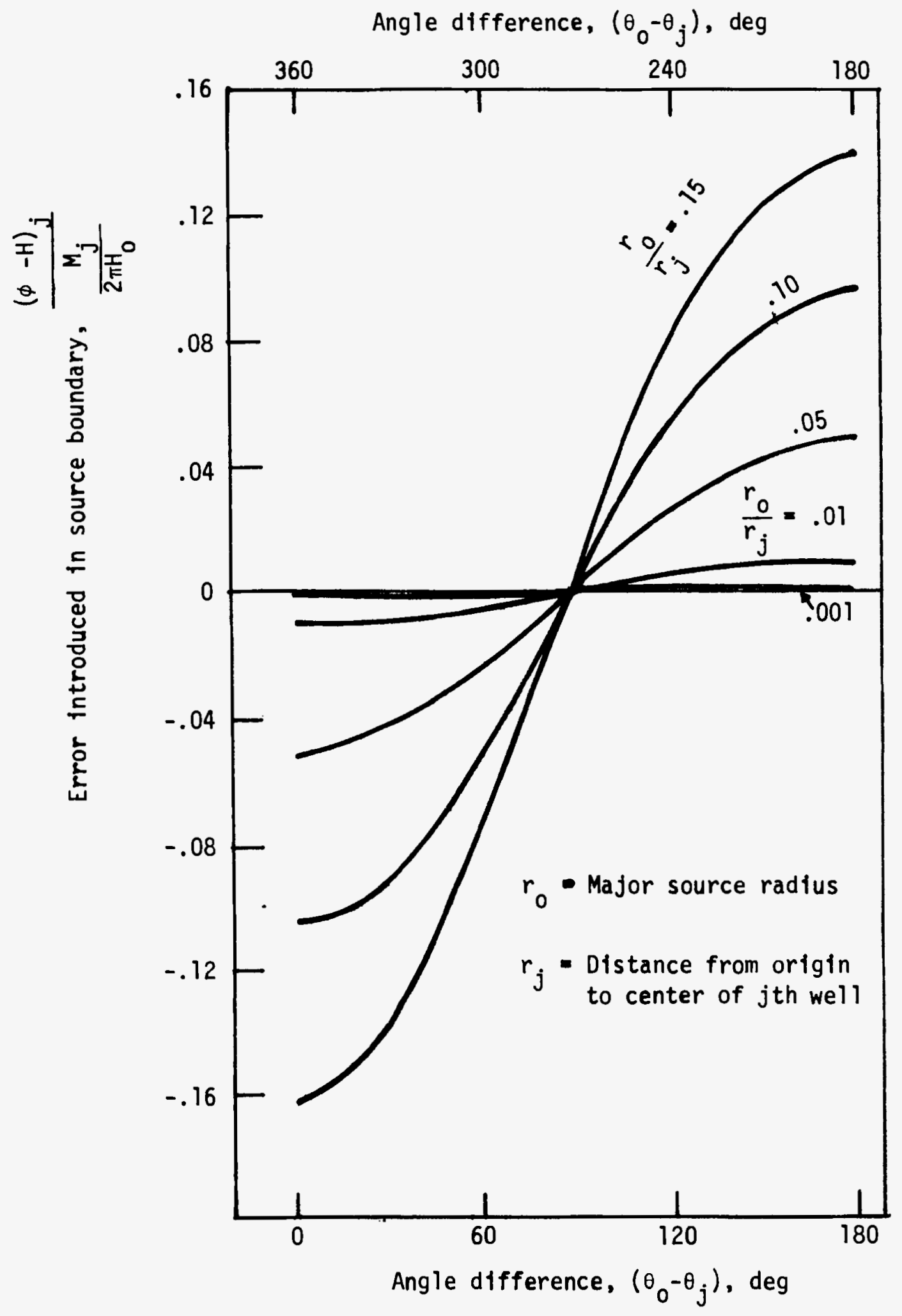

FIGURE A-1. Approximation Error at the Major Source or Pond Boundary Caused by the Proximity of the jth Well 


$$
\frac{r_{0}}{r_{j}}<0.01
$$

Equation $(A-14)$ is the criterion used to assure that $\varepsilon$ is small enough for general use.

We can assure conservatism in the calculated travel times of fluid particles by using the slightly higher gradients associated with flow to a finite remote boundary rather than to an infinite boundary. These slightly higher gradients result if all of the major source head, $H$, is dissipated at the finite radial distance $R$. In dimensionless form it is equivalent to stating that $H$ is dissipated at $x^{2}+y^{2}=1$, or more specifically,

$$
H-\frac{M_{0}}{2 \pi H_{0}} \ln \left(\frac{1}{r_{0}}\right)=0
$$

Solving for $\mathrm{M}_{0} /\left(2 \pi \mathrm{H}_{0}\right)$ gives

$$
\frac{M_{0}}{2 \pi H_{0}}=\frac{H}{\ln \left(\frac{1}{r_{0}}\right)}
$$

Substituting Equation $(A-16)$ into $(A-10)$ gives as the final dimensionless potential function:

$$
\begin{aligned}
\phi=H & -\frac{U R}{H_{0}} x+\frac{U R r_{0}^{2}}{H_{0}}\left(\frac{x}{x^{2}+y^{2}}\right)-\frac{H}{\ln \left(\frac{1}{r_{0}}\right)} \ln \left(\frac{\sqrt{x^{2}+y^{2}}}{r_{0}}\right) \\
& -\sum_{j=1}^{j=N} \frac{M_{j}}{2 \pi H_{0}} \ln \sqrt{\frac{\left(x-x_{j}\right)^{2}+\left(y-y_{j}\right)^{2}}{\left(x_{j}{ }^{2}+y_{j}{ }^{2}\right)}}, \frac{r_{0}}{r_{j}}<0.01
\end{aligned}
$$

where

$M_{j}=\frac{Q_{j}}{D_{0} K_{0}}$ is the well source or sink strength.

$Q_{j} \quad$ is the volume inflow or outflow rate of the well;

i.e., $Q_{j}$ is positive for an injection well and negative when a well is pumped. 
$D_{0}$ is the constant stratum thickness

$K_{0}$ is the uniform hydraulic conductivity, and the other terms are as already defined or as shown in Appendix $D$.

Equation $(A-17)$ can be shown to be a solution of the Laplace Equation that describes flow of an incompressible fluid in a homogeneous isotropic porous medium. Since the fluid is incompressible, the transient flow systems are impulsively generated by boundary conditions that change in time. In Equation ( $A-17$ ) the variables $H, U$, and $M_{j}$ through $Q_{j}$ may all be time dependent. Under many conditions of expected use for the model, the time dependence may not be known in detail. In these initial evaluations, it is often a matter of considering the consequences of various types of variation rather than detalled representation. Accordingly, considerable flexibility is needed and several functional forms for the time dependence were considered. From this evaluation came some particular functional forms. The most useful form found is a slight modification of the classical serpintine expression of the form

$$
W\left(t^{\prime}\right)=w_{0}+\frac{2\left(w_{0}-w_{m}\right)\left(\frac{t^{\prime}}{t_{n}^{\top}}+A\right)}{B\left(\frac{t^{\top}}{t_{n}^{\top}}+A\right)^{2}+C}
$$

where $w_{0}, w_{m}, t_{n}^{\prime}, A, B$ and $C$ are arbitrary parameters. This serpin equation form was used to describe the time dependence of $U, H$ and $Q_{j}$ with the specific parameters defined as shown in Table A-1. 
TABLE A-1. Definition of Parameters for the Serpintine Equation Form $(A-18)$

$\begin{array}{cccc}\begin{array}{c}\text { Parameter in } \\ \text { Equation }(A-18),\end{array} & \frac{\text { Parameter defined in serpintine forms for }}{U\left(t^{\prime}\right)} & H\left(t^{\prime}\right) & Q_{j}\left(t^{\prime}\right) \\ w_{0} & U 0 & H I & Q I_{j} \\ w_{m} & U M & H M & Q M_{j} \\ t_{n}^{\prime} & T M & T N & T N_{j} \\ A & A & D & D W_{j} \\ B & B & E & E W_{j} \\ C & C & F & F W_{j}\end{array}$

The second convenient functional form used to describe the time dependence of $H$ and $Q_{j}$ is

$$
w\left(t^{\prime}\right)=w_{m c}+w_{o c} \sin \left[2 \pi \frac{\left(t^{\prime}-t_{o c}\right)}{\left(t_{m c}-t_{o c}\right)}\right]
$$

which provides a continuous cyclic-type fluctuation. The parameters for describing $H$ and $Q_{j}$ are shown in Table $A-2$.

TABLE A-2. Definition of Parameters for the Cyclic Equation Form $(A-19)$

\begin{tabular}{ccc}
$\begin{array}{c}\text { Parameter in } \\
\begin{array}{c}\text { Equation } A-19 \\
W\left(t^{\prime}\right)\end{array}\end{array}$ & $\frac{\text { Parameter defined in cyclic form for }}{H\left(t^{\prime}\right)}$ & $Q_{j}\left(t^{\prime}\right)$ \\
\hline$w_{m C}$ & $H M C$ & $Q Q_{j}$ \\
$w_{O C}$ & $H A C$ & $Q A_{j}$ \\
$t_{O C}$ & $T O C$ & $T 0_{j}$ \\
$t_{m C}$ & $T M C$ & $T M_{j}$
\end{tabular}

A third form for the time-dependent head $H$ in Equation (A-17) is useful when considering worst-case accidentals leakage into the ground from liquid-storage facilities. It is the falling head case where the fluid level diminishes in the storage facility at the rate that fluid seeps 
from the structure. Consider the cylindrical fluid volume of radius $r_{0}^{\prime}$ and height $H^{\prime}$; then the instantaneous volume change $\frac{d v^{\prime}}{d t^{\prime}}$ or $Q^{\prime}$ the outflow rate is

$$
\frac{d v^{\prime}}{d t^{\prime}}=Q^{\prime}=-\pi\left(r_{0}^{\prime}\right)^{2} \frac{d H^{\prime}}{d t^{\prime}}
$$

but the instantaneous outflow rate, $Q_{0}$, is

$$
Q=\frac{2 \pi D_{0} K_{0} H^{\prime}}{\ln \left(\frac{R}{r_{0}}\right)}
$$

Substituting (A-21) into (A-20) gives upon rearranging

$$
\int_{H_{0}}^{H^{\prime}} \frac{d H^{\prime}}{H^{1}}=\int_{0}^{t^{\prime}}-\frac{2 D_{0} K_{0}}{\left(r_{0}^{\prime}\right)^{2} \ln \left(\frac{R}{r_{0}^{\prime}}\right)} d t^{\prime}
$$

and upon evaluating the integrals one obtains

$$
\frac{H^{\prime}}{H_{0}}=\exp \left[-\frac{2 D_{0} K_{0}}{\left(r_{0}\right)^{2} \ln \left(\frac{R}{r_{0}{ }^{l}}\right)} t^{\prime}\right]
$$

and using the Equations (A-2) to form the dimensionless equivalent yields

$$
H=\exp \left[-\frac{2 D_{0}}{H_{0} r_{0}{ }^{2} \ln \left(\frac{1}{r_{0}}\right)} t\right]
$$

which is the exponential expression for the declining head in the circular source as leakage occurs from storage facility.

Experience in using the above time-dependent forms shows them usually to be adequate. However, in some instances where specific forms are needed, it may be convenient to write a particular computer subroutine to replace the serpin form. Usually the six parameters 
provide sufficient input capacity for any special time-dependent routine that may be needed.

THE KINEMATIC PATHLINES

The equations for the fluid pathlines are available from Darcy's Law expressed as a pore velocity using the potential equations already derived. Specifically, the dimensional pore velocity, $\underline{u}^{\prime}$, is

$$
\underline{u}^{\prime}=-\frac{K_{0}}{p} \nabla^{\prime} \phi^{\prime}
$$

If the dimensionless velocity, $\underline{u}$, is

$$
\underline{u}=\frac{R}{K_{0} H_{0}} \underline{u}^{\prime}
$$

Using Equation (A-2) gives the dimensionless pore velocity expression

$$
\underline{u}=-\frac{1}{\mathrm{P}} \nabla \phi
$$

or in components

$$
\frac{d x}{d t}=u_{x}=-\frac{1}{p} \frac{\partial \phi}{\partial x}
$$

and

$$
\frac{d y}{d t}=u_{y}=-\frac{1}{P} \frac{\partial \phi}{\partial y}
$$

where the expression for $\phi$ is provided by the potential solution in Equation $(A-17)$. Differentiation of Equation ( $A-17)$ first with respect to $x$, then with respect to $y$ and substitution into Equations $(A-28)$ and $(A-29)$, respectively, gives the pair of pathline differential equations, i.e.,

$$
\begin{aligned}
\frac{d x}{d t}= & \frac{U R}{P H_{0}}\left\{1+\frac{r_{0}^{2}}{\left(x^{2}+y^{2}\right)}\left[\frac{2 x^{2}}{x^{2}+y^{2}}-1\right]\right\}+\frac{H}{P \ln \left(\frac{1}{r_{0}}\right)}\left(\frac{x}{x^{2}+y^{2}}\right) \\
& +\sum_{j=1}^{j=N} \frac{M_{j}}{2 \pi H_{0} P}\left[\frac{\left(x-x_{j}\right)}{\left(x-x_{j}\right)^{2}+\left(y-y_{j}\right)^{2}}\right],
\end{aligned}
$$


and

$$
\begin{aligned}
\frac{d y}{d t}= & \frac{U R}{P H_{0}}\left[\frac{2\left(r_{0}\right)^{2} x y}{\left(x^{2}+y^{2}\right)^{2}}\right]+\frac{H}{P \ln \left(\frac{1}{r_{0}}\right)}\left(\frac{y}{x^{2}+y^{2}}\right) \\
& +\sum_{j=1}^{j=N} \frac{M_{j}}{2 \pi H_{0}}\left[\frac{y-y_{j}}{\left(x-x_{j}\right)^{2}+\left(y-y_{j}\right)^{2}}\right]
\end{aligned}
$$

The simultaneous solution of these two pathline equations beginning from the initial conditions

$$
x\left(t_{0}\right)=x_{0}
$$

and

$$
y\left(t_{0}\right)=y_{0}
$$

yields the path of the fluid particle that was located at $x_{0}, y_{0}$ at time $t_{0}$. By successively considering other combinations of $x_{0}, y_{0}$ and $t_{0}$, i.e., other starting points and times, the entire field of fluid particle pathlines can be obtained.

The system of equations made up of $(A-30)$ through $(A-33)$ generally cannot be solved in closed form, particularly when $U, H$ and/or $M_{j}$ take on the time-dependent forms of Equations $(A-18),(A-19)$ and $(A-24)$, therefore, a modified fourth-order Runge-Kutta numerical method is conveniently used to calculate the pathlines (Gill, 1951). In this way the macroscopic flow paths of fluid particles are directly calculated.

\section{The Stream Function}

The stream function is needed to provide complete environmental results. The stream function is directly available from the previously derived potential function Equation $(A-17)$ as the complex conjugate. The stream function $\psi$ in dimensionless variables is 


$$
\begin{aligned}
\psi= & -\frac{U R}{H_{0}} y-\frac{U R r_{0}^{2} y}{H_{0}\left(x^{2}+y^{2}\right)}-\frac{H}{\ln \left(\frac{1}{r_{0}}\right)} \arctan \left(\frac{y}{x}\right) \\
& -\sum_{j=1}^{j=N} \frac{M_{j}}{2 \pi H_{0}}\left[\arctan \left(\frac{y-y_{j}}{x-x_{j}}\right)-\arctan \left(\frac{-y_{j}}{r_{0}-x_{j}}\right)\right]
\end{aligned}
$$

where all values of the arctangents are only in the rance of zero to $2 \pi$ Equation $(A-34)$ can be rewritten in polar coordinates $(r, \theta)$ to give

$$
\begin{aligned}
\psi=-\frac{U R}{H_{0}} r \sin \theta & -\frac{U R r_{0}^{2} \sin \theta}{H_{0} r}-\frac{H}{\ln \left(\frac{1}{r_{0}}\right)} \theta \\
-\sum_{j=1}^{j=N} \frac{M_{j}}{2 \pi H_{0}} & {\left[\arctan \left(\frac{r \sin \theta-r_{j} \sin \theta_{j}}{r \cos \theta-r_{j} \cos \theta_{j}}\right)\right.} \\
& \left.-\arctan \left(\frac{-r_{j} \sin \theta_{j}}{r_{0}-r_{j} \cos \theta_{j}}\right)\right]
\end{aligned}
$$

We note that $\psi=0$, when $r=r_{0}$ and $\theta=0$ and, further, that when $r=r_{0}$ and $\theta=2 \pi$ so that all of the outflow from the circular source is included, then $\psi=\psi_{S}$, which gives

$$
\psi_{s}=-\frac{2 \pi H}{\ln \left(\frac{1}{r_{0}}\right)}
$$

and using Equation (A-16) gives

$$
\psi_{S}=-\frac{M_{0}}{H_{0}}
$$

but the source strength $M_{0}=Q /\left(D_{0} K_{0}\right)$, so

$$
\psi_{S}=-\frac{Q}{D_{0} K_{0} H_{0}}
$$

where $Q$ is the volume outflow rate from the source. Equating $(A-37)$ with (A-39) and solving for $Q$ gives 


$$
Q=\frac{2 \pi D_{0} K_{0} H_{0} H}{\ln \left(\frac{1}{r_{0}}\right)}
$$

which, with all terms reduced to dimensional form, is identical to Equation $(A-21)$.

It is convenient to use a single reference outflow $Q_{0}$, which is obtained by setting $H=1$, i.e. $H^{\prime}=H_{0}$, in Equation $(A-40)$. That is,

$$
Q_{0}=\frac{2 \pi D_{0} K_{0} H_{0}}{\ln \left(\frac{1}{r_{0}}\right)}
$$

which corresponds to defining a $\psi_{0}$ through reducing Equation $(A-37)$ to

$$
\psi_{0}=-\frac{2 \pi}{\ln \left(\frac{1}{r_{0}}\right)}
$$

If Equation (A-34) is divided by $(A-42)$ and the resulting $\psi_{1} \psi_{0}$ is equated to $Q_{j} / Q_{0}$, then one obtains

$$
\begin{aligned}
\frac{Q_{i}}{Q_{0}} & =\frac{\text { UR } \ln \left(\frac{1}{r_{0}}\right)}{2 \pi H_{0}} y+\frac{U R \ln \left(\frac{1}{r_{0}}\right) r_{0}{ }^{2} y}{2 \pi H_{0}\left(x^{2}+y^{2}\right)}+\frac{H}{2 \pi} \arctan \left(\frac{y}{x}\right) \\
& +\sum_{j=1}^{j=N}\left[\frac{M_{j} \ln \left(\frac{1}{r_{0}}\right)}{4{ }^{2} H_{0}}\right]\left[\arctan \left(\frac{y-y_{j}}{x-x_{j}}\right)-\arctan \left(\frac{-y_{j}}{x_{0}-x_{j}}\right)\right]
\end{aligned}
$$

SIMPLIFIED CHEMICAL TRANSPORT WITH SORPTION

A single chemical species at trace concentration with equilibrium sorption is readily considered with only minor modification of the kinematic equations al ready provided. In particular, if the hydrodynamic dispersion is ignored since it is so very small in a homogeneous porous material, then the chemical transport equation using an equilibrium distribution coefficient, $K_{d}$, and the bulk density, $B_{d}$, of the porous material is 


$$
\nabla^{\prime} \cdot\left(C^{\prime} \underline{u}^{\prime}\right)=\left(1+\frac{B_{d} K_{d}}{P}\right) \frac{\partial C^{\prime}}{\partial t^{\prime}}
$$

or the dimensionless equivalent expression upon using Equations (A-2), (A-25) and $(A-26)$ is

$$
\nabla \cdot\left(C^{\circ} \underline{u}\right)=\left(1+\frac{B_{d} K_{d}}{P}\right) \frac{\partial C^{0}}{\partial t}
$$

where $C^{0}=C^{1} / C_{0}$ with the $C_{0}$ being the original source concentration at $t=0$. Expanding the equation gives

$$
\underline{u} \cdot \nabla C^{0}=k \frac{\partial C^{0}}{\partial t}
$$

since

$$
\nabla \cdot \underline{u}=\frac{1}{p} \nabla \cdot q \equiv 0
$$

by conservation of mass in a homogeneous material, and where

$$
K=\left(1+\frac{B_{d} K_{d}}{P}\right)
$$

Inspection of Equation (A-46) shows it to be a first-order partial differential equation, which is reduceable to the set of Characteristic Equations

$$
\frac{d x}{d t}=\frac{1}{K} v_{x}
$$

and

$$
\frac{d y}{d t}=\frac{1}{K} v_{y}
$$

But comparison with the kinematic Equations (A-28) and (A-29) shows that characteristic equations for the idealized contaminant transport are within a constant multiplier of the original kinematic expressions. Accordingly, it is no more difficult to solve for the idealized approximate chemicals transport equations; i.e., 


$$
\begin{aligned}
\frac{d x}{d t}= & \frac{U R}{P H_{0} K}\left\{1+\frac{r_{0}^{2}}{\left(x^{2}+y^{2}\right)}\left[\frac{2 x^{2}}{x^{2}+y^{2}}-1\right]\right\}+\frac{H}{K P \ln \left(\frac{1}{r_{0}}\right)}\left(\frac{x}{x^{2}+y^{2}}\right) \\
& +\sum_{j=1}^{j=N} \frac{M_{j}}{2 \pi H_{0} P K}\left[\frac{\left(x-x_{j}\right)}{\left(x-x_{j}\right)^{2}+\left(y-y_{j}\right)^{2}}\right] \\
\frac{d y}{d t}= & \frac{U R}{P H_{0} K}\left[\frac{2\left(r_{0}\right)^{2} x y}{\left(x^{2}+y^{2}\right)^{2}}\right]+\frac{H}{K P \ln \left(\frac{1}{r_{0}}\right)}\left(\frac{y}{x^{2}+y^{2}}\right) \\
+ & \sum_{j=1}^{j=N} \frac{M_{j}}{2 \pi P H_{0} K}\left[\frac{y-y_{j}}{\left(x-x_{j}\right)^{2}+\left(y-y_{j}\right)^{2}}\right]
\end{aligned}
$$

Equations $(A-51)$ and $(A-52)$ reduce identically to Equations $(A-30)$ and (A-31) when no exchange occurs. So if there is no exchange then $K_{d}=0$ in Equation $(A-48)$; hence $K=1$ so $(A-36)$ and $(A-37)$ reduce to the kinematic equations of $(A-51)$ and $(A-52)$. 
APPENDIX B

USER'S GUIDE FOR THE PRELIMINARY EQUATIONS MODELS 


\section{APPENDIX B \\ USER'S GUIDE FOR THE PREL IMINARY EVALUATION MODELS}

USING THE TERMINAL

The interactive PATHS program was written utilizing a conversational mode; it is tutorial and aids the user in providing the proper reply. Most responses will require a yes $(Y)$ or no $(N)$ answer or some numerical value. Details and examples of this will be given later. Other than knowing how to respond to prompting questions, the user needs little knowledge of computer commands.

Before working with the computer, bureaucratic details of being funded and given a project ID, user ID, password, and account number must be completed. Having these, a terminal and a phone, the Univac 1100/44 may be called by dialing 376-7841. After placing the phone in the acoustic coupler, the Univac will ask the user to type in the terminal ID (written on the terminal). The Univac responds by requesting the USERID/PASSWORD, PROJECT-ID, and address, as shown in the example following. Note that the symbol > (greater than) prompts the responses that are entered by the user.

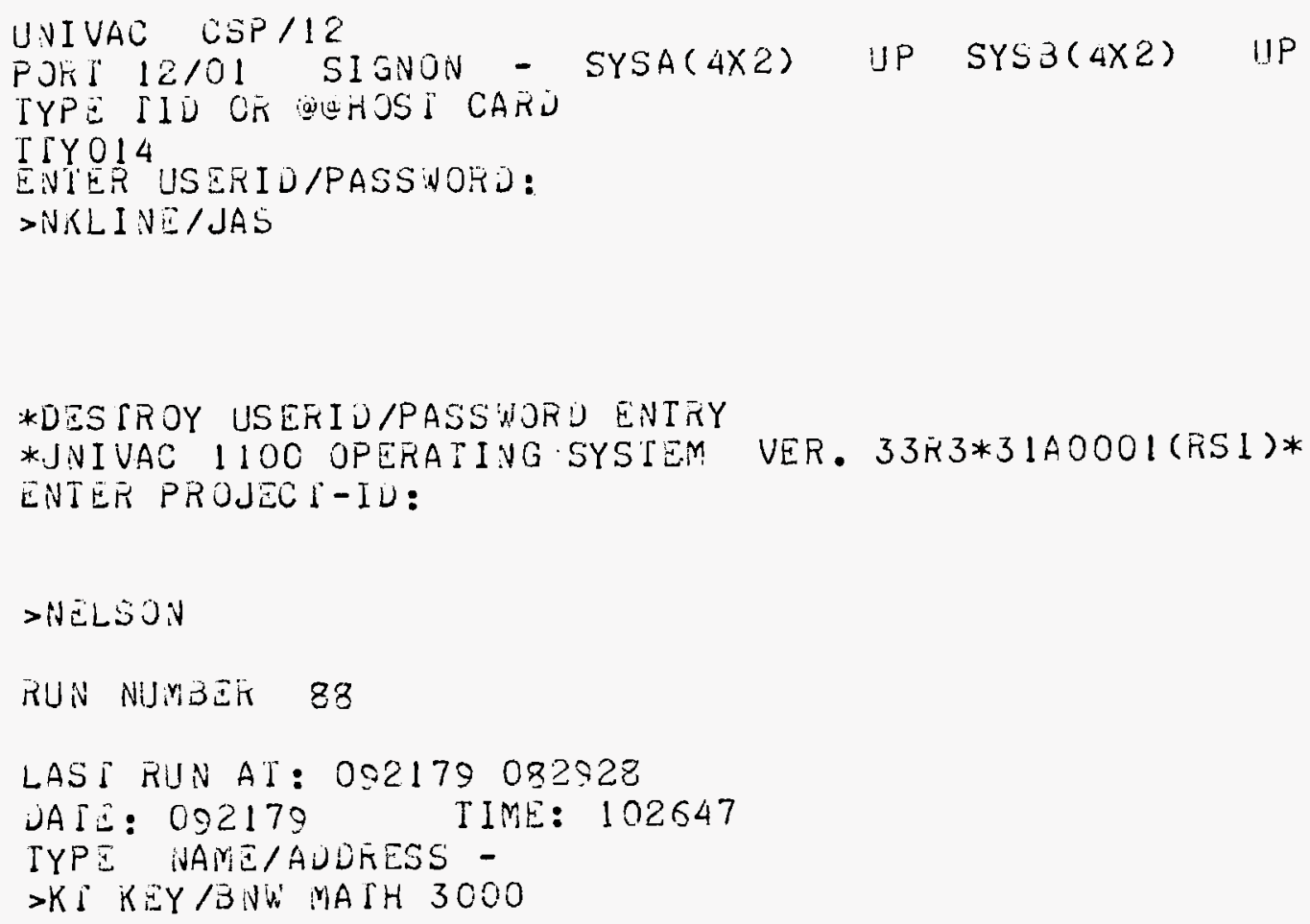


At this point, PATHS could be executed. The beginning sequence of this is

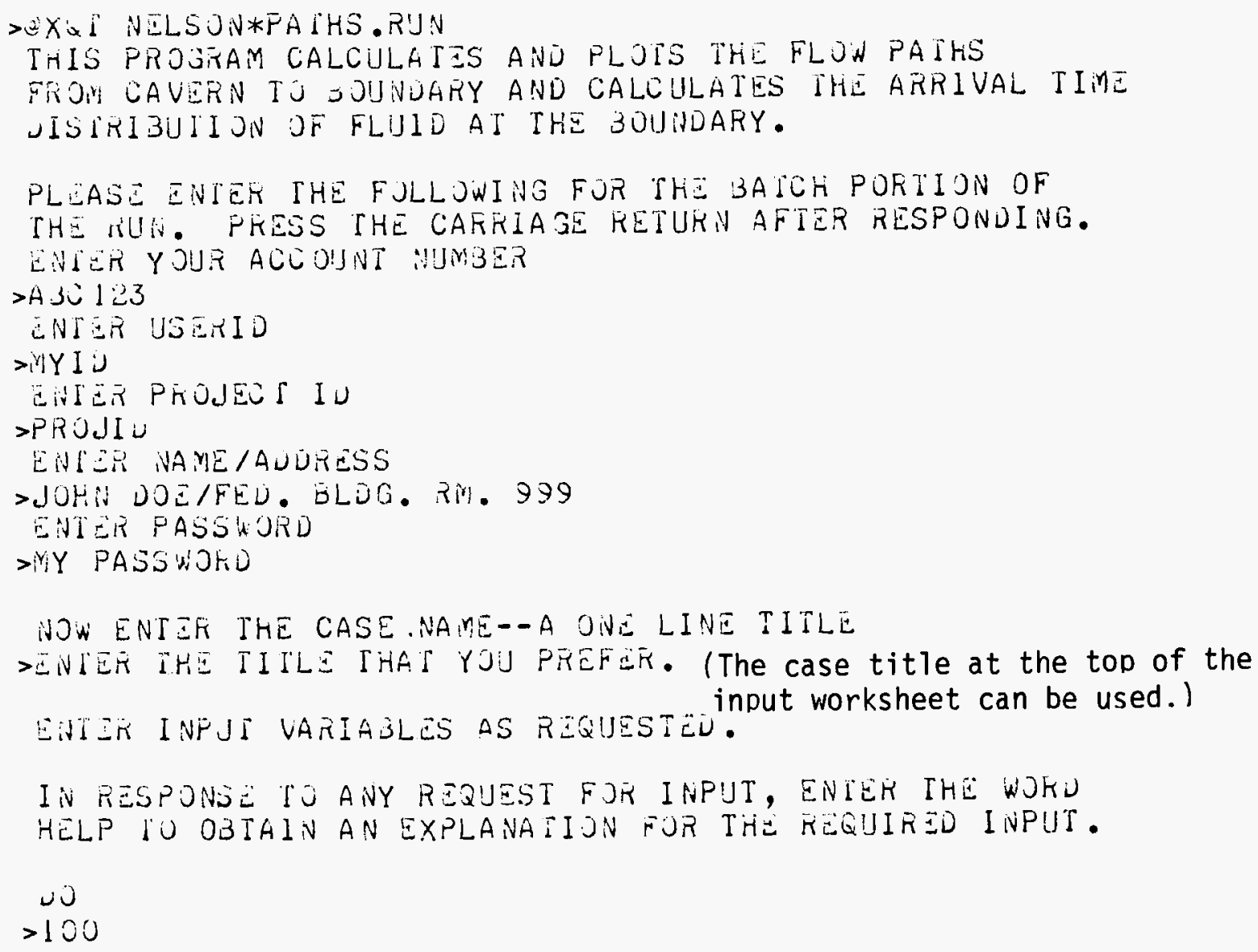

The PATHS program now has control and directs the user to respond appropriately. If you make a mistake while responding to PATHS, it can be erased (backspaced over). To do this, depress the control key and type the letter $H$. If the carriage has been returned and bad data thereby entered, PATHS can be terminated by typing the master character 0 . After this, begin again, starting with the QXQT statement. However, you may choose to note the mistake and continue with the intent of later modifying the job stream created. In this instance, continue to respond to all questions until the end. When PATHS asks if the batch job is to be submitted, reply NO. This way a copy of the job stream is saved. Following PATHS, the Univac EDITOR may be entered to modify the job stream appropriately for batch submittal. See "Using EDITOR for Minor Run Changes"for details. 
SAMPLE JOB

The following job stream was entered through PATHS as an example. See the input parameter worksheet from Table I in the report.

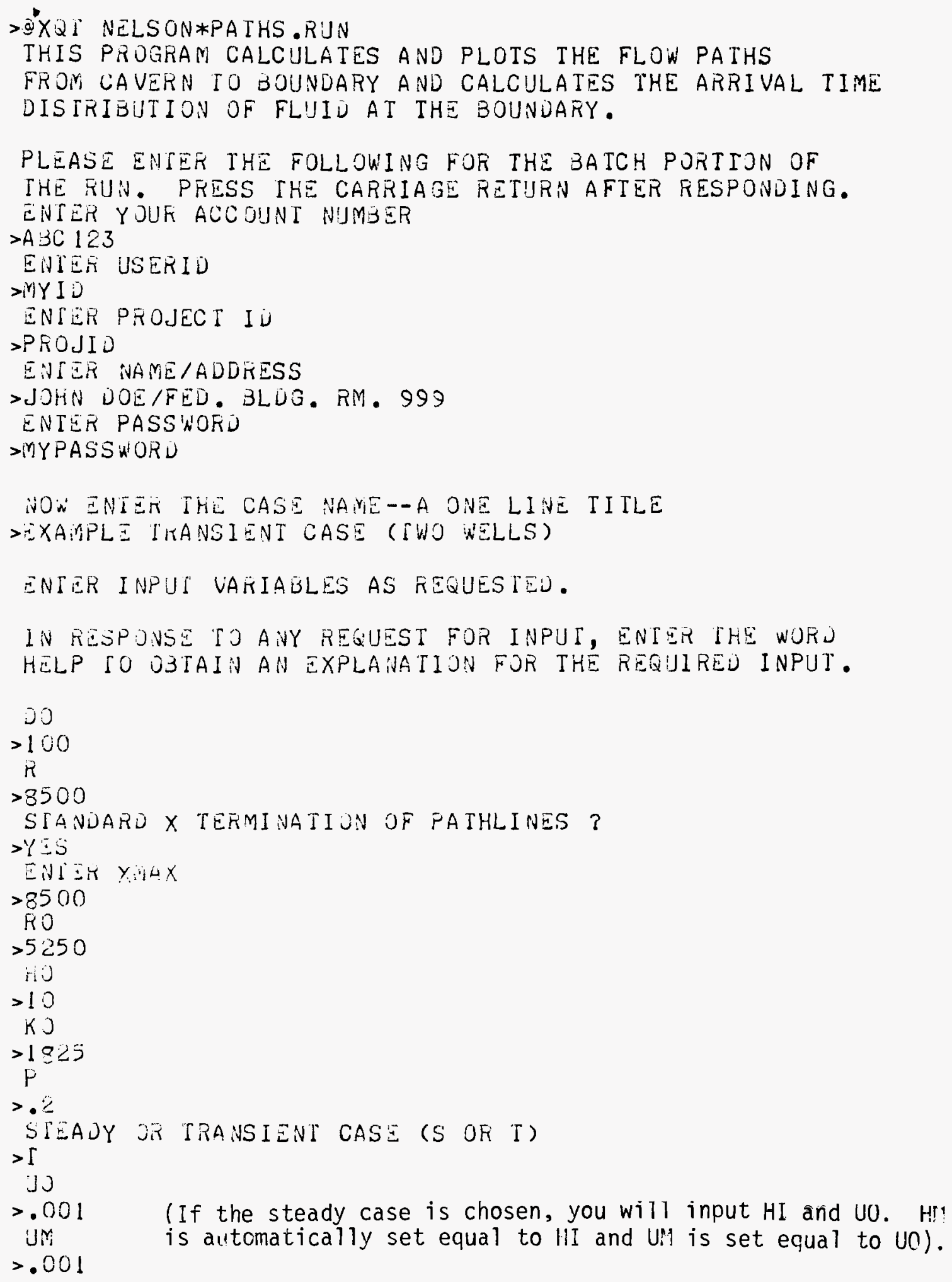




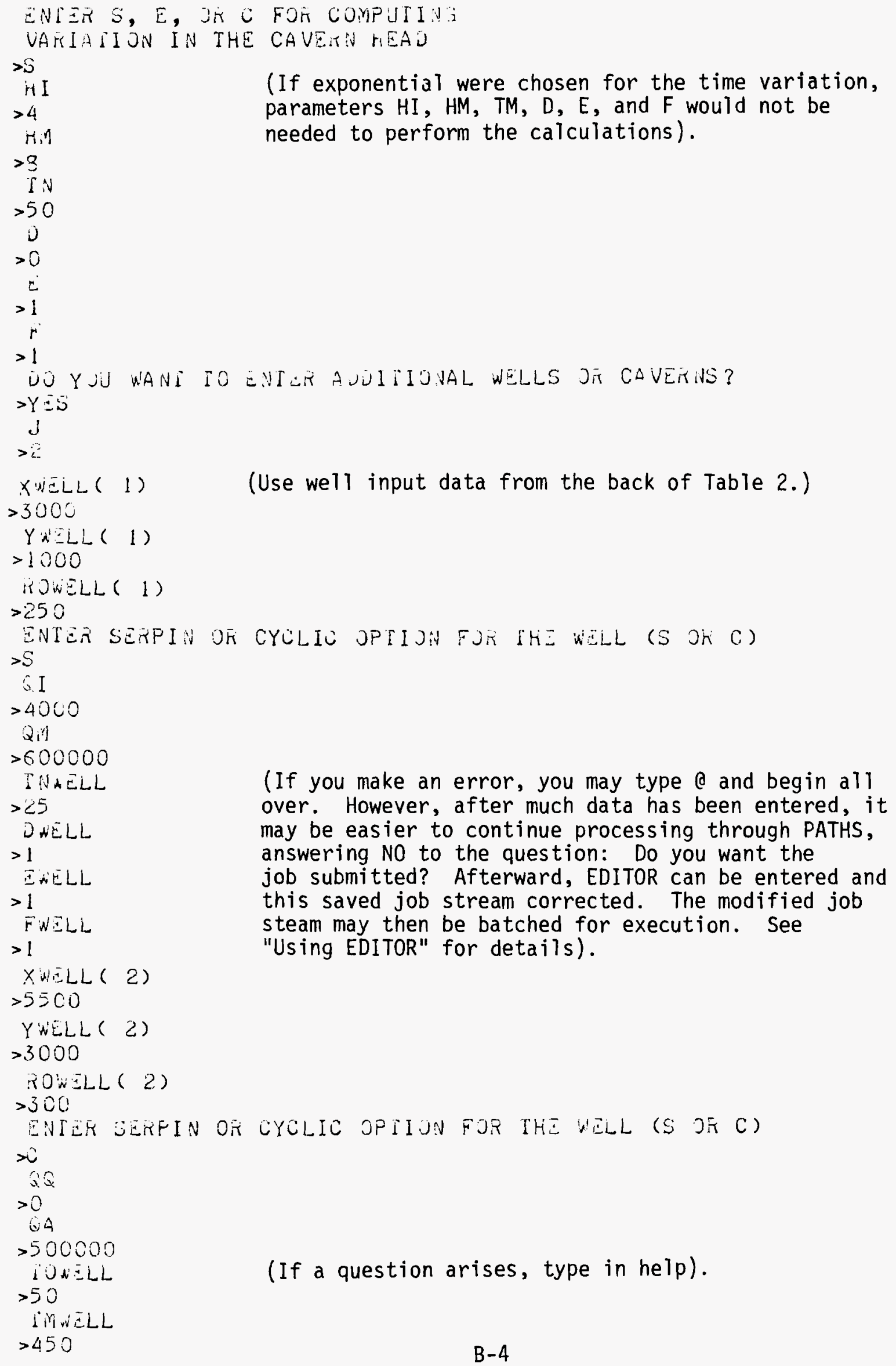




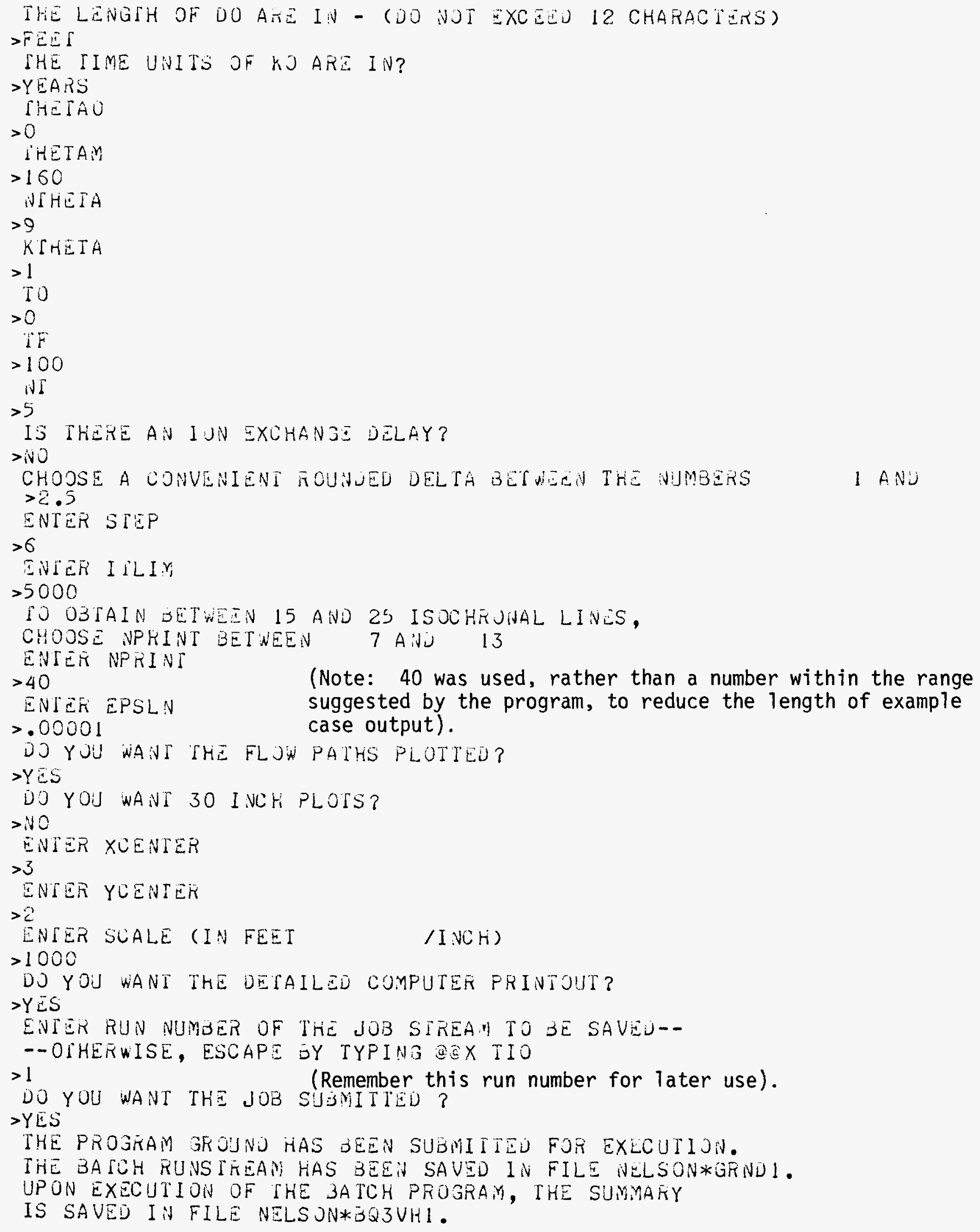




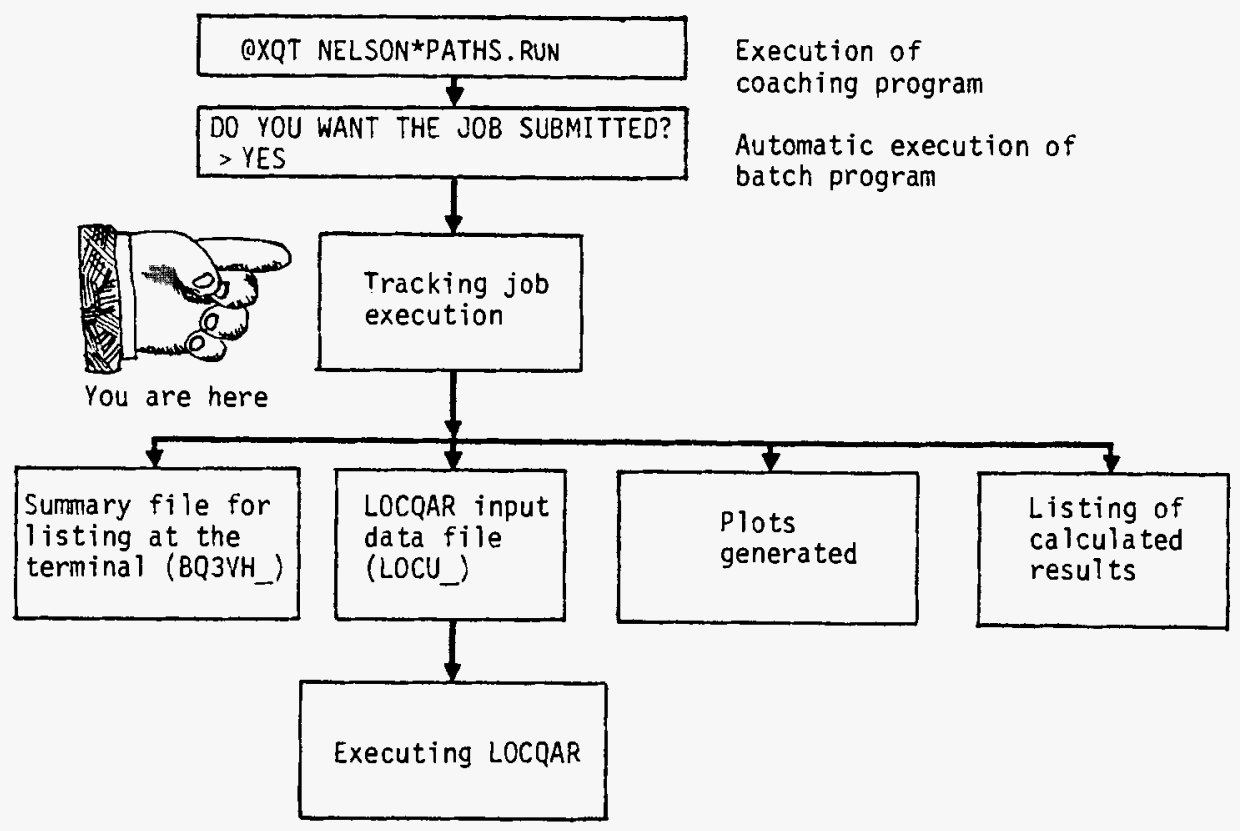

Finally, to quit interacting with the Univac properly, type OFIN and follow up with OeTERM. The carrier detect light will go off on the terminal and the phone can be taken off the acoustic coupler. However, after finishing with the interactive part of job submittal, it is a good idea to verify the successful entry of the batch portion into the execute queue. Also, you may wish to preview the summary file created by the batch run's (GROUND's) execution, and to execute the program LOCQAR. Discussions of these follow.

The detailed printed output from responding YES to the question: "Do you want the job submitted?" can be seen under the topic "Example Transient Case."

\section{TRACKING JOB EXECUTION}

After starting the batch job, type oecons to check its progress. Follow this by $T$ as shown below.

7.)

$\mathrm{T}$

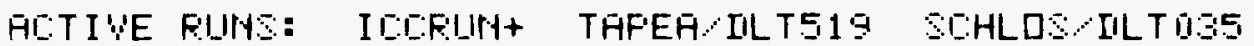

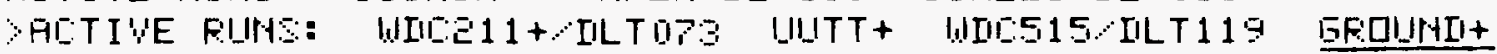


All the jobs currently in execution are listed. If another job GROUND is already queued, a later entry will by called GROUNE, and one after that GROUNF and so on.

Information on the progress of execution of a particular job can be obtained by typing RC and then the job name. This is shown below for GROUND.

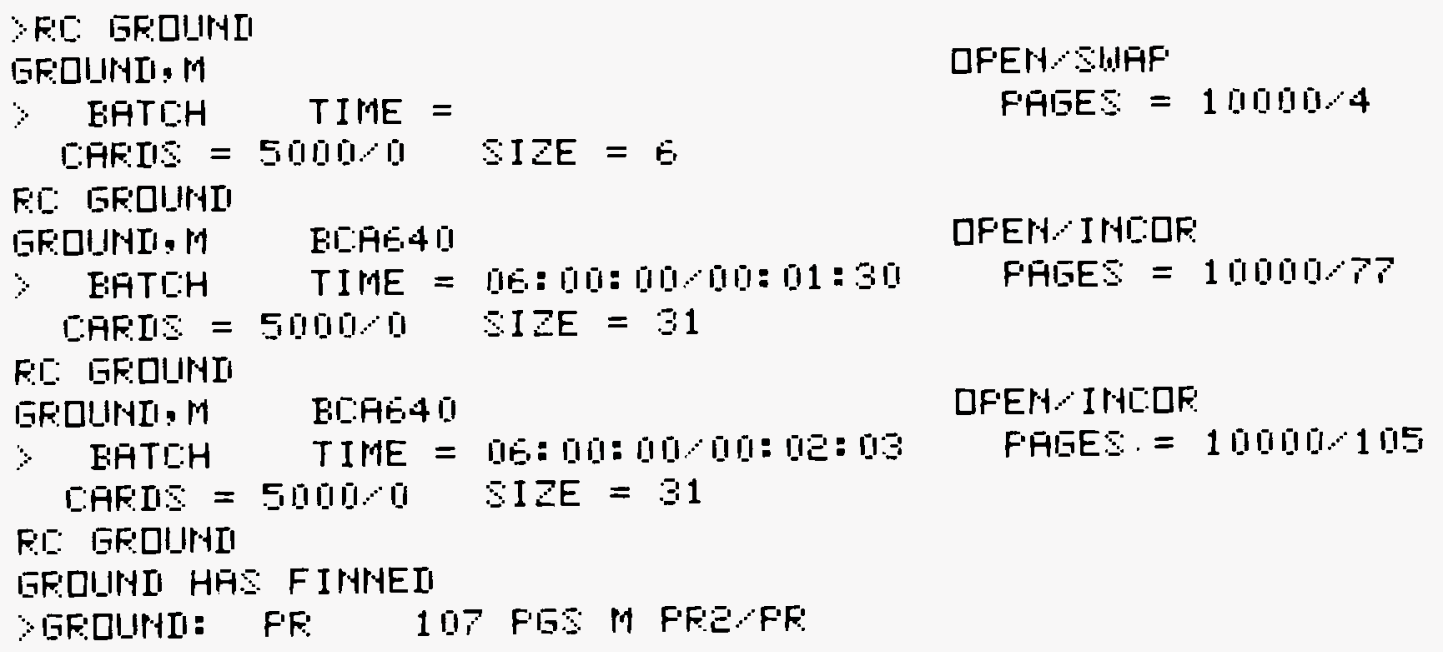

Notice that progress is monitored until the job has finished. of course, in normal practice, job monitoring to this detail is not necessary. Type OQEND CONS when finished monitoring the job. Once the batched job GROUND has finished successfully, the two files it generates (PROJID*BQ3VH_. and PROJID*LOCQ_.) are available for the user. (Note: PROJID is the user project ID and the _ is the run number. For the example transient problem, these are respectively NELSON*BQ3VH1. and NELSON*LOCQ1.).

SUMMARY FILE - BQ3VH_.

With the successful execution of the GROUND program, you may view from the terminal a summary of the flow paths calculated. This way you have the summary results and can partially review calculated results before the longer printed output is delivered. To do this type OED,R PROJID*BQ3VH_. followed by $P !$. This is shown with the ensuing results for the example case stored on NELSON*BQ3VHT.\#. 
$>$ QED, R NELSON*BQ3VH1.

READ-ONLY MODE

ED 15R2-[H]-09/20/79-15:05:28-(0,)

EDIT

$0:>P$ !

( $P$ ! means to print all lines in the file).

EXAMPLE TRANSIENT CASE (TWO WELLS)

THE DEPARTURE TIME IS

THE INITIAL OUTFLOW RATE IS CUBIC FEET

.000 YEARS

$.13006966+007$

PER YEARS

THE INITIAL FELATIVE CAVEFN HEAU IS

PATH NO. TRAVEL TIME YEARS

$15.93105+002$

$2 \quad 5.97578+002$

$31.50781+002$

$4 \quad 6.56093+002$

$54.52500+002$

$68.12856+002$

$79.08300+002$

$8 \quad 1.00088+00.3$

$91.15964+003$

$101.40907+003$ $x$

FEET

$8.50000+003-5.94146+002$

$8.49993+003$

$2.75648+003$

$3.49992+003$

$5.52440+003$

$8.49996+003$

$8.49993+003$

$8.49996+003$

$8.49999+003$

$8.49992+003$
$Y$

$$
\text { FEET }
$$

$8.53198+001$

$1.05426+003$

$2.14770+003$

$2.70168+003$

$4.07076+003$

4. $21505+003$

$4.30026+003$

$4.49577+003$

$4.10734+003$
PATH LENUTH FEEI

$8.28076+003$

$8.31150+003$

$2.74278+003$

$3.87105+003$

$6.33241+003$

$1.00956+004$

$1.06034+004$

$1.12869+004$

$1.21774+004$

$1.26985+004$ 
THE DEPARTURE TIME IS

25.000 YEARS

THE INITIAL OUTFLOW RATE IS CUBIC FEET $.23412538+007$

THE INITIAL RELATIVE CAVERN HEAD IS

.7200

\begin{tabular}{ccccc} 
PAIH NO. TRAVEL TIME & \multicolumn{1}{c}{ X } \\
YEARS & FEET & Y FET & PATH LENGTH \\
1 & $6.15849+002$ & $8.49999+003$ & $-5.44676+002$ & $8.27626+003$ \\
2 & $6.20566+002$ & $8.49996+003$ & $1.46096+002$ & $8.31424+003$ \\
3 & $1.73750+002$ & $2.76808+003$ & $1.03996+003$ & $2.76965+003$ \\
4 & $6.78774+002$ & $8.49996+003$ & $2.10892+003$ & $8.89020+003$ \\
5 & $7.22543+002$ & $8.49994+003$ & $2.47132+003$ & $9.36523+003$ \\
6 & $8.65077+002$ & $8.49995+003$ & $4.02887+003$ & $1.01362+004$ \\
7 & $9.35311+002$ & $8.49995+003$ & $4.10902+003$ & $1.06107+004$ \\
8 & $1.02123+003$ & $8.49992+003$ & $4.23700+003$ & $1.12974+004$ \\
9 & $1.18065+003$ & $8.50000+003$ & $4.48307+003$ & $1.21531+004$ \\
10 & $1.41295+003$ & $8.49995+003$ & $4.08009+003$ & $1.26239+004$
\end{tabular}

THE DEPAKTURE TIME IS 50.000 YEARS

THE INITIAL OUTFLOW RATE IS CUBIC FEEI $.26013932+007$

THE INITIAL RELATIVE CAVERN HEAU IS .8000 PAIH NO. TRAVEL TIME
YEARS

$x$ FEET

$8.49996+003-5.08899+002$

$8.49995+003$

$2.753 .69+003$

$8.49972+003$

$8.49995+003$

$8.49996+003$

$8.49997+003$

$8.50000+003$

$8.50000+003$

$8.49993+003$
$Y$

FEET

$1.69379+002$

$1.04029+003$

1. $97734+003$

$2.27654+003$

$3.75909+003$

$3.93656+003$

$4.13010+003$

$4.44799+003$

$4.03909+003$
PATH LENGTH FEEI

8. $27236+003$

$8.31034+003$

$2.74411+003$

$8.87098+003$

$3.35390+003$

$1.00119+004$

$1.05183+004$

$1.12026+004$

$1.20519+004$

$1.25146+004$ 
THE DEPARTURE TIME IS

IHE INITIAL OUTFLOW RATE IS CUOIL FEET PER YUARS

THE INITIAL RELATIVE CAVERN MEAU IS

.7692

$\begin{array}{cllll}\text { PATH NO. TRAVEL TIME } & \text { X } & \text { Y } & \text { PATH LENGTH } \\ \text { YEARS } & \text { FEET } & \text { FEEI } & \text { FEET } \\ 1 & 6.75536+002 & 8.49998+003 & -4.79104+002 & 8.26912+003 \\ 2 & 6.79238+002 & 8.49997+003 & 1.80307+002 & 8.30669+003 \\ 3 & 2.23750+002 & 2.75079+003 & 9.33653+002 & 2.72304+003 \\ 4 & 7.35234+002 & 3.49793+003 & 1.34440+003 & 8.84856+003 \\ 5 & 7.97763+002 & 8.49999+003 & 2.16613+003 & 9.31521+003 \\ 6 & 6.25312+002 & 5.20091+003 & 3.00368+003 & 6.48025+003 \\ 7 & 9.68368+002 & 8.49993+003 & 3.75754+003 & 1.04148+004 \\ 8 & 1.04691+003 & 8.49992+003 & 4.02259+003 & 1.10936+004 \\ 9 & 1.21218+003 & 8.49993+003 & 4.41300+003 & 1.19453+004 \\ 10 & 1.43027+003 & 3.49096+003 & 3.99631+003 & 1.24079+004\end{array}$

THE DEPARTURE TIME IS

100.000 YEARS

THE INITIAL OUTFLOW RAIE IS CUSIC FEET PEK YEAT̃S

THE INITIAL KELATIVE CAVERIN HEAJ IS

PATH NU. TRAVEL TIME $X$ YEARS $17.05409+002$

$27.08822+002$

$32.49375+002$

$47.66269+002$

$58.32177+002$

$6 \quad 6.40781+002$

$79.81083+002$

$8 \quad 1.05883+003$

$9 \quad 1.22978+003$

$101.43966+00.3$
$X \quad Y$

FEET

$8.49994+003-4.50975+002$

$8.49996+003$

$2.75395+003$

$8.49994+003$

$8.49994+003$

$5.29290+003$

$8.49993+003$

$3.49996+003$

$8.49996+003$

$8.49999+003$
FEET

$1.87686+002$

$9.64524+002$

$1.73988+003$

$2.12171+003$

$2.73342+003$

$3.60303+003$

$3.92747+003$

$4.37746+003$

$3.96292+003$
PATH LENGIH FEET

$8.26644+003$

$3.30387+003$

$2.72327+003$

$8.82357+003$

$9.26736+005$

$6.50668+003$

$1.03224+004$

$1.09901+004$

$1.18447+004$

1. $23099+004$

ZOF: 111

$0:>E X I T$

NO CORRECTIONS APPLIEO.

After the summary file has been listed on the terminal and control is returned to the user, i.e.; when the system prints the symbol >, type in EXIT to get out of the editor.

These summary results are the basic arrival data required to evaluate the contamination problem. Specifically, the above results are contained in Table 3 in the body of the report. 


\section{EXECUTING LOCQAR}

After GROUND has completed execution and after the summary file BQ3VH has been reviewed, the LOCQAR program can be executed to calculate fluid arrival locations and outflow quantities. To execute LOCQAR from the terminal, type OXQT NELSON*LOCQAR.RUN . NOW LOCQAR asks for the information it needs. Like PATHS, LOCQAR is tutorial and aids in answering its questions. Typing HELP solicits clarification of LOCQAR's questions, as shown below.

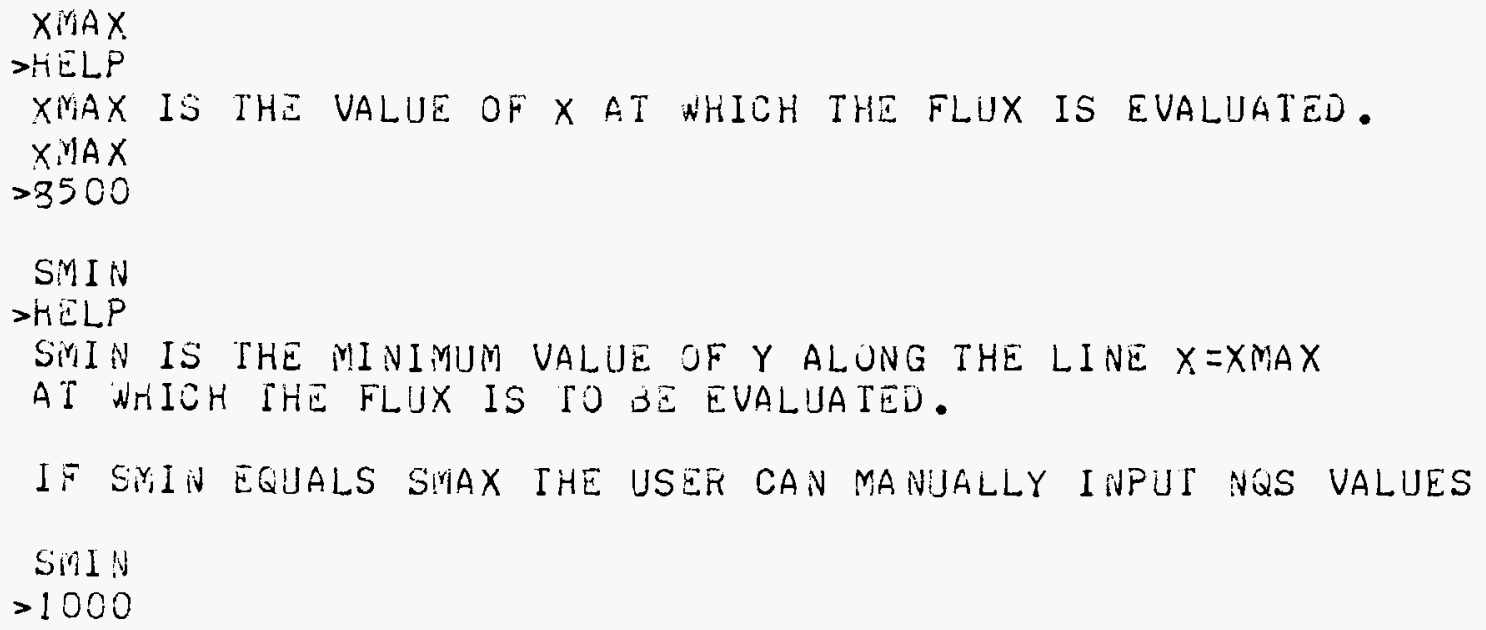

Following is an execution of LOCQAR using the file created by the transient case. 
>EXQT NELSON*LOCQAK.KUN

ENTER RUN NUMOER USED IN PROGRAM PATHS. IF PATHS NUT

PREVIOUSLY RUN, DO NOT CONTINUE WITH THIS PROGRAM.

$>1$

ENTER CASE NAME

>EXAMPLE IRANSIENT CASE (TWO WELLS)

XIAXX

$>3500$

SMI iN

$>-4000$

(If SMIN and SMAX are input as the same number, NQS irregular locations of $s$ can be input).

\footnotetext{
SIMA

$>4000$

NQSS
}

$>3$

ATMIN IN UNITS OF YEARS

$>600$

A TMAX II UUITS OF YEARS

$>650$

IA I

(If ATMIN and ATMAX are input as the same number,

NAT irregular times can be input).

FLUID ARAIVAL LOCATIONS AND OUTFLUN QUANIITIES FOR

EXAYPLE ITANSIENT CASE (IWO WELLS)

ARRIVAL TIME

YEARS
$.600000+003$
$.600000+003$
$.600000+003$
$.650000+003$
$.650000+003$
$.650000+003$
S,LOCATIJNS

OF OUTFLON

FEET

$-.400000+004$

.000000

$.400000+004$

$-.400000+004$

.000000

$.400000+004$
OUTFLOW RATE IN

CUBIC FEET /YEATSS /FEET $.209556+003$

$.221875+003$

$.223360+003$

$.206351+003$

$.212106+003$

$.206661+003$

(These results are the arrival outflow data required to evaluate the contamination problem. They are contained in Table 4 in the report). 
USING EDITOR FOR MINOR RUN CHANGES

Often it is quicker for the user to edit the batch runstream created by PATHS rather than to create a new job stream by rerunning PATHS. To facilitate this, the following flow diagram shows the data names read by the GROUND program. Most of these names can be recognized from the input parameter work sheet data in Table 1. of the report. The others, superscripted by an asterisk (*), are variables set by PATHS. They are primarily used to direct the flow of execution of the GROUND program.

1. QRUN GROUND, account-id/user-id,project-id-20 . name/address

2. OIDENT . name/address

3. QPASSWD pasSWord

4. OASG, UP BQ3VH.

5. QUSE 3., BQ3VH'.

6. OTP, $W$ VERST $X * \overline{9}$ VERS12./MAPPS

7. QRL\$ $\$$ GRAFX.VRSFP

8. $\$$ PARAMS MODEL $=1200, X M A S=300$

9. \$END

10. QXQT NELSON*GROUND. RUN

11. TEST CASE NAME ( $A$ one line title)

12. $\mathrm{R}, \mathrm{R}, \mathrm{HO}, \mathrm{KO}$

13. RO, RO, Do, UO

14. UM, P, TM

15. PATH*, KD,BD

16. CHEM, PROJ, VH3*, IPROJ*, PTSZ*

17. $A, B, C$, KTHETA

18. THETAO, THETAM, TO, NTHETA

19. TF, TMAX, EPSLN, ITLIM

20. DELTA, TN, STEP, NT

21. XMAX, XCENTER, YCENTER, NPRINT

22. SCALE, D, E, F

23. HI, HM, P9

24. HMC, HAC, TOC, TMC

25. SS, J, P

26. ROWELL(J), XWELL(J)

27. YWELL $(J), \operatorname{TNWELL}(J)$

28. QI $(\mathrm{J}), \operatorname{QM}(\mathrm{J}), \operatorname{DWELL}(\mathrm{J})$

29. $\operatorname{EWELL}(\mathrm{J}), \operatorname{FWELL}(\mathrm{J}), Q A(\mathrm{~J}), Q Q(\mathrm{~J})$

30. TOWELL $(J), \operatorname{TMWELL}(J)$

31. WSS $(J) *$

NOTE: The variable VH3 contains the run number used by the PATHS system for a particular job. In the example transient case the value of $\mathrm{VH} 3$ is 1 .

38. VS

39. WS

40. CS

(When THETAO = THETAM, a list of XSTART and YSTART values are printed out here). 
To explicate further, the batch run steam of the sample problem for the transient case is shown below:

>ED, VIULSON*GRNU!.

ED $15.72-[H !-09 / 20 / 79-15: 19: 58-(0,1)$

EDI

$0:>$ LNP!

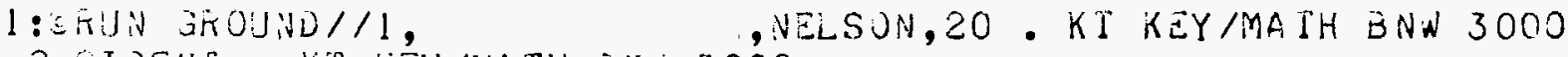
2: IDENR - KS KEY/MATH SNW 3000

$3:$ בPASSWJ JAS

4: $A$ AS 3 ,UP BQ3VHI.

5: USE S.,DG 3VH1.

6:@ IP, W VERS IX*9VLRS 12. MMAPPS

$7: \triangle R L \$ * G R A F X . V R S F P$

8: TPARA YIS MODEL $=1200, X M A X=300$

9: \$END

10:XXE NELSON*GROUND . TUN

11 : XXMMLE TRANSIENI CASE (TWO WELLS)

12: $.85000+004 \quad .85000+004 \quad .10000+002 \quad .18250+004$

$13: .25000+003 \quad .25000+003 \quad .10000+003 \quad .10000-002$

$14: \quad .10000-002 \quad .20000+000 \quad .10000+001$

15: $.00000 \quad .00000 \quad .00000$

15: $\quad$ NELSJV $\quad 1.6-1$

17: $.10000+001.10000+001 \cdot .10000+001 \quad 1$

13: .00000 $.16000+003$

$19: \quad .10000+003 \quad .00000$

$20: .25000+001 \cdot .50000+002$

1: $.35000+004 \quad .30000+001$

2:: $\quad .10000+004$

$23: \quad .40000+001$

$24: \quad 00000$

$25: 5 \mathrm{ERPIN}$

¿6: $.25000+003$

$27: \quad .10000+004$

$23: \quad .40000+004$

¿s: $.10000+001$

30: .00000

$31:$ : IRPL :

.00000

.00000

$.10000-0045000$

$60000+0015$

$.20000+001 \quad 40$

$.30000+001$

.00000 2.00000

$.10000+001$

$.10000+001$

उट: $\quad .30000+003$

33: $\quad .30000+004$

34: $.00000 \quad .00000$

35: $.00000 \quad .00000$

$36: .50000+002 \quad .45000+003$

$.10000+001$

$.00000 \quad .00000$

$.30000+004$

$.25000+002$

$.60000+006$

$.10000+001$

$.10000+001$

.00000

.00000

$37: O Y C L I C$

$33:$ FEE I

उЭ:Y:ARि

$40: 1$

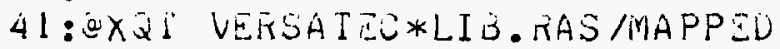

$42: ख \Gamma P S V$ MAPPS

$E J F: 43$

$43: \backsim \bar{F} I N$

$0:>\operatorname{CXII}$

LINES: 43 ASLII

This can be compared with the sample data entered earlier in the PATHS

program. (Already shown under "Sample Job.") 
Note the first command on this listing: QED, UQ NELSON*GRND1. . This brings the run stream generated to the Univac EDITOR. NELSON is the PROJECT ID entered in PATHS under which the batch file is cataloged. GRNDI is the file name. GRND is always the prefix, and the number appended, 1 in this case, is the number of the job stream the user gave PATHS. (See the note near the end of topic "Sample Job" or item 78 in the detailed run stream, Appendix C). Next, the edit command LNP! lists the entire run stream for viewing. With this list the data can be checked and modified as desired. For example to change variable $.85000+004$ on line 18 to $.96000+003$, one can do the following:

18 (Positions to line 18)

C /.85000+004/.96000+003/ 1

This would make the change. The tailing 1 says to make the change only to the first line. If this change were to be made to any like variables in the ensuing 10 lines, you should enter $\mathrm{C}-/ .85000+004 / .96000+003 / 1$.

\section{STARTING JOB EXECUTION}

After the batch stream has been modified, type EXIT. This frees the file with all the changes that have been made and contro $\overline{l e a v e s}$ the EDITOR. (To leave EDITOR with the batch stream left in its original state, type OMIT.) To submit the file into the input stream for execution, tvpe OSTART NELSON*GRND1.

[Note: For additional detailed information on most of the available EDITOR commands and system control commands refer to UNIVAC 1100 Series EXEC 8 Hardware/Software Summary (UP-7824 Rev. 1).] 
CAUTION

When starting an execution of GROUND, it is important to realize that GROUND itself will generate and catalog two files: the summary file PROJID*BQ3VH_. and the data file read by LOCQAR, cataloged PROJID*LOCQ_. . (Once again PROJID is the user project ID, and the _ stands for the job run number.) If these files should exist from a prior run of GROUND, they will precipitate a fatal error should GROUND be reexecuted. Two alternatives are available to the user: the first, and simplest, is to delete these files if they exist. This is done by typing ODELETE followed by the file name. The example below shows the deletion of the file NELSON*BQ3VH1..

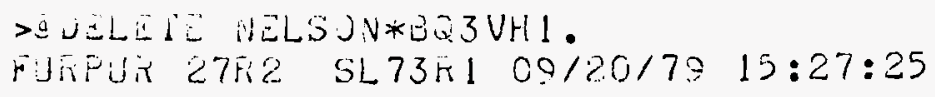

Alternatively, you could change the number of the file BQ3VH . that is used on cards 4, 5 and 13 of the run stream (see "Using EDITOR"). Thus $B Q 3 V H 1$. could be changed to $B Q 3 V H 9$. if BQ3VH9. does not already exist. Along with this, the internally assigned and cataloged file LOCQ_., should have its file number changed appropriately. It is set by variable VH3.. (See line 13, in "Using EDITOR".)

As BQ3VH1. was changed to BQ3VH9., VH3 should be changed from 1 . to 9. .

\section{FILES}

Keeping track of the files accumulated by the PATHS program can be done by taking an audit of the files cataloged. Do this by typing OAUDIT as shown in the following example. 


\begin{tabular}{|c|c|c|c|c|c|c|c|c|}
\hline $\begin{array}{l}\text { TEAIEY } \\
\text { C:DUNT }\end{array}$ & $\begin{array}{l}\text { HIGH } \\
\text { FEF }\end{array}$ & $\begin{array}{l}\text { TFK } \\
M A \%\end{array}$ & $\because \frac{D F}{H E G}$ & & $\overline{\mathrm{ALS}}$ & $\begin{array}{c}\text { IIATTE } \\
\text { C:REATEI }\end{array}$ & $\begin{array}{r}\text { LAST } \\
\text { ASE }\end{array}$ & FILE MAMME \\
\hline $\begin{array}{l}35 \\
45\end{array}$ & $\begin{array}{l}01 \\
71\end{array}$ & $\begin{array}{l}1 \mathrm{EST} \\
11 \mathrm{TT}\end{array}$ & $\begin{array}{r}35 \\
25.5\end{array}$ & $\begin{array}{l}F \\
F\end{array}$ & $\begin{array}{l}\mathrm{E} \\
\mathrm{E}\end{array}$ & $\begin{array}{l}012478 \\
012578\end{array}$ & 0413 & 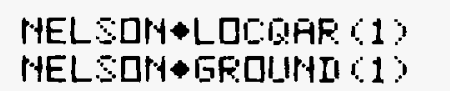 \\
\hline 41 & $\theta .7$ & $141 \mathrm{~T}$ & 94 & $P$ & $\mathrm{~B}$ & 0112478 & 0413 & NELSOH\$F'ATHSC1\% \\
\hline 1 & i1 & $1 Е \Xi T$ & 1 & $\mathrm{~F}$ & B & 041378 & 0413 & HELSDH+EISWH1 C1\% \\
\hline 1 & 1. & 1ЁT & Z & $\mathrm{F}$ & $\mathrm{B}$ & 041178 & 04411 & HEL SOH+EOSWHS (1) \\
\hline$z$ & 1 & $1 E \mathrm{ET}$ & 3 & $\mathrm{~F}$ & $\mathrm{~B}$ & 0421279 & 04212 & MELSDH*BFHIG 61$)$ \\
\hline 1 & 1َ & $1 \mathrm{EQT}$ & 1 & $\mathrm{~F}$ & $\mathrm{~B}$ & 0441209 & 04112 & MELSOH -LDEDG 613 \\
\hline$\Xi$ & 1 & $1 \mathrm{EET}$ & 4 & $\mathrm{~F}$ & $\mathrm{E}$ & 041278 & 0412 & HELSOH+EFHIIE C \\
\hline 1 & 1) & $1 \mathrm{ET}$ & 1 & $\mathrm{~F}$ & $\mathrm{E}$ & $0412<78$ & 0412 & MELSOH+LDCOS 61 \\
\hline 1 & 11 & $1 こ B T$ & 1 & $\mathrm{~F}$ & $\mathrm{E}$ & 041278 & 0412 & HELSOH+EOSWHBC1) \\
\hline 1 & 01 & $1 \Xi \Xi T$ & 4 & $\mathrm{~F}$ & $\mathrm{~B}$ & 0407789 & 14412 & MELSQM+101S \\
\hline 34 & 33 & $1 \mathrm{EBT}$ & 1 & $F$ & $\mathrm{E}$ & 0401178 & 0411 & MELS $\square$ H $\$$ TEMF $(1)$ \\
\hline 30 & $\theta \bar{Z}$ & 5001 & 9 & $F$ & $\mathrm{E}$ & 041878 & 0413 & NELSON•FEUISIOH 1 : \\
\hline 3 & 29 & $1 Е \mathrm{ET}$ & 10 & $F$ & $\mathrm{~B}$ & $0407>78$ & 04412 & HELSㅁ-UIT IL 1$)$ \\
\hline
\end{tabular}

TOTAL: 14 FILES CO DISABLEI, O LHLQAIEIY ISIMG EOU TRACKS.

Files should be deleted when they are no longer needed. This avoids paying for unneeded disc storage, and reduces the likelihood of trying to create files with file names already cataloged.

\section{EXAMPLE TRANSIENT CASE}

The printed output following comes from entering information to the PATHS program shown in "Sample Job". Notice the individual path histories for each of the 10 paths followed by the summary page. This would be repeated five 
times for the transient cases for the years $0,25,50,75$, and 100 . However, to save space only the first is completely shown and primarily summary information is subsequently shown. This summary information, incidentally, is the same as that obtained from file BQ3VH1, under "Summary File - BQ3VH_" previously. The complete output for the example transient case is provided on microfiche near the end of Appendix $C$.

The five plots that follow are also from this run. Normal production plots need not have such large numbers along the pathlines. Thev have been macie larger here so they will be legible.

Following the output of the example transient case, a steady case is presented to further illustrate some additional alternatives. Among these features are the ion exchange delay and the input of irregularly located starting coordinates for the pathlines. 


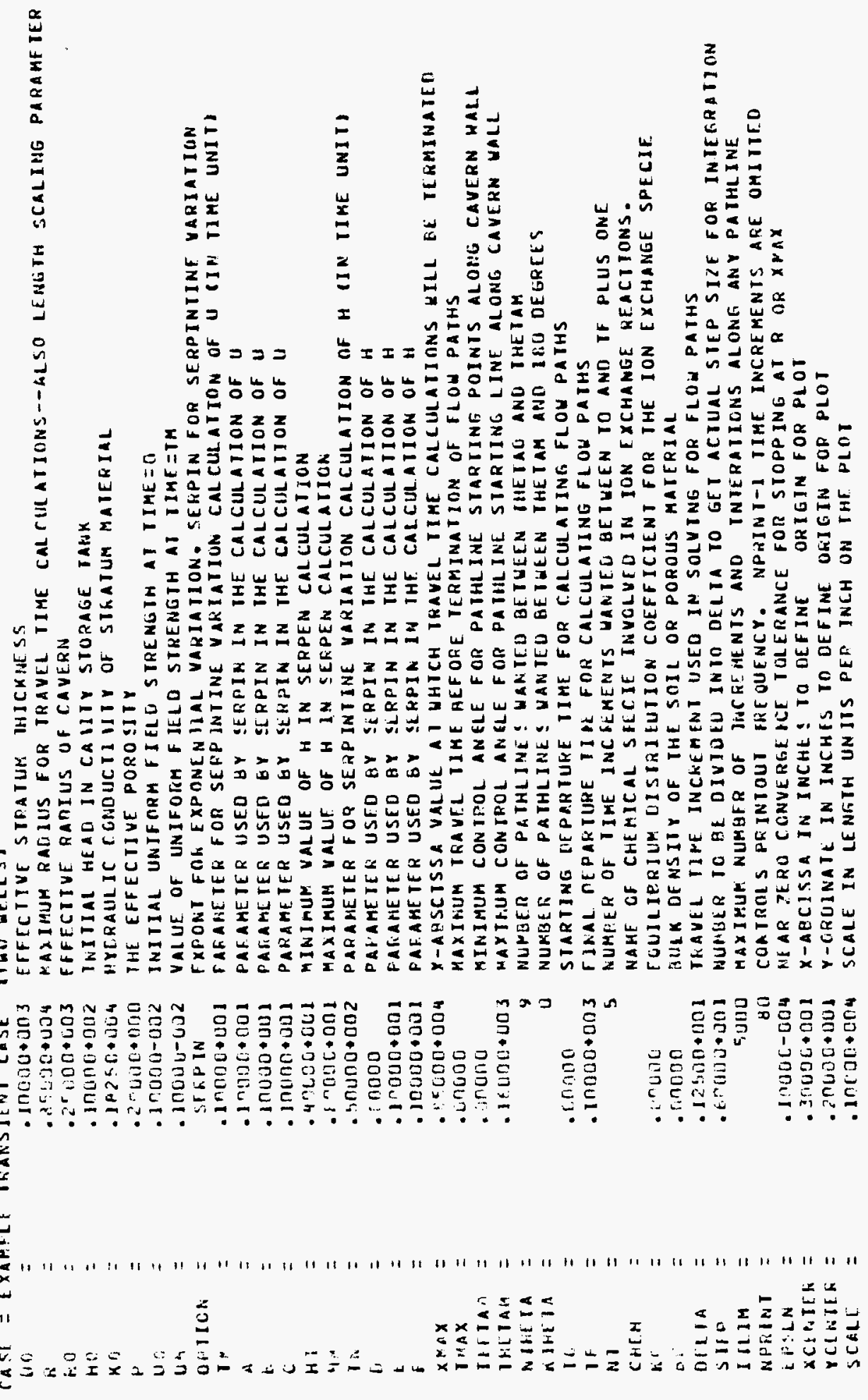




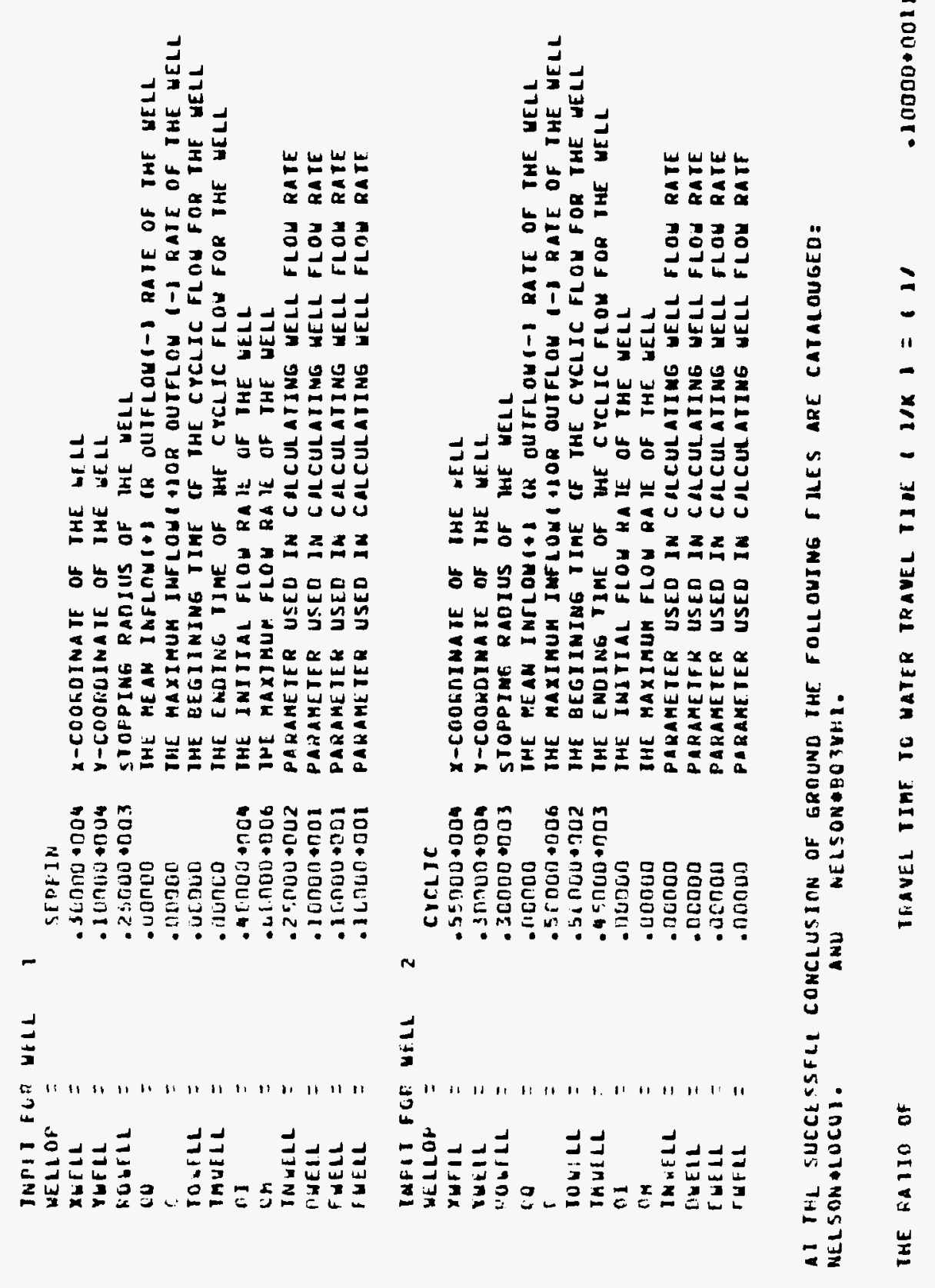




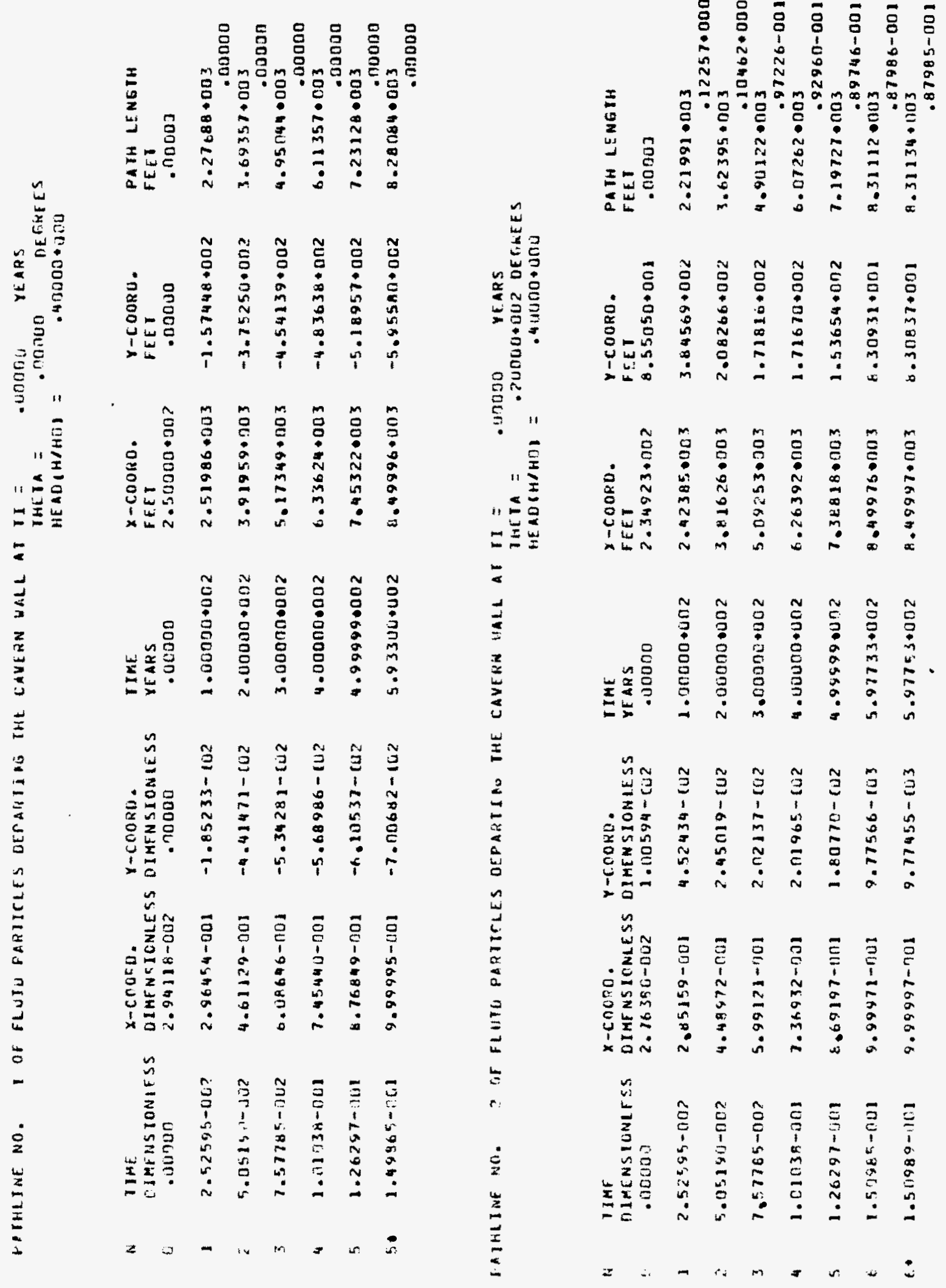



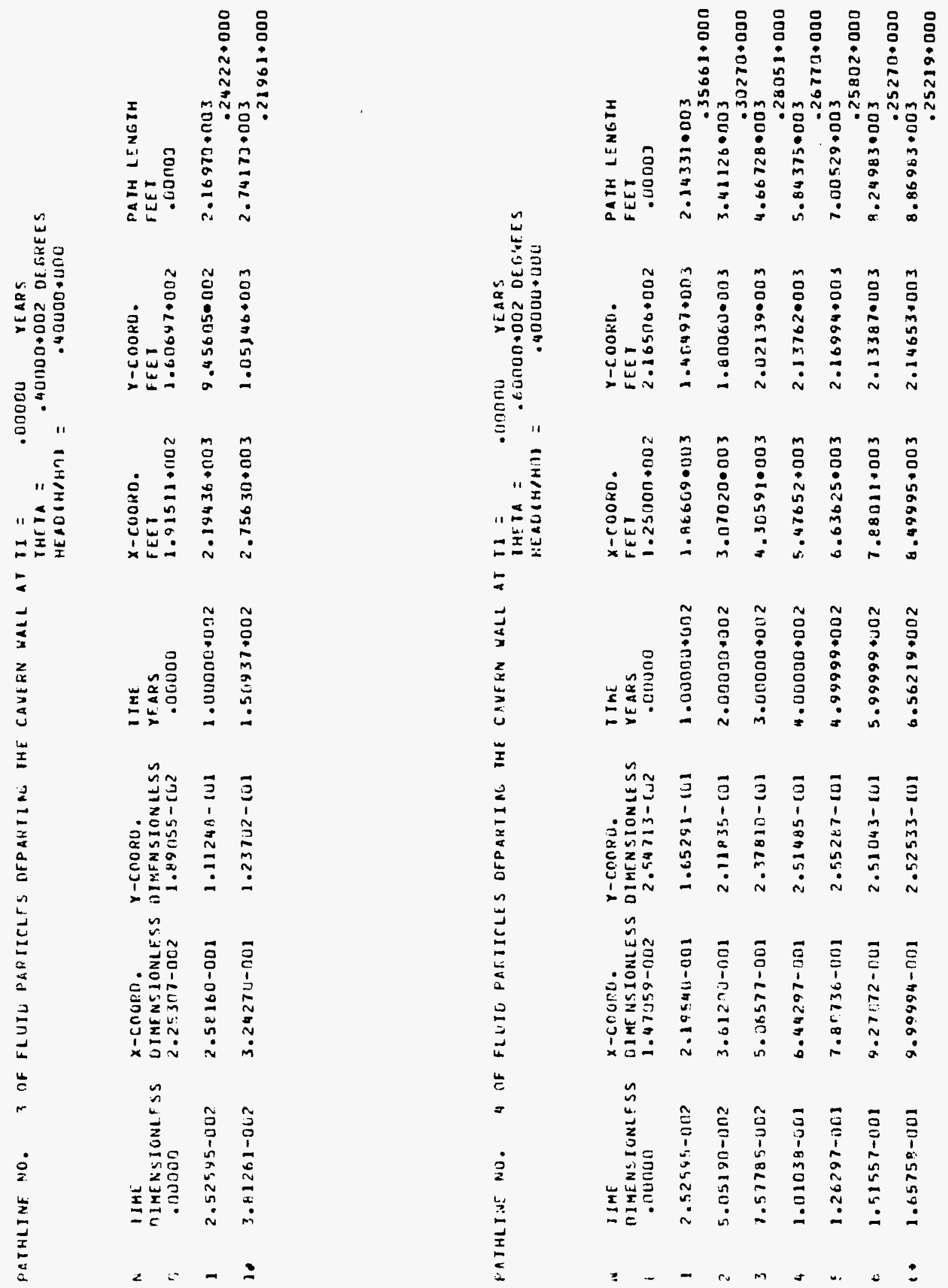

$$
\begin{aligned}
& =
\end{aligned}
$$

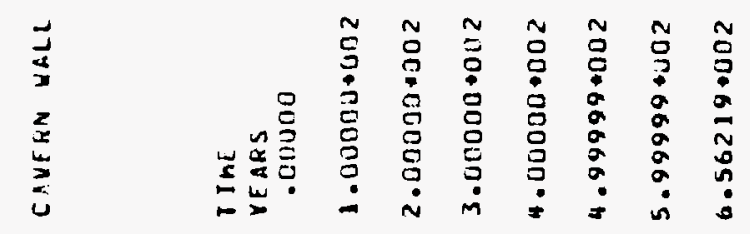

I

2
$\vdots$
$a$
0
0
0

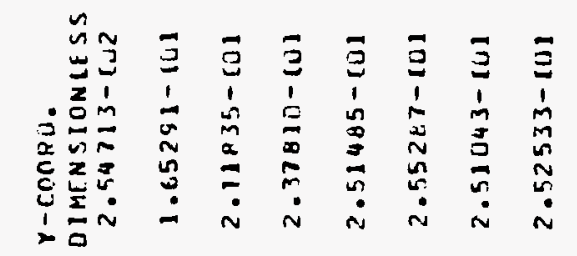

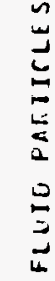

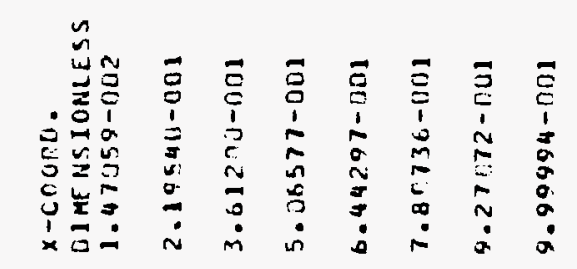

ह

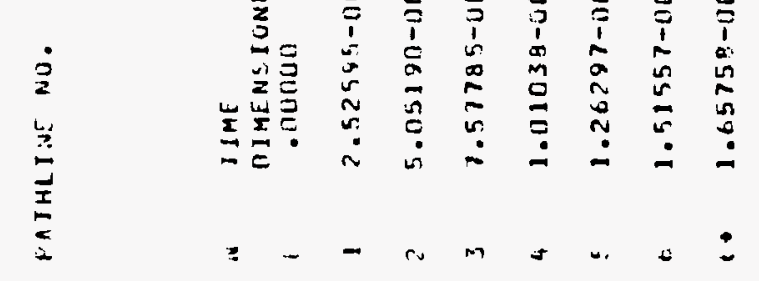



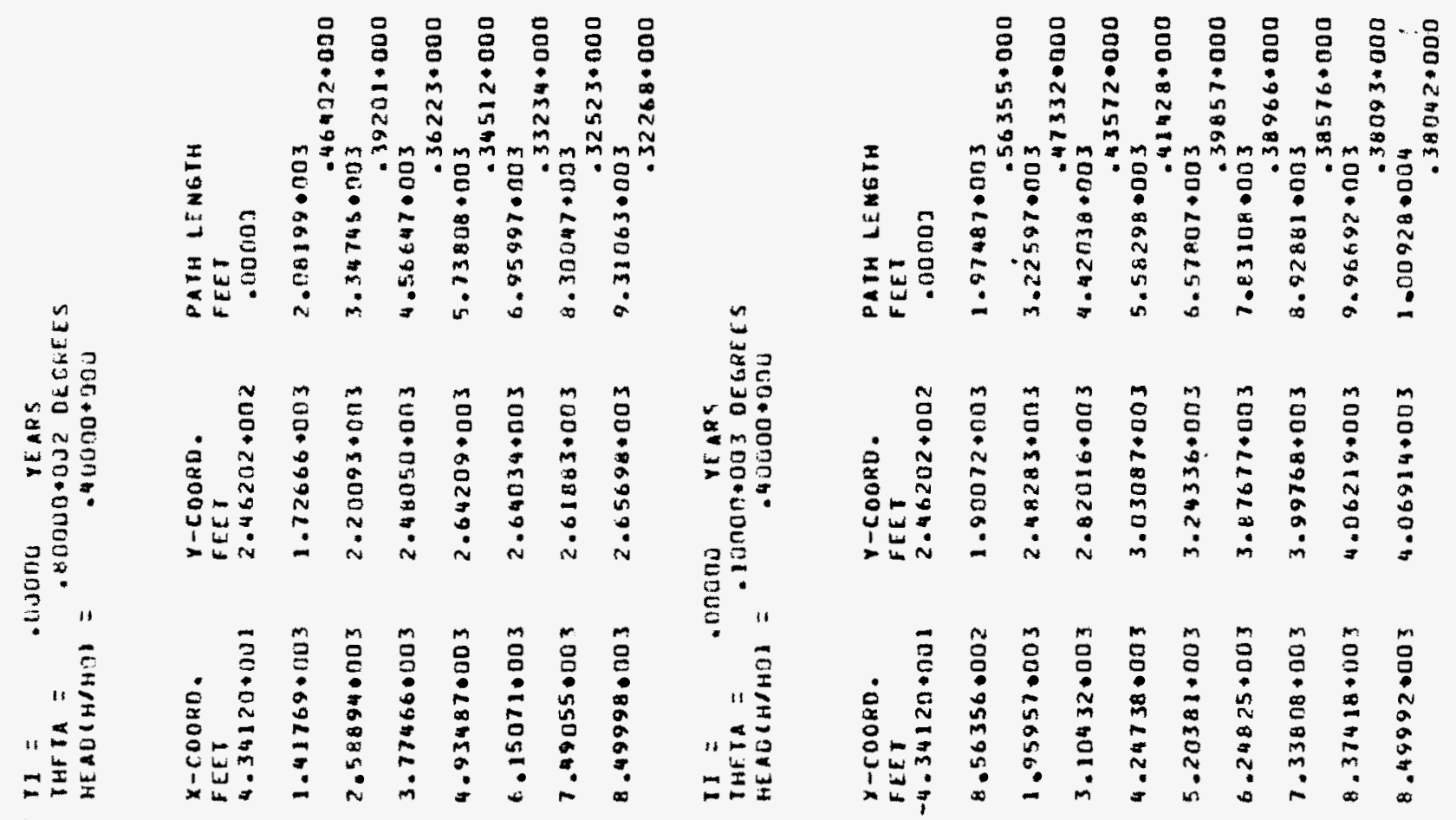

ב $=$
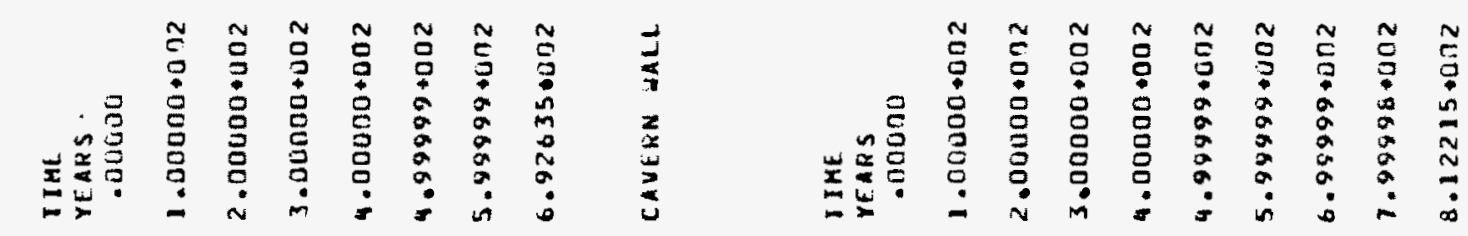

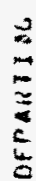<smiles>C1CCCCC1</smiles>

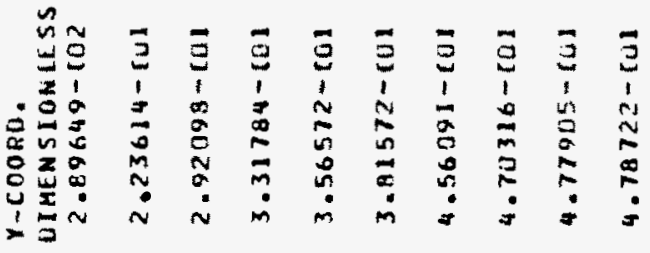
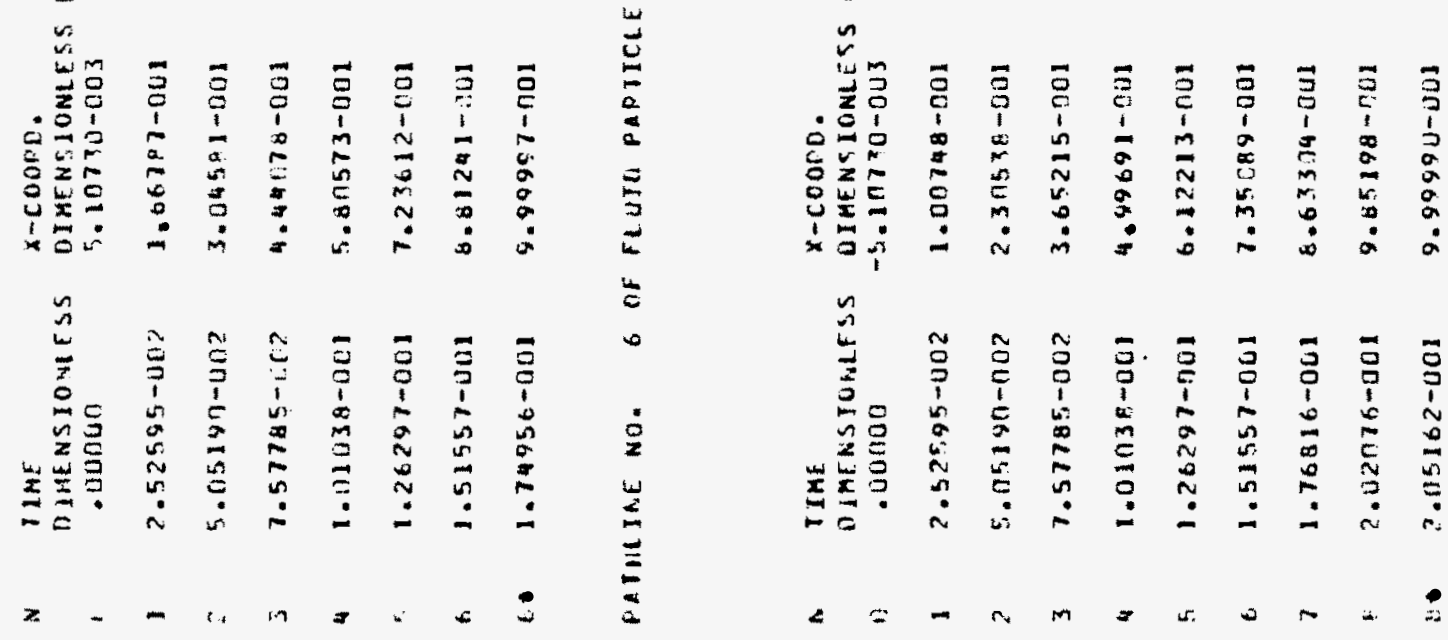


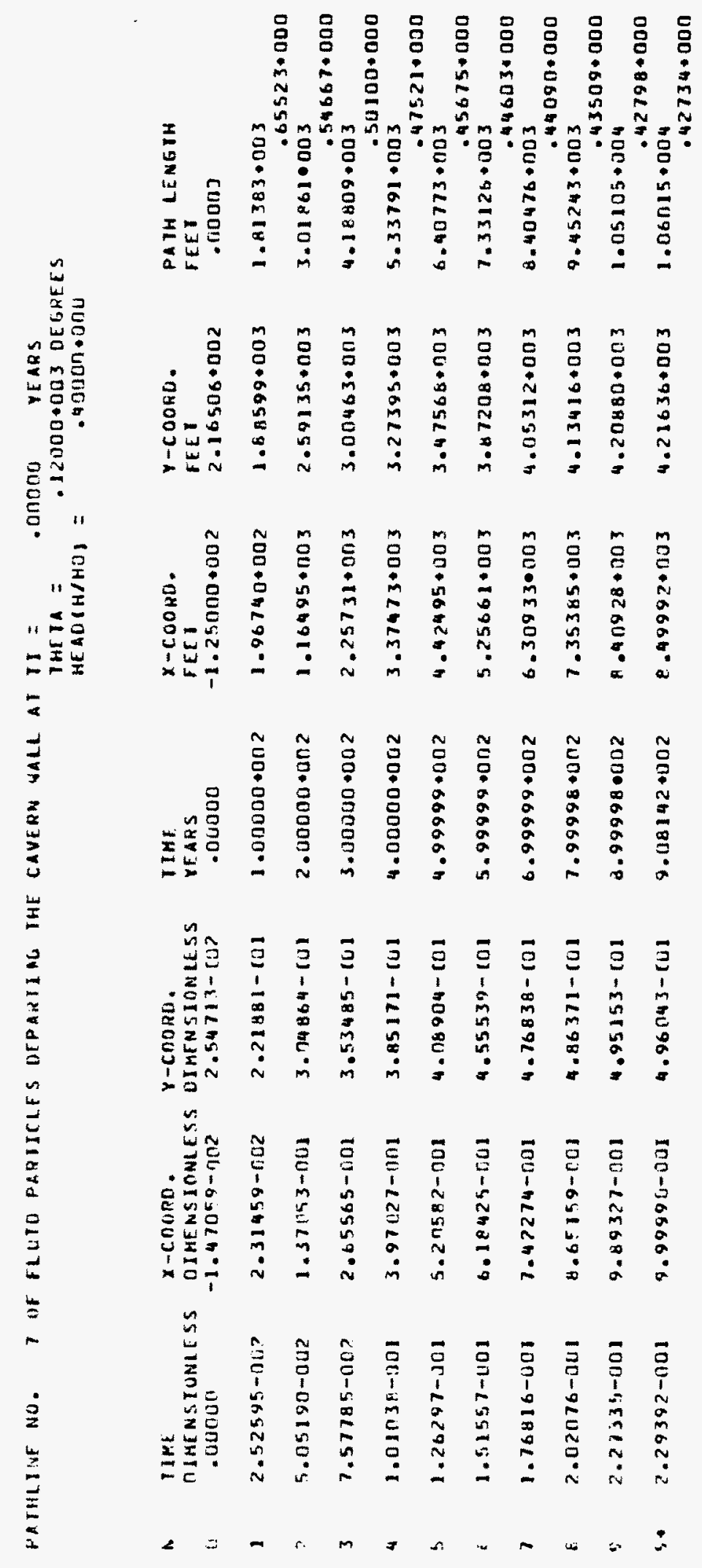




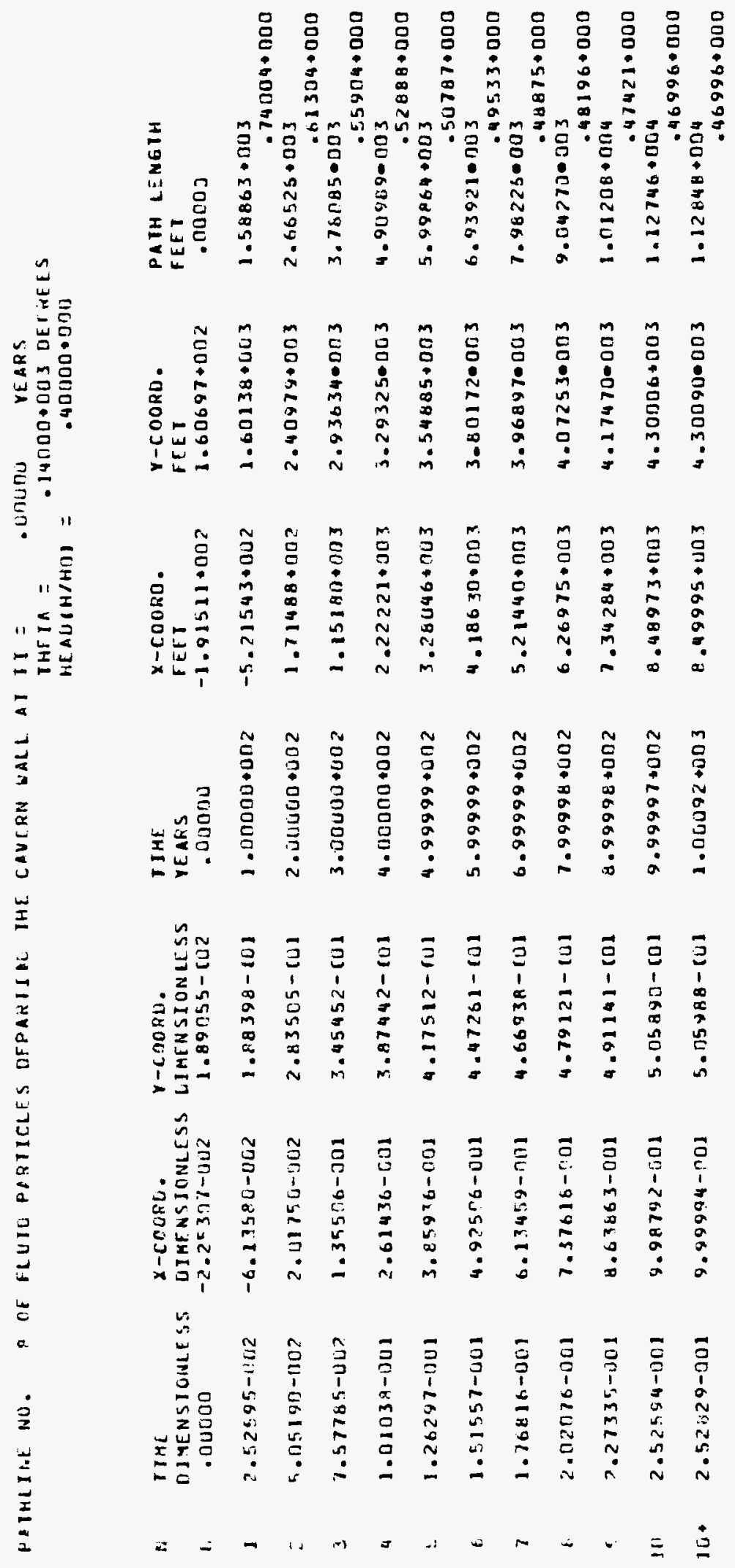

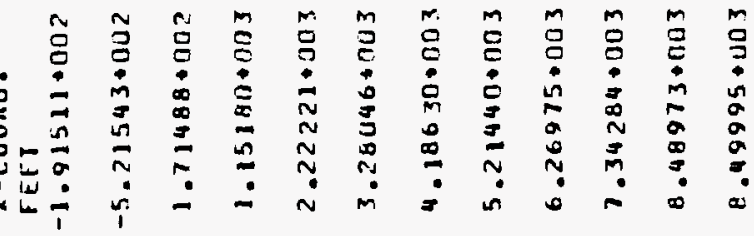




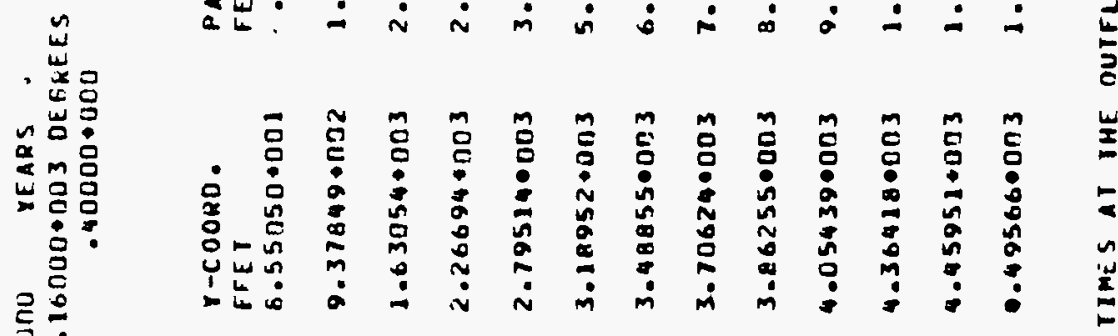

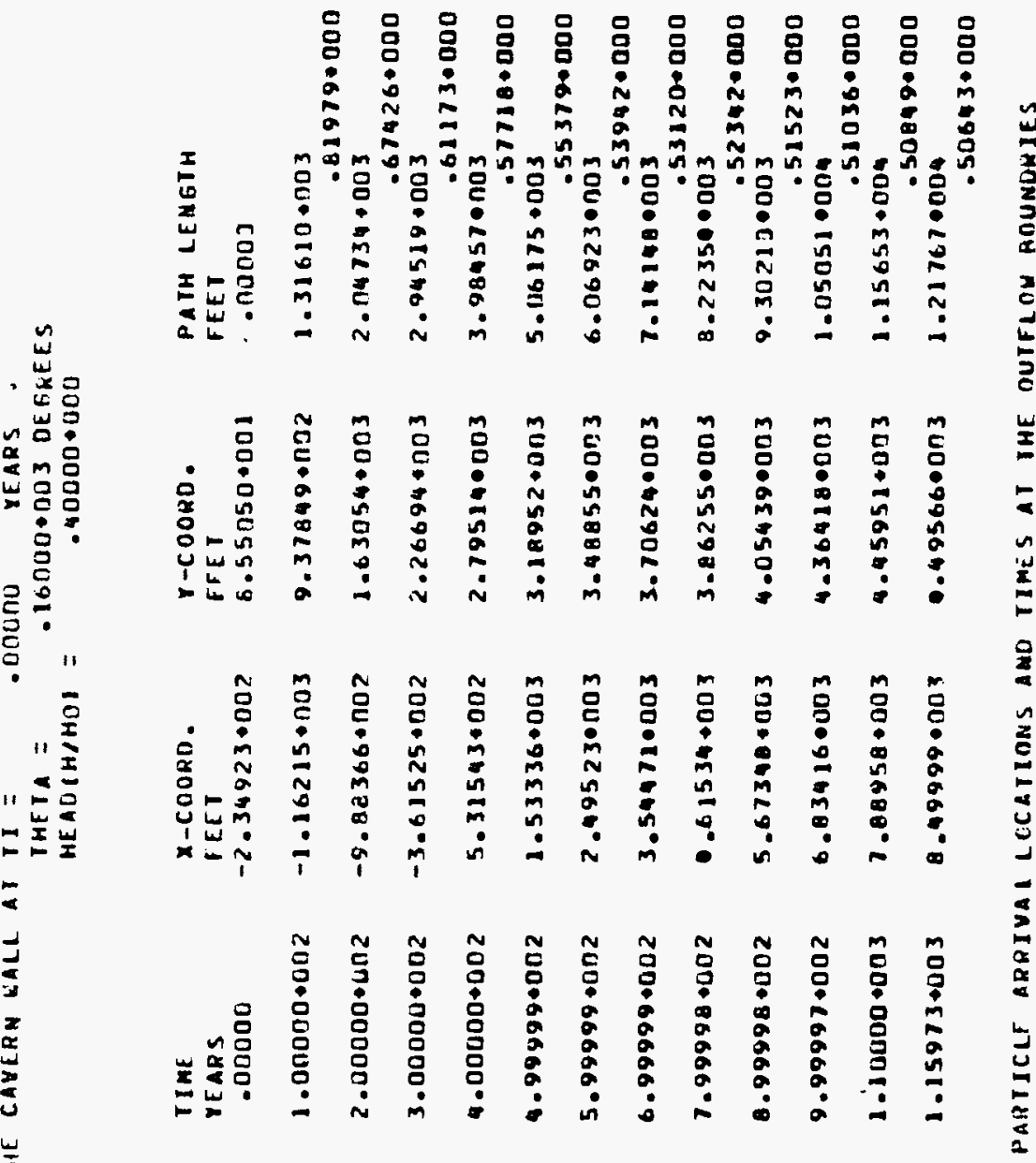

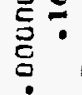

$\leftrightarrows$

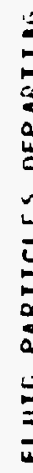

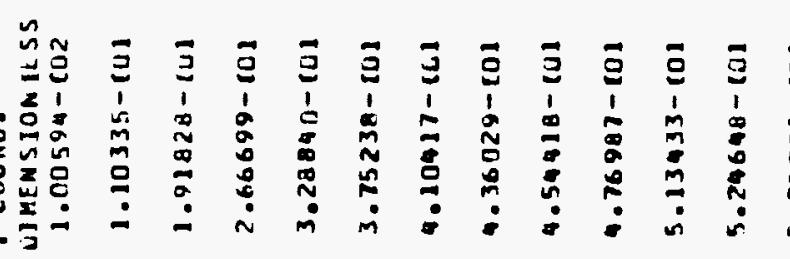

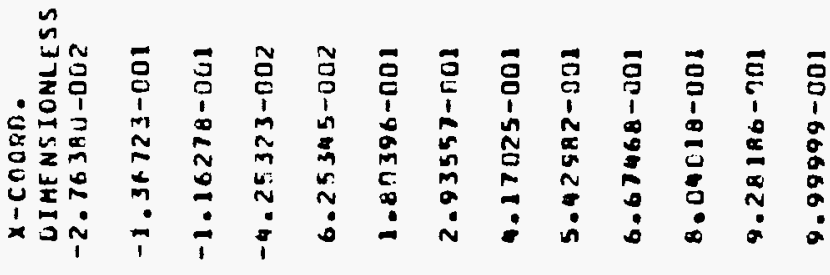

年

年

प 采

근

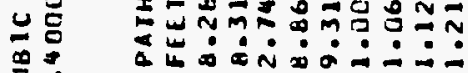

$\stackrel{\infty}{a}$

돌

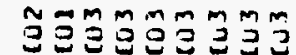

$\because:$ :

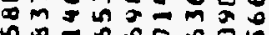

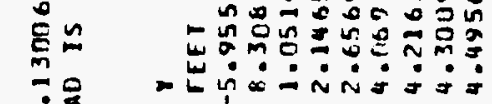

78

ᄂ

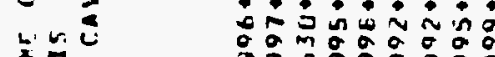

$2-$

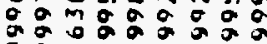

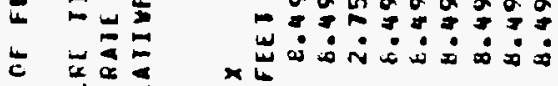

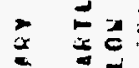

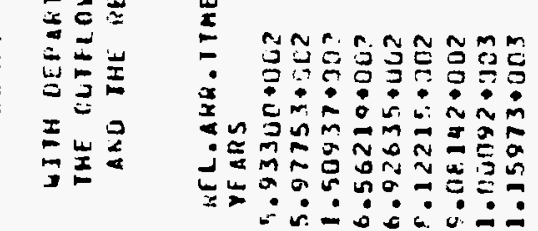

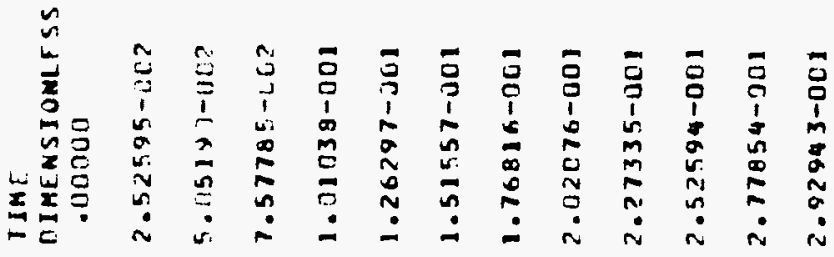

ב 

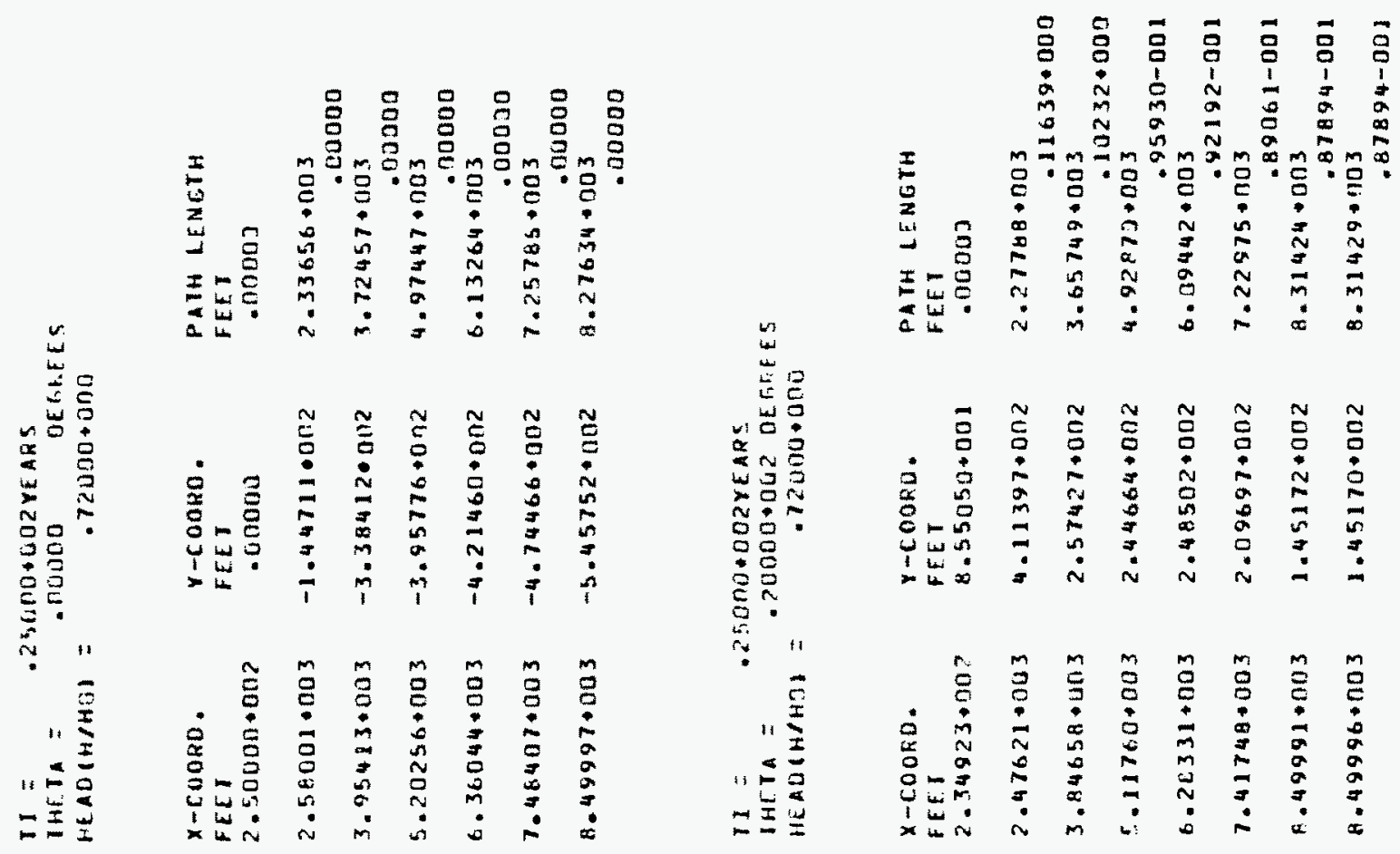

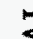

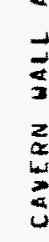

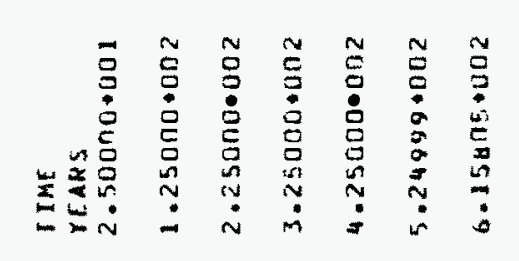

焉
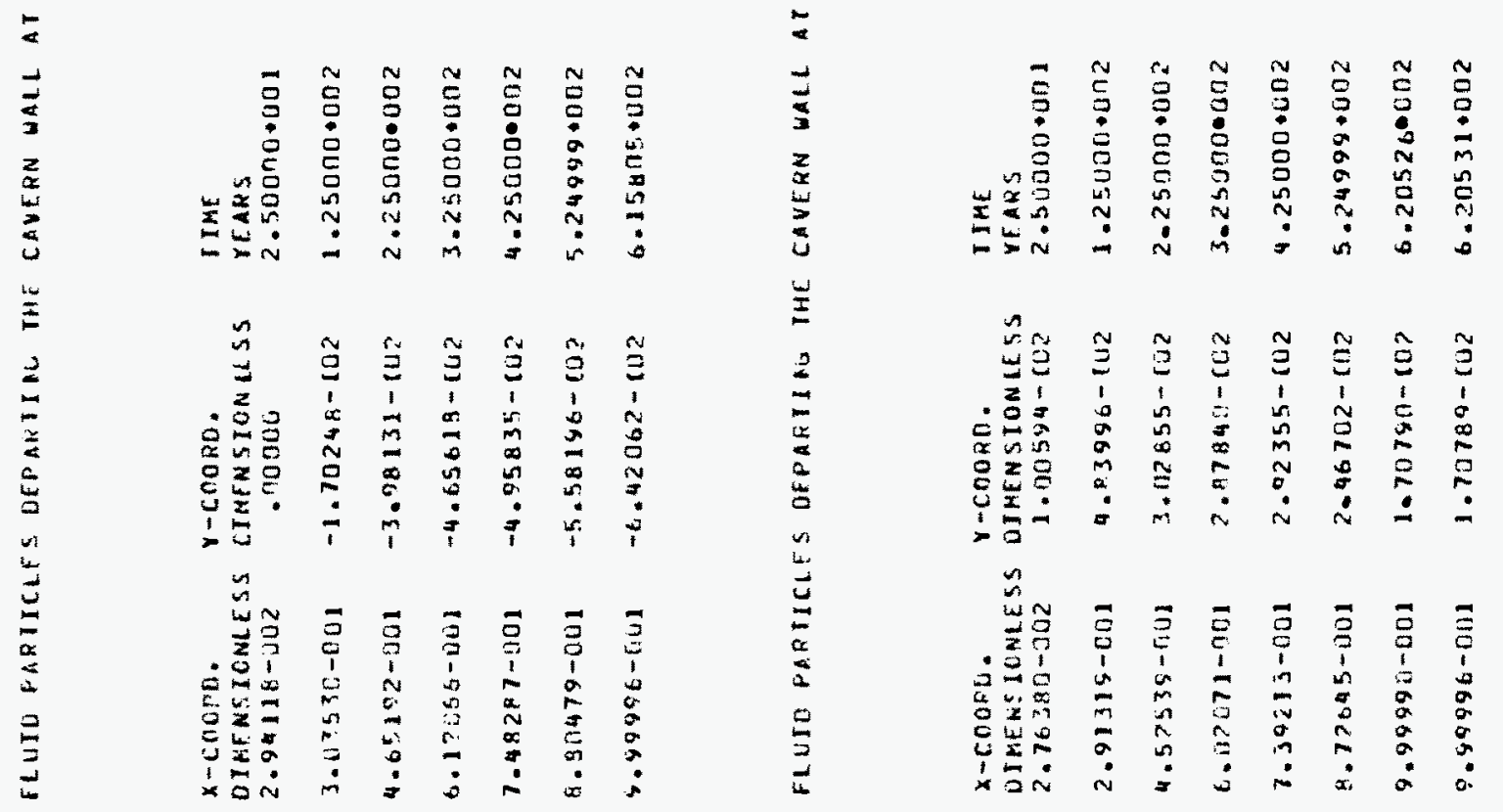

5
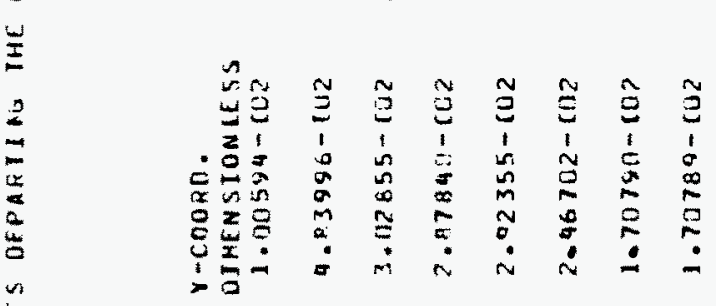

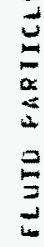

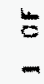

จ

要
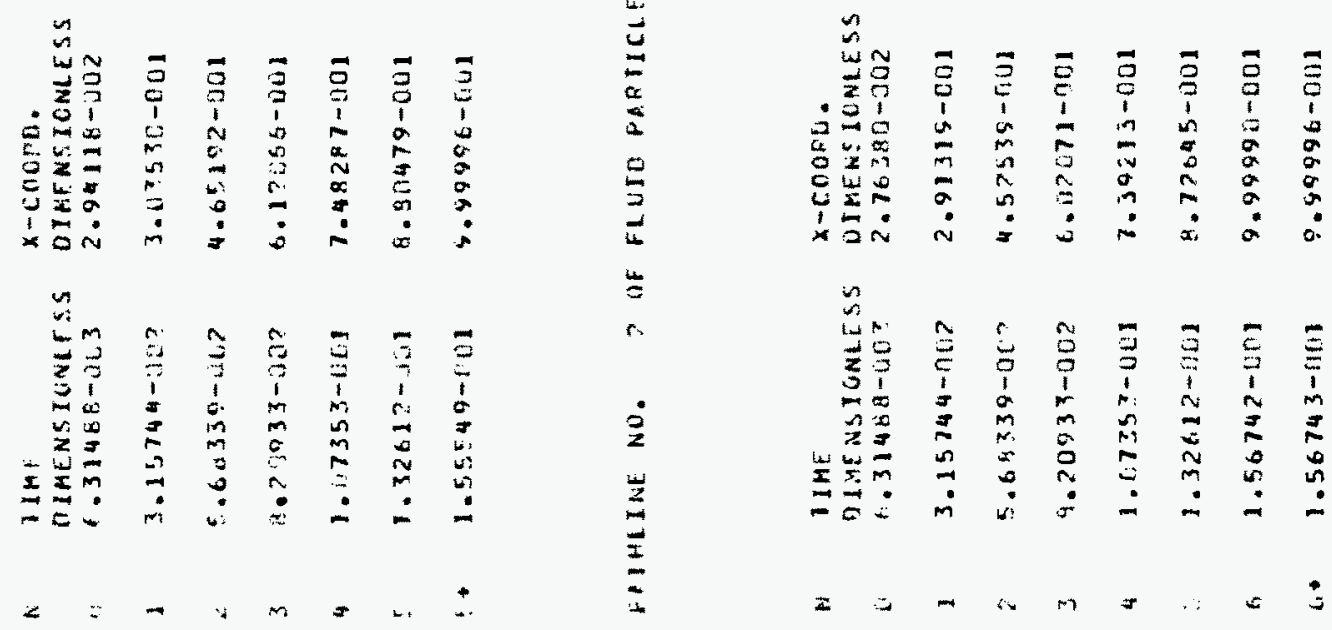

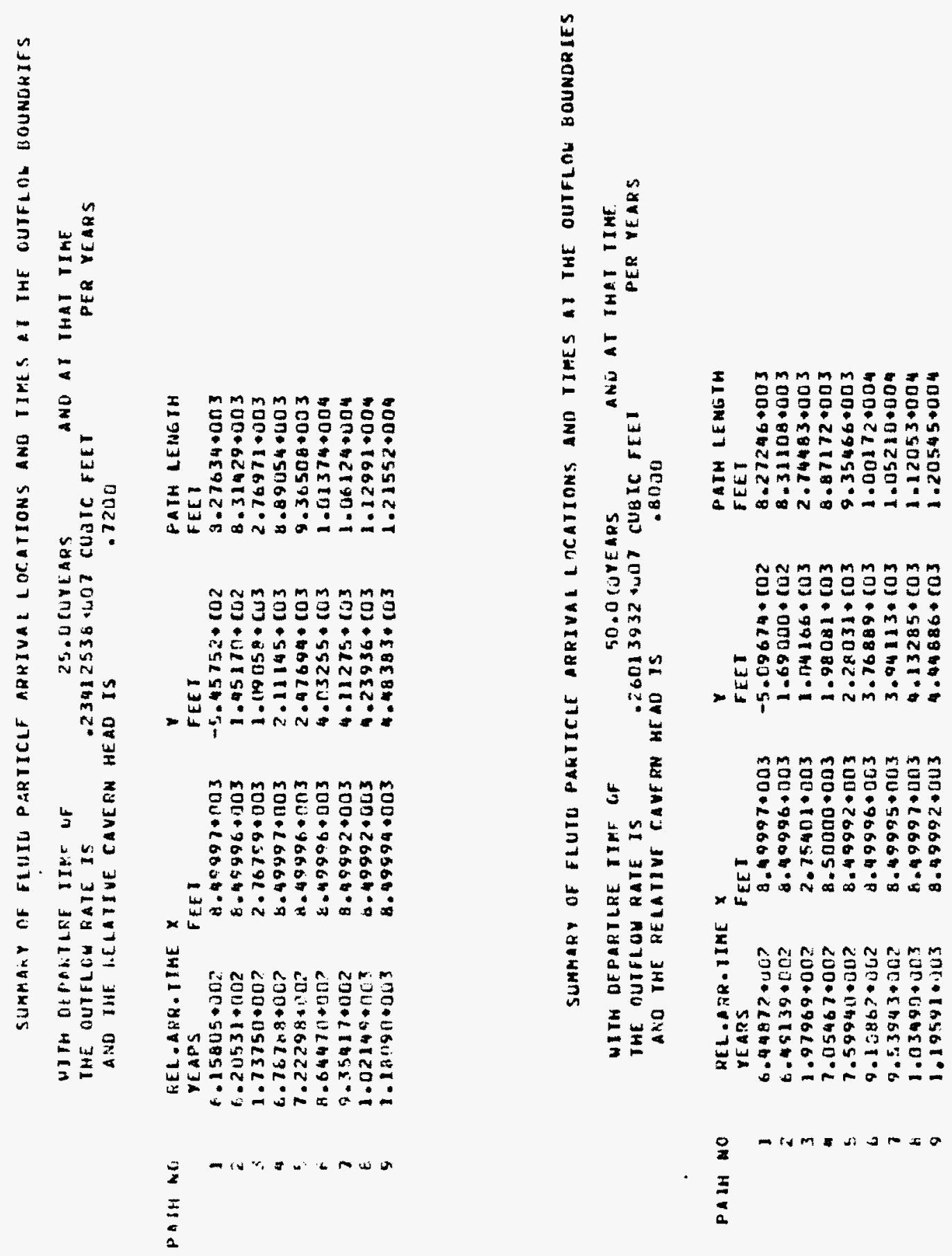

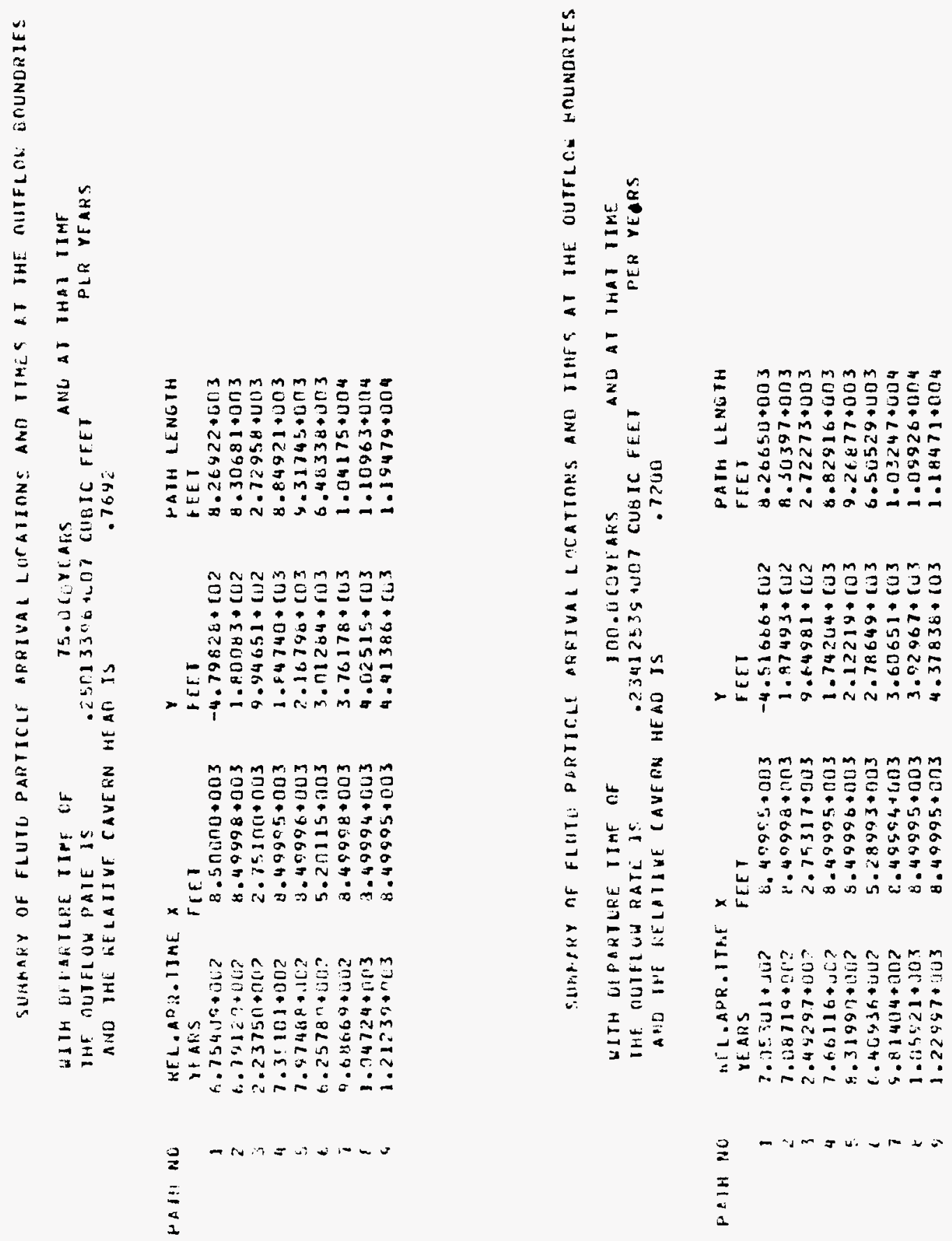


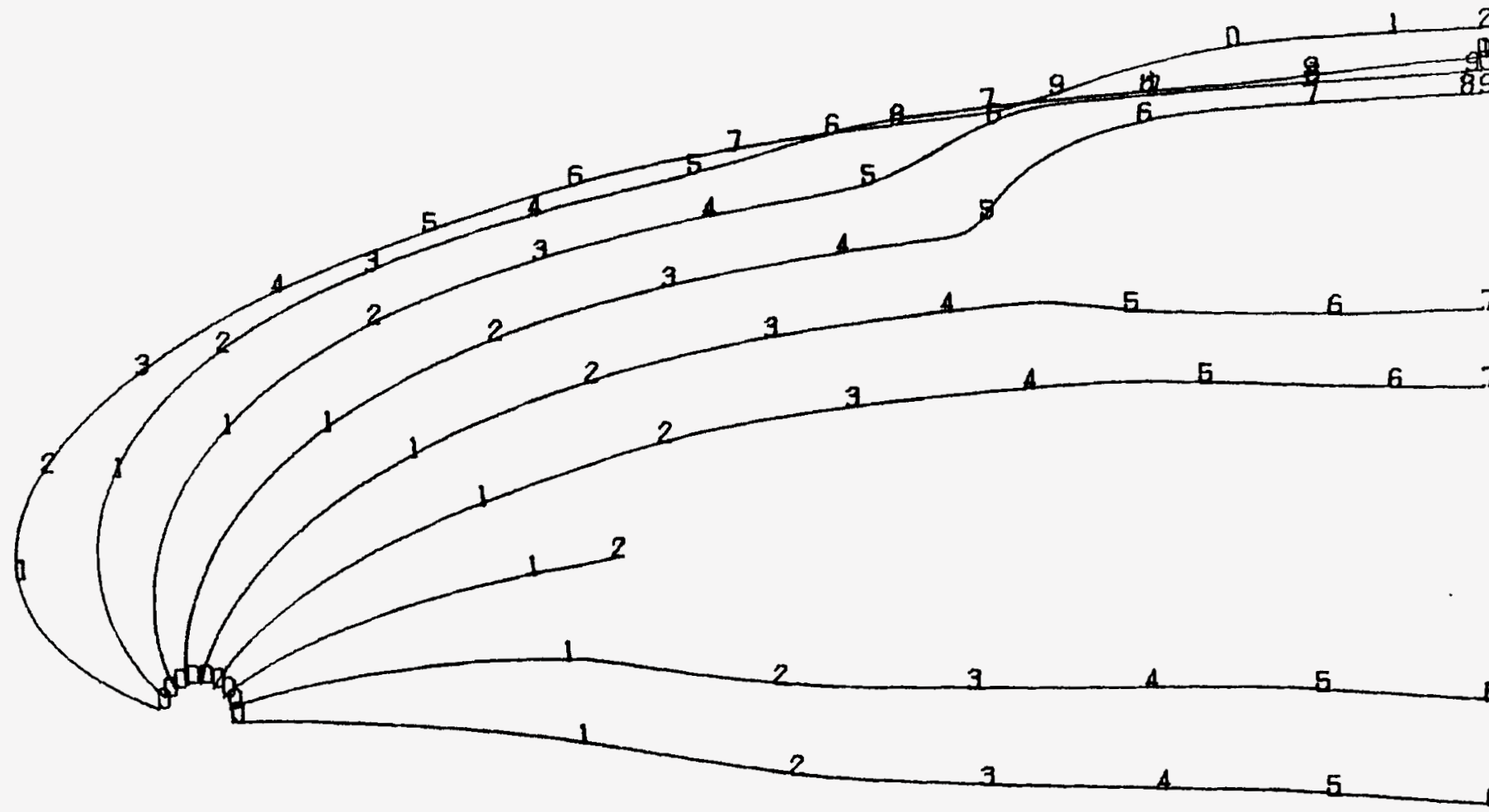

EXAMPLE TRANSIENT CASE (TWO WELLS) DEPARTURE TIME $=0.00$ SCALE $I$ INCH $=1000$ YEARS

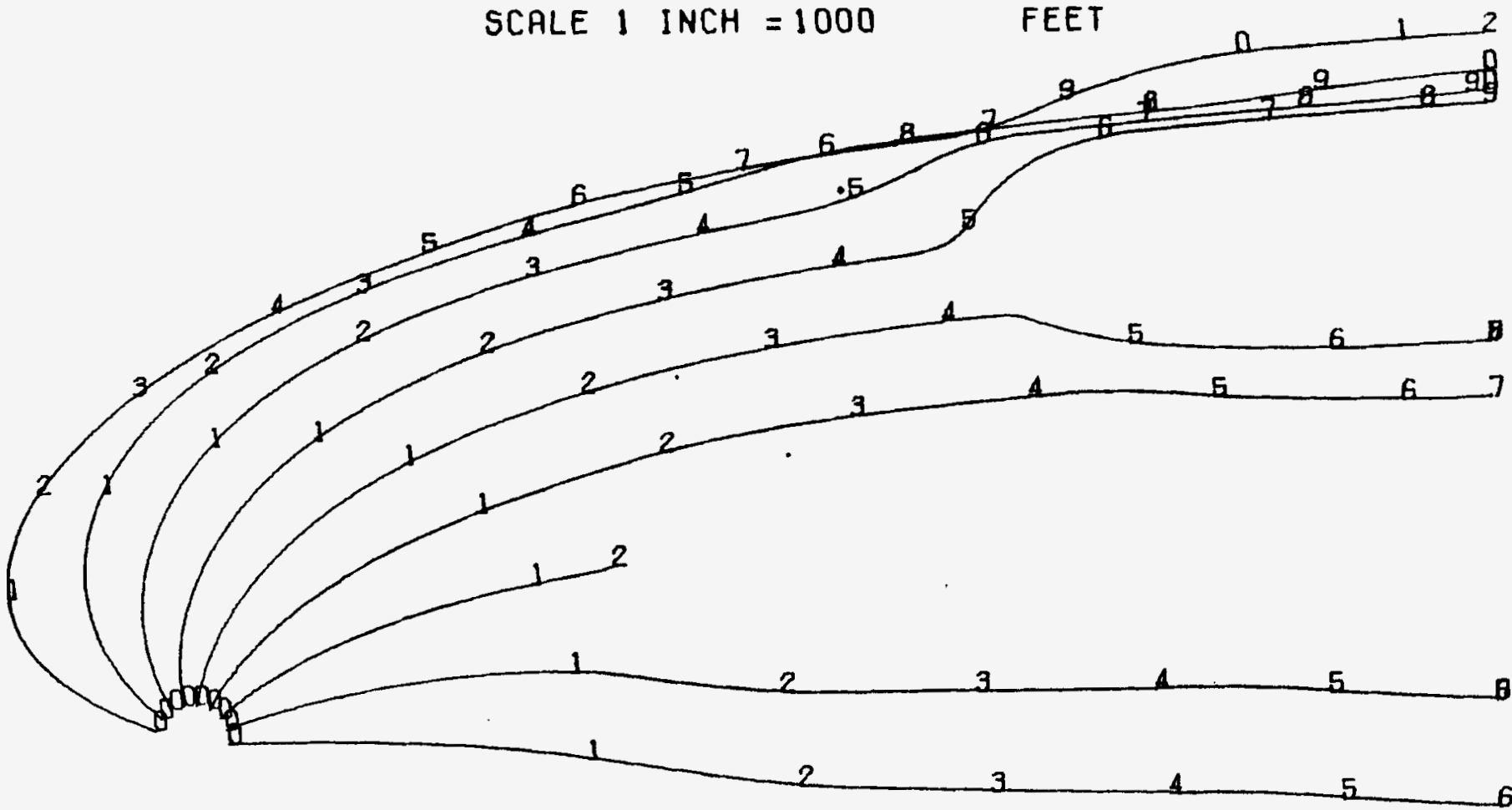

EXAMPLE TRANSIENT CASE (TWO WELLS) DEPARTURE TIME $\Xi 25.00$ SCALE 1 INCH $=1000$ YEARS FEET 

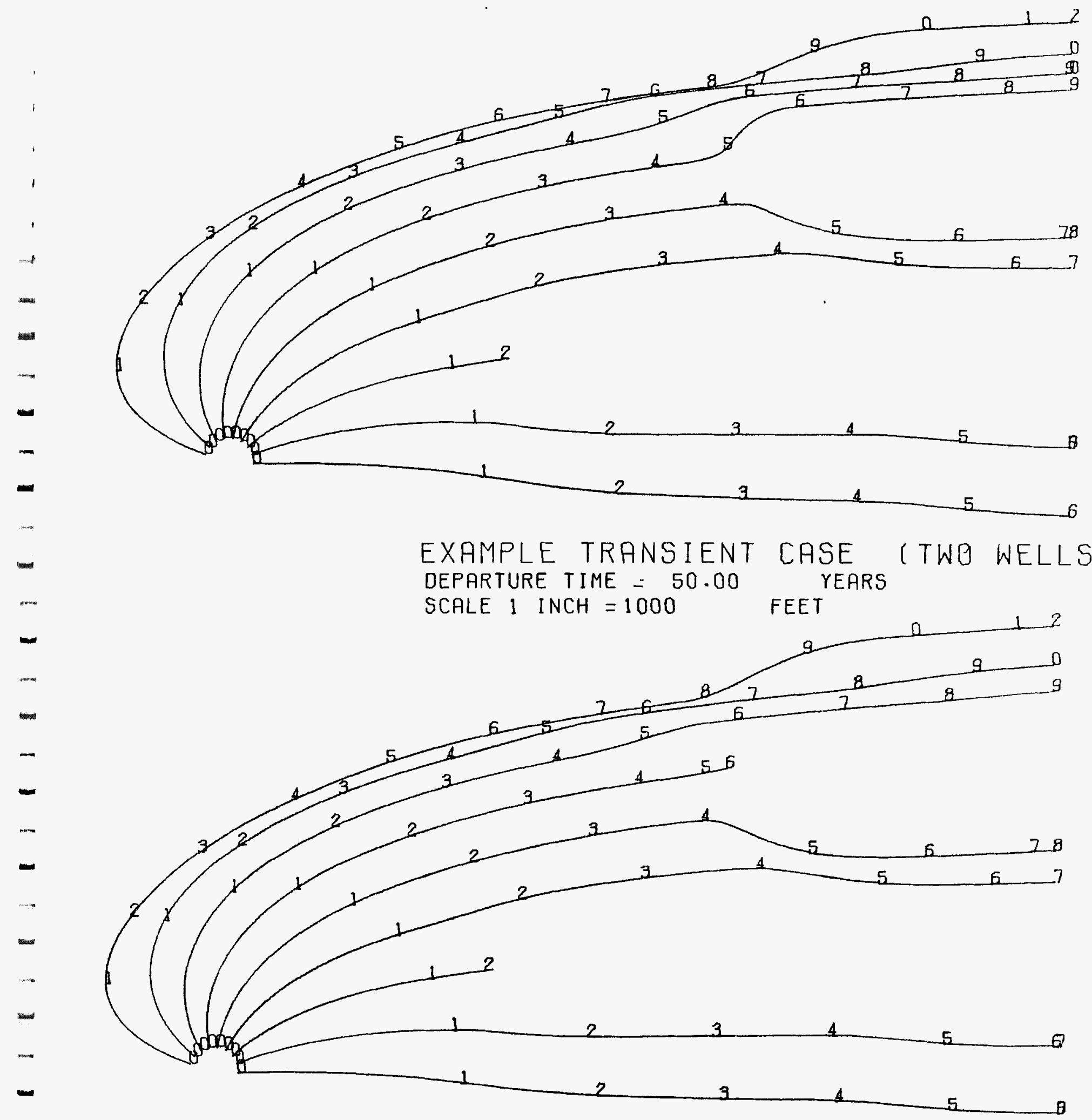

EXAMPLE TRANSIENT CASE (TWO WELLS) DEPARTURE TIME $=75.00$ SCALE I INCH $=1000$ FEET YEARS 


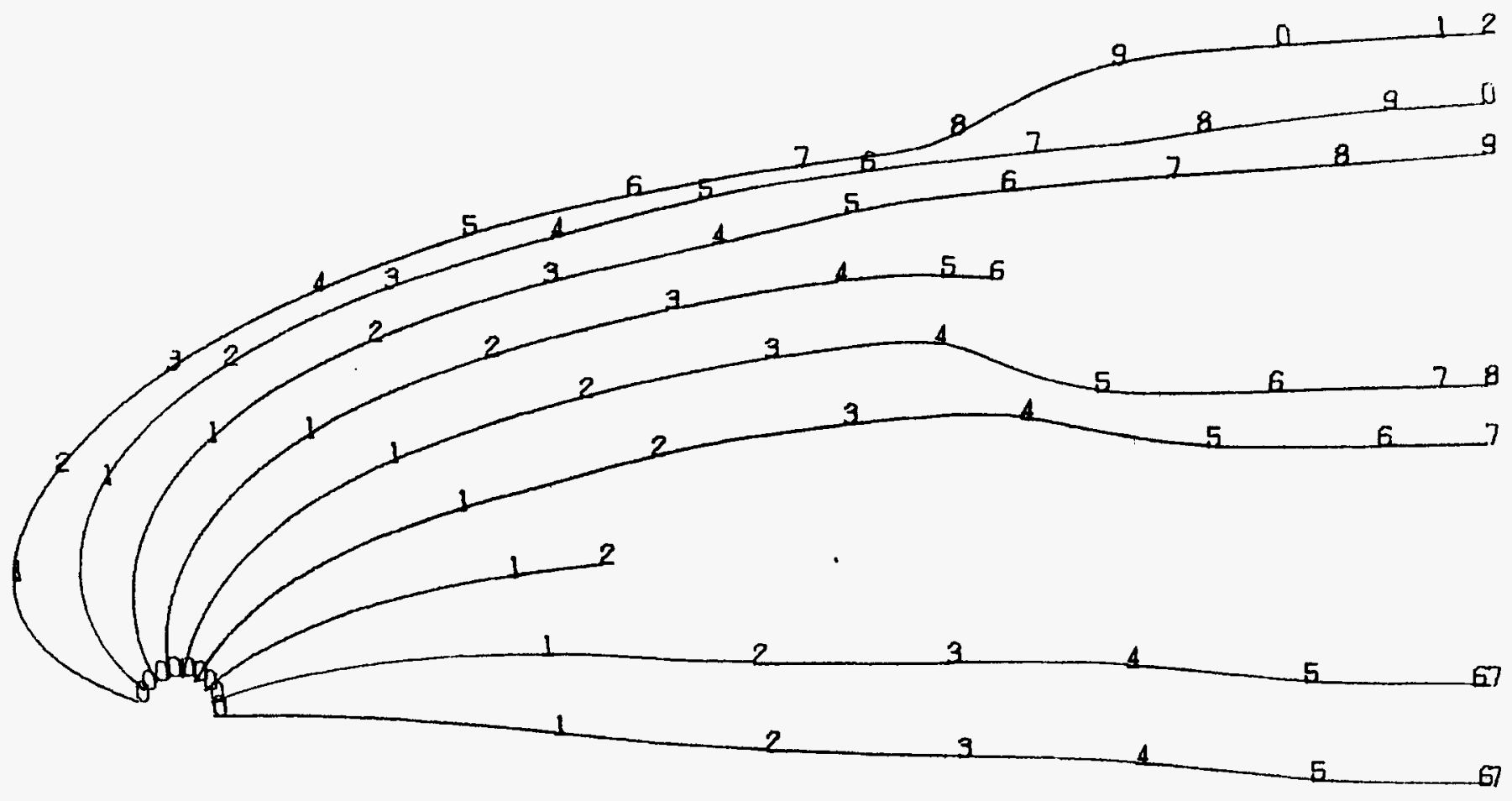

EXAMPLE TRANSIENT CASE (TWO WELLS) DEPARTURE TTME $=100.00$ SCALE 1 [NCH -1000 FEET 
TABLE B-1. Input Parameter Worksheet for Example Steady Case with Tc-99 Exchange INPUT PARAMETER WORKSHEET

\section{CASE: Stoady Flow with $T_{c}-99$ Exchange}

1. $100 \mathrm{ft} .=D_{0}$ is the stratum thickness.

2. $8500 \mathrm{ft}_{\mathrm{t}}=\mathrm{R}$ is the distance to the boundary. Units must be the same as $D_{0}$.

3. $8500 \mathrm{ft}=\mathrm{XMAX} / \mathrm{TMAX}$ are the stopping distance or time for pathlines.

4. $250 \mathrm{ft} .1=r_{0}$ is the cavern or pond radius. Units must be the same as $0_{0}$.

5. $\frac{4 \mathrm{ft}_{2}}{4}=\mathrm{H}_{0}$ is the head in the cavern. Units must be the same as $D_{0}$.

6. $1825 \mathrm{ft}_{\mathrm{f}}$ re $\mathrm{K}_{0}$ is the stratum hydrautic conductivity. Length units must be the same as $D_{0}$. Whatever time units are in $k_{0}$ sets the units of the travel time.

7. $\frac{0.2}{2}=P$ is the effective porosity.

8. $-5=S$ or $T$. A steady $(S)$ or transient $(T)$ case.

9. $0.001=v 0$ is the initial uniform gradient value. See Figure 1 .

10. $=U M$ is the laterial gradient value. See Figure 1 .

11. $=T M$ in time units of $K_{0}$.

12. _____ $=A, B, C$ are three time-related integers.

13. $=S$ or $E$ or $C$. Use the serpin (S), exponential (E), or cyclic (C) head variation in the cavern.

14. $4 \mathrm{ft}$. $=H I$ is the initial head.

15. $=H M$ is the maximum head.

16. $=T N$ in time units of $K_{0}$.

17. ___ _ $=D, E, F$. See Figure 1 .

18. $L=\mathrm{J}$ is total number of wells.

19. $\frac{5^{\circ}}{2}=\theta 0$ is the angle (deg) around the cavern wall to the starting point for the first pathline.

20. $5^{0}=O M$ is the maximum angle (deg) to the last pathline starting point along the cavern wall.

21. $\frac{18}{18}=N \Theta$ is the number of pathlines to be generated See back of form from $\theta 0$ to and including $O M$. 22. $=K \theta$ is the number of pathlines wanted between OM and $179.99+{ }^{\circ}$.

23. $=t_{0}$ is the departure time of the first fluid particles leaving the cavern.

24. $=t_{f}$ is the departure time of the final fluid particles.

25. $=N T$ is the number of equally spaced departure times beginning

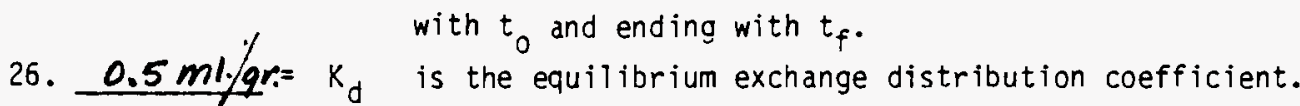

27. $1.9 \mathrm{gr} / \mathrm{cc}=\mathrm{B}_{d}$ is the bulk density of the porous material.

28. $L \mathrm{LL}=$ inch wide plots are desired. Request either a 30" or 11" wide by 30" plot.

29. $3 m$. $=$ XCENTER The location ( $x \& y$ in inches) on the plot where

30. $\frac{L 1 \mathbb{L}_{2}}{2}=$ YCENTER the cavern center is to be located.

31. $1000 f_{. / 2}=$ SCALE is the scale for the plot. Length in units of $D_{0}$ per inch. 
SERPIN OPTION

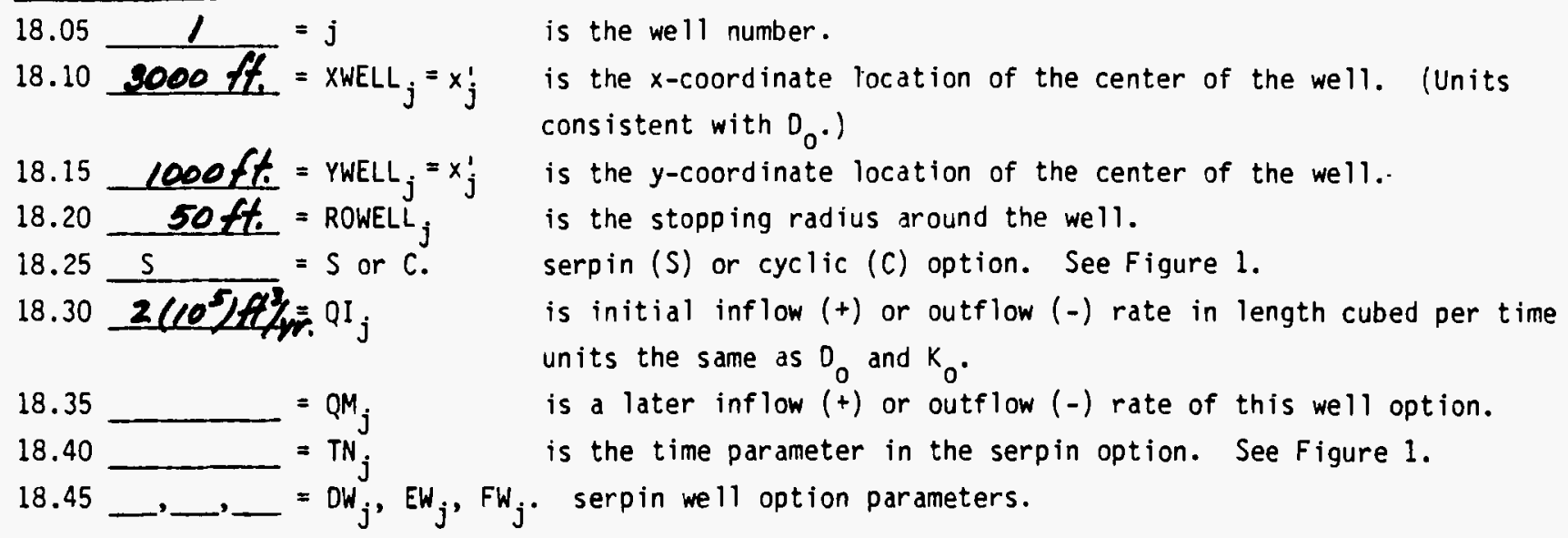

\section{CYCLIC OPTION}

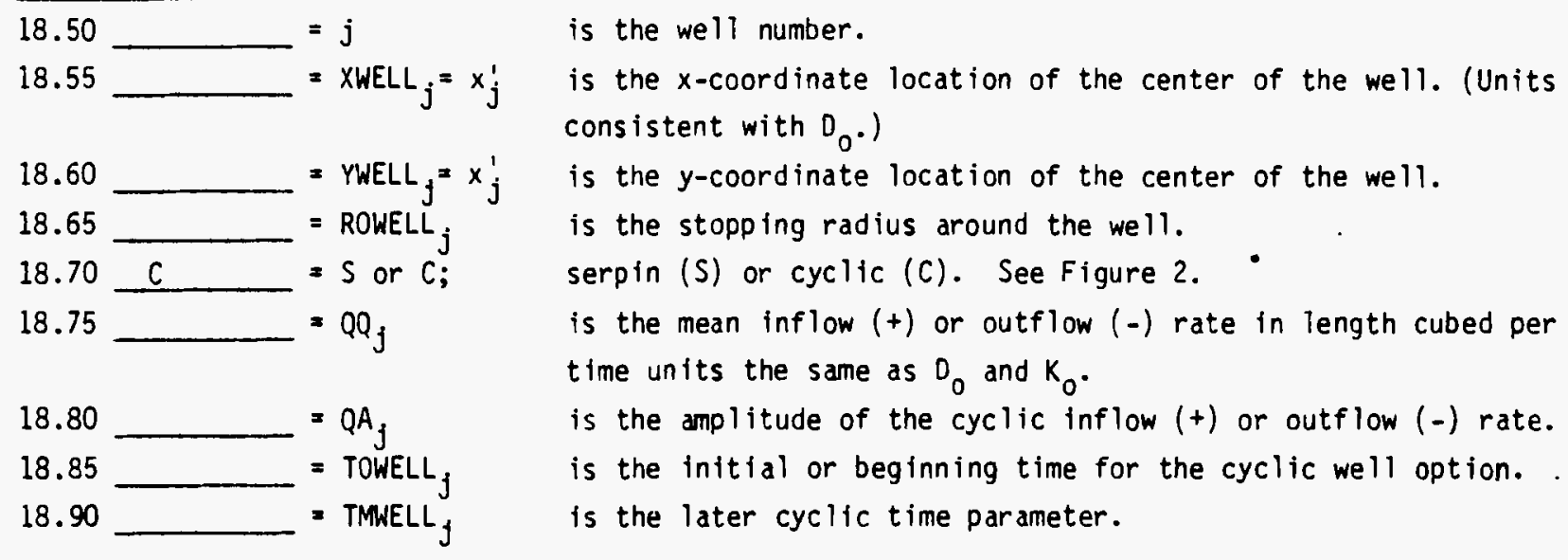

PATHLINE - IRREGULAR STARTING COORDINATES

(If $\ominus 0$ in Item 19 equals $\Theta M$ in Item 20 then $N \Theta$ pathlines will be generated from the individual coordinates provided below.)

21. $18=N O$ is the number of input data sets to be entered for starting pathlines $(1 \leq 1 \leq N \theta)$.

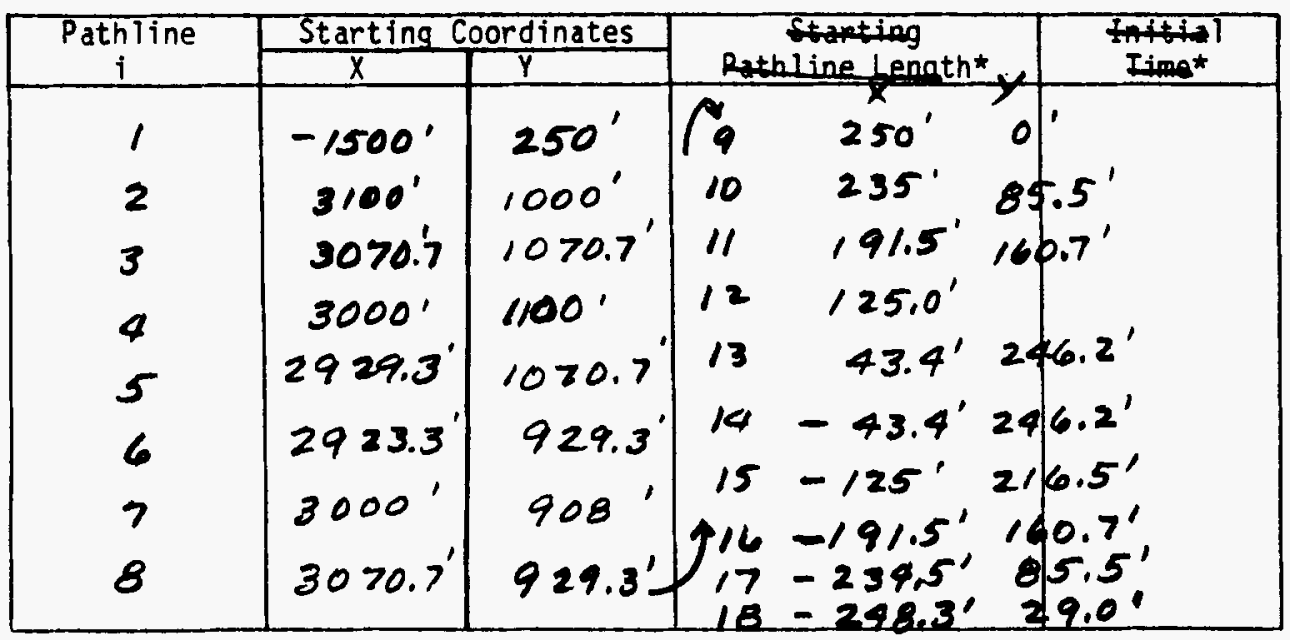




\section{EXAMPLE STEADY CASE}

The second example case involves a steady flow system but the ion exchange delay for a single contaminant is illustrated. Also the special irregular starting location feature for pathlines is used. The completed input parameter worksheet for the example steady case in Table B-1 is shown.

After signing on the Univac and providing user ID, passwords, etc., then PATHS can be executed as follows using the input values from the worksheet or as requested by the program.

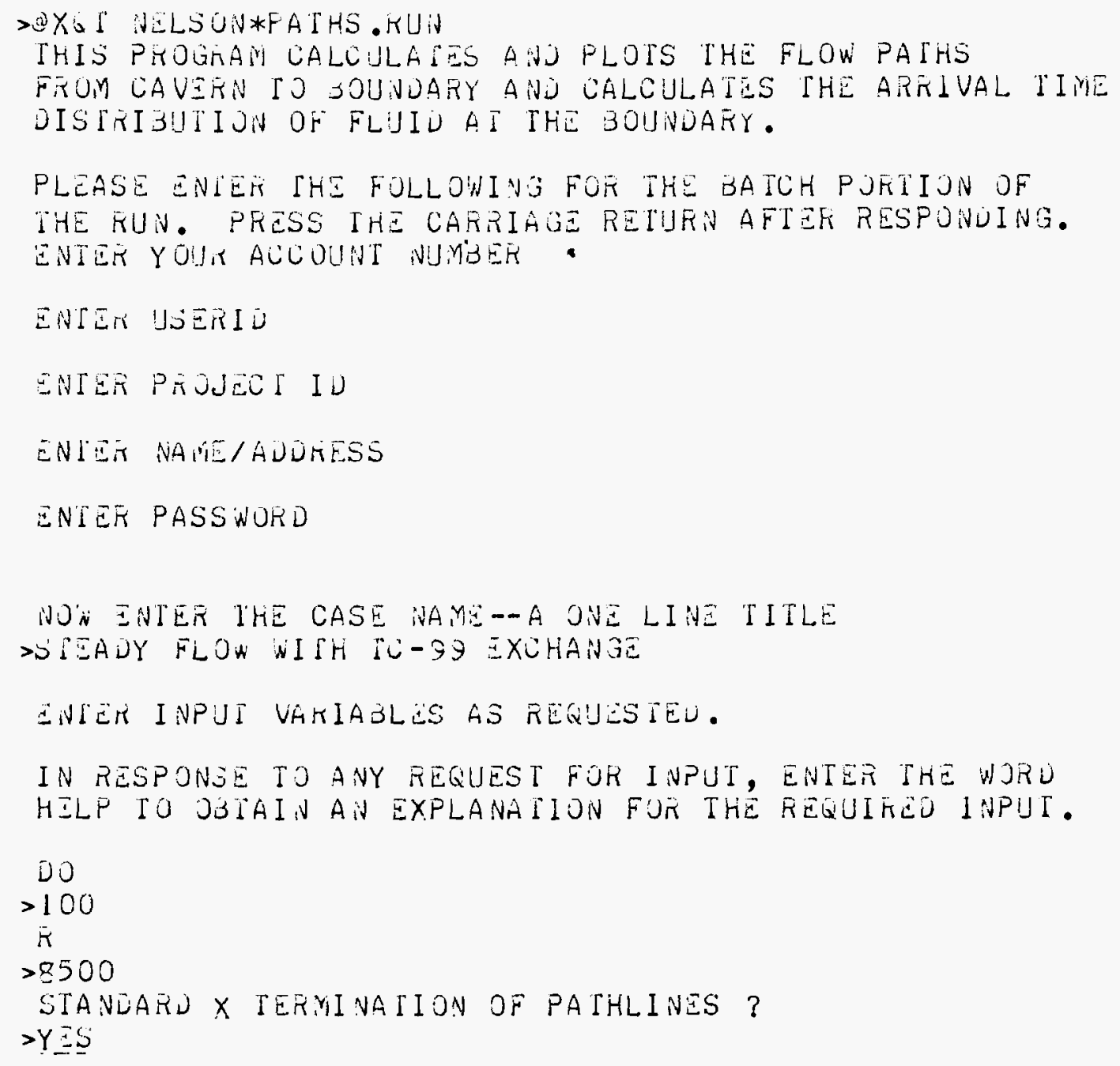




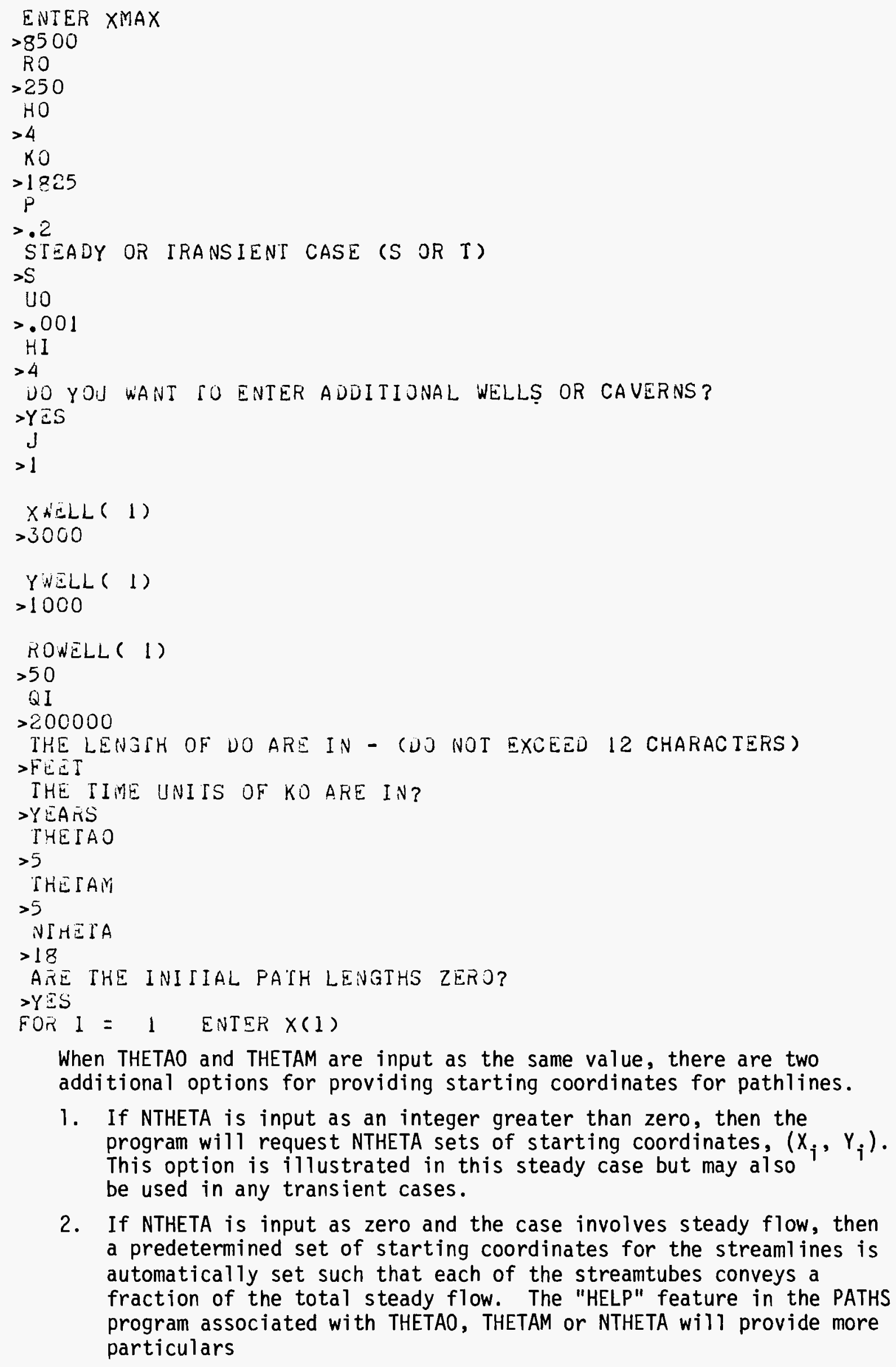

1. If NTHETA is input as an integer greater than zero, then the program will request NTHETA sets of starting coordinates, $\left(X_{i}, Y_{i}\right)$. This option is illustrated in this steady case but may also be used in any transient cases.

2. If NTHETA is input as zero and the case involves steady flow, then a predetermined set of starting coordinates for the streamlines is automatically set such that each of the streamtubes conveys a fraction of the total steady flow. The "HELP" feature in the PATHS program associated with THETAO, THETAM or NTHETA will provide more particulars 


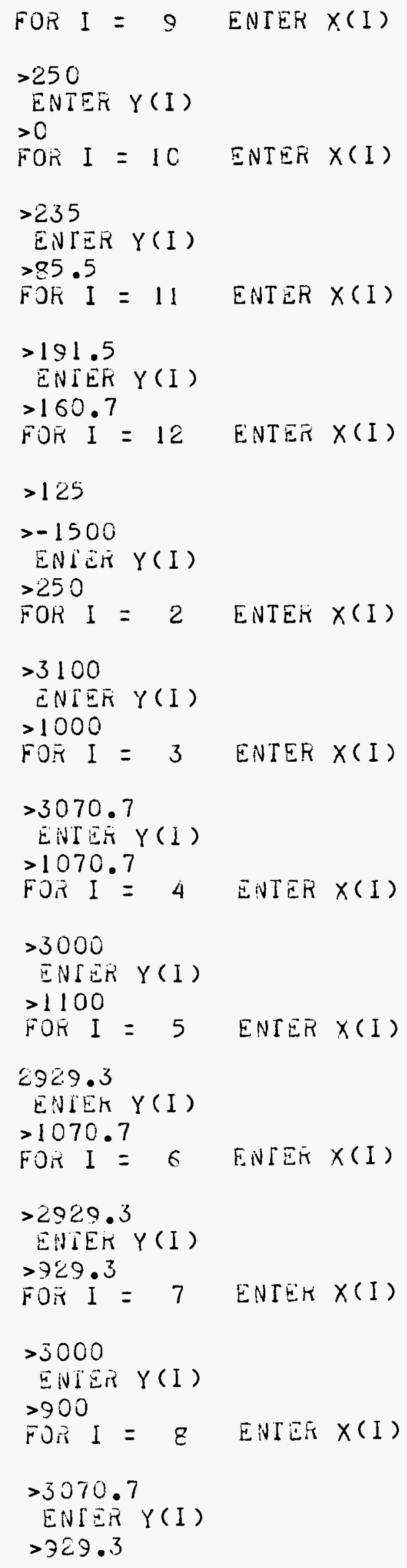

The control key and letter $\mathrm{H}$ erase and back up option was used in $X(I)$ for $I=5$. 
ENTER Y (I)

$>216.5$

FOR I $=13$ ENTER $X(I)$

$>43.4$

ENIER Y (I)

$>246.2$

FOR I $=14$ ENTER $X(I)$

$>-43.4$

ENTER Y (I)

$>246.2$

FOR $I=15$ ENTER $X(I)$

$>-125$

ENTER Y (I)

$>216.5$

FOR $\dot{I}=16$ ENTER $\times(I)$

$>-191.5$

ENTER Y (I)

$>160.7$

FOR I $=17$ ENTER $X(I)$

$>-234.9$

ENTER Y (I)

$>85.5$

FOR $I=18$ ENTER $X(I)$

$>-248.3$

ENI

$>29$

IS THERE AN IUN EXCHANGE DELAY?

$>Y E S$

CHEMICAL NAME

PTECHNETIUM

KD?

$>.5$

उ० ?

$>1.9$

CHOOSE A CONVENIENT ROUNDED DELTA BETWEEN THE NUMEERS

$>10$

ENTEK STEP

$>6$

ENTER IILIM

$>5000$

TO OSTAIN BETWEEN 15 ANL 25 ISOCHRONAL LINES,

CHOOSE NPRINT DETWEEN 15 AND 25

ENIGK NPRINT

$>50$

ENTER EPSLN

$>.00001$

UO YOU NANT THE FLON PATHS PLOIIED?

$>Y E S$

DO YOU HANT 30 INCH PLOTS?

$>\mathrm{NO}$

11 


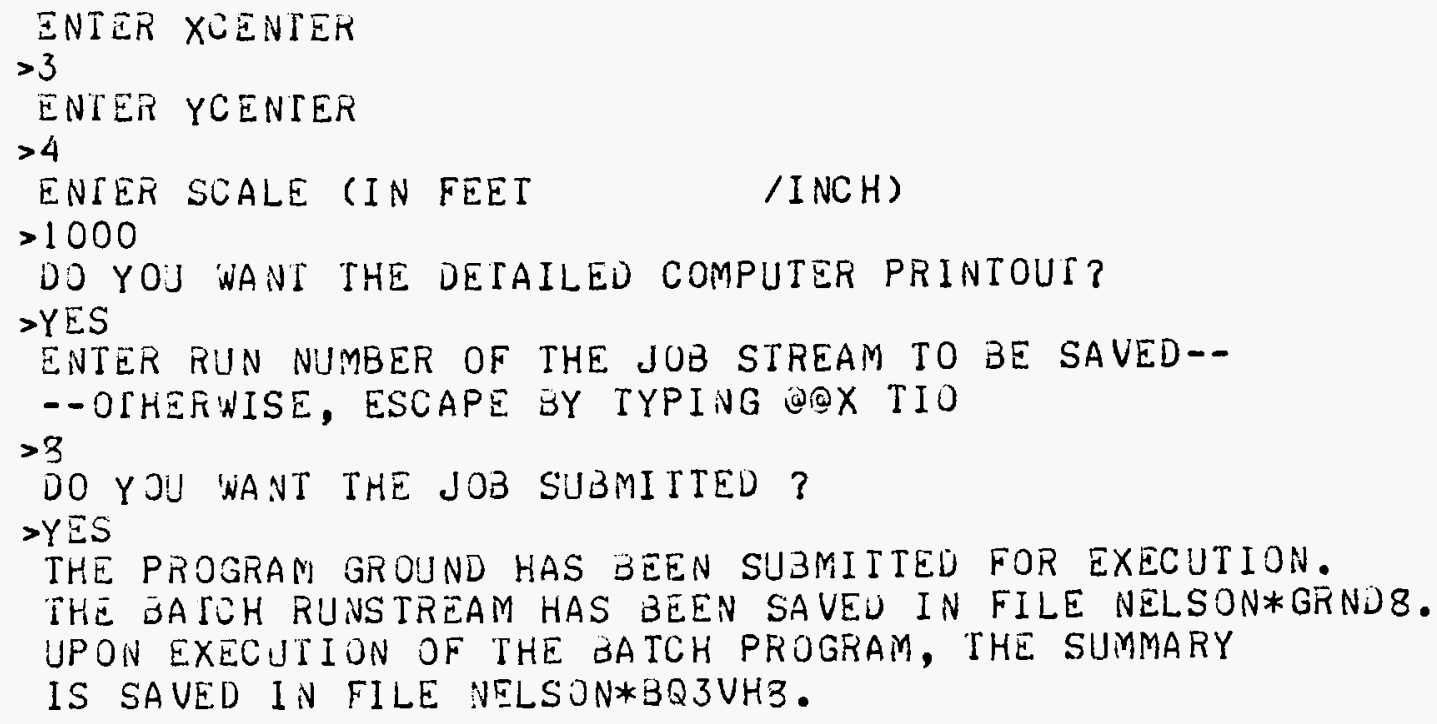

THE PROGRAM GROUND HAS BEEN SUBMITIED FOR EXECUTION. THE OATEH RUNSTREAM HAS BEEN SAVEU IN FILE NELSON*GRND\&. UPON EXECUTION OF THE OATCH PROGRAM, THE SUMMARY

IS SAVED IN FILE NELSON*BQ3UHB.

The last computer output indicates the summary input file was completed and the batch run submitted. The summary file is: $\rightarrow$ GEU, R NELSON*GRND8. READ-ONLY MODE

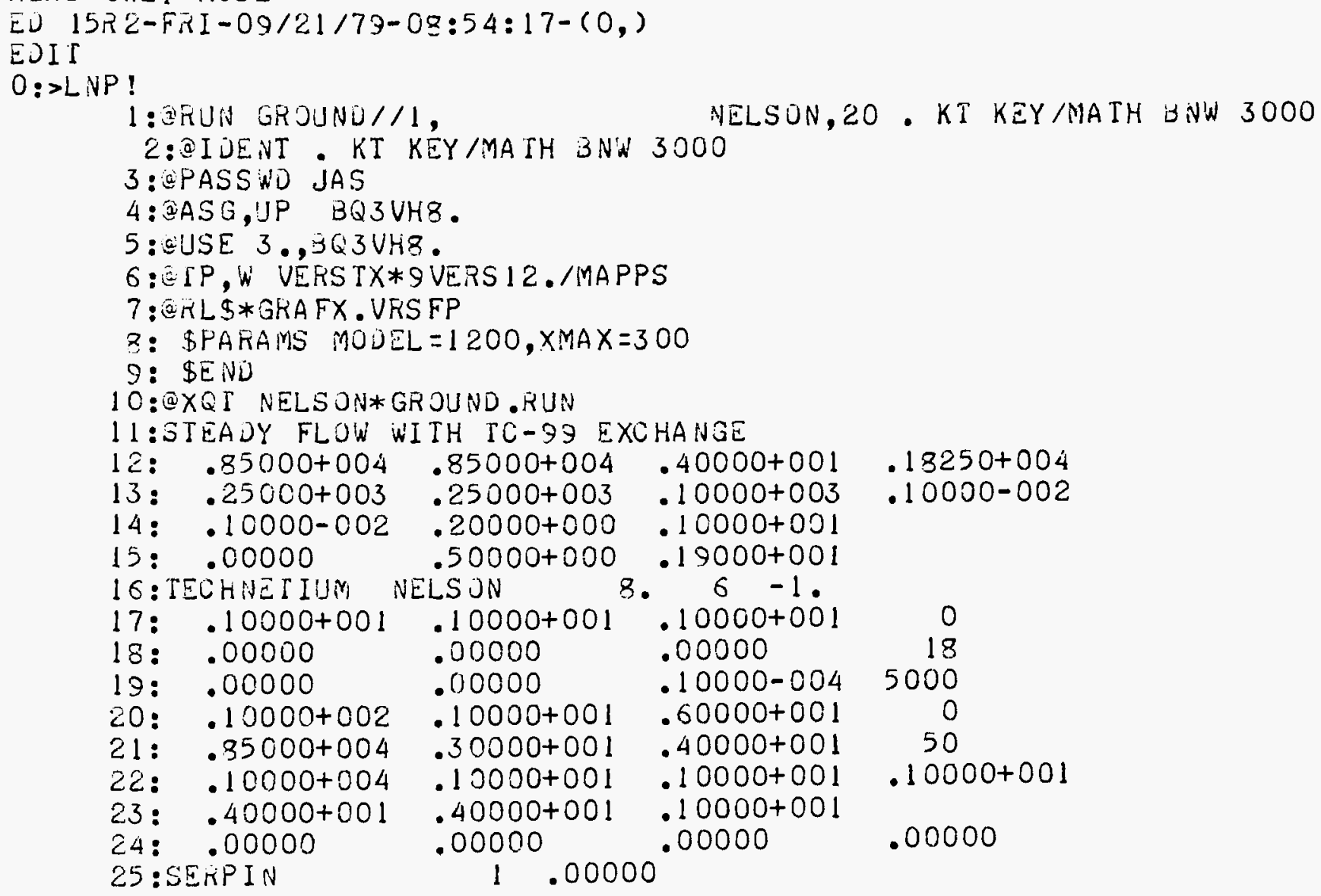




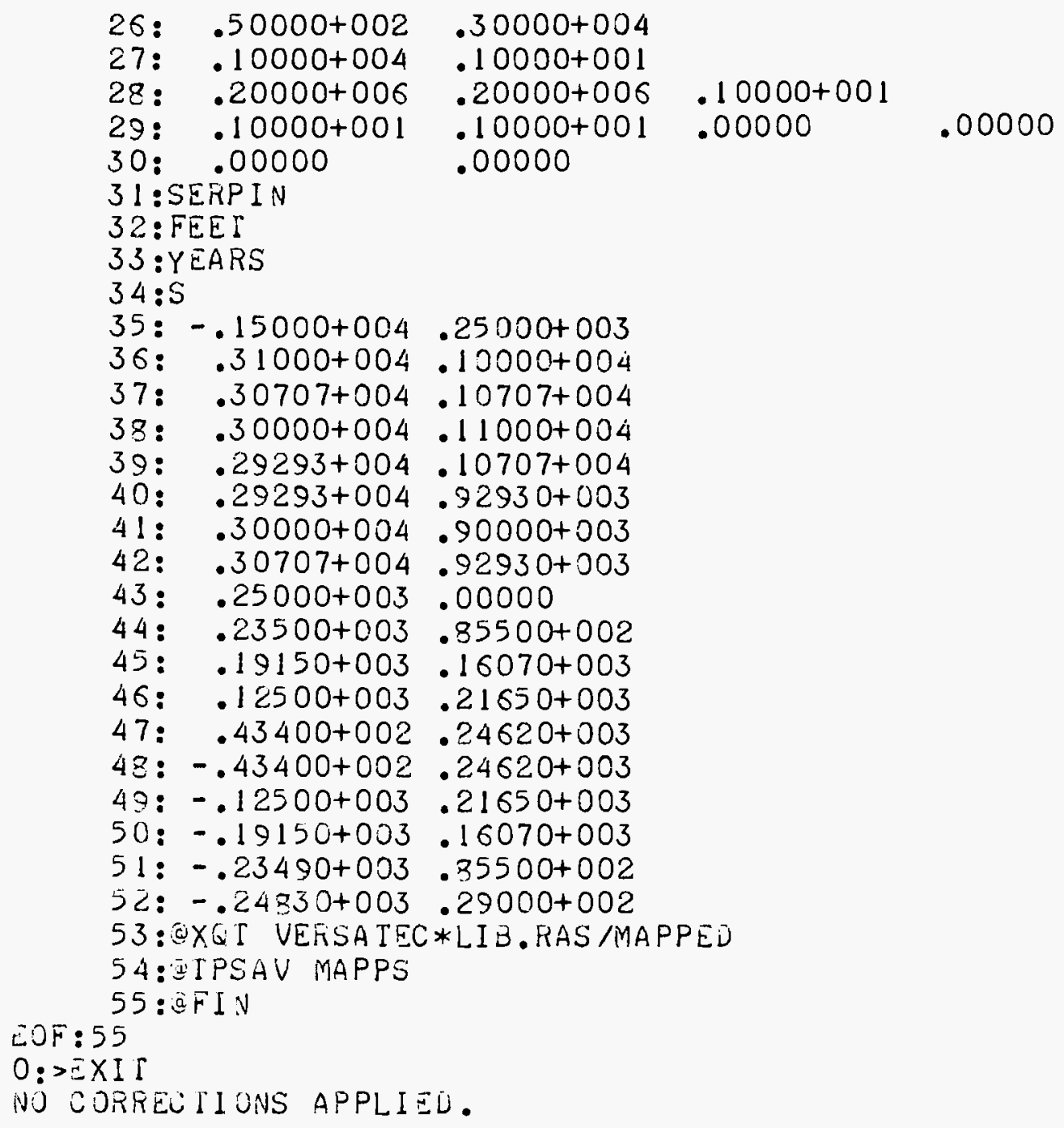

With the successful completion of the batch run GROUND, the user may obtain the summary arrival results over the terminal. To do this, you type QED, R PROJID*BQ3VH_ (use 8 in the blank for this example) followed by P!. The results obtained are: 
>0OU,R NELSJH*3G3VHB.

REAU-JULY YUJDE

(D) $1528-1) J i v-09 / 24 / 79-02: 32: 47-(0$,

EDI I

$0:>P$ !

SIEAUY FLON WIN LU-99 EXCHANGE

CHE JEPART JAE TIME IS

IHE IVIIIAL OUTFLUW TATE IE UJOIL FËI
.000 YZARS $.13006766+007$

THE INITIAL KRLATIVE CAVET̃N MEAU IS

1.0000

\begin{tabular}{|c|c|c|c|c|c|c|}
\hline & $\begin{array}{l}1 \\
2 \\
3 \\
4 \\
5 \\
6 \\
7 \\
8 \\
9 \\
10 \\
11 \\
12 \\
13 \\
14 \\
15 \\
16 \\
17 \\
18\end{array}$ & $\begin{array}{l}\text { TAAVEL TINE } \\
\text { YEARS } \\
7.03939+003 \\
2.60996+003 \\
2.63660+003 \\
2.69242+003 \\
2.76461+003 \\
2.72738+003 \\
2.66218+003 \\
2.62043+003 \\
3.71934+003 \\
3.73679+003 \\
3.84378+003 \\
4.05101+003 \\
4.23655+003 \\
4.43543+003 \\
4.79952+003 \\
5.20045+003 \\
5.82404+003 \\
6.73896+003\end{array}$ & $\begin{array}{l}X \\
F .2 \Gamma \\
3.49996+003 \\
8.49996+003 \\
8.49999+003 \\
8.49996+003 \\
8.49999+003 \\
8.49997+003 \\
3.49996+003 \\
8.49996+003 \\
3.49993+003 \\
8.49999+003 \\
8.49995+003 \\
8.49993+003 \\
8.49995+003 \\
8.49995+003 \\
8.49997+003 \\
3.49994+003 \\
8.50000+003 \\
3.49992+003\end{array}$ & $\begin{array}{l}Y \\
F=1 \\
3.66636+003 \\
1.19431+003 \\
1.39617+003 \\
1.55522+003 \\
1.64711+003 \\
7.76091+002 \\
8.52353+002 \\
9.97939+002 \\
-3.91366+002 \\
9.08907+001 \\
5.55590+002 \\
1.93095+003 \\
2.32213+003 \\
2.66444+003 \\
2.95771+003 \\
3.20748+003 \\
3.42508+003 \\
3.55977+003\end{array}$ & $\begin{array}{c}\text { CUM FLJX } \\
2 / 60 \\
3.221 \leq 4-001 \\
1.82262-001 \\
2.15197-001 \\
2.41123-001 \\
2.56091-001 \\
1.13947-001 \\
1.26493-001 \\
1.50196-001 \\
9.23118-001 \\
1.92155-003 \\
7.73015-002 \\
3.02275-001 \\
3.65770-001 \\
4.21143-001 \\
4.68443-001 \\
5.02614-001 \\
5.43521-001 \\
5.65033-001\end{array}$ & $\begin{array}{r}\text { PAH LN1A } \\
\text { FEE1 } \\
1.10242+004 \\
5.40405+003 \\
5.44250+003 \\
5.55244+003 \\
5.67900+003 \\
5.63973+003 \\
5.52556+003 \\
5.43518+003 \\
8.26442+003 \\
8.29923+003 \\
2.43004+003 \\
8.72495+003 \\
9.00049+003 \\
9.34066+003 \\
9.73179+003 \\
1.01910+004 \\
1.07400+004 \\
1.12922+004\end{array}$ \\
\hline
\end{tabular}

$E O F: 31$

$0:>\operatorname{XXIT}$

NO CORKECTIONS APPLIED.

The detailed computer printout for the example steady case is provided on the following pages. Also at the end of the printout, the plot for the steady flow system is shown. 

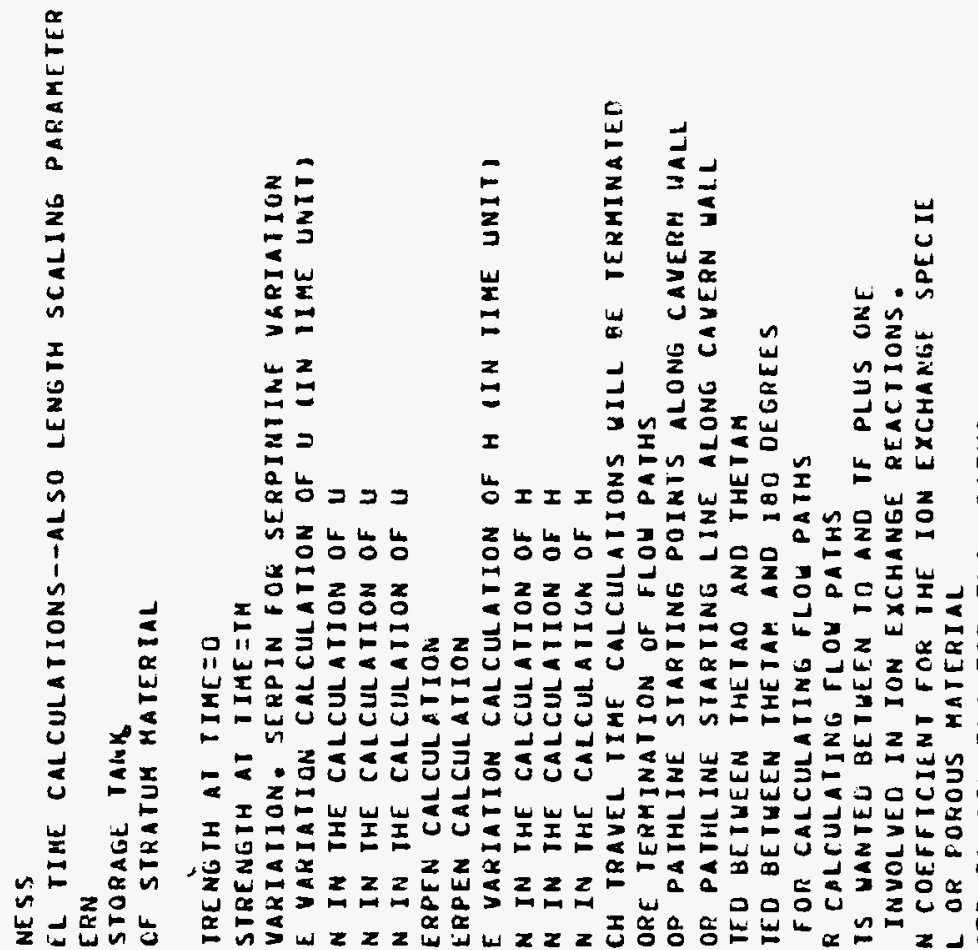

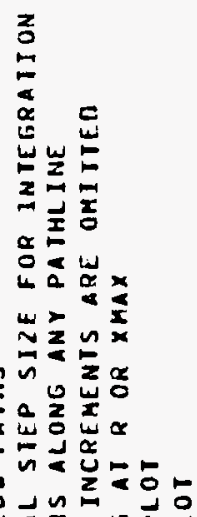

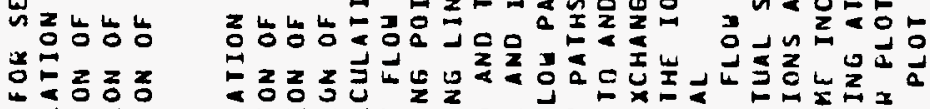

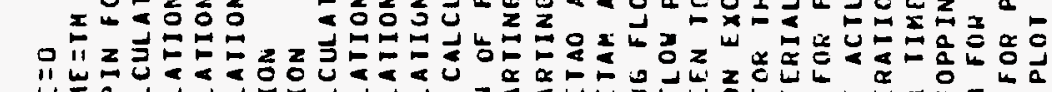

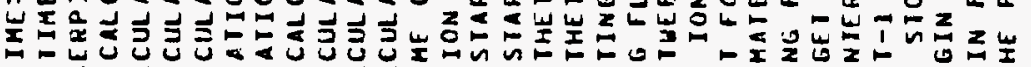
In

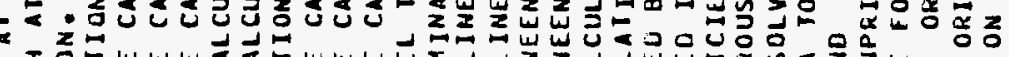

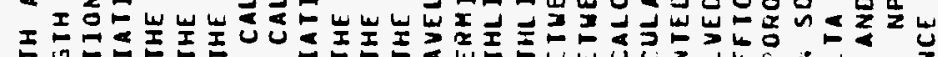

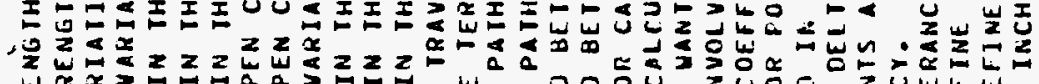

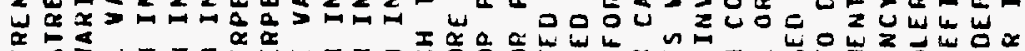

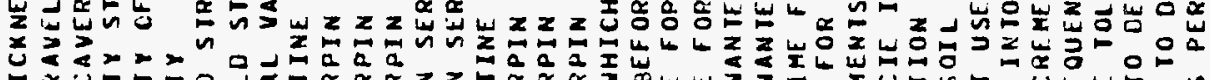
I-

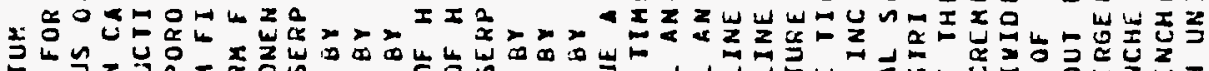

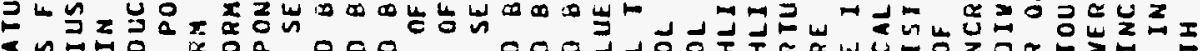

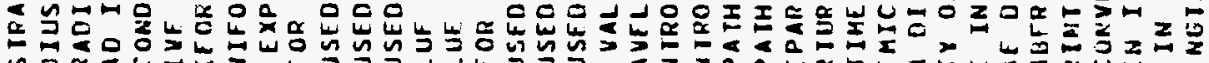

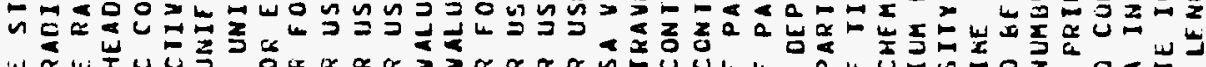

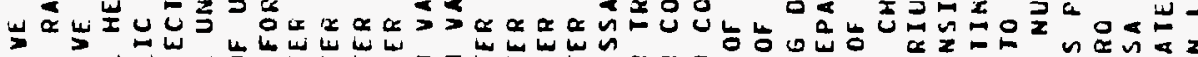

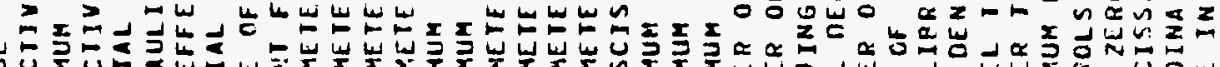

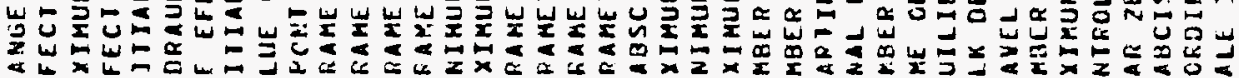

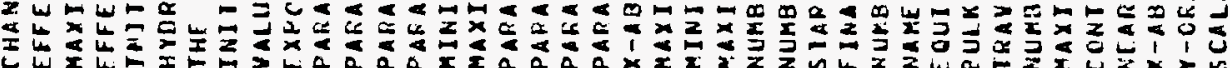

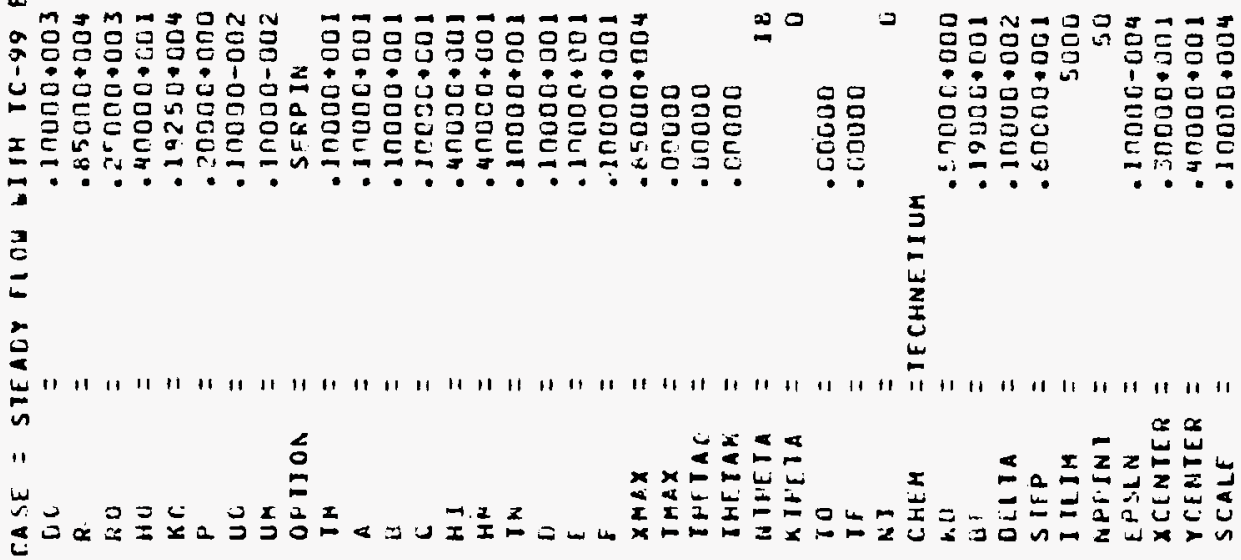




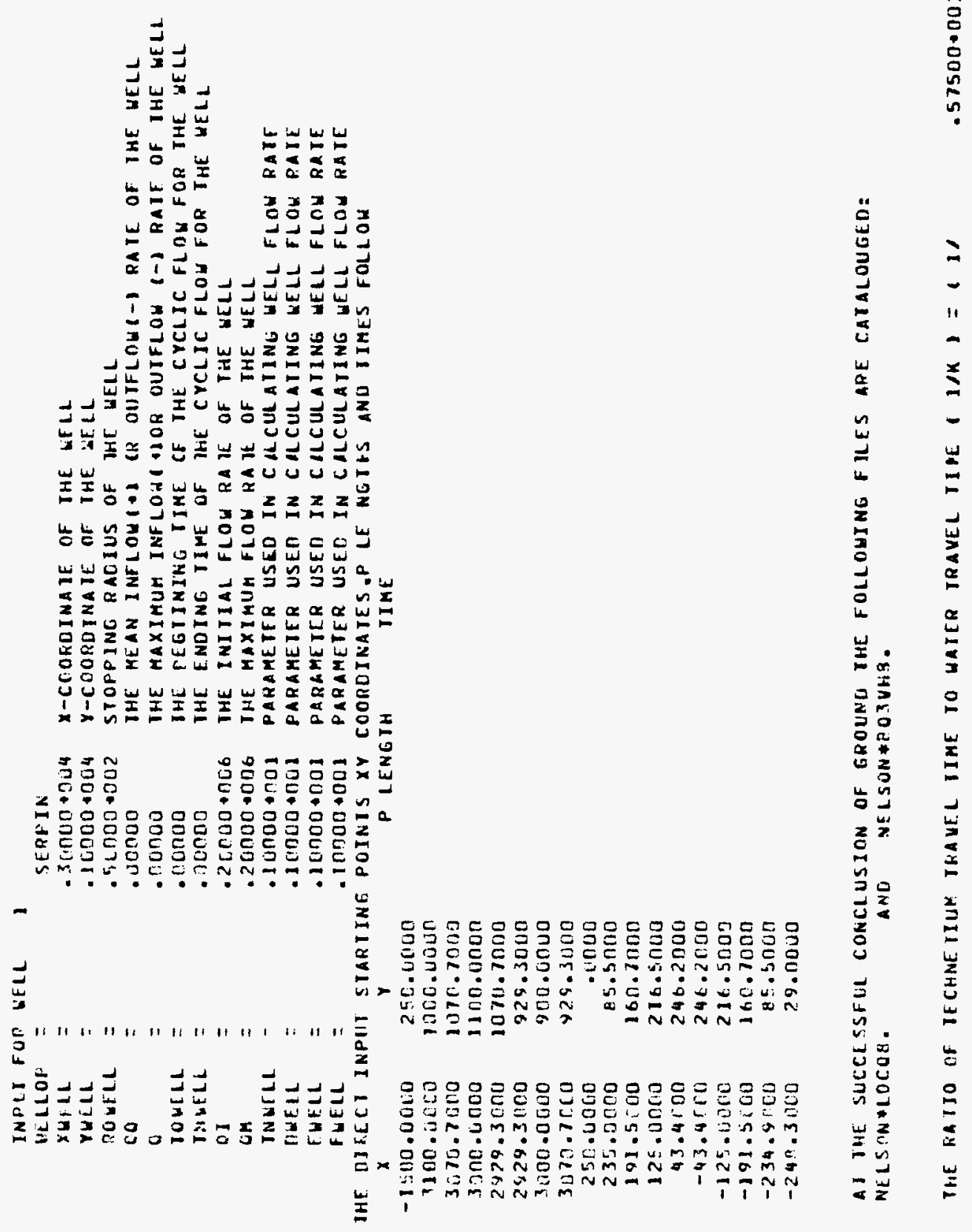




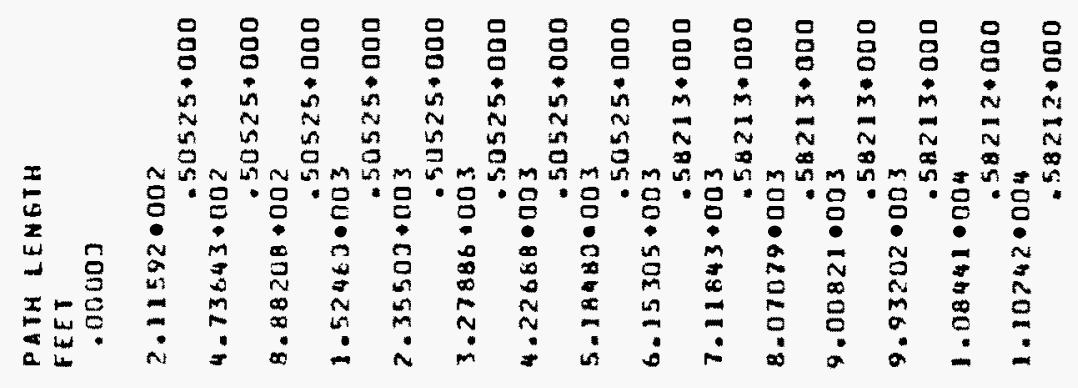

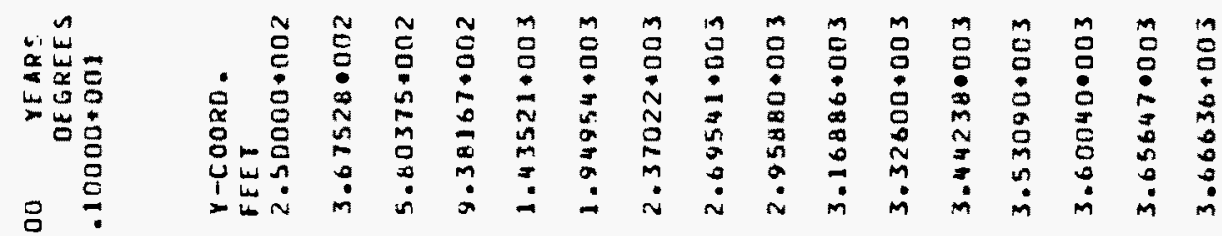

을을

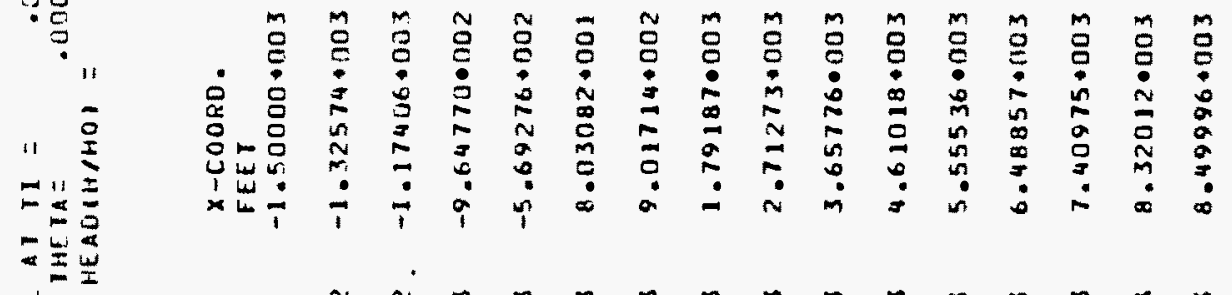

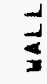

2
$\vdots$
$\vdots$
$\vdots$

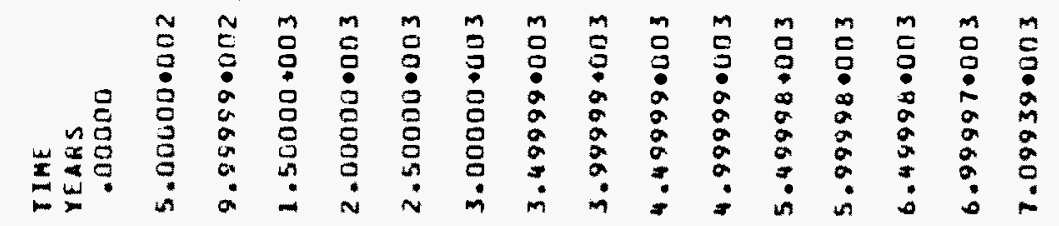

I

2

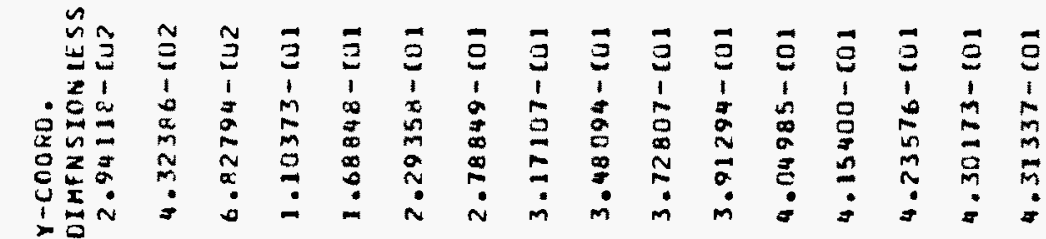

2

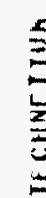

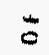

0

$\frac{\dot{2}}{2}$
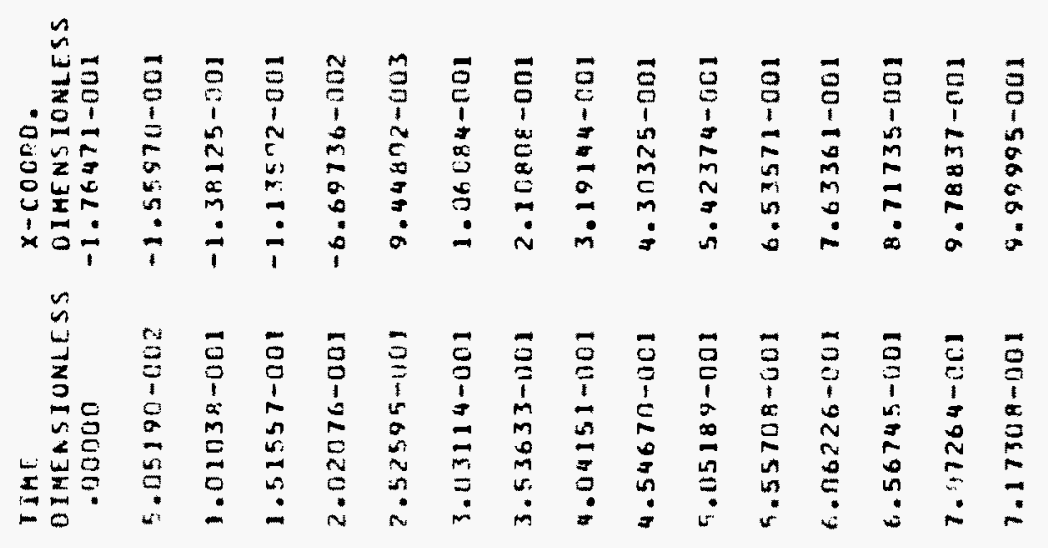

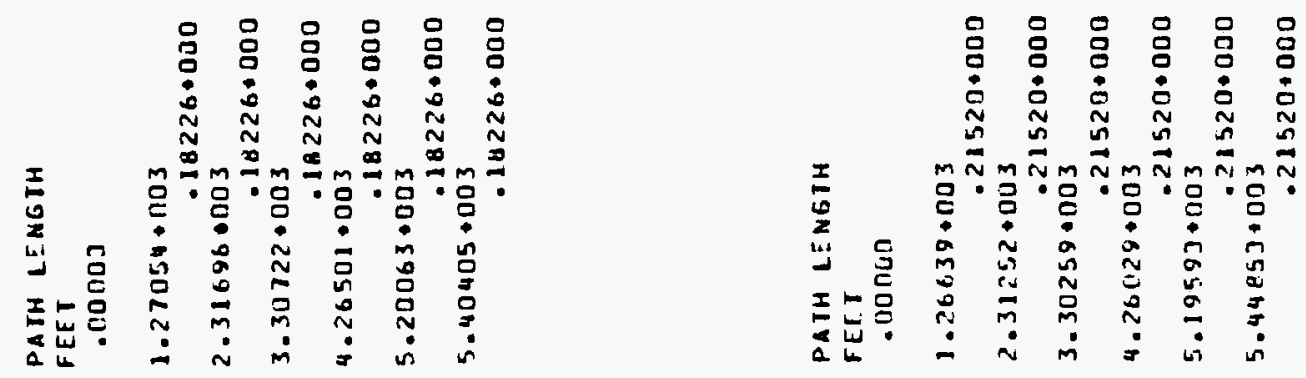

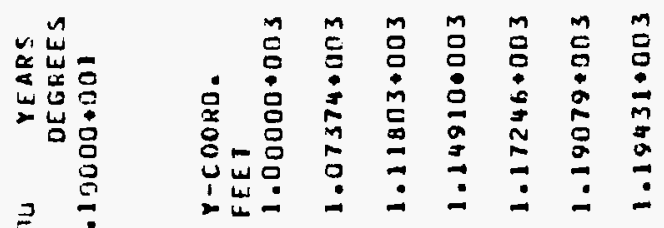
导号

茥㘳

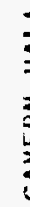

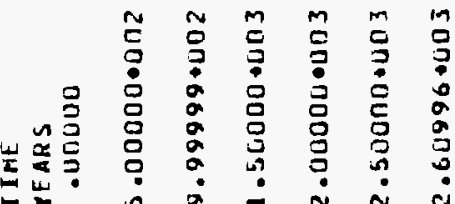

吾

a

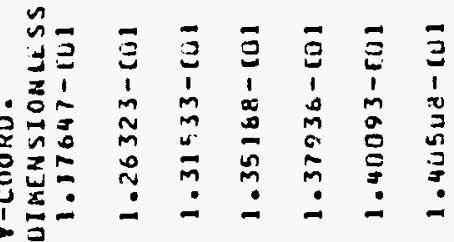

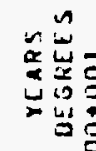

$$
\text { 最 }
$$

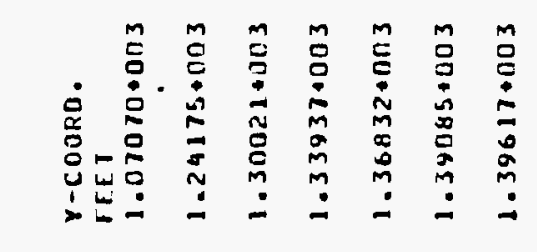

"

उ

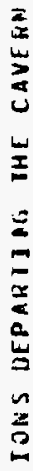
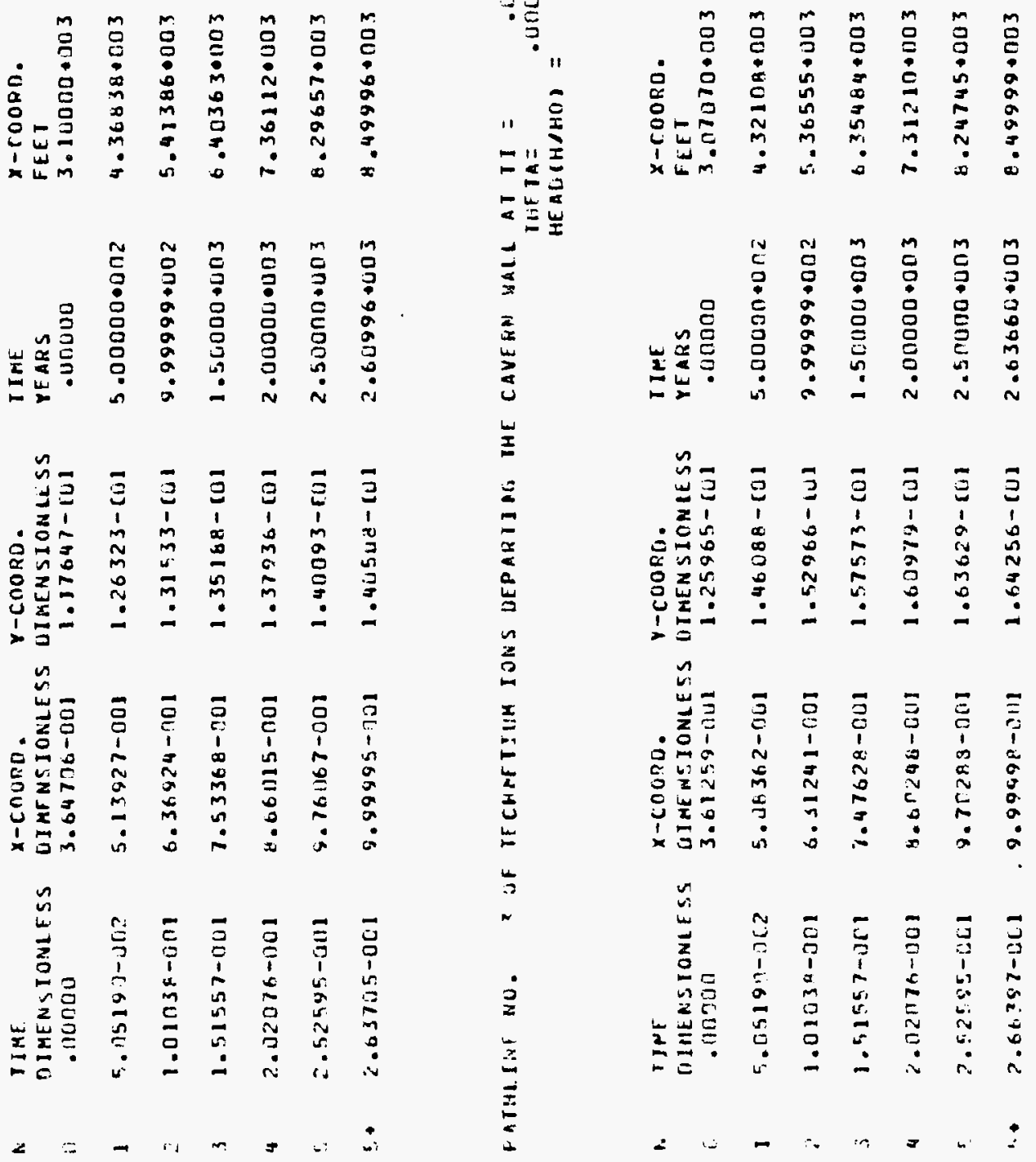

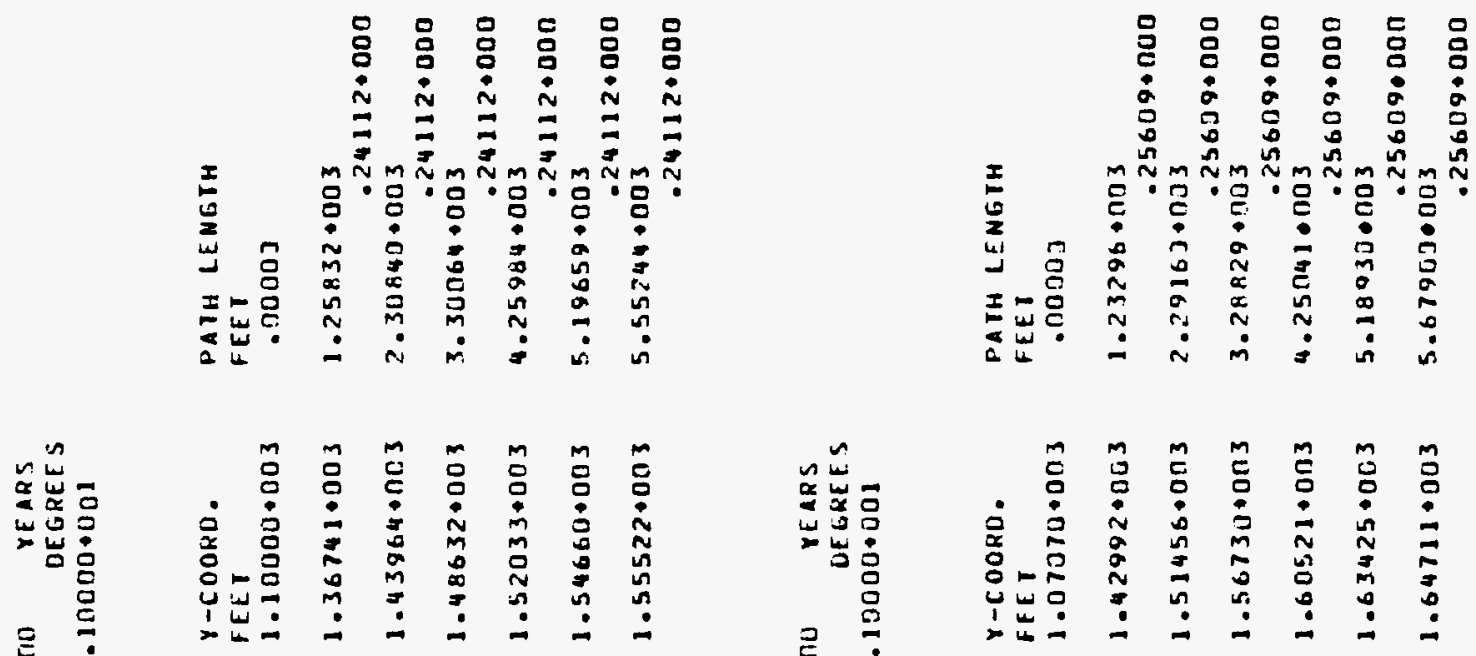

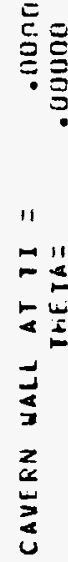

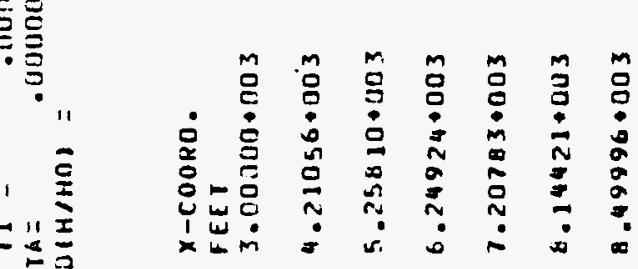

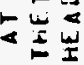

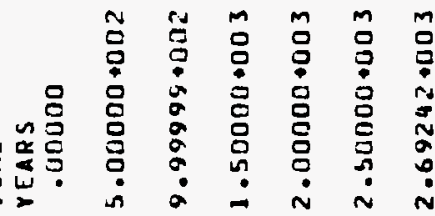

三

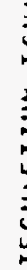

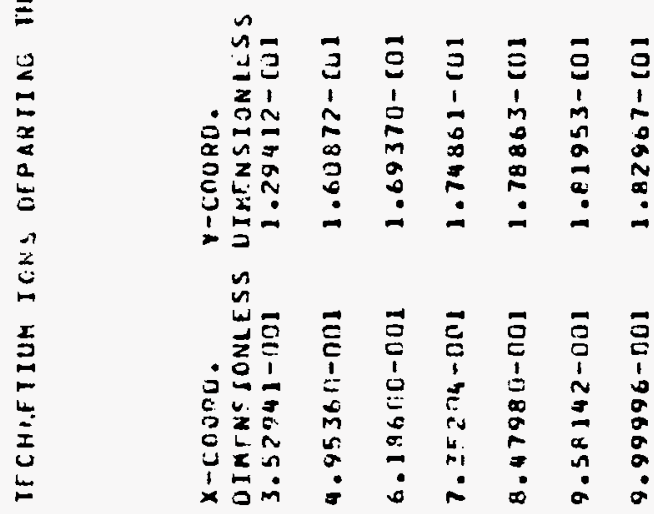

5

$=$

jo

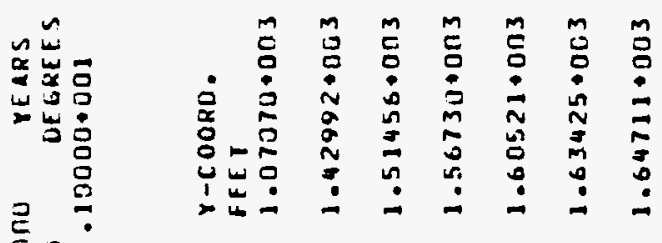

$$
\text { 五 }
$$

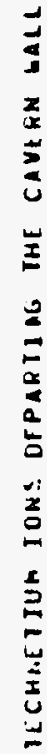
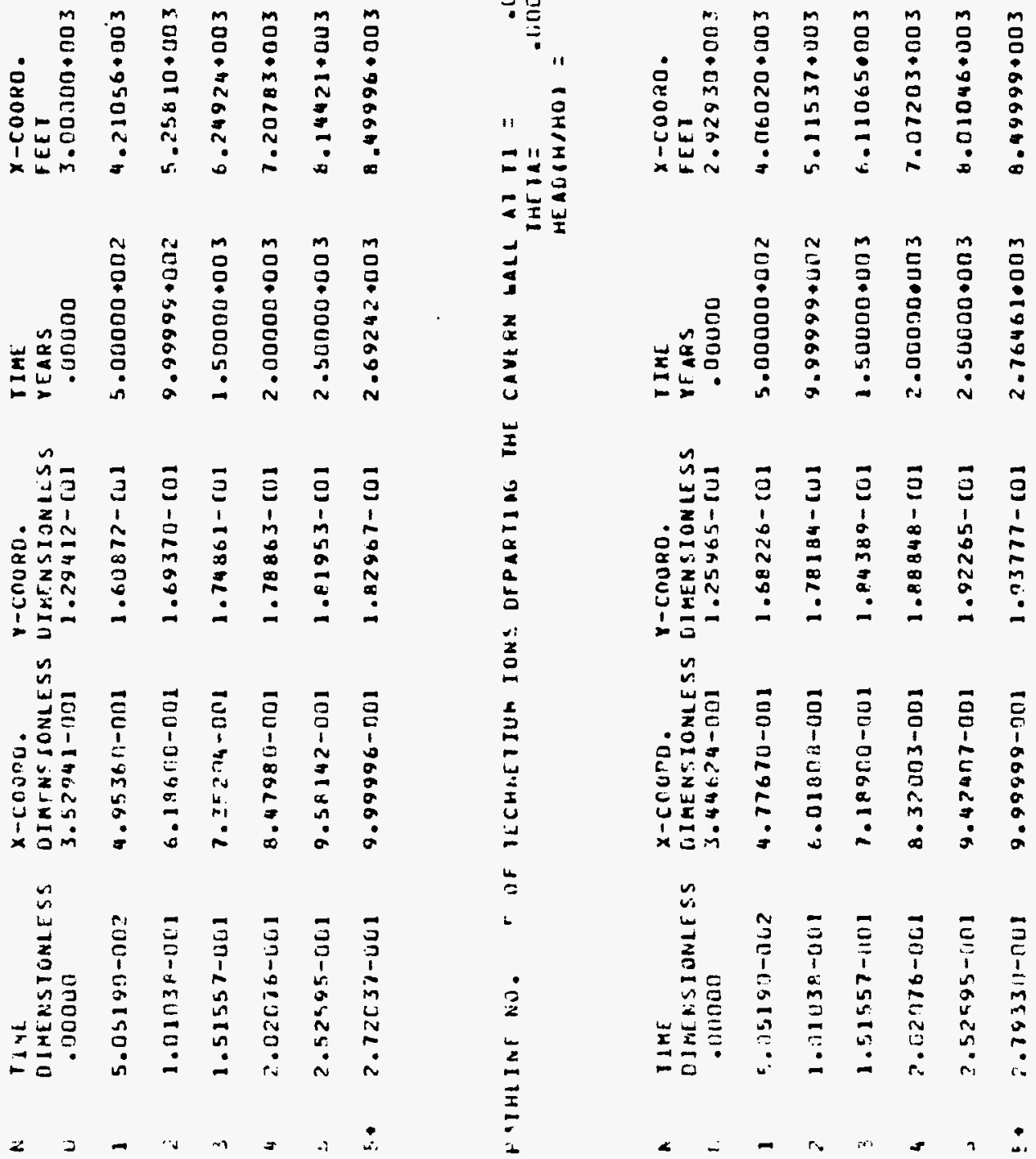

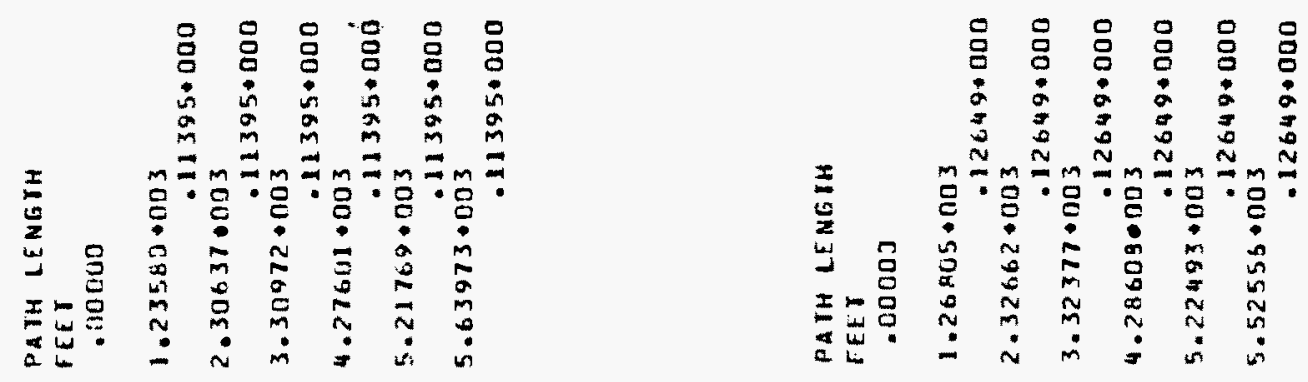

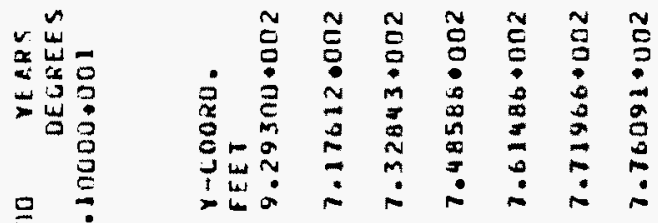

号号

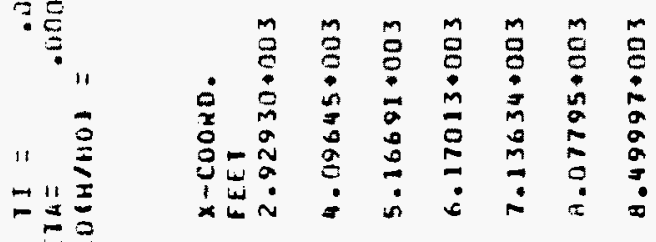

㗱

$\frac{1}{3}$
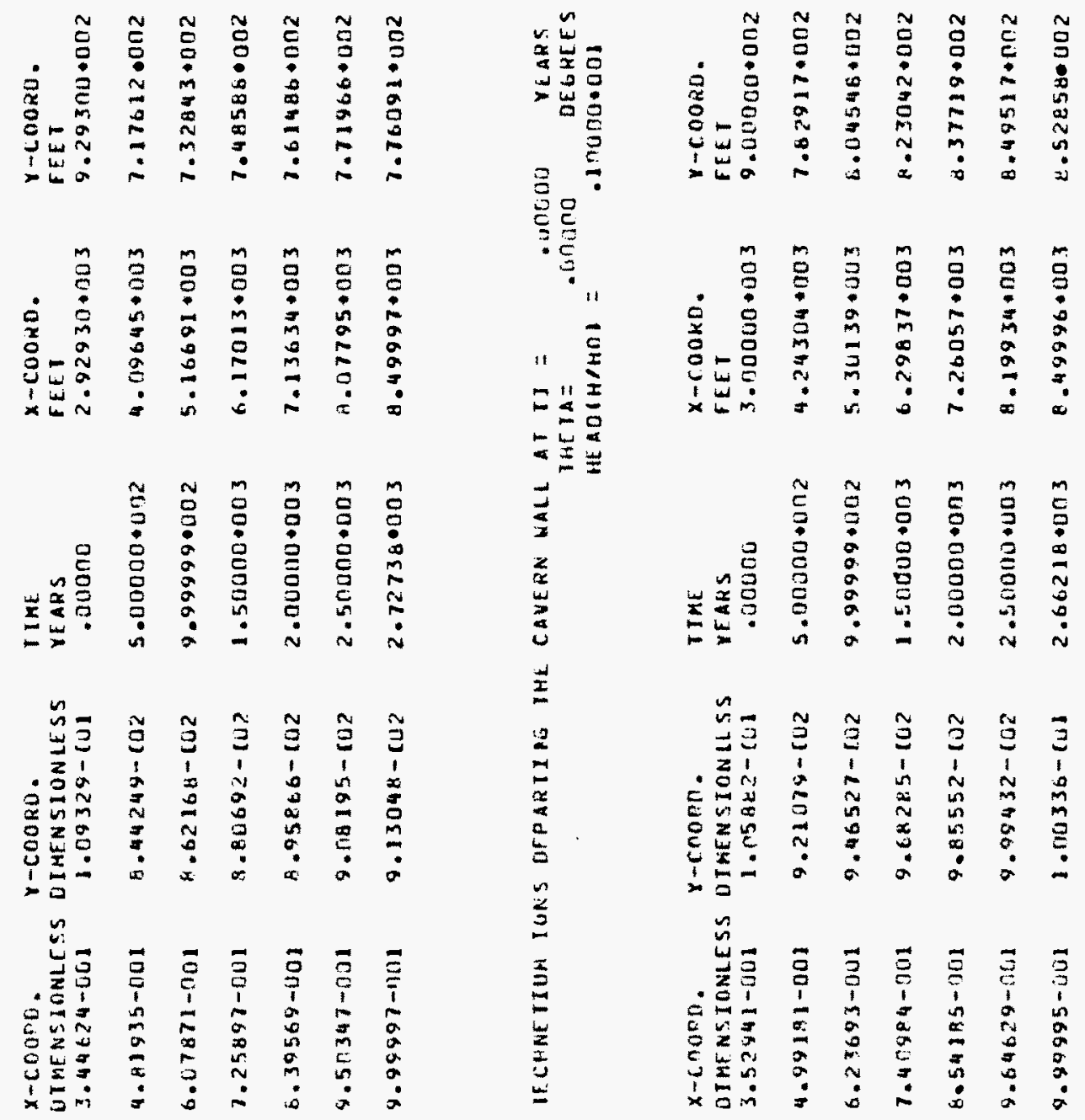

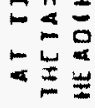

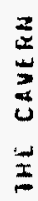

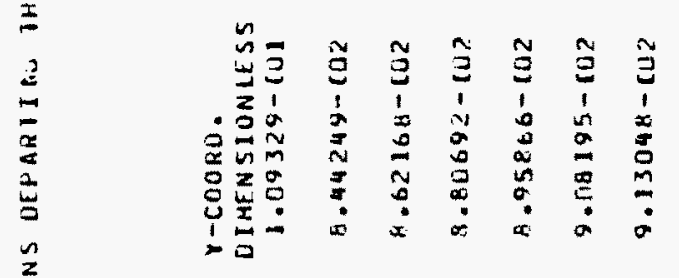

ż

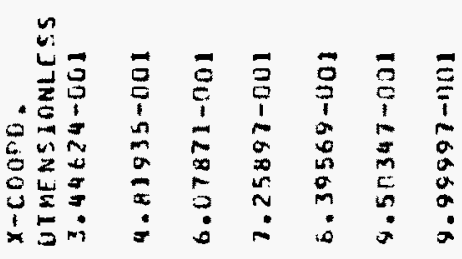

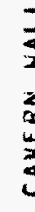

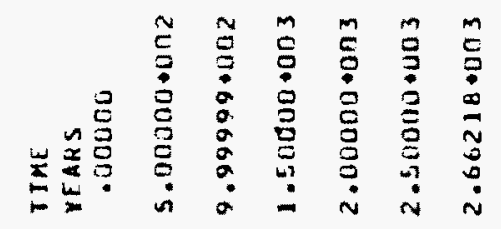

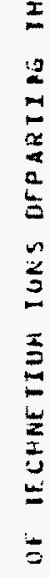

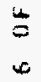

$\dot{8}$
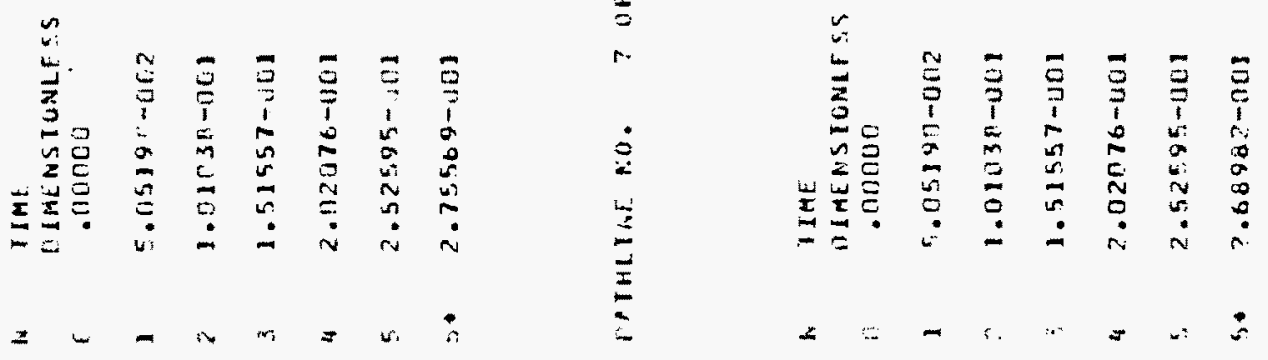

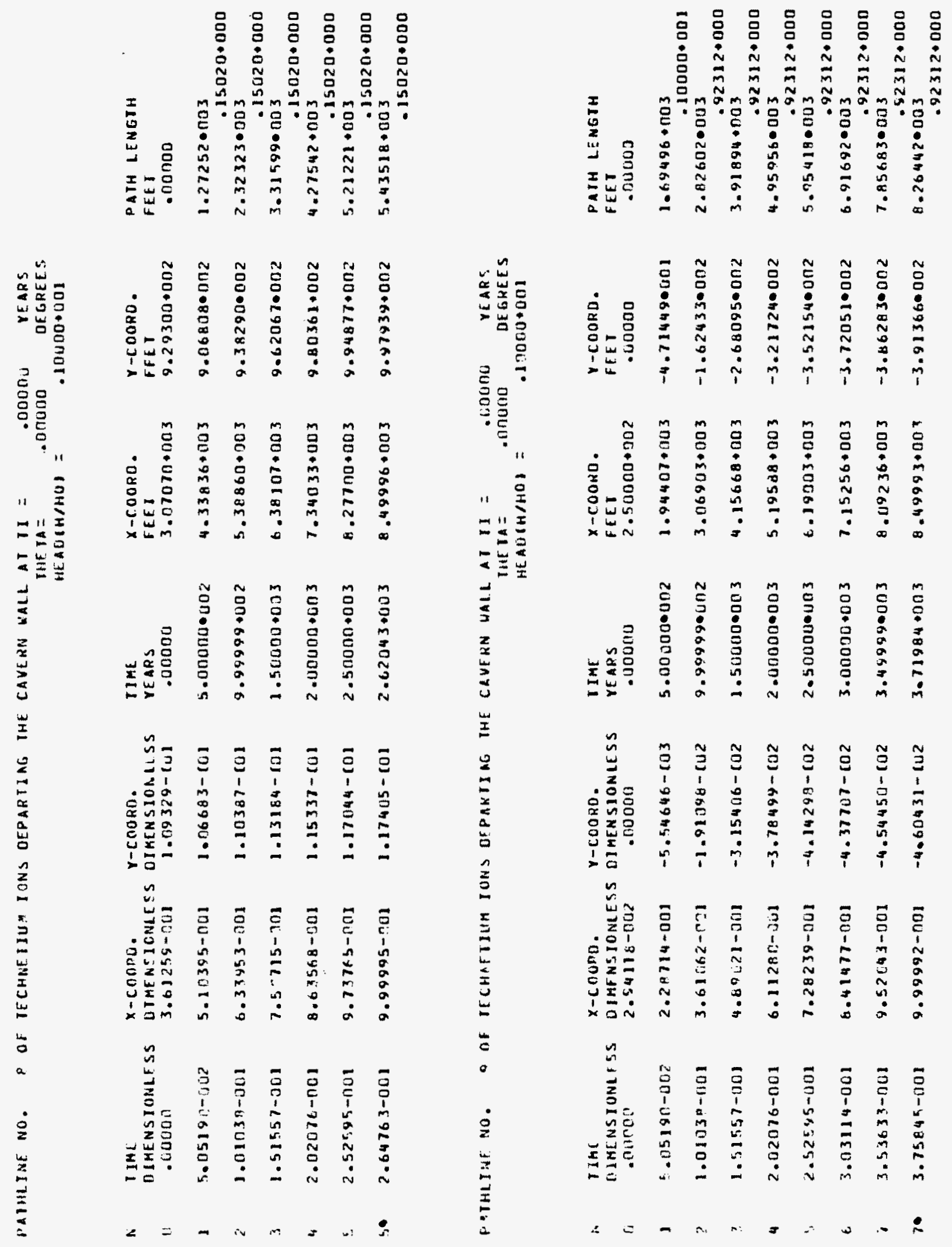

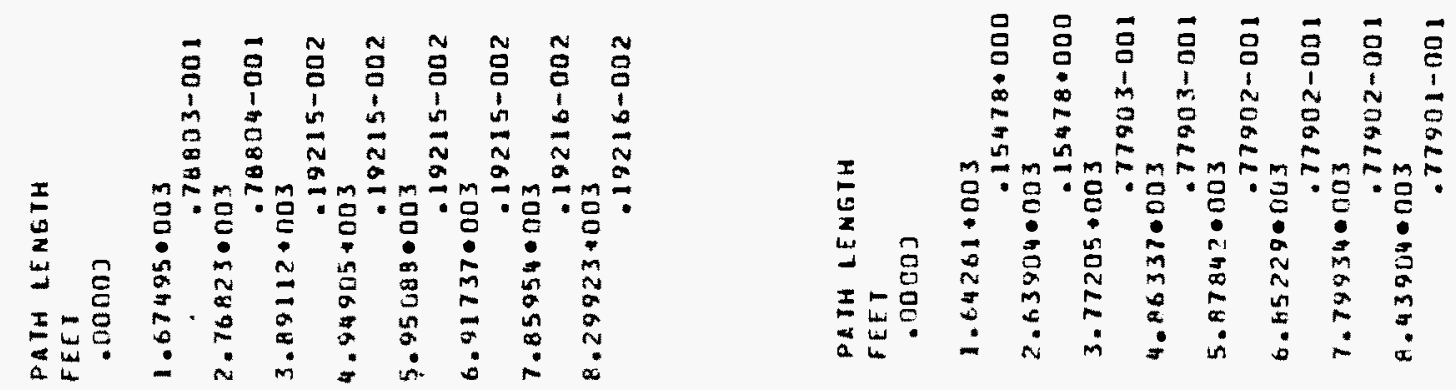

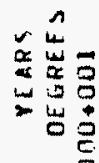

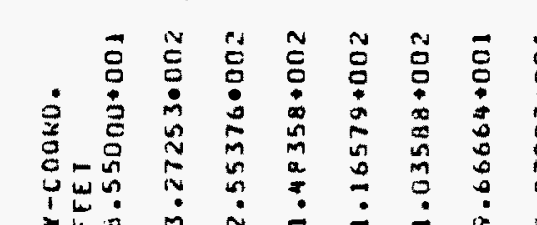

号曷

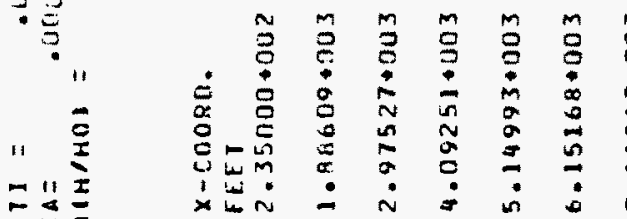

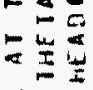
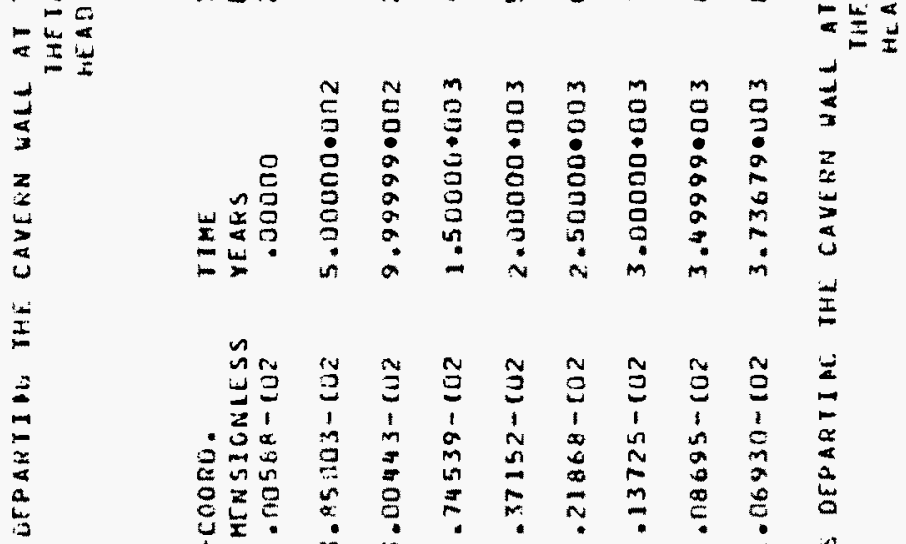

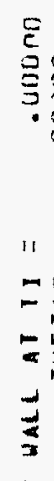

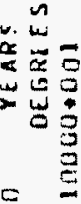

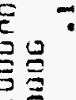

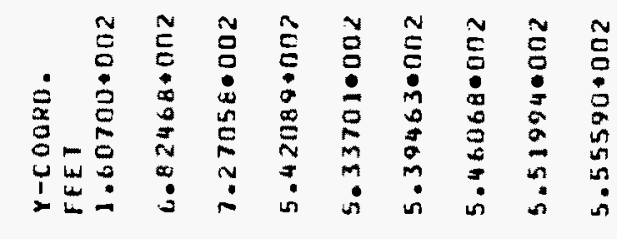

岳喜号
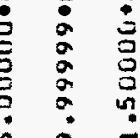

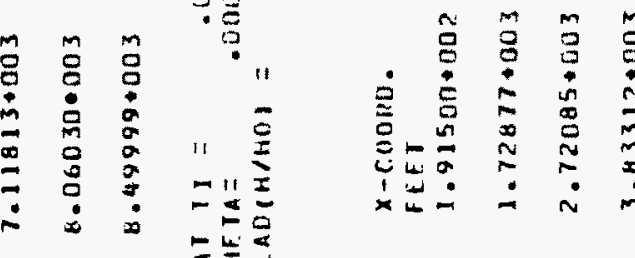
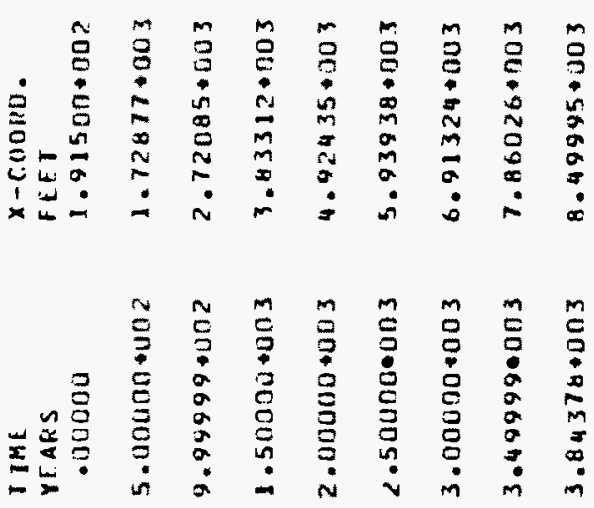

至

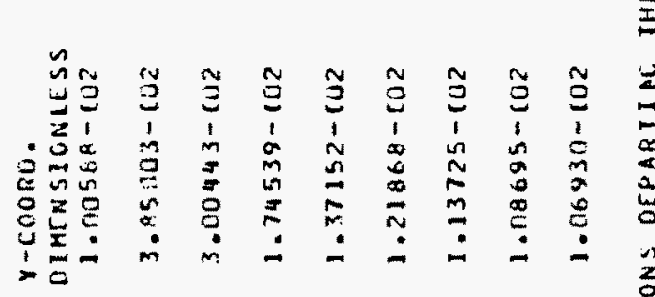

范

i்
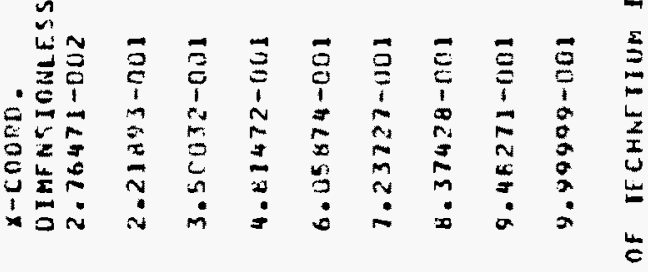

5

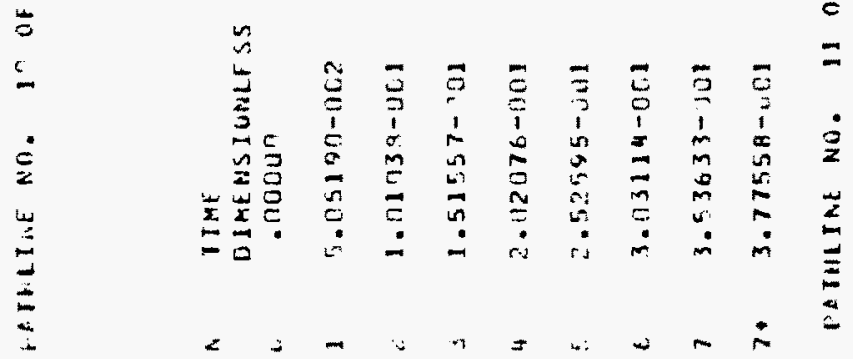



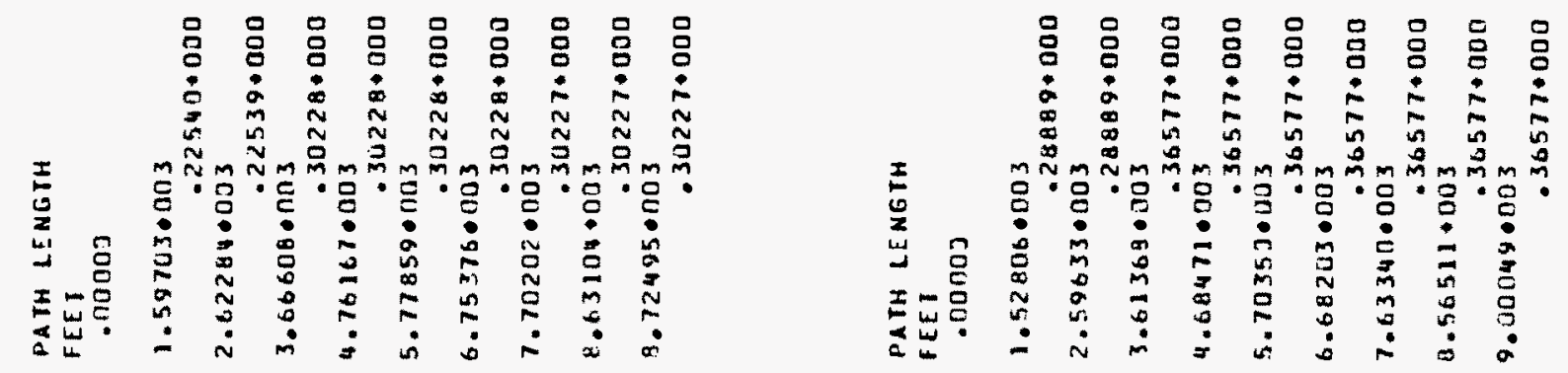

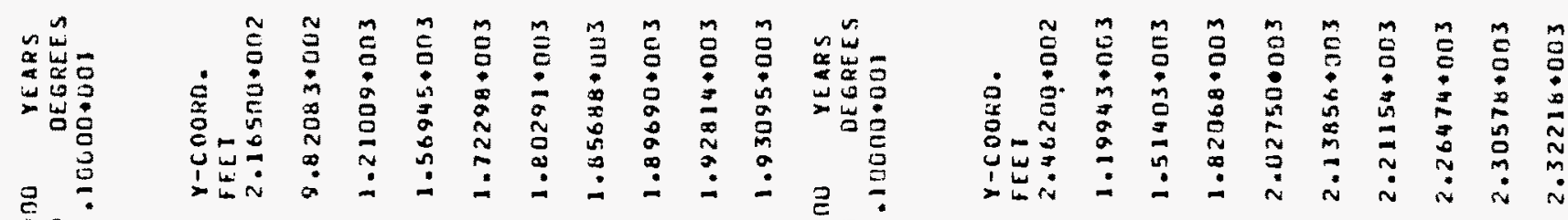
煦吉

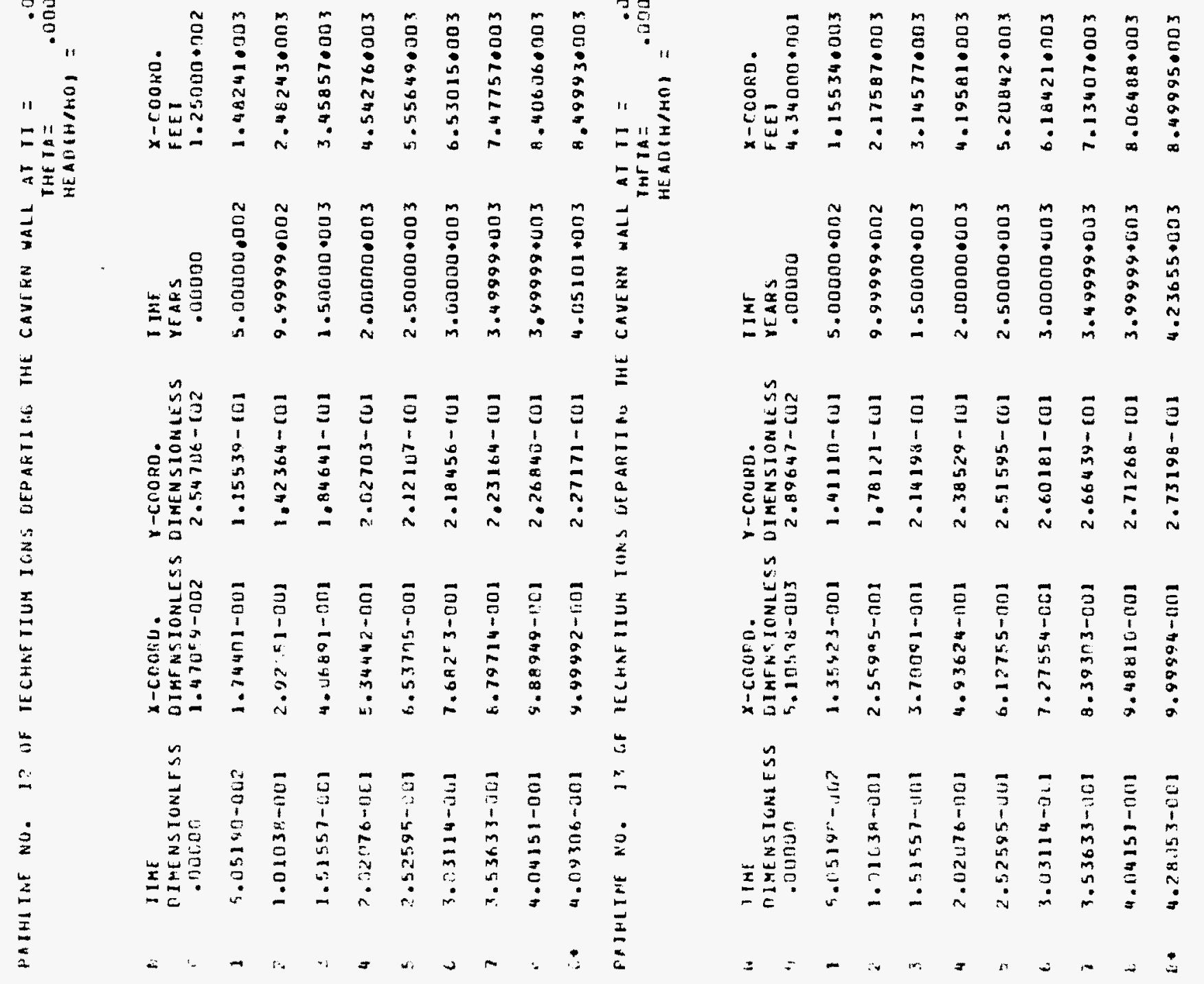



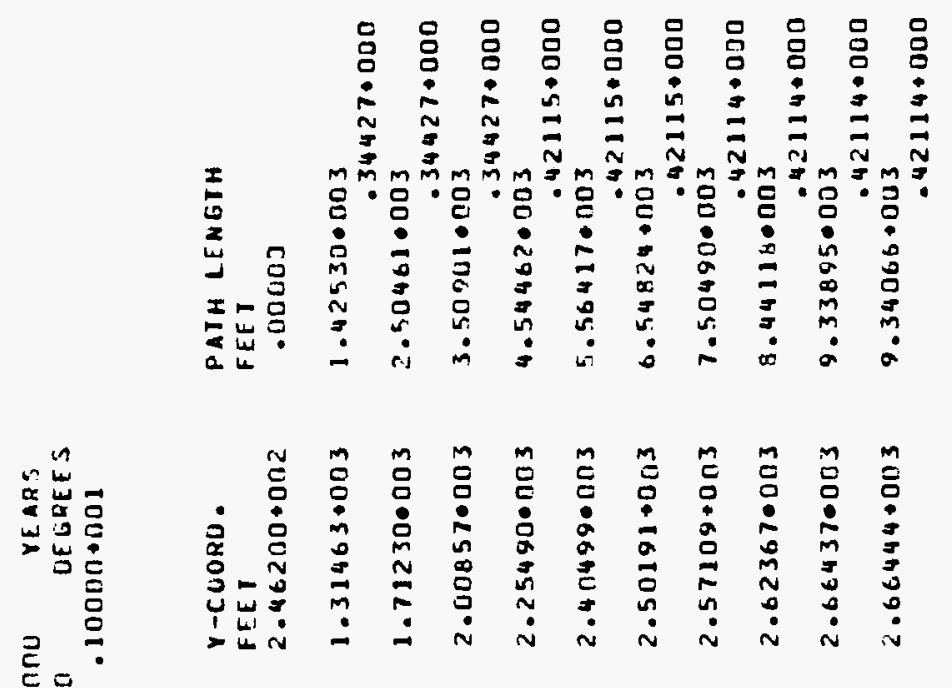

㗁

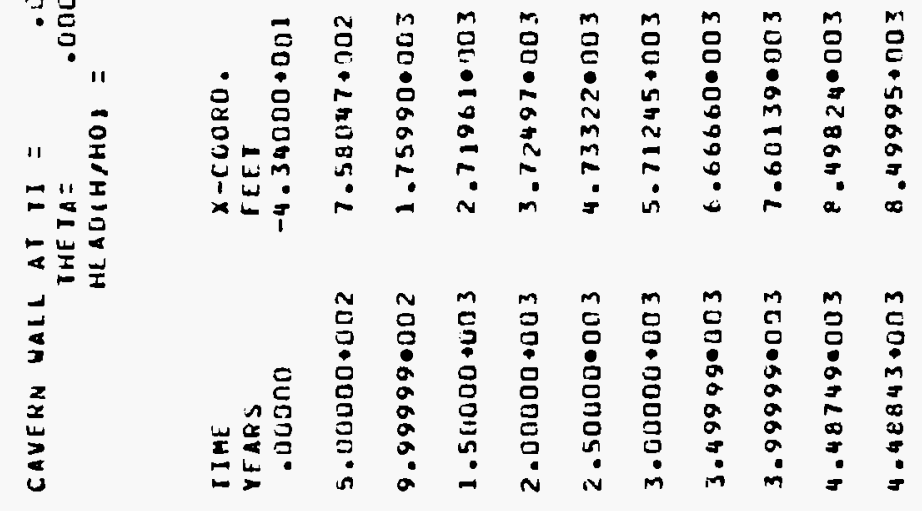

至

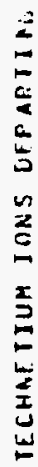

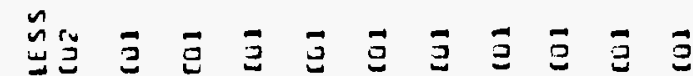

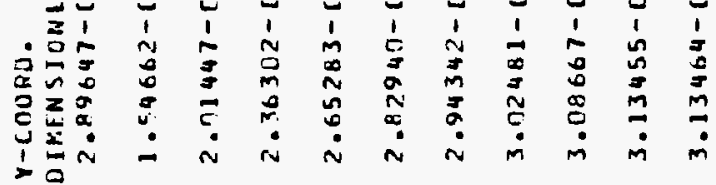

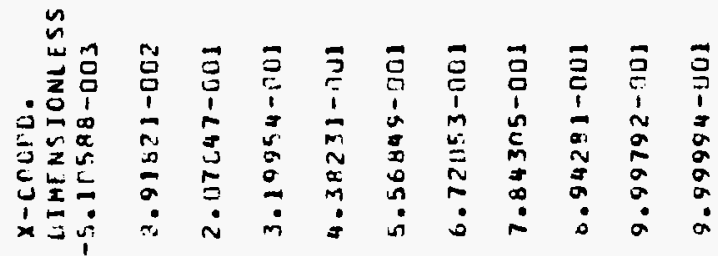

$\Xi$

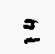

$\dot{2}$

$\stackrel{\square}{\Xi}$

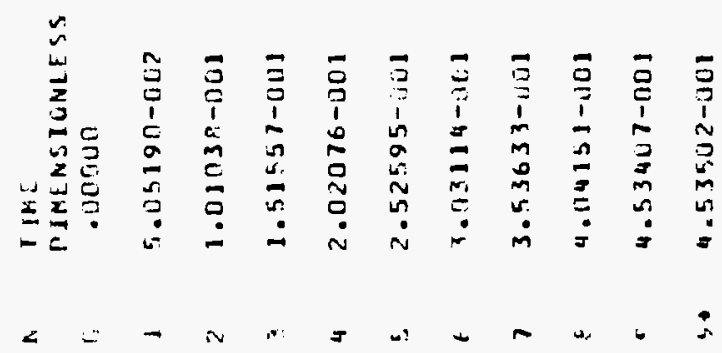




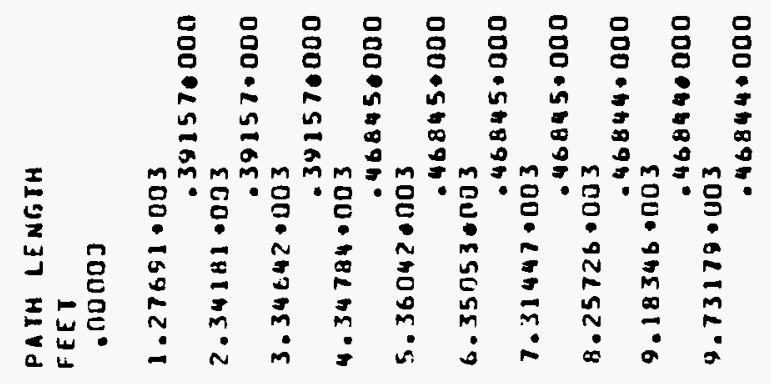

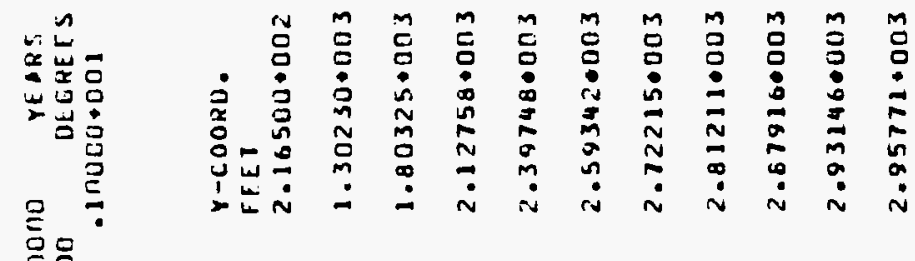

题吕

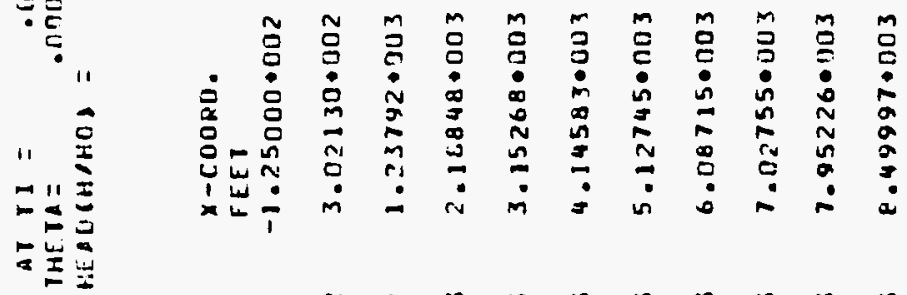

J

$\ddot{\alpha}$

$\underset{⿱}{\mathbb{2}}$

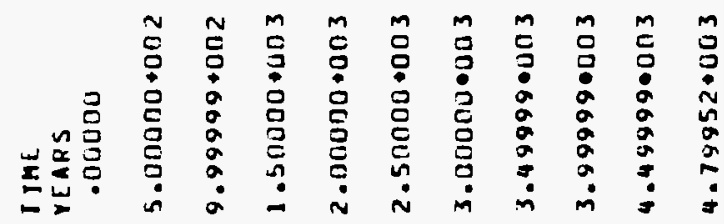

至

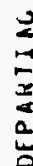

3

5

望
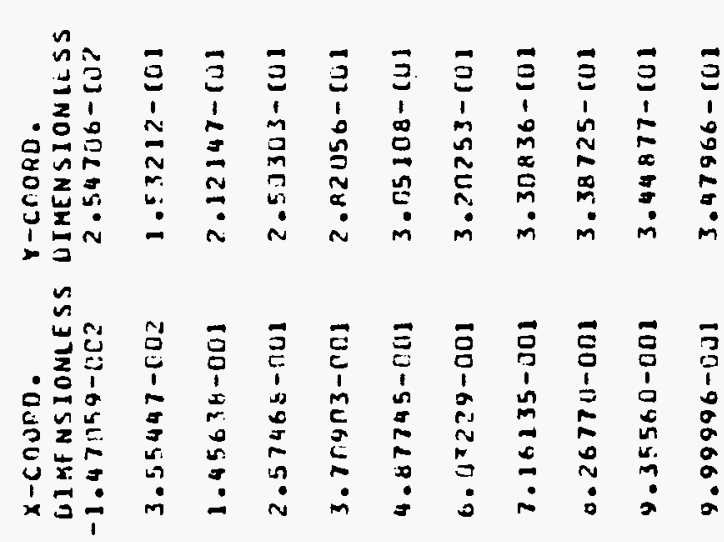

岩

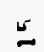

$\dot{0}$

吾

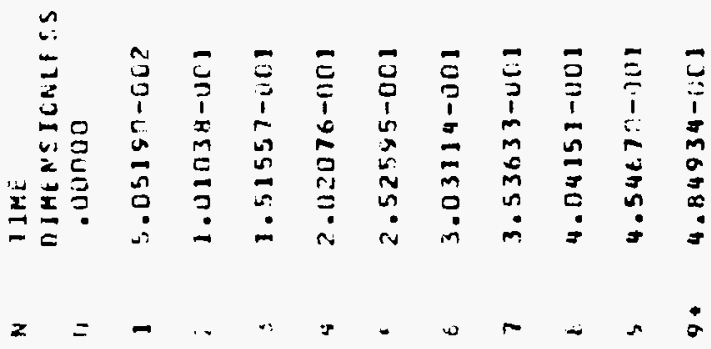




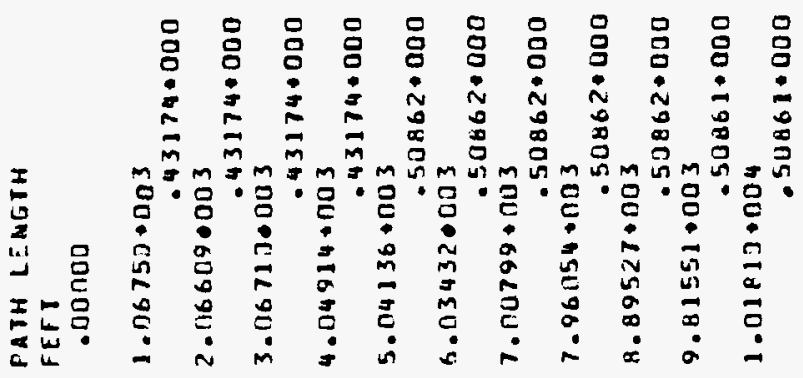

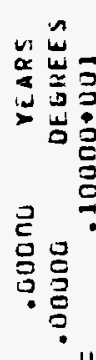

$=$ - 11

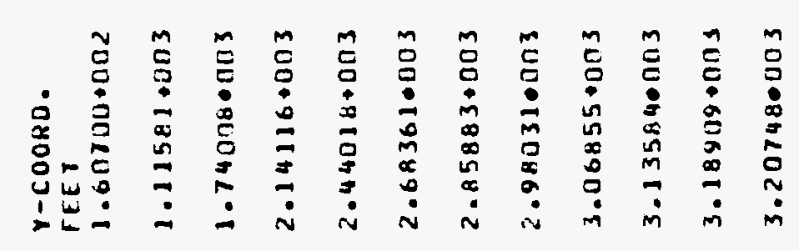

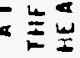

$\frac{2}{2}$
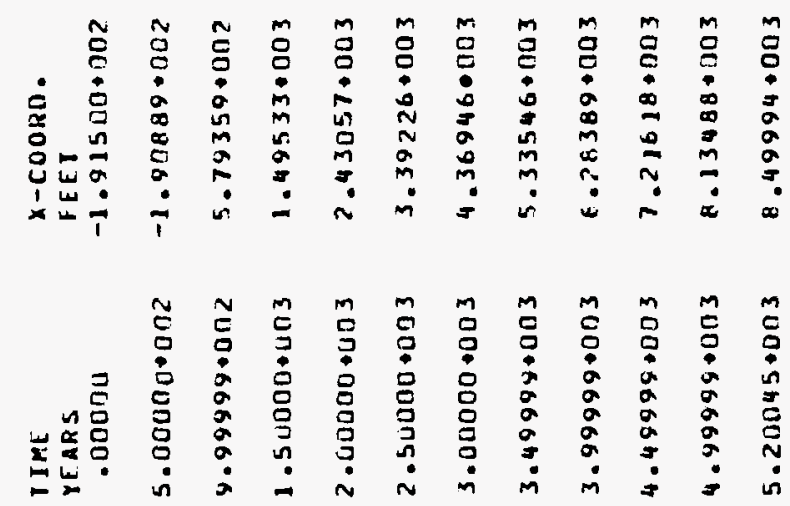

I

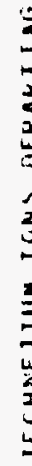
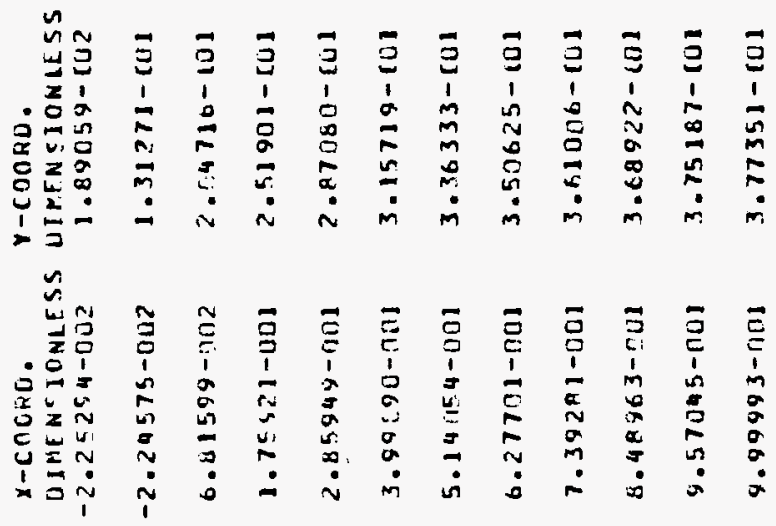

둘

$=$

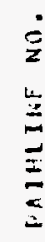

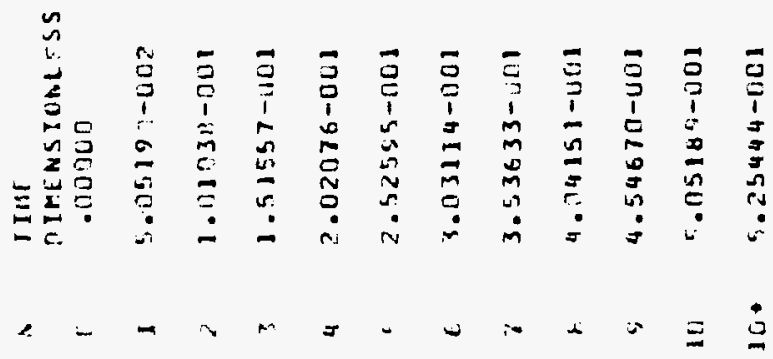



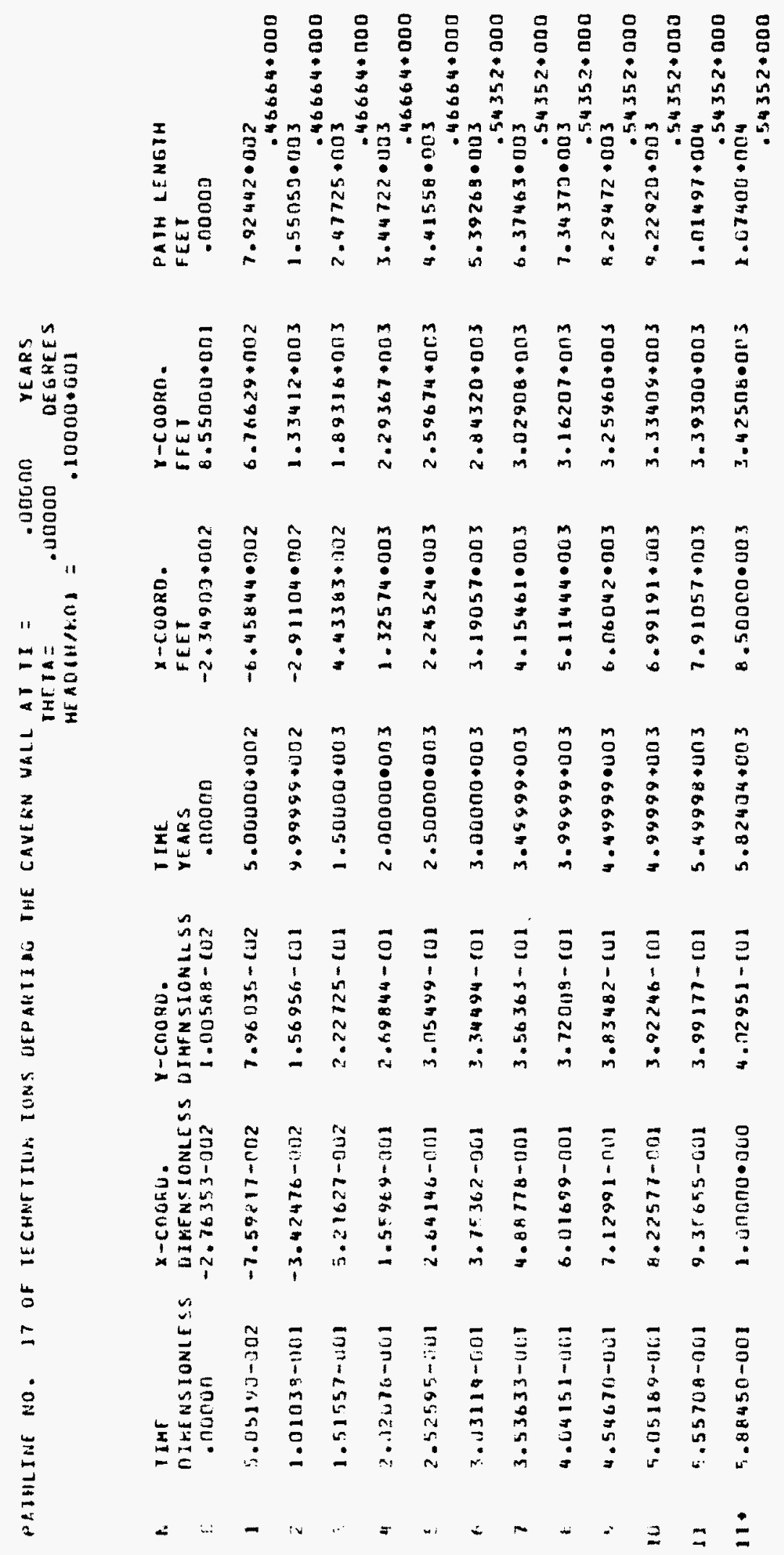

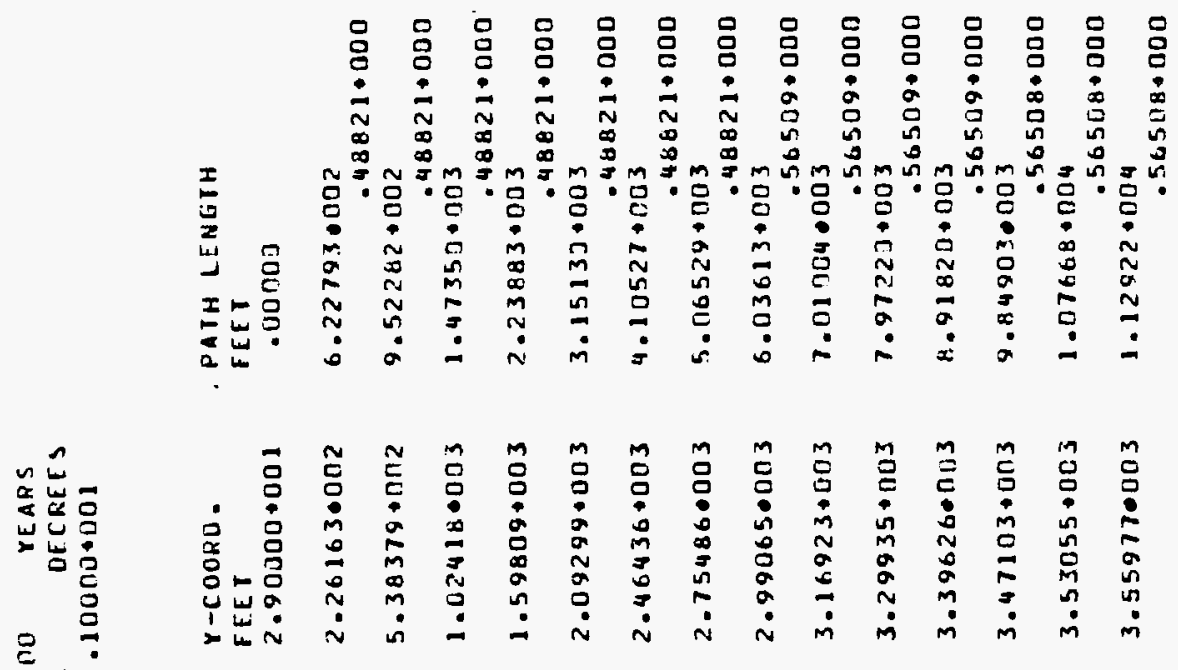

号

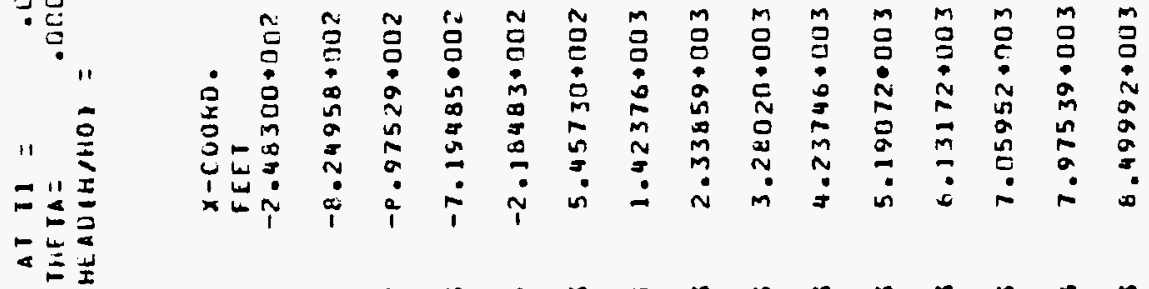

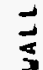

농

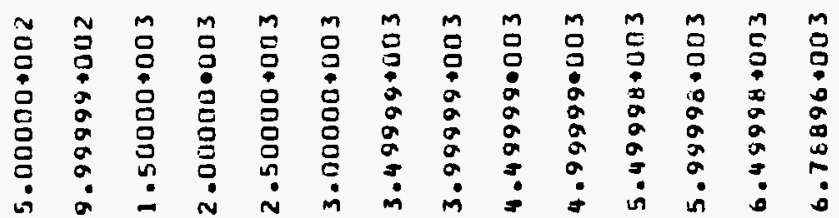

ほ

苛

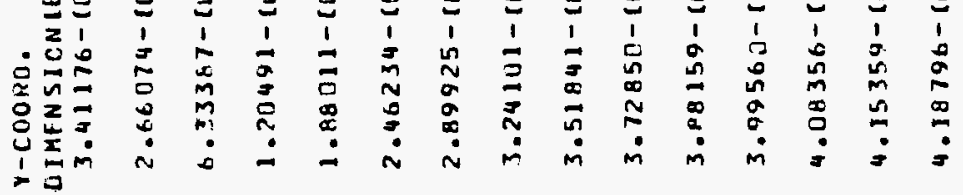

$\underset{3}{3}$

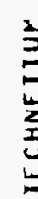

เ

-
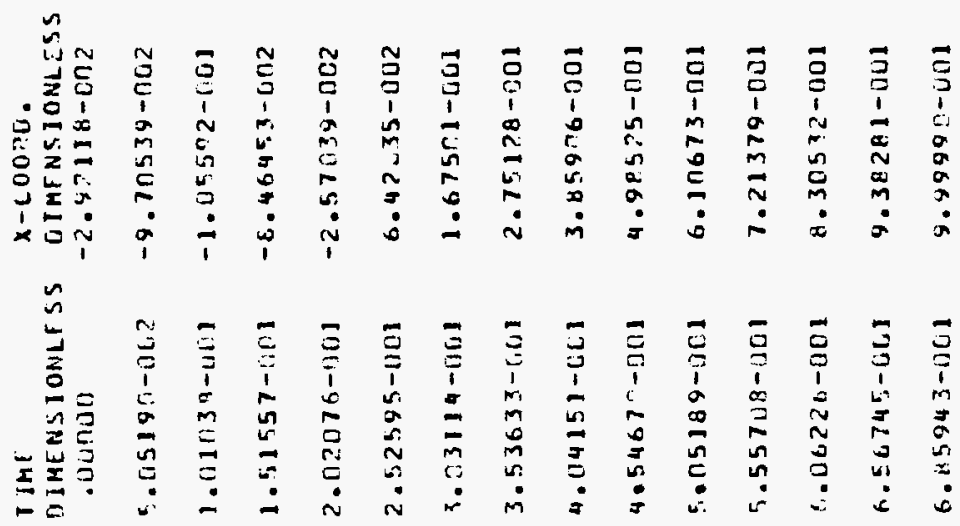


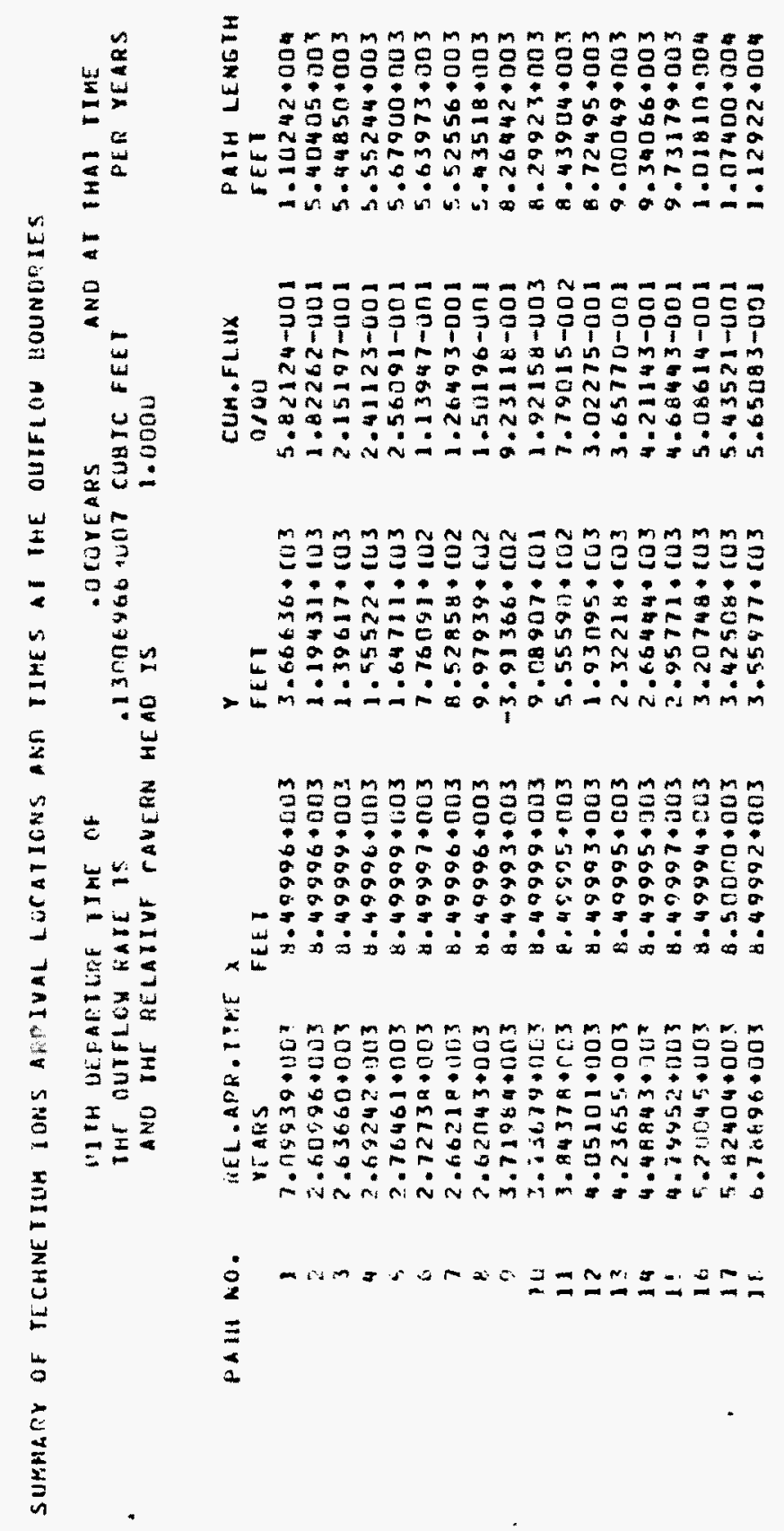




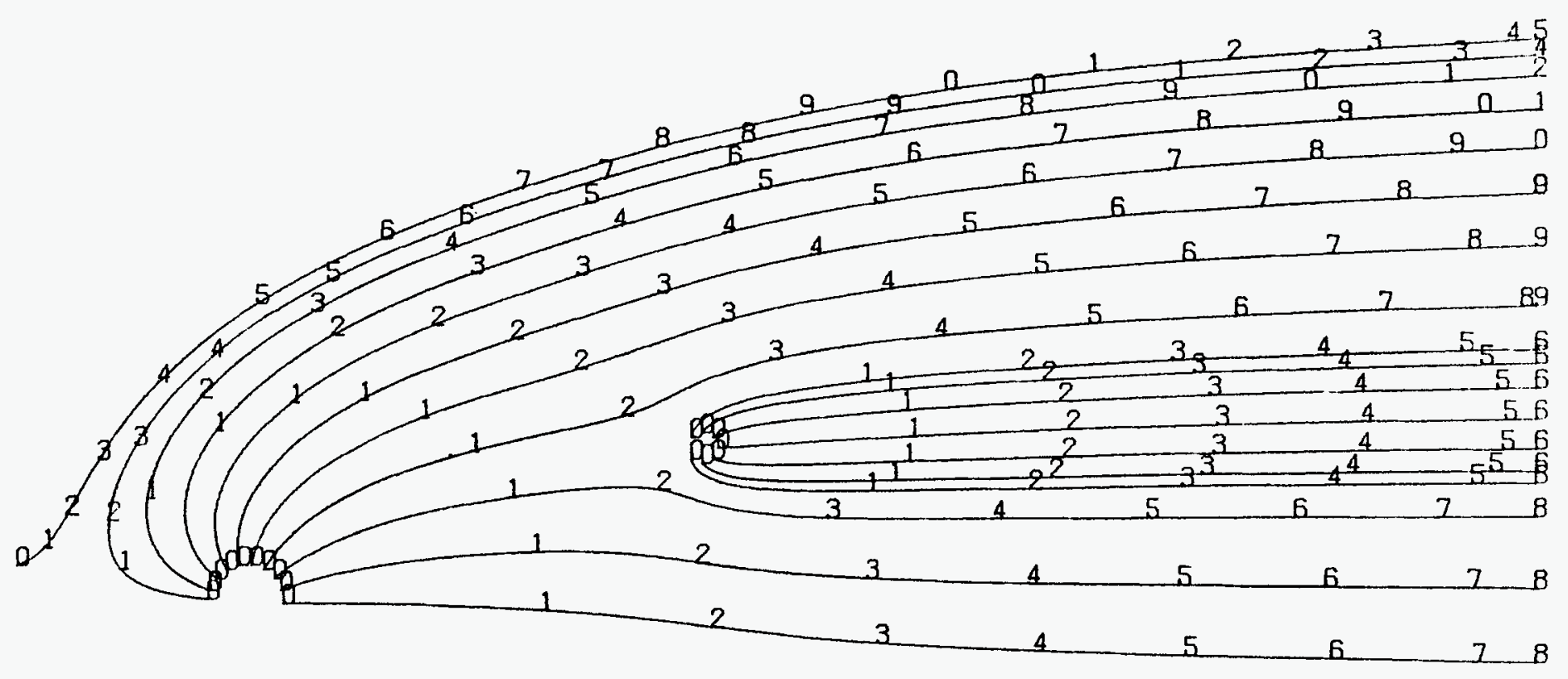

STEADY FLOW WITH TC-99 EXCHANGE DEPARTURE TIME $=0.00$ SCALE 1 INCH $=1000$ FEET 


\section{APPENDIX C}

MAINTAINING OR MODIFYING THE COMPUTER PROGRAMS 


\section{APPENDIX $C$}

\section{MAINTAINING OR MODIFYING THE COMPUTER PROGRAMS}

A synopsis of the overall PATHS program and related routines is presented here. A complete listing of the codes and test cases, on microfiche, is included at the end of this appendix. The following discussion also shows the relationships between the various programs and the corresponding files they generate.

In large measure, the information in this appendix is incidental to what the program user needs to get $h$ is work done. For someone who must maintain or modify the PATHS system, however, this overview is essential.

\section{OVERVIEW OF PATHS SYSTEM}

What we so far have called PATHS is actually a global name for three related FORTRAN programs. These programs are PATHS, GROUND, and LOCQAR. PATHS and LOCQAR previously were coded in BASIC; now all three are available in ASCII FORTRAN on the Univac 1100/44 time sharing EXEC operating system.

PATHS is an interactive program that prompts the user to enter all information necessary to create a coded file. The file is a run stream that can be batched to execute GROUND. This batch program performs the lion's share of the calculations. GROUND calculates the fluid travel time along each flow path, the coordinates of each path, and the distance traveled. In addition, calculations are saved that make it possible to generate CalComp plots showing the flow paths graphically. GROUND also writes a file summarizing the fluid arrival calculations. This may be viewed from the terminal after GROUND finishes execution, thereby giving the user a capsulized view of results before the run is printed and delivered. GROUND also generates a binary data file. This file feeds LOCQAR, which can be executed after the completion of GROUND. 
Like PATHS, LOCQAR is interactive, but solicits very little data before calculated results of outflow location and rates are printed.

Pictorially, the flow through the system is as follows:

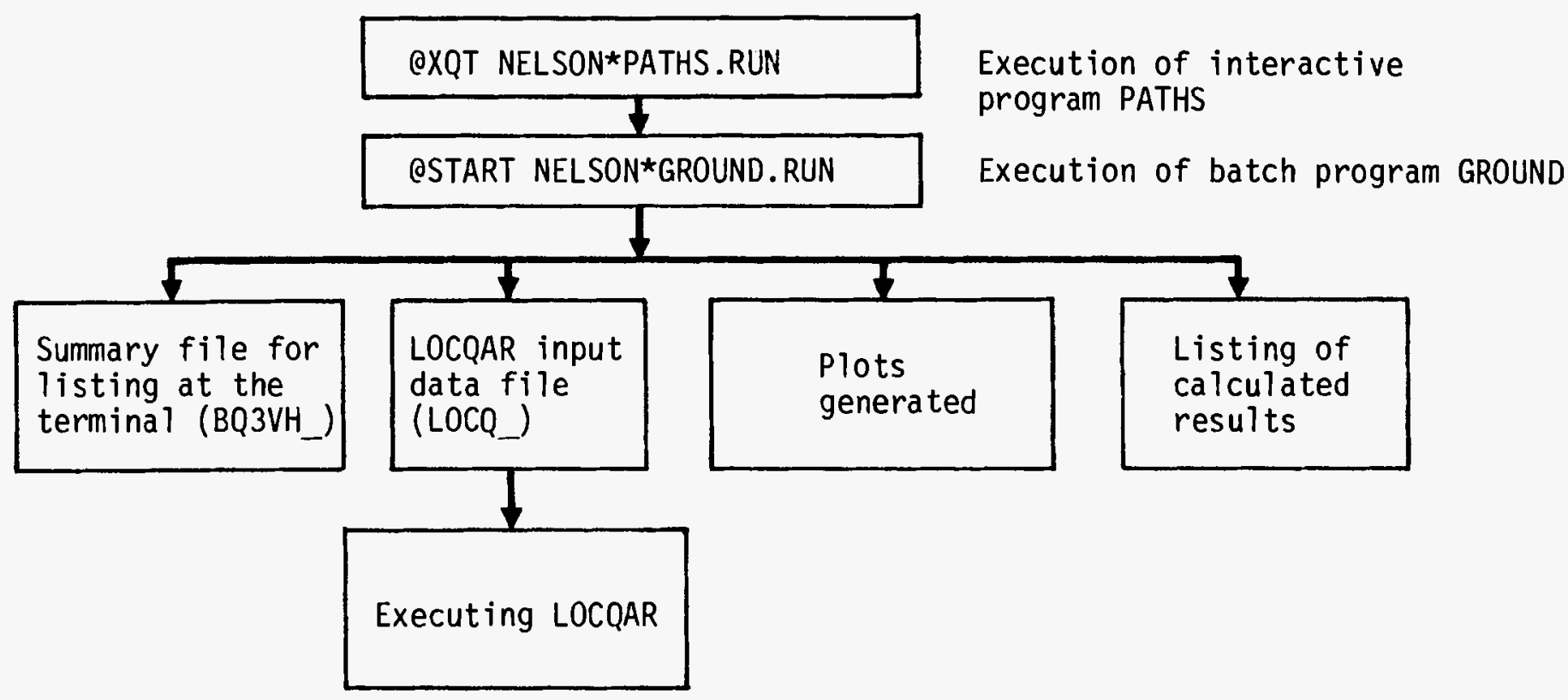

PROGRAMS

LOCQAR

LOCQAR is the simplest of the three programs. It is a short (325-cards) program that reads the binary data file created by GROUND and then interacts with the user for more information, asking about ten questions. (See Appendix B for an example of usage.) Only the last 100 lines of code are used to process data and print out the results via the terminal. LOCQAR uses only one subroutine, SEEBIT, which interprets information from the terminal. 
Currently LOCQAR is maintained as source, relocatable, and absolute under the file and element name NELSON*LOCQAR.RUN. .

\section{PATHS}

PATHS is relatively long (1440 cards), because it is an interactive code. Operationally, it is simple and straightforward, flowing linearly through the code, asking the user questions, slowly building up a reservoir of data to create a job stream for the GROUND program.

By using CALL FACSF, PATHS creates internally an SDF file catalogued under the user's project ID and the file name GRND_. GRND has appended the job number entered by the user. This file is opened, closed, and freed by PATHS. It is also batched for execution if the user desires.

PATHS has several subroutines, all but two of which are trivial, only writing out information helpful to the user. The two non-trivial subroutines are SEEBIT and BLANKS, used to read information from the terminal. Currently PATHS is maintained as source, relocatable, and absolute under the file and element name NELSON*PATHS. RUN.

\section{Data Entered}

The following detailed input sequence has been prepared to show the procedure for using PATHS to collect draft input data.

The PATHS input sequence list includes all of the variables that the program requires, in the order each is requested. It also shows explicitly the program flow and how various input variables are skipped from entry based on the responses to the questions. While probabiy too detailed for most terminal work, it is useful in maintaining or modifying the interactive PATHS program. 


\section{Detailed Input Data Sequence List}

(CONTROL CARD INFORMATION)

1. $=$ ACCT Enter your account number.

2.

3. $\_$- PROJ Enter your project ID.

4. ___ ADDRES Enter your name/address.

5. $\quad$ PASSWD Enter your password.

(DATA FOR PROGRAM GROUND)

6. $=D O=D_{0} \quad$ is the stratum thickness.

7. $=R \quad$ is the distance to the boundary. (Units consistent with DO).

8. Standard distance or T termination of pathline. (Yes or No) If Yes:

9. $=$ XMAX is the terminating abscissa value.

If No:

9 . $=$ TMAX is entered if desired; the maximum travel time for flow paths.

10. __ $=R O=r_{0}$ is the cavern radius. (Units consistent with DO.)

11. ___ $=\mathrm{HO}=\mathrm{H}_{\mathrm{O}}$ is the head in the cavern. (Units consistent with DO.)

12. $=K O=K_{0}$ is the stratum hydraulic conductivity. (Units consistent with D0. Whatever time units are involved in hydraulic conductivity sets the units for the travel time.)

13. $=\mathrm{P}$ is the effective stratum porosity.

14. _ $S$ or $T$ steady or transient cases.

15. $=U 0$ is the initial uniform gradient.

If STEADY case skip to 22

16. = UM is a later gradient value. (See Figure 1.) 
If no STEADY case skip to 21

17. $=T M$

is the time parameter of the gradient equation in time units of $\mathrm{Ko}$.

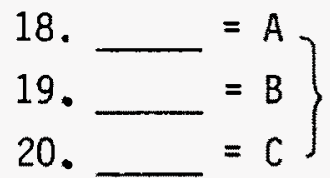

Parameters used in the calculation of the uniform gradient.

21. Enter $S, E$ or $C$ (serpin, exponential or cyclic) for computing variation in the cavern head. (See Figures 1 and 2.)

If $E$ skip to 32 . If $C$ skip to 28 .

22. $=\mathrm{HI}$

23. $=H M$

If $H I$ is equal to HM skip to 32 .

24. $=\mathrm{TN}$

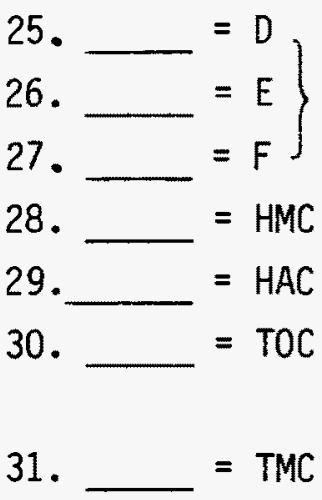

is the initial value of the cavern head in units of $\mathrm{H}_{0}$.

Maxmimum value of the head in units of $\mathrm{H}_{0}$.

is a time parameter. Units consistent with TM for the variation of the uniform gradient $U$.

Parameter used in serpin option to calculate H. Skip to 32 .

is the mean cavern head.

is the amplitude of the cyclic head. is the beginning time of the cyclic flow from the cavern.

is the ending time of the cyclic flow from the cavern.

32. Are there additional wells or caverns? (Yes or No)

If no skip to 48 .
33. $\ldots \mathrm{J}=\mathrm{j}$
is the number of wells.
34. $\_$XWELL $=x_{j}$
is the $x$ coordinate of the well.
35. $\_$YWELL $=y_{j}$
is the $y$ coordinate of the well.
36. $=$ ROWELL
is the stopping radius of the well.
If steady case skip to 38 
37. Is well serpin or cyclic? (S or $C$ )

If cyclic skip to 44

38. $=\mathrm{QI}$

is the initial flow rate of well (see Figure 2).

39. is the maximum flow rate of well.

40. $\_$TNWELL $=\mathrm{TN}_{j}$ $=\mathrm{QM}$ flow rate

41. Parameters used by the serpin

42. 43. option to calculate the well flow rate.

Return to 34 until all wells have been read. After all wells have been read skip to 48 .

44. $=Q_{j}$

45. $=Q A_{j}$

46. $=$ TOWELL

47. $=$ TMWELL is the mean inflow $(+)$ or outflow $(-)$ rate of the well.

is the amplitude about the mean inflow $(+)$ or outflow (-) of the well. is the beginning time of the cyclic flow of the well. is the ending time of the cyclic flow of the well.

Return to 34 until all wells have been read. After all wells have been read continue at 48 .

48. $=V S$

Max 12 character unit label of DO's length.

49. Max 12 character time units of KO.

50.

$=W S$

Max 12 character time units of k0.

$=$ THETAO $=\theta 0$ the angle in degree around the cavern well to the starting point for the first pathline.

51. $=$ THETAM $=\theta M$ the maximum angle in degrees to the lost pathline starting point along the cavern wall. 
52. $=$ NTHETA $=N e$ the number of equally spaced pathlines desired along the cavern wall that will be generated beginning with THETA and ending with THETAM.

If THETAO is not equal to THETAM skip to 58.

53.

54.

55.

If initial path lengths are zero skip 56 and 57.

56.

57. Enter L-path length in units of 00.

Enter starting TIME in units the same as time units of KO.

Return to 54 until NTHETA have been read, then skip to 59 .

58.

$=$ KEHETA is the number of pathlines that will be generated between THETAM and $179.99(+)^{0}$.

59. $=T_{0}=t_{0}$ is the departure time in units of KO of first fluid fluid particles leaving the cavern for which calculations will be made.

If steady case skip to 63 .

60. $=T F=t_{f}$

61. $=N T$

If T0 is not equal to TF skip to 63 .

62. $=T$ is the departure time in units of $K 0$ of final fluid particles leaving the cavern for which calculations will be made. is the number of equally spaced departure times beginning with TO and ending with TF that will be calculated.

Enter all NT time increments from the terminal.

Repeat 62 until all NT have been read.

63. Is there an ion exchange delay? (Yes or No) If no skip to 67 .

64. $=$ CHEM

65. $=K D=K_{d}$ is the chemical name of the ion (12 character name max.)

is the equilibrium distribution coefficient 


$$
\begin{aligned}
& \text { 66. } \_B D=B_{d} \quad \text { is the bulk density of the porous } \\
& \text { material in units consistent with } K D \text {. } \\
& \text { 67. } \ldots \text { DELTA is the time increment used in computing flow along a } \\
& \text { given path. (Program PATH aids in providing range for } \\
& \text { proper selection.) }
\end{aligned}
$$

73. Are 30-inch-high plots desired? (If not 11 inch high plots result.)

74. = XCENTER

The $(x, y$ coordinates in inches of the cavern

$\left.\begin{array}{l}\text { 75. } \_ \text {YCENTER } \\ \text { 76. SCALE }\end{array}\right\}$ center to be plotted from $(0,0)$ lower left corner of the plot window. is the scale factor in units/inch to be used in the plot.

77. Is detailed computer printout desired? (Yes or No)

78. Enter the job run number. (Digits from 1 to 9)

79. Is the job to be submitted? (Yes or No)

(Note: The job stream created is saved as the runstream PROJ*GRND_. Where PROJ is the project ID (item number 2) and is the job run number (item number 78). PROJ*GRND_ is available for modification through EDITOR for job submittal also.) 
GROUND

The GROUND program calculates flow pathlines and arrival times. It is a program of about 1150 cards. Apart from the output data GROUND generates on each path of flow, it creates a summary file BQ3VH_ of path data, a binary file for LOCQAR called LOCQ_, and CalComp plots. (NOTE: The dash_ is for the appended number, the number of the run set in the PATHS program.)

GROUND begins by reading the data created by PATHS. It then prints this data read, identifying it for the user. Next the variables read in are scaled and the beginning time loop is started. If the run is a steady case, only one starting time for the flow paths calculated is used. However, for transient cases, the program loops back to pick up the next starting time flow paths are to be calculated for. Execution continues like this until the final starting time is reached that flow paths are to be calculated for.

With the beginning of each pathline to be calculated, initializing is done, including the initializing for setting up the $x$ and $y$ arrays for plotting the paths. Depending on cavern behavior or type of flow subroutines HM, SERPIN or CYCLE will be called to calculate exponential, serpin or cyclic flow. Next, the possible influence of wells on the flow is introduced. A call to subroutine RKDE is made, which in turn calls function DYWELL to obtain the incremental numerical solution through a modified Runge-Kutta technique (Gi11, 1951). This process is continued for each pathline until the terminating distance (XMAX) or terminating time (TMAX) is reached.

As each pathline is calculated, every NPRINT (see item 70 of PATHS input data sequence list) interval of data is printed; i.e., the ( $x, y)$ coordinates of the point plus the time and distance traveled. At the end of the pathline, the final line is printed and also saved for the summary print out of final locations and times for all path lines are calculated. Also if plots are desired, a call is made to subroutine WRIT at the end of each pathline calculated to have it plotted. Then a new pathline is begun and cycled through as before until the find pathline is processed. With the final pathline calculated, GROUND comes to conclusion, unless it is a transient case in which the entire execution of pathline flow begins again, but with a new starting time. 
Apart from the subroutines already mentioned, program GROUND calls subroutine BOX to encase the plots generated. Subroutines SIMP and NEWTON remain a part of the code but they are not used. They are maintained for possible use later.

Currently program GROUND is maintained as source, relocatable, and absolute under file and element name NELSON*GROUND. RUN. Because GROUND calls the Calcomp routines in plotting, it is necessary to include this library of routines when creating the relocatable and absolute files, namely:

(o MAP , IS , NELSON*GROUND. RUN

IN NELSON*GROUND, RUN

LIB CALCOMP*LIB.

END

Variable Names

Because GROUND reads the variables originally solicited from the user by the program PATHS, a flow diagram of how they are read follows. Also, because GROUND frequent ly renames these variables, this flow diagram should be compared with the variable list in Appendix $B$ under the discussion "Using EDITOR". As an example, note that the variables for row 9 of PATHS are respectively: $R, R, H O$, KO while GROUND names them respectively: $S$, RMAX, HO, EKO. The lines in this flow diagram are numbered to correspond to their counterpart in Appendix B. 
VARIABLES READ BY GROUND

8. TITLE

9. S, RMAX, HO,EKO

10. RO, ROS,TP,UO

11. RM,P,TM

12. $P A T H, A A K D, B B D$

13. CHEM, PROJ, VH3, IPROJ

14. AST, BST, CST, KTHETA

1:. THETAO, THETAM, TO, NTHETA

16. TF, TIMEX, EPSLN, ITLIM

17. DELTA,NT , STEP,NT

18. XMAX, XC , YC, ISK

19. SC,DST, EST, FST

20. GST, OST, XTEST, YSTOPI

21. HMEAN, HAMP, TOCYC, TMCYC

22. PARAMA , NWELL, P1

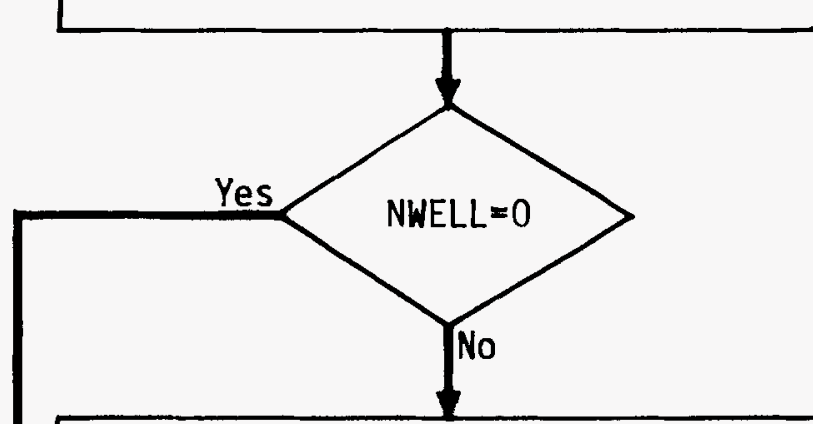

23. ROWELL (I), XWELL (J)

24. YWELL(I),TNWELL(I)

25. QI(I), QM(I),DWELL(I)

26. $\operatorname{EWELL}(I), F W E L L(I), Q(I), Q Q(I)$

27. TOWELL (I), TMWELL (I)

28. WELLOP(I)

35. JLEN

36. JTIM

37. CASE

a

C -11 


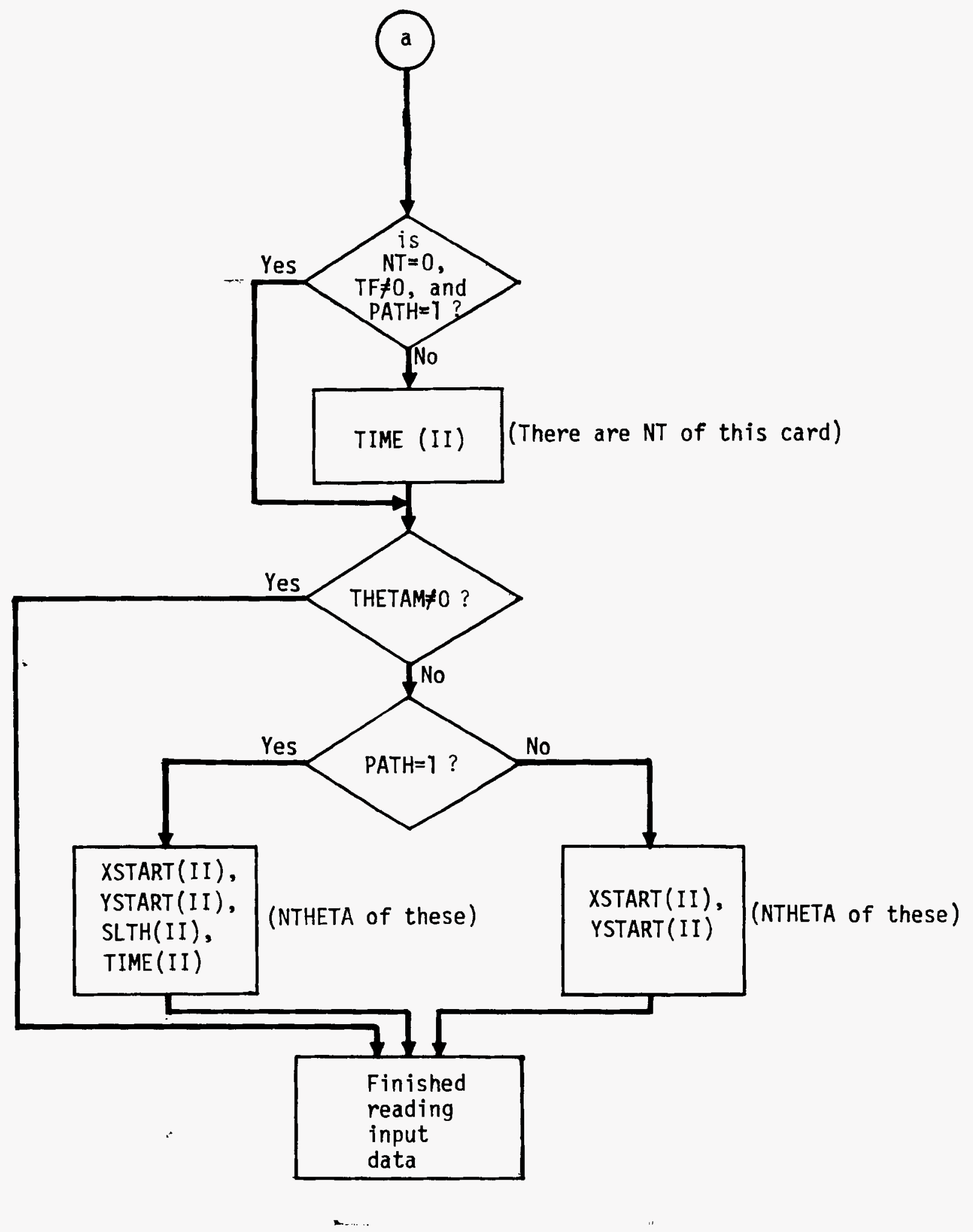




\section{PROGRAM LISTINGS AND OUTPUT FOR TEST CASES}

The complete listings of the PATHS, GROUND and LOCQAR program are provided on microfiche. The first test case is the "Example Transient Case (Two Wells)" described in the body of the report and illustrated in Appendix B. Most of the output of the first test case was also shown in Appendix $B$ though some of the detail printout was omitted. The complete output listing is provided on microfiche attached to the back cover. The second test case is the "Steady Flow with Tc-99 Exchange" illustrated in Appendix B. The complete listing of the output for test case 2 is also included in the microfiche envelope. 
APPENDIX D

DEFINITIONS OF TERMS 


\section{APPENDIX D}

\section{DEFINITIONS OF TERMS}

Units

A is a parameter in the $W\left(t^{\prime}\right)$ and $U\left(t^{\prime}\right)$ time-dependent functions (see Figure 1).

$B$ is a parameter in the $W\left(t^{\prime}\right)$ and $U\left(t^{\prime}\right)$ time-dependent function (see Figure 1).

None

Bd is the bulk density of the porous material.

$\mathrm{FT}^{2} / \mathrm{L}^{4}$

C

is a parameter in the $W\left(t^{\prime}\right)$ and $U\left(t^{\prime}\right)$ time-dependent function (see Figure 1).

$T^{2}$

$C^{\prime} \quad$ is the contaminant concentration in the flowing groundwater.

$\mathrm{FT}^{2} / \mathrm{L}^{4}$

$C^{\circ} \quad$ is the dimensionless contaminant concentration (see Equation $\mathrm{A}-45$ ).

None

$C_{1}$

is a constant in the dimensionless potential function.

None

$\mathrm{C}_{0}$

is the initial concentration in the pond or cavern.

$\mathrm{FT}^{2} / \mathrm{L}^{4}$

$C_{0}^{\prime}$

is a constant to be determined in the potential

function.

$\mathrm{FL} / \mathrm{F}$

$D=D W E L L$ is a parameter in the $H\left(t^{\prime}\right)$ time-dependent function (see Figure 1).

T DW
$j$ is a time parameter in the flow rate, $Q_{j}\left(t^{\prime}\right)$, for the
jth well (see Figure 1).

$T$

$D_{0} \quad$ is the stratum thickness (see Table 1).

$E=E W E L L$ is a parameter in the $W\left(t^{\prime}\right)$ time-dependent function (see Figure 1).

None EW
$j \quad$ is a time parameter in the flow rate, $Q_{j}\left(t^{\prime}\right)$, for the
jth well (see Figure 1$)$.

None

$F=F W E L L$ is a parameter in the $H\left(t^{\prime}\right)$ time-dependent function (see Figure 1). 
Units

$F(t) \quad$ indicates a function of time, $t$. None

$\begin{array}{ll}\mathrm{FW}_{\mathrm{j}} & \text { is a time parameter in the flow rate, } Q_{j}\left(t^{\prime}\right) \text {, for } \\ \text { the } j \text { th well (see Figure } 1 \text { ). } & \mathrm{T}^{2}\end{array}$

$H$ is the dimensionless head at any time, $t$, in the cavern or pond. None

$H^{\prime}$ is the time-dependent energy head in the cavern or pond.

$\mathrm{FL} / \mathrm{F}$

$\mathrm{H}_{\mathrm{O}} \quad$ is the initial or steady head in the cavern (see Equation $\mathrm{A}-2$ ).

$\mathrm{HI}$ is a parameter in the time-dependent cavern head equation (see Figure 1).

$\mathrm{TN}_{\mathrm{j}} \quad$ is a time parameter in the flow rate, $Q\left(t^{\prime}\right)$, function for the jth well (see Figure 1).

TOWELL $_{j}$ is the initial time parameter in the cyclic flow rate, $Q\left(t^{\prime}\right)$, function for the jth well (see Figure 2).

TMWELL $_{j}$ is the later cyclic time parameter in the flow rate, $Q\left(t^{\prime}\right)$, for the jth well (see Figure 2).

TNWELL $_{j}$ is a computer-used name equivalent to $\mathrm{TN}_{j}$.

$U$ is the time-dependent uniform gradient strength. $\mathrm{L} / \mathrm{L}$

UO is a parameter in the time-dependent uniform gradient function (see Figure 1).

UM is a parameter in the time-dependent uniform gradient function (see Figure 1).

$W\left(t^{\prime}\right)$ is the general serpin equation form of time dependence (see Figure 1 or Equation A-18).

$W_{T} \quad$ is the contaminant outflow rate (see Equation 17 ). F/T

XMAX is the stopping distance for pathlines in the positive $x$ coordinate direction (see sketch in Table 1).

XCENTER is the $x$-coordinate in inches for the origin $x^{\prime}=0$, $y^{\prime}=0$ for plots (see Table 1). 
Units $\operatorname{XWELL}_{j}=x_{j}^{\prime}$ is the $x$-coordinate location of the center of

YCENTER is the $y$-coordinate in inches for the origin $x=0$, $y=0$ for the automatic machine plots (see Table 1).

$\mathrm{YWELL}_{j}=y_{j}^{\prime}$ is the $y$-coordinate location of the center of

$\mathrm{J}=\mathrm{N} \quad$ is the total number of wells.

None

HM is a parameter in the time-dependent cavern head equation (see Figure 1).

None

$K$ is the ratio of the exchangeable ion travel time to that of the fluid (see Equation 13).

None $\begin{array}{ll}k_{d} & \text { is the equilibrium exchange distribution coefficient } \quad F T^{2} / 4_{L} \\ \text { (see Equations } 13, A-48) .\end{array}$

$K_{0} \quad$ is the hydraulic conductivity.

$L^{3} / T L^{2}(L)$

$K \theta=K T H E T A$ is the number of pathlines that will be generated between $\theta M$ and $179.99(+)^{\circ}$ originating on the cavern wall 1 .

None

L denotes length units.

$M_{0} \quad$ is the pond or cavern source strength.

$M_{j}=\frac{Q_{j}}{D_{0} K_{0}}$ is the well strength of the $j$ th well.

$N=J \quad$ is the total number of wells in the flow system. None

NT is the number of equally spaced departure times beginning with $t_{0}$ and ending with $t_{f}$ that will be calculated (see Table 1).

None

$\mathrm{N} \theta$ is the number of equally spaced pathlines along the cavern wall that will be generated beginning with $\theta 0$ and ending with $\theta \mathrm{M}$.

None

P is the effective porosity.

None

Q is the leakage rate from the cavern (see Equation A-40). 


\section{Units}

$Q_{\mathbf{j}} \quad$ is the cumulative flow rate (see Equation A-43). $L^{3} / T$

$Q_{j} \quad$ is the volume inflow or outflow rate of the $j$ th well. $L^{3 / T}$

QI $j$ is the initial inflow $(+)$ or outflow $(-)$ rate for the
serpin well option (see Equation $A-18$ and Table $A-1) . \quad L^{3} / T$

QM $j \quad \begin{aligned} & \text { is the maximum inflow }(+) \text { or outflow }(-) \text { rate for the } \\ & \text { serpin well option (see Equation } A-18 \text { and Table } A-1) . \quad L^{3} / T\end{aligned}$

$Q_{j} \quad$ is the mean inflow $(+)$ or outflow $(-)$ rate for the cyclic option of time dependence for well flow (see Equation A-19 and Table A-2).

$Q A_{j} \quad$ is the amplitude of the cyclic well inflow (+) or outflow (-) rate (see Equation A-19 and Table A-2). L $L^{3} / T$

$Q_{0} \quad$ is a constant leakage rate from the cavern used as a scaling value (see Equation 9).

Q' is the leakage rate from the cavern (see Equation A-20).

$R$ is the distance (radial) to the groundwater outflow area, or the remote boundary. It also is used in scaling (see Equation A-2).

ROWELL $_{j}$ is the numerical stopping radius around the $j$ th well (see Table 1).

SCALE is the scale used in the automatic plots (see Table 1).

L/inch

T denotes the arrival time and also time units.

TMAX is the stopping time along the pathlines (see Table 1).

TM is a time parameter in the $U\left(t^{\prime}\right)$ function (see Figure 1).

TN is a time parameter in the $H\left(t^{\prime}\right)$ function (see Figure 1).

g is the gravitational scalar. 
Units

j as a subscript denotes the variable applies to the jth well.

None

In is the natural logarithm to the base e. None

p is the fluid pressure.

$F / L^{2}$

$q^{\prime} \quad$ is the unit fluid outflow rate across the boundary; i.e., into the river. $q=\frac{R}{D_{0} K_{0} H_{0}} q^{\prime}$ is the dimensionless fluid flow rate across the $\quad$ None

$r \quad$ is the dimensionless radial coordinate variable in cylindrical coordinates.

None

$r^{\prime} \quad$ is the radial variable in cylindrical coordinates.

$r_{0}^{1} \quad$ is the effective cavern radius.

$r_{0} \quad$ is the dimensionless effective cavity radius.

None

s is the location along the outflow boundary; i.e., along the river (see Equation 17).

$t$ is the dimensionless time variable (see Equation $A-2)$.

None

t' is the time variable.

$t_{0} \quad$ is the departure time of the first fluid particles leaving the cavern wall or from the other specified locations.

None

$t_{0}^{\prime} \quad$ is the departure time of the fluid particles from a given location.

$w_{0}$ is a parameter in the serpin equation (see Figure 1 or Equation A-18).

None

$W_{\text {oc }}$ is a parameter in the cyclic equation (see Figure 2 or Equation A-19).

None

$W_{m} \quad$ is a parameter in the serpin equation (see Figure 1 or Equation $\mathrm{A}-18$ ).

None 
Units

$w_{m c} \quad$ is a parameter in the cyclic equation (see Figure 2 or Equation A-19).

None

$x^{\prime}$ and $y^{\prime}$ are the Cartesian coordinates.

$x$ and $y$ are the dimensionless Cartesian coordinates (see Equation A-2).

None

$x_{j}$ and $y_{j}$ are the coordinates of the center of the $j$ th well. None

$x_{0}$ and $y_{0}$ are the dimensionless coordinates defining the cylindrical cavern wall (see Equations 5 and 6 ).

None

$\rho \quad$ is the fluid mass density.

$\mathrm{FT}^{2} / \mathrm{L}^{4}$

$\theta \quad$ is the angular coordinate variable in cylindrical coordinates. (The $x$-coordinate axis is along $\theta=0)$.

Degrees

$\theta_{j} \quad$ is the angular coordinate of the center of the $j$ th well (see Figure A-1).

Degrees

${ }_{\theta 0}=$ THETAO is the angle around the cavern wall to the starting point of the first pathline generated (see Table 1).

Degrees

$\theta M=$ THETAM is the maximum angle around the cavern wall to the starting point of the last regularly spaced pathline generated (see Table 1).

Degrees

$\phi^{\prime}=\frac{p}{\rho g}+z$

is the dimensional potential energy in the stratum. LF/F

$\phi \quad$ is the dimensionless potential head (see Equations A-2 and $A-17)$.

None

$\nabla \quad$ is the del operator; i.e., $\frac{\partial}{\partial x} \underline{i}+\frac{\partial}{\partial y} \underline{j}$

None

$\nabla^{\prime} \quad$ is the dimensionless del operator; i.e.,

$$
\frac{\partial}{\partial x^{\top}} \stackrel{i}{ }+\frac{\partial}{\partial y^{\prime}} \mathfrak{j}
$$

$1 / L$

$\underline{u} \quad$ is the dimensionless macroscopic pore velocity vector (see Equation A-27).

None

U' is the macroscopic pore velocity vector (see Equation A-25). 
Units

${ } x$ is the dimensionless velocity component in the $x$ coordinate direction.

None

$U_{y} \quad$ is the dimensionless component in the $y$-coordinate direction.

None

is stream function (see Equation A-34).

None

$\psi_{0}$

is the steady scaling source strength (see Equation A-42).

None

$\psi_{s} \quad$ is the cumulative outflow from the circular source (see Equation A-37).

None 


\section{DISTRIBUTION}

No. of

Copies

OFFSITE

A. A. Churm

DOE Chicago Patent Group

9800 South Cass Avenue

Argonne, IL 60439

27
DOE Technical Information Center

C. S. Allred, Deputy Director Department of Water Resources Annex 2 Statehouse

Boise, ID 83720

2 Argonne National Laboratory

Reference Library 9800 South Cass Avenue

Argonne, IL 60439

Yehuda Bachmat, Project Director Holcomb Research Institute

Butler University

Indianapolis, ID 46206

H. 0. Banks, Consulting Engineer

3 Kittie Lane

Belmont, CA 94002

Batte lle Memorial Institute

Office of Nuclear Waste

Isolation

Attn: Beverly Rawles

505 King Avenue

Columbus, $\mathrm{OH} 43201$

Prof. T. H. Bigford

Nuc lear Engineering Department

University of California

Berkeley, CA 94720
No. of

Copies

Pat Brannen

Inter-Environmental Consultants

11511 Katy Freeway

Houston, TX 77079

John Bird

Geo logy Department

Cornel1 University

Ithaca, NY 14853

J. D. Bredehoeft

U.S. Geological Survey

Water Resources Division

Reston, VA 22092

2 Brookhaven National Laboratory

Reference Section

Information Division

Upton, Long Island, NY 11973

R. H. Brooks

Associate Professor

Department of Agricultural

Engineering

Oregon State University

Corvaliis, OR 97331

W. H. Brutsaert

Cornell University

School of Civil Engineering

B22 Bailey Hall

Ithaca, NY 14850

S. L. Burks

School of Biological Sciences

Ok lahoma State University

Stillwater, OK 74074 
No. of

Copies

20 Wayne A. Carbiener

Office of Nuclear Waste

I so lation

Battelle Memorial Institute

505 King Avenue

Columbus, $\mathrm{OH} 43201$

Keros Cartwright

Geologist and Head

Hydrogeology and Geophysics Section

Illinois State Geological Survey

Urbana, IL 61801

Clinton M. Case

Associate Res. Professor

Center for Water Resources

Research

Desert Research Institute

University of Nevada

Reno, NV 89507

T. P. Chang, PhD, Chief

Program Support Branch

Ind iana State Board of Health

$1330 \mathrm{~W}$. Michigan

Ind ianapolis, IN 46206

D. L. Clough, Director, Water Quality Div., Water

Resources Department

State Office Building

Montpelier, VT 05602

C. G. Clyde, Associate Director

Utah Water Research Laboratory 82

Utah State University

Logan, UT 84322

Neville G. W. Cook

Dept. of Materials Science and Mineral Engineering

Hearst Mining Building

University of California

Berkeley, CA 94720
No. of

Copies

Carl R. Cooley

DOE Office of Waste Management

Washington, D. C. 20545

C. S. Desai, Professor

Department of Civil Engineering

V.P.I. and S.U.

Blacksburg, VA 24061

C. L. Dodson

Director

Water Research Institute

West Virginia University

Morgantown, WV 26506

Environmental Protection Agency

Office of Radiation Programs

Technology Assessment Division

M/S AW559

Washington, DC 20460

Robert M. Garrells

Department of Geologic Sciences

Northwestern University

Evanston, IL 60201

Col in A. Heath

DOE Division of Waste Management

Washington, DC 20545

William M. Hewitt

Office of Nuclear Waste

Isolation

Battelle Memorial Institute

505 King Avenue

Columbus, $\mathrm{OH} 43201$

Peter L. Hofmann

Office of Nuclear Waste

Isolation

Battelle Memorial Institute

$505 \mathrm{King}$ Avenue

Columbus, $\mathrm{OH} 43201$ 
No. of

Copies

L. J. Johnson, Group Leader

Environmental Studies

Hea 1th Research Division

Los Alamos Scient if ic Laboratory

Los Alamos, NM 87545

Dr. Robert Kaufman

Environmental Protection Agency

P.0. Box 15077

Las Vegas, NV 89114

J. W. Keely

Chief of Subsurface

Environmental Research Branch

Robert S. Kerr Research

Laboratory

P.0. Box 1198

Ada, OK 74820

Muzaffer Kehnemuyi

Office of Nuclear Waste

Isolation

Battelle Memorial Institute

505 King Avenue

Columbus, $\mathrm{OH} 43201$

Bruce Kennedy, Chief

Technical Information

Southwest Fla. Water Management

District

5060 U.S. 41 South

Brooksville, FL 33512

Kenneth Kipp

U.S. Geological Survey

WRD

Mail Stop 413

Denver Federal Center

Denver, CO 80225

John F. Kircher

Office of Nuclear Waste

Isolation

Battelle Memorial Institute

505 King Avenue

Columbus, $\mathrm{OH} 43201$
No. of

Copies

2 Lawrence Berkeley Laboratory

Reference Library

University of California

Berkeley, CA 94720

2 Lawrence Livermore Laboratory

Reference Library

P.0. Box 808

Livermore, CA 94550

2 Los Alamos Scientific Laboratory

Reference Library

P.0. Box 1663

Las Alamos, NM 87544

J. N. Luth in

University of California at Dav is

Department of Water Sciences and Engineering

Davis, CA 95616

Gilbert Levine, Director

Water Resources

Water Resources and Marine

Sciences Center

Hollister Hall

Corne 11 University

Ithaca, NY 14853

J. B. Martin

Asst. Director for Radioactive Waste Mgmt Branch

NRC Division of Materials and

Fuel Cycle Facility Licensing

Washington, DC 20555

R. F. McGhee

Modeling Group Leader

N.C. Division of Environmental Management

P.0. Box 27687

Raleigh, North Carolina 
No. of

Copies

John T. McGinn is

Office of Nuclear Waste Isolation

Battelle Memorial Institute

505 King Avenue

Columbus, $\mathrm{OH} 43201$

M. H. Meyer

Chief of Planning

Iowa Natural Resources Counc il

James W. Grimes Building

East 14th and Grand Avenue

Des Moines, IA 50319

Jerome Milliman

Department of Economics

University of Florida

Gainesville, FL 32601

Al Murrey, Chief

Water Quality Bureau

Department of Health and Welf are

Statehouse

Boise, ID 83720

2 Barry Naft

NUS Corporation

4 Research Place

Rockville, MD 20805

J. 0. Neff

Department of Energy

Columbus Program Office

505 King Avenue

Columbus, $\mathrm{OH} 43201$

2 Neil A. Norman

Environmental Sciences

Department

Bechtel National Inc.

P.0. Box 3965

San Francisco, CA 94105

2 Oak Ridge National Laboratory

Central Research Library

Document Reference Section

Oak Ridge, TN 37830
No. of

Copies

F. L. Parker

Dept. of Environmental Eng.

Vanderbilt University

Nashville, TN 37235

N. L. Peterson, Director

Division of Water Supply and Pollution Control

North Dakota State Department of Health

State Capitol

Bismarck, ND 58505

G. F. Pinder

Dept. of Civil Engineering

Princeton University

Princeton, NJ 08540

T. A. Prickett, Engineer

Illino is State Water Survey

Box 232

Urbana, IL 61801

Dr. W. L. Powers, Director

Kansas Water Resource Research Institute

Water Annex

Kansas State University

Manhattan, KS 66506

R. F. Post

Chief, Environmental Resources

Branch

U.S. Army Corps of Engineers

1135 U.S. P.O. and Customs House

St. Paul, MN 55101

J. B. Robertson, Hydrologist

USGS - WRD

345 Middlefield Rd.

Men lo Park, CA 94025

2 Savannah River Laboratory

Reference Library

Aiken, SC 29801 
No. of

Copies

B. L. Schmalz

ERDA

Idaho Falls, ID 83401

G. Segol

Bechtel National, Inc.

50 Beale Street

San Francisco, CA 94119

3 E. S. Simpson, Professor

Department of Hydrology and Water Resources

University of Arizona

Tucson, AZ 85721

Howard P. Stephens

Sand ia Laboratories

P.0. Box 5800

Albuquerque, NM 87115

David B. Stewart

U.S. Geological Survey

National Center 959

Reston, VA 22092

Terry Thurman

Chief Water Quality Division

Oklahoma Water Resources Board

5 th Floor Jim Thorpe Building

Oklahoma City, OK 73105

Robert Williams

Electric Power Research Inst.

$3412 \mathrm{Hillview} \mathrm{Avenue}$

P.0. Box 10412

Palo Alto, CA 94304

John Wilson

Parsons Laboratory for Water Resources and Hydrodynamics

Department of Civil Engineering

Building 48-209

Massachusetts Institute of Techno logy

Cambridge, MA 02139
No. of

Copies

FOREIGN

Van Den Akker, C, Hydrologist

Municipal Water Works of Amsterdam

Condensatorweg 54

Amsterdam/Sloterdyk

THE NETHERLANDS

D'Allessandro Avogadro

Commission of European

Commun ities

Joint Research Centre

I-21020 Ispra (Varese)

ITALY

V. K. Barwell

Environmental Research Branch

Atomic Energy of Canada Limited

Chalk River, Ontario KOHIJO

CANADA

Jacob Bear, Professor

Vice President for Academic Affairs

Department of Civil Engineering

Technion, Israel Institute of Technology

Haifa,

ISRAEL

A. Van Der Beken, Professor

Vrije Universiteit Brussel

Pleinlaan 2

B-1050 Brussel

Eshel Bresler

Head, Division of Soil Physics

Institute of Soils and Water

Volcani Center, A.R.0.

P.0. Box 6 Bet Dagen

ISRAEL 
No. of

Copies

Center for Atomic Energy

Documentation (2AED)

Attn: Dr. Bell

Postfach 3640

D-7500 Kar lsruhe

$F . R$. of GERMANY

Erik Erikksson

Department of Physical Geography

University of Uppsala

Box 554

S-751 22 Uppsala 1

SWEDEN

E. 0. Frind, Assistant Professor

Department of Earth Sciences

University of Water 100

Water loo, Ontario

CANADA

Ferruccio Gera

Radiation Protection and Waste Management Division

Nuc lear Energy Agency/OECD

38 boulevard Suchet

75016 Paris

FRANCE

Robert Gilliam

Department of Earth Sciences

Water 100, Ontario

CANADA

K. H. Hubenthal

Bundesministerium fur Forschung und Technologie

Stressemannstrasse 2

Postfach 200706

D-5300 Bonn

F.R. Of GERMANY

2 INIS Clearinghouse

International Atomic Energy Agency

P.0. Box 590

A-1011, Vienna

AUSTRIA
No. of

Copies

Klaus Kuhn

Institut fur Tiefagerung

Wissenschaftliche Abteilung

Berliner Strasse 2

3392 Clausthal - Zellerfeld

$F . R$. of GERMANY

Hans W. Levi

Hahn-Meitner-Institut fur Kernforschung

Glienicker Strasse 100

1000 Ber lin 39

$F . R$. of GERMANY

Library

Studsvik Energiteknik $A B$

S-611 01 Nykoping

SWEDEN

Ghislain de Marsily

Directeur du Centre

d'Informatique Geologique

Ecole Nationale Superieure

Des Mines de Paris

35, Rue Saint-Honore

77305 Fontainebleau

FRANCE

Ted Munn

Atmospheric Environment Service 4905 Duffer in Street

Downsview, Ontario N3H 5T4

CANADA

Glenn Merrett

Storage and Disposal Branch

Whiteshell Nuclear Research

Establ ishment

Tinawa, Manitoba ROE ILQ

CANADA

Franz Peter Oester le

Physikalisch-Chemische Bundesanstalt

Bundesallee 100

D-3300 Braunschweig

F.R. of GERMANY 
No. of

Copies

Tön is Papp

Karnbrans les akerhet

Fack . 10240

Stockholm

SWEDEN

J. R. Philip, Chief

Division of Environmental Mechanics - CSIRO

P.0. Box 821

Canberra City A.C.T. 2601,

AUSTRAL IA

3 F. W. Schwartz

Ass istant Professor

Department of Geology

University of Alberta

Edmonton,

CANADA

Jehoshua Schwarz

Tahal - Consulting Engineering Ltd.

P.0. Box 11170

Tel Aviv,

ISRAEL

Georges Vachaud

Maitre de Recherches

Institut de Mechanique de Grenoble

USMG - BP 53

F 38041-Grenoble Cedex

FRANCE

Tjalle Vandergraff

Atomic Energy of Canada Limited

Whiteshe 11 Nuclear Research

Establishment

Tinawa, Manitoba ROE 1LQ

CANADA

Egbert Schapermeier

Battelle-Institute e.V.

Am Romerhof 35

D-6000 Frankfurt am Main 90

$F . R$. of GERMANY
No. of

Copies

ONSITE

4 DOE Richland Operations Office

J. L. Rhodes

H. E. Ransom

J. J. Schreiber

F. R. Standerfer

2 Rockwell Hanford Operations

R. A. Deju

Rockwel1 Document Control

80 Pacific Northwest Laboratory

G. L. Benson

D. L. Bradley

R. W. Bond

A. Brandstetter (10)

C. R. Cole

F. H. Dove

S. R. Gupta

M. A. Harwe 11

K. T. Key

M. R. Kreiter

J. S. Light

J. W. Lindberg

R. W. Nelson (35)

A. M. Platt

A. E. Reisenauer

R. J. Serne

D. J. Silviera

C. S. Simmons

J. K. Soldat

J. F. Washburn

Technical Information Library (5)

Publishing Coordination (2)

Water and Land Resources

Library (10) 


\section{MODEL USERS FORM}

If you wish to be on the distribution list for future model computer code and report revisions, please fill out the form below and return it to Dr. Albin Brandstetter.

PATHS

REQUEST FOR MODEL REPORT REVISION

Name
Tit le and Affiliation
Address
Date Signature

Please fill out this form and mail to:

Dr. Albin Brandstetter

Project Manager, AEGIS

Pacific Northwest Laboratory

P.0. Box 999

Richland, WA 99352

U.S.A. 
